Final Report

On the Project Entitled

\title{
A Reversible Planar Solid Oxide Fuel-Fed Electrolysis Cell and Solid Oxide Fuel Cell for Hydrogen and Electricity Production Operating on Natural Gas/Biomass Fuels
}

\author{
Sponsored by \\ Golden Field Office, U.S. Department of Energy \\ Contract No. DE-FC36-04GO14350 \\ Submitted to: \\ Project Manager: Dr. David Peterson \\ Golden Field Office \\ U.S. Department of Energy \\ 1617 Cole Blvd. \\ Golden, CO 80401
Submitted by
Dr. Greg Gege Tao (Principal Investigator)
Materials and Systems Research, Inc.
5395 West 700 South
Salt Lake City, UT 84104
Phone: (801) 530-4987
FAX: (801) 530-4820

Effective Date of Contract: September 30, 2004

Contract Expiration Date: March 31, 2007, Reporting Period: 09/30/2004 - 03/31/2007

March 31, 2007 


\section{EXECUTIVE SUMMARY}

The principal objective of the project was to develop a solid oxide fuel-assisted electrolysis technique to co-generate hydrogen and electricity directly from a fuel at a reduced cost of electricity. A solid-oxide fuel-assisted electrolysis cell (SOFEC) is an electrochemical device, in which an oxidizable fuel is fed to the anode and steam is fed to the cathode. On the cathode, the steam is dissociated into oxygen ions that are transported through an oxygen ion-conducting electrolyte to oxidize the fuel on the anode. The dissociated hydrogen and residual steam are exhausted from the cathode and then separated by condensation of the steam to produce pure hydrogen. The rationale was that in such an approach the fuel provides a chemical potential in place of the external electrical potential conventionally used to drive electrolysis cells, such as solid oxide electrolysis cells (SOEC). To fulfill this objective, solid oxide fuel-assisted electrolysis cells (SOFECs), which were comprised of 8YSZ electrolytes sandwiched between thick anode supports and thin cathodes, were constructed and experimentally evaluated at various operation conditions on lab-level button cells with $2 \mathrm{~cm}^{2}$ per-cell active areas as well as on bench-scale stacks with $30 \mathrm{~cm}^{2}$ and $100 \mathrm{~cm}^{2}$ per-cell active areas. To reduce the concentration overpotentials, pore former systems were developed and engineered to optimize the microstructure and morphology of the Ni+8YSZ-based anodes. Chemically stable cathode materials, which possess good electronic and ionic conductivity and exhibit good electrocatalytic properties in both oxidizing and reducing gas atmospheres, were developed and materials properties were investigated. In order to increase the specific hydrogen production rate and thereby reduce the system volume and capital cost for commercial applications, a hybrid system that integrates the technologies of the SOFEC and the solid-oxide fuel cell (SOFC), was developed and successfully demonstrated at a $1 \mathrm{~kW}$ scale, co-generating hydrogen and electricity directly from chemical fuels. To our knowledge, this was the first reported demonstration of such a hybrid system operating at this scale.

The important results of this project are briefly described below. Details will be delineated within the body of this final technical report.

1. A ( $\mathrm{La}, \mathrm{Sr})(\mathrm{Cr}, \mathrm{Mn}) \mathrm{O}_{3}$ (LSCM) cathode material was developed and demonstrated to be electrocatalytically and chemically stable under both reducing and oxidizing atmospheres. Processes were also developed to fabricate nano-sized LSCM powders.

2. LSCM-based composite cathodes were developed and optimized for cell applications. Evaluation of the LSCM-based cathode was performed in button-cells operated in three modes: SOFC, SOEC and SOFEC.

3. SOFEC test results successfully demonstrated that for the electrolyzer assisted with a fuel, the external electricity required to split water can be significantly reduced by the fuel chemical energy. It was thus made possible to develop a highly electrically efficient hydrogen generation system built upon the SOFEC technology.

4. A long-term test was performed in the SOFC mode on a button cell with the LSCMbased cathode. Over the 5000-hour test, the LSCM-based composite cathode demonstrated high stability and low rates of degradation. 
5. A system and efficiency model of a hybrid stack comprised of SOFECs and SOFCs was developed and successfully used to simulate the hybrid stack characteristics.

6. A cost analysis of cogenerating hydrogen and electricity using the hybrid technology was developed and used in the performance model of the hybrid stack. The analysis performed for a forecourt hydrogen production application showed that the combined costs of the hybrid stack, BOP, and feedstock were less than the electricity cost associated with the traditional water electrolysis.

7. Anode-supported SOFECs and SOFCs were fabricated successfully with the optimized pore former additive.

8. The concept of the hydrogen generation method based on the SOFEC technology was successfully demonstrated using numerous short stacks of 2 to 10 cells per-stack with 100 $\mathrm{cm}^{2}$ per-cell active areas. Stacks were first evaluated at $800^{\circ} \mathrm{C}$ in the SOFC mode as a baseline, followed by SOFEC operation. Short stacks were capable of either generating up to 200 watts power or producing up to 1.7 standard liters of hydrogen per minute in the SOFC mode and the SOFEC mode, respectively.

9. Hybrid stacks with multiple SOFCs and SOFECs were successfully designed, constructed, and tested, demonstrating the viability of hydrogen and electricity cogeneration technology at a $1 \mathrm{~kW}$ scale. At $770^{\circ} \mathrm{C}$, a 33-cell hybrid stack comprised of 20 SOFECs and 13 SOFCs was capable of producing 5.4 standard liters of hydrogen per minute and simultaneously generating 225 watts of electricity net when syngas was used as the fuel. 
TABLE OF CONTENTS

PAGE

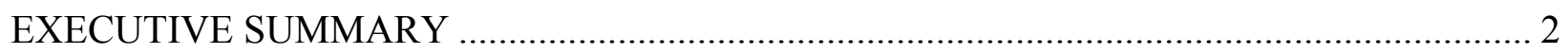

Technical Objectives of the Proposed Work ...................................................................... 7

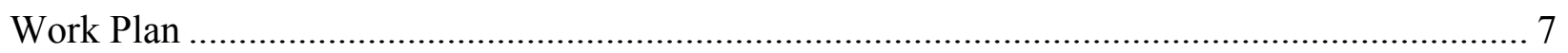

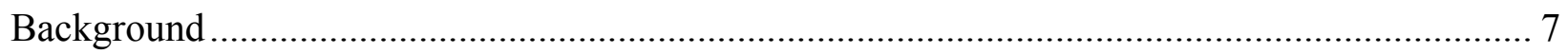

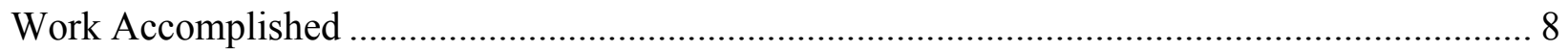

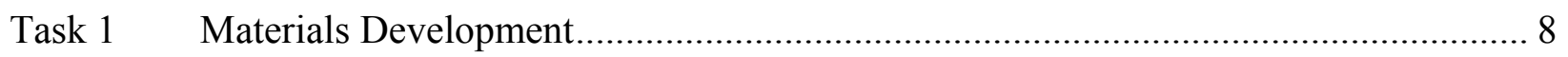

Task 1.1 Cathode Materials Acquisition ......................................................................... 9

Task 1.2 Electrical Conductivity Studies of LSM, LSCr, and LSCM ................................ 11

Task 1.3 LSCM Electrode Characterization Using Impedance Spectroscopy ...................... 12

Task 1.4 Long Term Stability Test of Symmetric Cells with LSCM Electrodes................... 12

Task 2 Efficiency Modeling of Stack and System ..................................................... 12

Task 2.1 Hybrid Stack Performance Model ........................................................................ 12

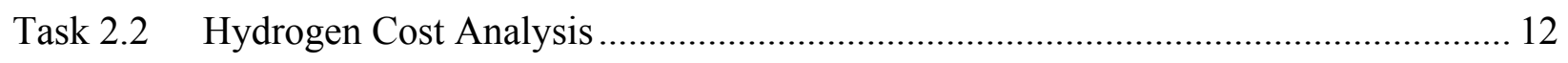

Task 3 Cell, Stack, and Manifold Design and Development .......................................... 12

Task 4 Fabrication of Anode-Supported SOFECs and SOFCs ..................................... 12

Task 5 Single Button Cell Testing in SOFC/SOFEC Mode............................................ 12

Task 5.1 Button Cell Test Fixture Construction.............................................................. 12

Task 5.2 LSCM Cathode Optimization ...................................................................... 12

Task 5.3 Button Cell Testing in the SOFC, SOEC, and SOFEC Modes .............................. 12

Task 5.4 Long-Term Stability Test of Cells with LSCM-Based Cathode ............................. 12

Task $6 \quad$ Fabrication of Non-cell Components and Seals ................................................ 12

Task 7 Proof of Concept, Short SOFEC/SOFC Stacks Testing ....................................... 12

Task 7.1 Catalyst Effects on Stack Performance.............................................................. 12

Task 7.2 SOFEC Concept Validation on 2"x2" Short Stacks ............................................ 12

Task 7.3 SOFEC Concept Validation on 4"x4" Short Stacks ............................................ 12

Task 8 Post Test Characterization of SOFECs and SOFCs .......................................... 12

Task 9 Assembly and Test of SOFEC-SOFC 1 kW Stacks .......................................... 12

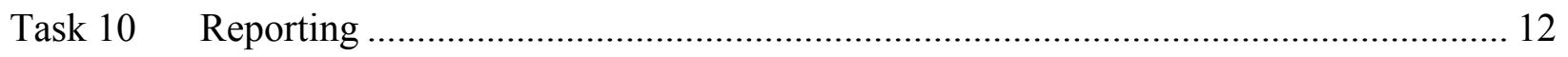




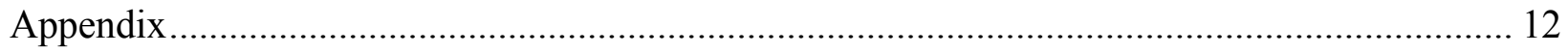

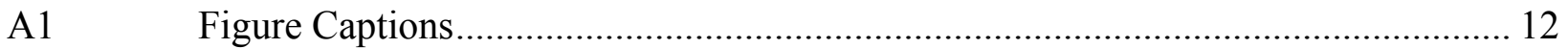

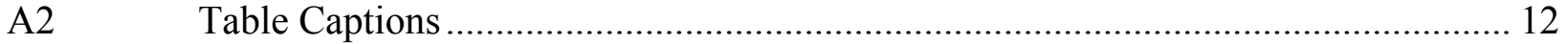

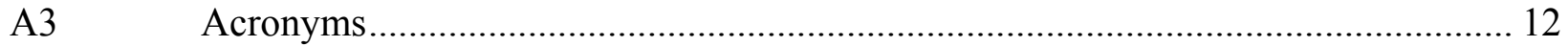




\section{Final Report}

Project Title:

A Reversible Planar Solid Oxide Fuel-Fed Electrolysis Cell and Solid Oxide Fuel Cell for Hydrogen and Electricity Production Operating on Natural Gas/Biomass Fuels

Project Period:

September 30, 2004 to March 31, 2007

Date of Report:

March 31, 2007

Recipient:

Materials and Systems Research, Inc.

Award Number:

DE-FC36-04GO14350

Working Partners:

Materials and Systems Research, Inc. (MSRI); the University of Missouri-Rolla (UMR), and Aker Industries, Inc. (AI)

Cost-Sharing Partners:

MSRI, UMR, and AI

\section{Contact:}

Greg Gege Tao, Ph.D. (Principal Investigator)

Phone: (801) 530-4987 Ext. 30

Email: gtao@msrihome.com

DOE Manager:

David Peterson, Ph.D. (Golden Field Office, Project Officer)

Phone: (303) 275-4956

Email: david.peterson@go.doe.gov 


\section{Technical Objectives of the Proposed Work}

The objective of this project was to develop a solid oxide fuel-assisted electrolysis technique to generate both hydrogen and electricity directly from hydrocarbon fuels. The objectives were:

- To develop and optimize cathode materials for the reversible solid oxide fuel-assisted electrolysis cell (SOFEC) and solid oxide fuel cell (SOFC) operating under both reducing and oxidizing environments.

- To perform electrochemical testing in SOFEC/SOFC modes with single button cells at temperatures between $700^{\circ} \mathrm{C}$ and $800^{\circ} \mathrm{C}$ to either electrolyze steam to produce hydrogen or generate electricity.

- To demonstrate the SOFEC/SOFC technology producing both hydrogen and electricity in a short stack.

- To develop and evaluate the state-of-the-art composite stack concept capable of generating $1 \mathrm{~kW}$ worth of electricity and/or hydrogen.

\section{Work Plan}

Task 1 Materials Development

Task 2 Efficiency Modeling of Stack and System

Task 3 Cell, Stack, and Manifold Design and Development

Task 4 Fabrication of Anode-Supported SOFECs and SOFCs

Task 5 Single Button Cell Testing in SOFC/SOFEC Mode

Task 6 Fabrication of Non-Cell Components and Seals

Task 7 Proof of Concept, Short SOFEC/SOFC Stacks Testing

Task 8 Post Test Characterization of SOFECs and SOFCs

Task 9 Assembly and Test of SOFEC-SOFC 1 kW Stacks

Task 10 Reporting

\section{Background}

Hydrogen has been long recognized as a potential chemical fuel to meet US energy needs while reducing carbon dioxide and other greenhouse gases emissions. There are numerous processes to produce hydrogen, such as conventional electrolysis and steam reforming natural gas or coal on an industrial scale, and thermochemical water splitting, photoelectrochemical processes and biological processes on a small scale. However, none of these technologies are sufficient to meet the needs of a hydrogen-based economy. For the traditional steam electrolysis using a solid oxide electrolysis cell (SOEC), which operates at $1000^{\circ} \mathrm{C}$ (e.g. HOT ELLY), a typical input voltage of 1.284 volts (the "thermoneutral voltage") is required to disassociate steam, corresponding to an adiabatic specific energy of $34.152 \mathrm{kWh} / \mathrm{kg} \mathrm{H} \mathrm{H}_{2}\left(0.11656 \mathrm{MBtu} / \mathrm{kg} \mathrm{H} \mathrm{H}_{2}\right)$. With perfect heat exchange from products to reactants, $39.383 \mathrm{kWh} / \mathrm{kg} \mathrm{H}_{2}(0.13441 \mathrm{MBtu} / \mathrm{kg}$ $\mathrm{H}_{2}$ ) is required. This leads to large electricity costs and low system efficiency, and has made hydrogen production with the SOEC-based technology uncompetitive with other processes. Presently, the cost of hydrogen produced by the other conventional electrolysis technologies is over $50 \mathrm{kWh}$ (e) per kg of hydrogen for alkaline or PEM electrolysis. Consequently, hydrogen produced by steam reformation of natural gas represents the only currently available economical 
means of mass-producing hydrogen. However, purification of the hydrogen stream, separation of the effluent carbon dioxide, and additional infrastructure, for instance hydrogen storage, distribution pipeline build-up, supply chain, and transportation from hydrogen central production factory to hydrogen end user, add appreciable costs, thus making steam reformation inappropriate for small-scale applications, such as an automobile refueling station.

An attractive alternative is to use a reversible SOFC with direct chemical potential assists to produce not only clean hydrogen for onsite applications, but also to deliver electricity to powerparks directly from either natural gas (which has well established distribution infrastructure national wide) or from locally available renewable resources. A solid oxide fuel-assisted electrolysis cell (SOFEC) is an electrochemical device, similar to a SOFC that generates electricity from a fuel on the anode side and air at the cathode side. Substituting the air at the cathode of the SOFC by steam as an oxidant, the SOFEC is formed to generate hydrogen by dissociating the steam into hydrogen and oxygen ions. Along the residual steam, the dissociated hydrogen exhausts from the SOFEC cathode and then separated by condensation of the steam, forming a pure hydrogen gas. Meanwhile, oxygen ions transport through an oxygen ionconducting electrolyte and oxidize the fuel at the SOFEC anode. In this approach the fuel provides a chemical potential in place of the electrical potential, conventionally used to drive electrolysis cells.

Because of the similar nature of the SOFC and SOFEC, technologies previously developed for the SOFC can be leveraged for the SOFEC development. The project recipient has been conducting extensive research and development in past years to engineer intermediatetemperature high performance anode-supported SOFC (IT-SOFC) electrical power generation systems by optimizing the cell materials and microstructures.

\section{Work Accomplished}

Work completed in this program is described in what follows.

Task 1 Materials Development

Materials development was a joint research effort by UMR and MSRI in which prospective cathode materials for the SOFEC application were developed and characterized. The following paragraphs describe the steps which were taken to bring the task to successful completion.

Choice of cathode materials: A SOFEC, comprised of an oxygen ion-conducting electrolyte sandwiched between two electrodes, is an electrochemical cell in which an oxidizable fuel is fed to the anode and steam is fed to the cathode. At the cathode, the steam is dissociated into oxygen ions that are transported through the electrolyte to oxidize the fuel on the anode. The dissociated hydrogen and the residual steam are exhausted from the cathode and separated by condensing the steam. In this approach the fuel on the anode provides a chemical potential in place of the electrical potential conventionally used to drive electrolysis cells. Also, by switching its cathode feed from steam to air, the SOFEC can be operated in the SOFC mode to generate electricity from the anode fuel, giving the SOFEC stack superior operational flexibility. 
To provide for such flexibility, the cathode material of the SOFEC must possess good electronic and ionic conductivity, exhibit sufficient electrocatalytic properties, and be stable in both oxidizing (in the SOFC operating mode) and reducing (in the SOFEC operating mode) atmospheres. Consequently, manganites or ferrites, typical cathode materials developed for SOFCs, may not be suitable for use as SOFECs cathodes because they either decompose or have too much thermal expansion. This task was aimed at developing a redox stable cathode for the SOFEC application. Mixed conducting perovskite-type oxides were investigated, synthesized, and tested for their stability over a wide range of oxygen activity conditions.

A literature search was carried out before material selection activities were completed. Chromites, such as $(\mathrm{La}, \mathrm{Ca}) \mathrm{CrO}_{3}(\mathrm{LCC})$ or $(\mathrm{La}, \mathrm{Sr}) \mathrm{CrO}_{3}$ ( $\mathrm{LSCr}$ ), have been proven to possess good electronic conductivity and to be stable in oxidizing and reducing environments, making them suitable for use as cathode materials. When LSCr is prepared such that the B-sites are doped by other multivalent transition elements, for instance Mn, oxygen vacancies are generated when the material is exposed to a reducing atmosphere at high temperatures. The research group led by Irvine ${ }^{*}$ studied the $\mathrm{La}_{0.75} \mathrm{Sr}_{0.25} \mathrm{Cr}_{0.5} \mathrm{Mn}_{0.5} \mathrm{O}_{3}$ (LSCM) as a SOFC anode to replace the nickel anode used for the conventional SOFC. Their results showed that the electrochemical performance of the LSCM anode was comparable to that of $\mathrm{Ni}+\mathrm{YSZ}$ anode. Based on the available information, (La,Sr) $\mathrm{MnO}_{3}$ (LSM), (La,Sr) $\mathrm{CrO}_{3}$ (LSCr) and ( $\left.\mathrm{La}, \mathrm{Sr}\right)(\mathrm{Cr}, \mathrm{Mn}) \mathrm{O}_{3}$ (LSCM) were selected as candidate materials for the SOFEC application. Since there was insufficient data available on these materials over the temperature and oxygen activity ranges of interest, their electrical properties and chemical stability were evaluated and are discussed in following paragraphs. The area specific resistance (ASR) of the materials and impedance of the LSCM symmetrical cells were also investigated.

\section{Task 1.1 Cathode Materials Acquisition}

Since LSM and LSCr have been standard cathode materials for SOFC applications, commercial products were purchased directly from Praxair Inc. On the other hand, LSCM powders were prepared in-house using a series of water-based chemical preparation techniques: glycine-nitrate, ethylene glycol, citric acid, sucrose, or ammonium nitrate, in nano size. All were annealed at $600^{\circ} \mathrm{C}$ for 2 hours in order to minimize the residual hydrocarbons. The resulting powders were prepared as inks, screen-printed onto alumina and YSZ substrates, and sintered at temperatures ranging from $1200^{\circ} \mathrm{C}$ to $1400^{\circ} \mathrm{C}$ for 2 hours in air for further evaluation. The printed LSCM films were then examined with an optical microscope to inspect if they were uniform and were scratched by a razor blade to qualitatively evaluate the adhesion of the powder to the substrate and itself. The powders prepared by glycine-nitrate, sucrose, and ammonium nitrate showed poor sinterability and poor adhesion to substrates due to agglomeration of nano size powders. However, although the nano-sized powders obtained from the ethylene glycol were also agglomerated, the particles were sufficiently soft to be broken into nano particles by the sonication. Figure 1 (a) and (b) show the differences between the particles before and after the sonication process. The resulting fine powders remained suspended in ethanol for at least 24 hours after the initial ultrasonic processing. These fine powders were separated from the agglomerates by pouring the top layer of the alcohol into another beaker, followed by a drying process in an oven.

\footnotetext{
${ }^{*}$ S. Tao and J.T.S. Irvine, Nature Materials, 2(5), 320 (2003)
} 


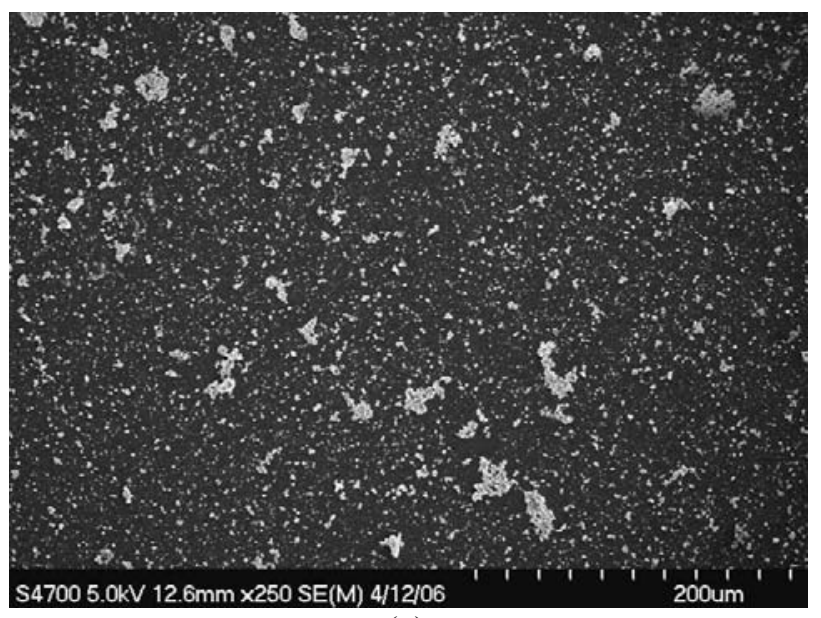

(a)

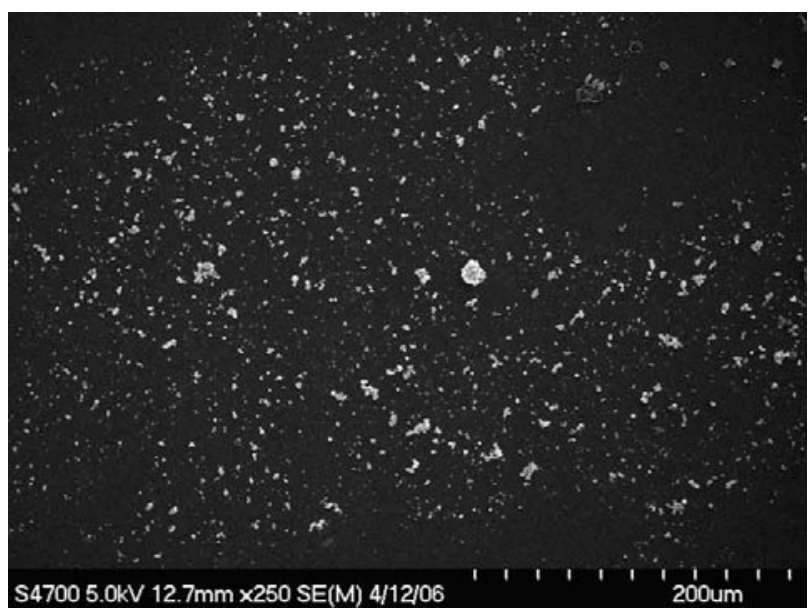

(b)

Figure 1. LSCM using ethylene glycol before sonication (a) and after sonication (b)

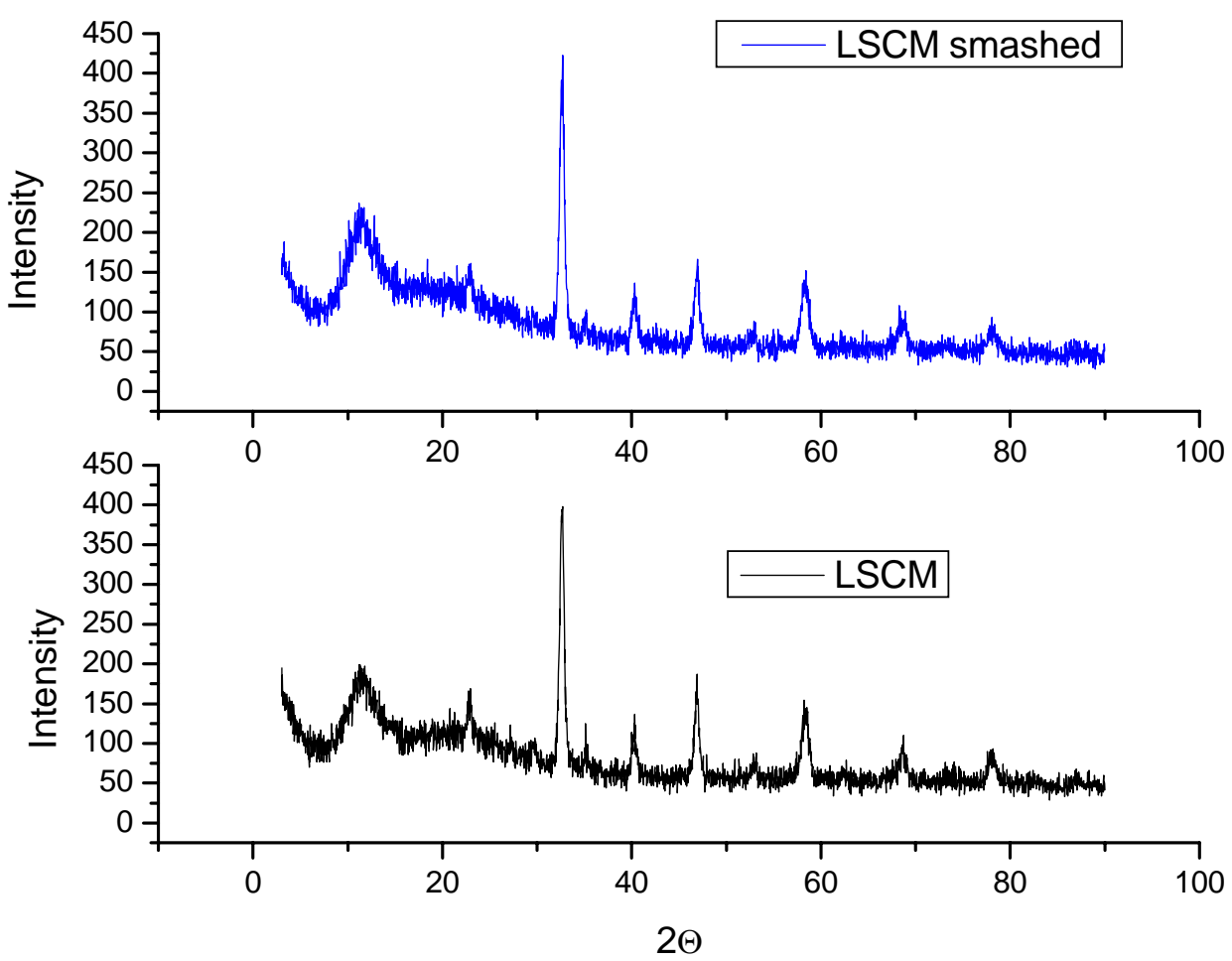

Figure 2. XRD patterns of the as-prepared LSCM and the smashed LSCM powders

Optimization of LSCM: By changing the cation concentration of the LSCM solution, the quality such as particle size, dispersability etc., was improved without changing the composition of the LSCM powders. Some of the prepared LSCM powders were then milled with a tungsten ball in a vial with tungsten lining using a pulverizing and blending machine. The powders then underwent characterization using X-Ray Diffraction (XRD), the results of which were compared 
with both the as-prepared and the milled LSCM powders. As shown in Figure 2, no difference is observed between the as-prepared and the milled-LSCM powders. Nevertheless, optical micrographs of these two powders, shown in Figure 3, exhibit less agglomeration and better dispersion of the LSCM powder after milling than the as-prepared powder.

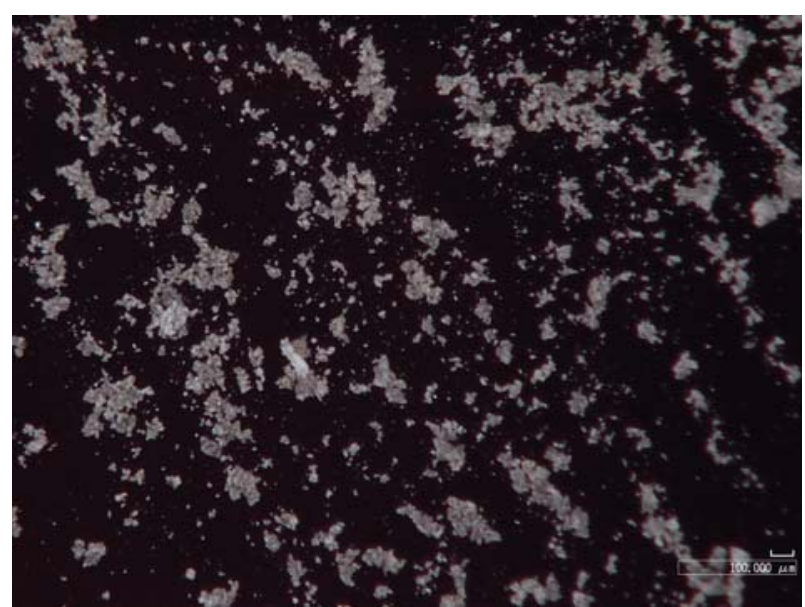

(a)

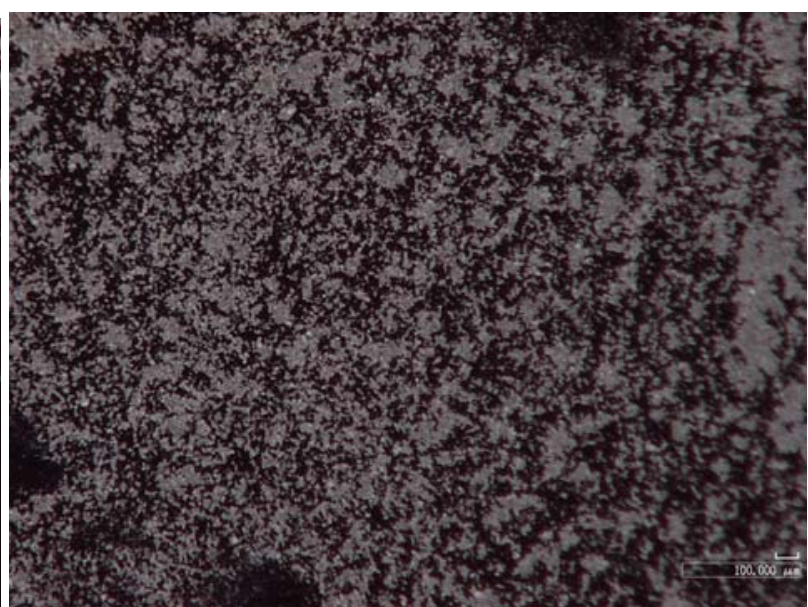

(b)

Figure 3. Optical micrographs of LSCM powders (a) as-prepared; (b) after milling with a tungsten ball in a vial

\section{Task 1.2 Electrical Conductivity Studies of LSM, LSCr, and LSCM}

The oxygen activity limit before breakdown (chemically and/or mechanically) of LSM $\left(\mathrm{La}_{0.7} \mathrm{Sr}_{0.3} \mathrm{MnO}_{3}\right)$, LSCr $\left(\mathrm{La}_{0.7} \mathrm{Sr}_{0.3} \mathrm{CrO}_{3}\right)$, and LSCM $\left(\mathrm{La}_{0.75} \mathrm{Sr}_{0.25} \mathrm{Cr}_{0.5} \mathrm{Mn}_{0.5} \mathrm{O}_{3}\right)$ has been investigated by measuring the electrical conductivity as a function of oxygen activity and temperature. The LSM, LSCr, and LSCM powders were iso-pressed with $10 \mathrm{kpsi}$ forming pellets that were then sintered in air at $1400^{\circ} \mathrm{C}$ for 5 hours. Densities of the sintered samples were measured and compared with the theoretical densities of the corresponding materials. The sintered pellets were then cut into solid rectangular bars for electrical conductivity measurements, which were taken as a function of oxygen activity at the temperature range between 500 and $800^{\circ} \mathrm{C}$. The conductivity measurements were carried out using the D.C. fourpoint probe electrical conductivity method with four Pt contact wires. A Solartron Analytical 1470 Cell Tester was used to measure current changes by the potentiolstatic method and the instrument was connected to a personal computer to measure the current change between the two outer Pt wires.

Electrical conductivity of LSCr as a function of oxygen activity and temperatures: The electrical conductivity studies of LSCr were made first as a function of oxygen activity in the temperature range of 500 to $800^{\circ} \mathrm{C}$, and the results are shown in Figure 4 . At $500^{\circ} \mathrm{C}$, neither n-type conductivity was observed near oxygen activity at $1 \times 10^{-35}$, nor did dissociation take place, implying a strong chemical stability of LSCr under that low oxygen activity atmosphere. However, the electrical conductivity of LSCr was too low for use as a cathode in the present application. The electrical conductivity as measured was approximately $10 \mathrm{~S} / \mathrm{cm}$ in the oxygen activity range between air and $1 \times 10^{-15} \sim-20$ (depending on temperatures) and dropped sharply 
below that oxygen activity range. This was due to the oxygen vacancy creation, which resulted in a lower concentration of hole $\left(\mathrm{p}=\left[\mathrm{La}^{\prime}{ }_{\mathrm{Sr}}\right]-2\left[\mathrm{~V}^{*}{ }_{\mathrm{O}}\right]\right)$.

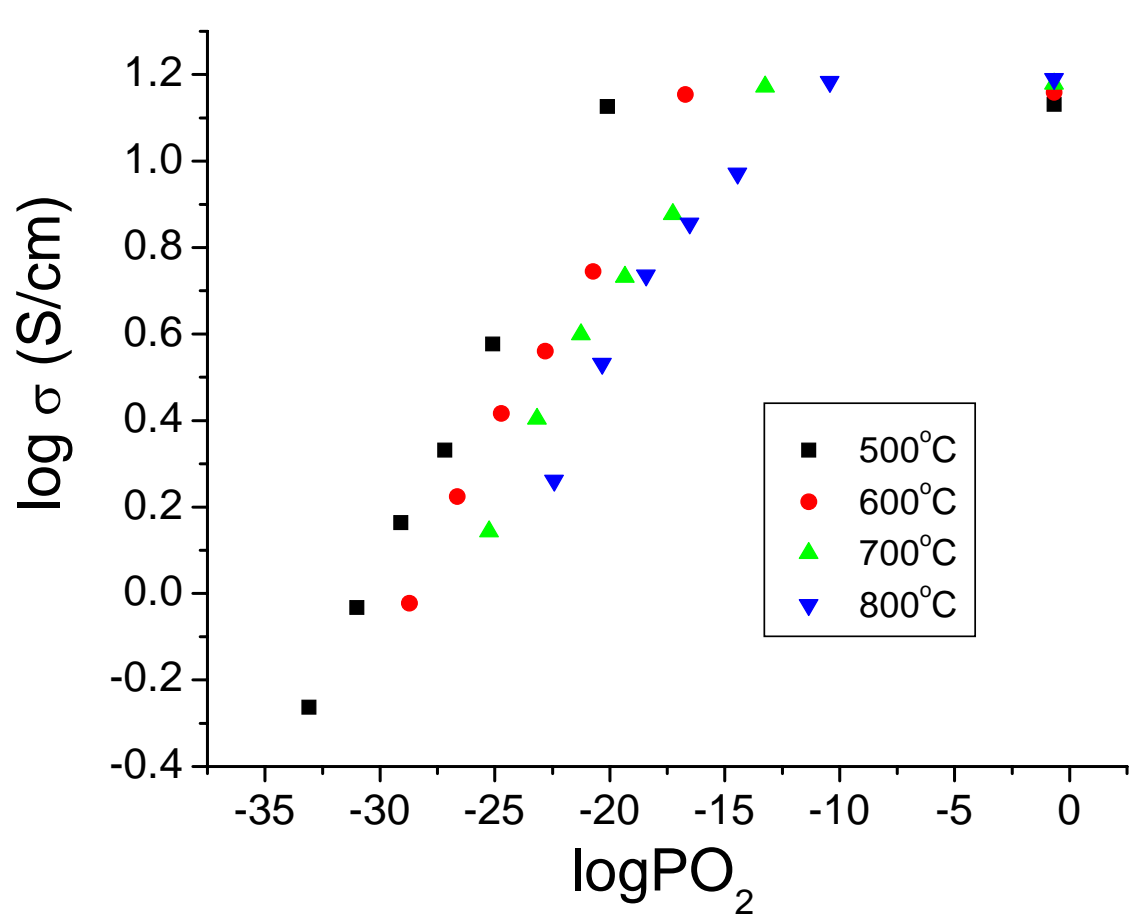

Figure 4. Electrical conductivity of LSCr as a function of temperatures and oxygen activities

Electrical conductivities of LSCr, LSM, and LSCM as a function of oxygen activity at $800^{\circ} \mathrm{C}$ : The electrical conductivity measurements were carried out at both UMR and MSRI on porous specimens of LSCM, LSCr and LSM, because over the temperatures and oxygen activity range of interest, and the time required to equilibrate a dense specimen would be measured in weeks. Though the use of porous specimens may lead to an issue with obtaining absolute conductivity values, the behavior to changing ambient conditions will not be influenced. The density of the sintered samples was $\sim 65 \%$ of the theoretical density for LSM and LSCr, and $\sim 80 \%$ for LSCM. Figure 5 shows the conductivity results as a function of oxygen activity at $800^{\circ} \mathrm{C}$. The electrical conductivity of LSCM is about $4 \sim 10 \mathrm{~S} / \mathrm{cm}$ in air at the temperature range between 500 and $800^{\circ} \mathrm{C}$, lower than those of both LSCr and LSM, which are $13 \sim 15 \mathrm{~S} / \mathrm{cm}$ and $49 \sim 56 \mathrm{~S} / \mathrm{cm}$, respectively. As shown in the figure, the oxygen activity at which the electrical conductivity starts to decrease is composition dependent, with LSCr being the most stable, LSM the least stable, and LSCM in between.

As anticipated, the porous LSCM sample had lower conductivities than the higher density LSCM because of the influence of porosity. As seen in Figure 5, the electrical conductivity of the LSCM with $95 \%$ of the theoretical density at $800^{\circ} \mathrm{C}$ in air increases to $27 \mathrm{~S} / \mathrm{cm}$, which agrees with the conductivity value obtained by both MSRI and UMR. 


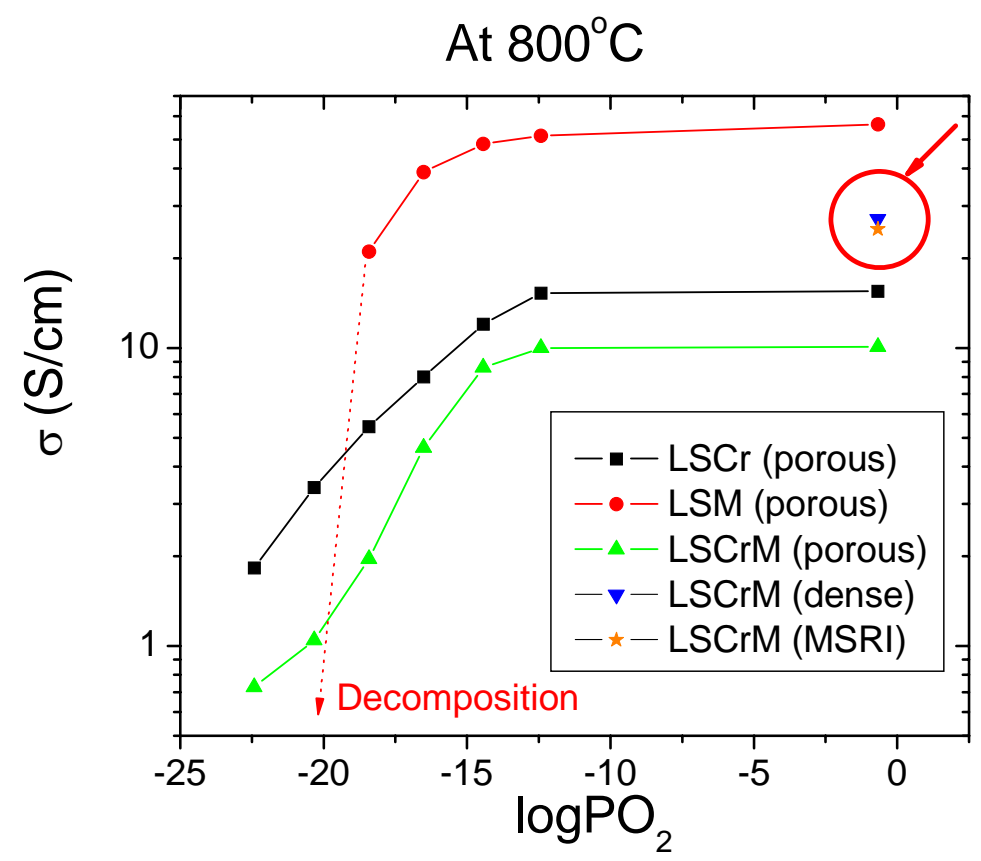

Figure 5. The conductivities of LSCr, LSM, and LSCM as a function of oxygen activity at $800^{\circ} \mathrm{C}$

Redox stability of LSM, LSCr, and LSCM as a function of oxygen activity and temperature: One of the advantages of the SOFEC is its versatility of operation, either in the fuel cell mode or in the electrolyzer mode. Such flexibility requires cathode stability after redox cycles. The redox stability test was therefore carried out by measuring the electrical conductivity as a function of the oxygen activity between 1 (air) and $10^{-34}\left(99 \% \mathrm{CO}\right.$ balanced with $\left.\mathrm{CO}_{2}\right)$, with temperatures ranging between 500 and $800^{\circ} \mathrm{C}$.

Figure 6 shows the electrical conductivity of LSM after redox cycles. All the measured changes were reversible except for that at $5 \times 10^{-21}$ atm oxygen $\left(90 \% \mathrm{CO}-10 \% \mathrm{CO}_{2}\right)$ tested at $800^{\circ} \mathrm{C}$. Under this condition, the electrical conductivity of LSM dropped to $0.1 \mathrm{~S} / \mathrm{cm}$ and didn't recover to the original conductivity in air $(56 \mathrm{~S} / \mathrm{cm})$ due to a crack of the LSM when cycling between air and $5 \times 10^{-21} \mathrm{~atm}$. XRD was carried out on the LSM samples which were heated at $800^{\circ} \mathrm{C}$ in air and the atmosphere of $90 \% \mathrm{CO}-10 \% \mathrm{CO}_{2}\left(5 \times 10^{-21} \mathrm{~atm}\right)$. As shown in Figure 7, the LSM sample cooled in the $90 \% \mathrm{CO}-10 \% \mathrm{CO}_{2}$ atmosphere showed an evidence of the formation of a secondary phase. Interestingly, there was no evidence of the secondary phase after annealing of LSM in the $90 \% \mathrm{CO}-10 \% \mathrm{CO}_{2}$ atmosphere, when the atmosphere was switched to air prior to cooling. It is concluded that LSM is stable in redox testing and fully reversible at least in terms of electrical conductivity in the range of air $\sim 8 \times 10^{-30}$ (at $500^{\circ} \mathrm{C}$ ) and $4 \times 10^{-19}$ (at $800^{\circ} \mathrm{C}$ ) (if cracking does not occur). 


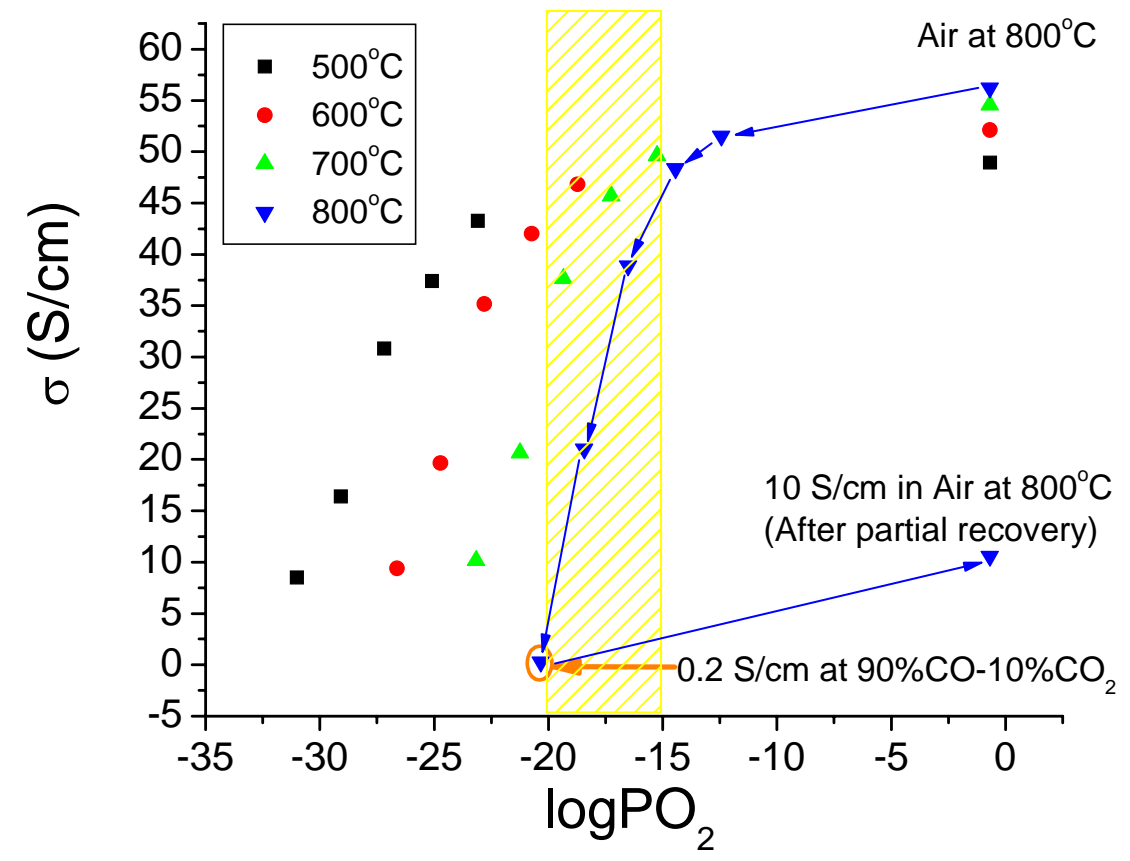

Figure 6. Electrical conductivity of LSM as a function of oxygen activity and temperature

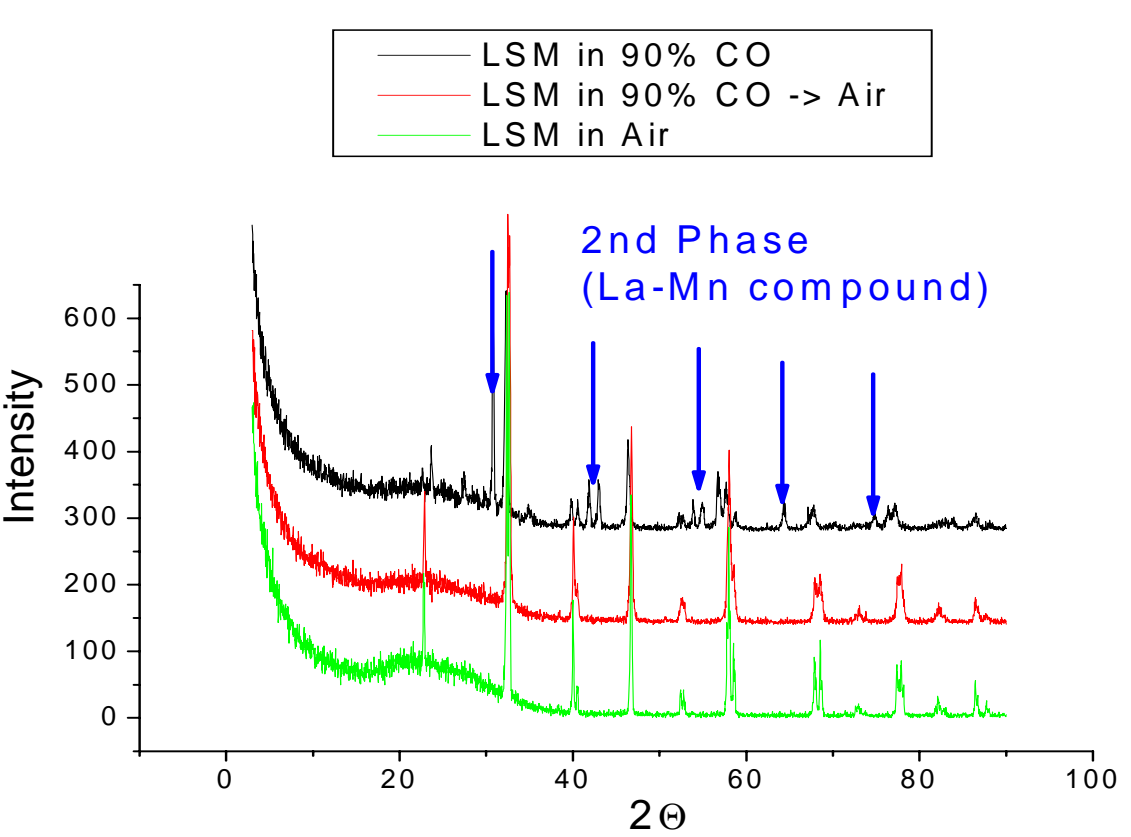

Figure 7. XRD of LSM quenched in Air, $90 \% \mathrm{CO}-10 \% \mathrm{CO}_{2}$, and treated in $90 \% \mathrm{CO}-10 \% \mathrm{CO}_{2}$ followed by in air at $800^{\circ} \mathrm{C}$ 
A similar redox stability test was carried out on $\mathrm{LSCr}$ as a function of oxygen activity at $800^{\circ} \mathrm{C}$. After several redox cycles in $99 \% \mathrm{CO}-1 \% \mathrm{CO}_{2}$ at $500 \sim 800^{\circ} \mathrm{C}$, $\mathrm{LSCr}$ remained stable, as shown in Figure 8.

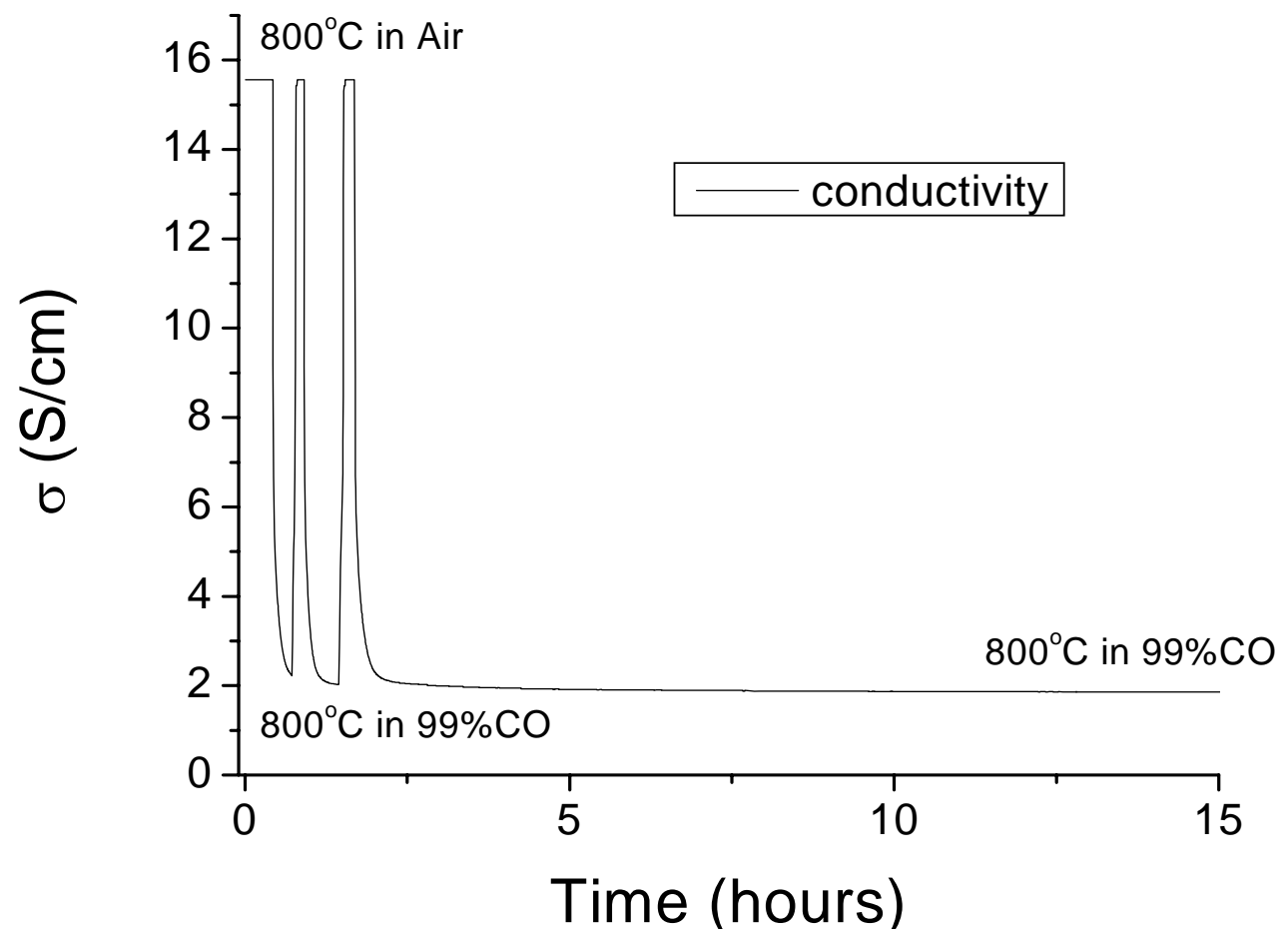

Figure 8 . Redox stability test of LSCr as a function of oxygen activity at $800^{\circ} \mathrm{C}$

Using the same procedure developed for the conductivity measurement, the conductivity of LSCM was measured at $800^{\circ} \mathrm{C}$. Figure 9 shows the results of the redox test of LSCM as a function of oxygen activity and temperatures. As shown in the figure, LSCM is more stable than LSM, since the electrical conductivity appears to be reversible when the LSCM sample was cycled between air and the $99 \% \mathrm{CO}-1 \% \mathrm{CO}_{2}$ atmosphere at $800^{\circ} \mathrm{C}$. Such data suggest that LSCM has sufficient stability to function as a cathode for the fuel-assisted electrolysis cell applications. 


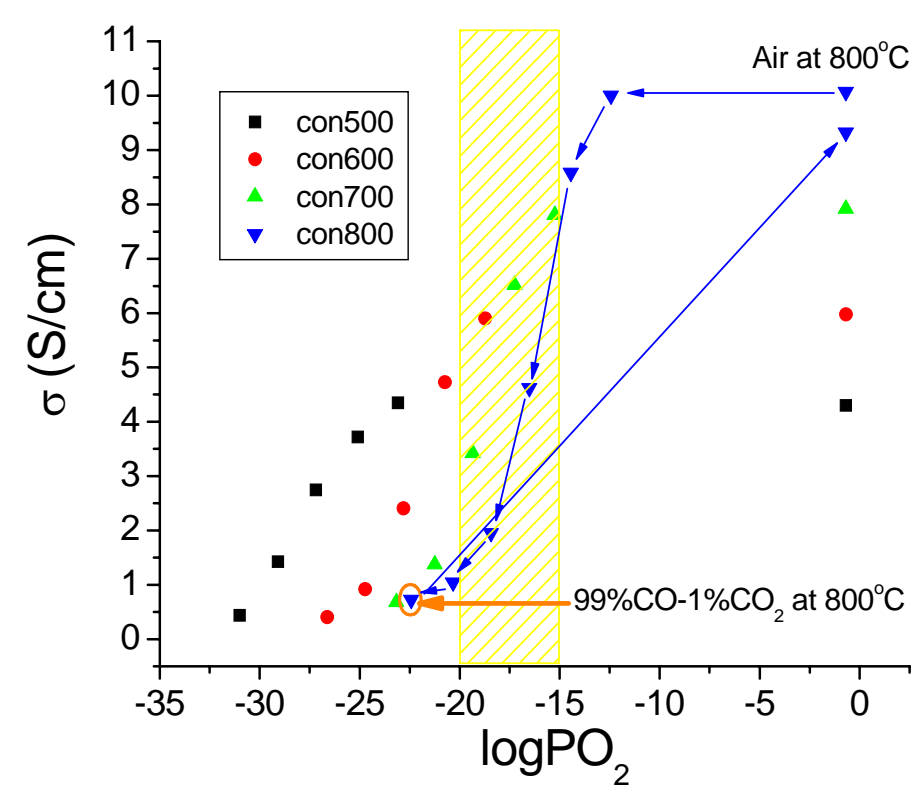

Figure 9. Electrical conductivity of LSCM as a function of oxygen activity and temperature

\section{Task 1.3 LSCM Electrode Characterization Using Impedance Spectroscopy}

The conductivity and redox tests over temperatures and oxygen activities suggested that LSCM had sufficient stability to perform as a cathode for SOFECs. Impedance spectroscopy was therefore used to evaluate the performance of LSCM on symmetrical cells with either Ag or Pt current collectors. Figure 10 (a) and (b) show the test results of these cells, which were performed with both electrodes under an air atmosphere. The intersection between the Z'-axis and the impedance spectrum at the high frequency range was considered to be the electrolyte resistance (ohmic resistance). The resistance of the YSZ electrolyte was estimated based on the thickness of the YSZ electrolyte (i.e., about $130 \mu \mathrm{m}$ ) which yielded an ASR of the YSZ about $0.4 \Omega \mathrm{cm}^{2}$. Therefore, if the measured ASR exceeds $0.4 \Omega \mathrm{cm}^{2}$, the additional sources of resistance such as interfacial contact resistances will be considered. As shown in Figure 10 (a), an extra resistance was observed when $\mathrm{Ag}$ was used as the current collector. In order to investigate the extra resistance introduced, the $\mathrm{Ag}$ current collect was replaced by Pt. It is interesting that the extra resistance no longer existed and the value of the YSZ electrolyte resistance was close to $0.4 \Omega \mathrm{cm}^{2}$, suggesting nearly no ASR contributed from the contact and electrodes. 


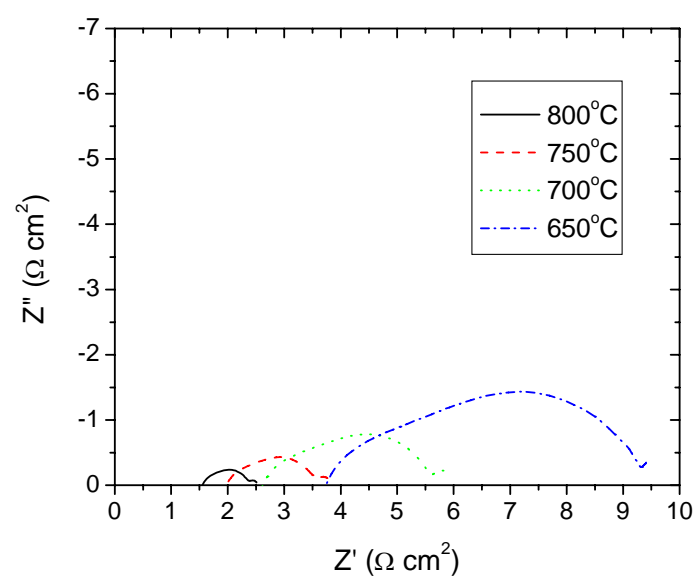

(a)

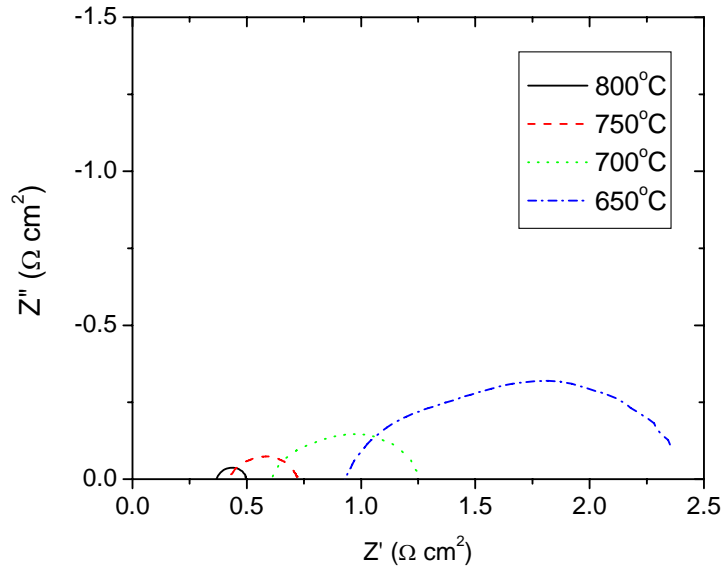

(b)

Figure 10. The impedance spectra of LSCM symmetrical cells with (a) Ag as the current collector and (b) $\mathrm{Pt}$ as the current collector during the symmetrical cell tests

\section{Task 1.4 Long Term Stability Test of Symmetric Cells with LSCM Electrodes}

Symmetric cells were constructed on 8YSZ electrolyte supports and operated in the SOFC mode. In an effort to investigate the resistance sources in the LSCM symmetrical cells, impedance spectroscopy was carried out during the fuel cell tests. Cells were first operated under an air atmosphere as a baseline to identify the sources of ohmic ASR, followed by tests with a wet hydrogen gas $\left(3 \% \mathrm{H}_{2} \mathrm{O}-10 \% \mathrm{H}_{2}\right.$-balanced $\left.\mathrm{N}_{2}\right)$ atmosphere at $800^{\circ} \mathrm{C}$. Figure 11 and Figure 12 are the impedance spectra obtained with the air atmosphere on both sides of the cell, and with air on one side but wet hydrogen on the other side, respectively. As a comparison, the impedance spectra of air on both sides are also plotted in Figure 12. The electrode active areas were 0.3 $\mathrm{cm}^{2}$, and the thickness of the 8YSZ electrolyte support was $100 \mu \mathrm{m}$. The ohmic ASR of the electrolyte was estimated to be $\sim 0.3 \Omega \mathrm{cm}^{2}$, which coincided with the experimental data extracted from Figure 11 (the intersection between the semi-circle at the high frequency range and the Z'-axis). This suggests no additional resistance is presented when air flows over both electrodes, but that additional resistances are present when wet hydrogen replaces air on one side of the electrode, as shown in Figure 12. The source of the additional resistance could be due to the interfacial resistance between electrodes and current collectors. 


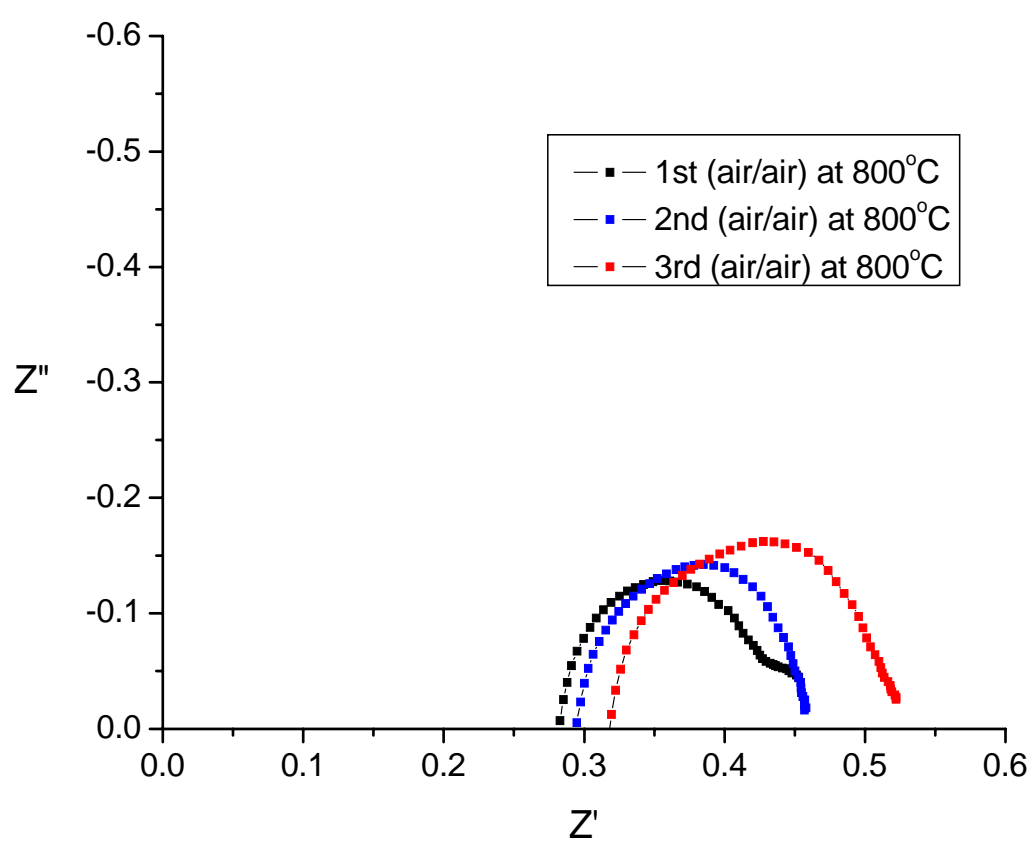

Figure 11. Impedance spectroscopy of a symmetric cell with both LSCM electrodes in air atmosphere at $800^{\circ} \mathrm{C}$ (electrode area $=0.3 \mathrm{~cm}^{2}$ )

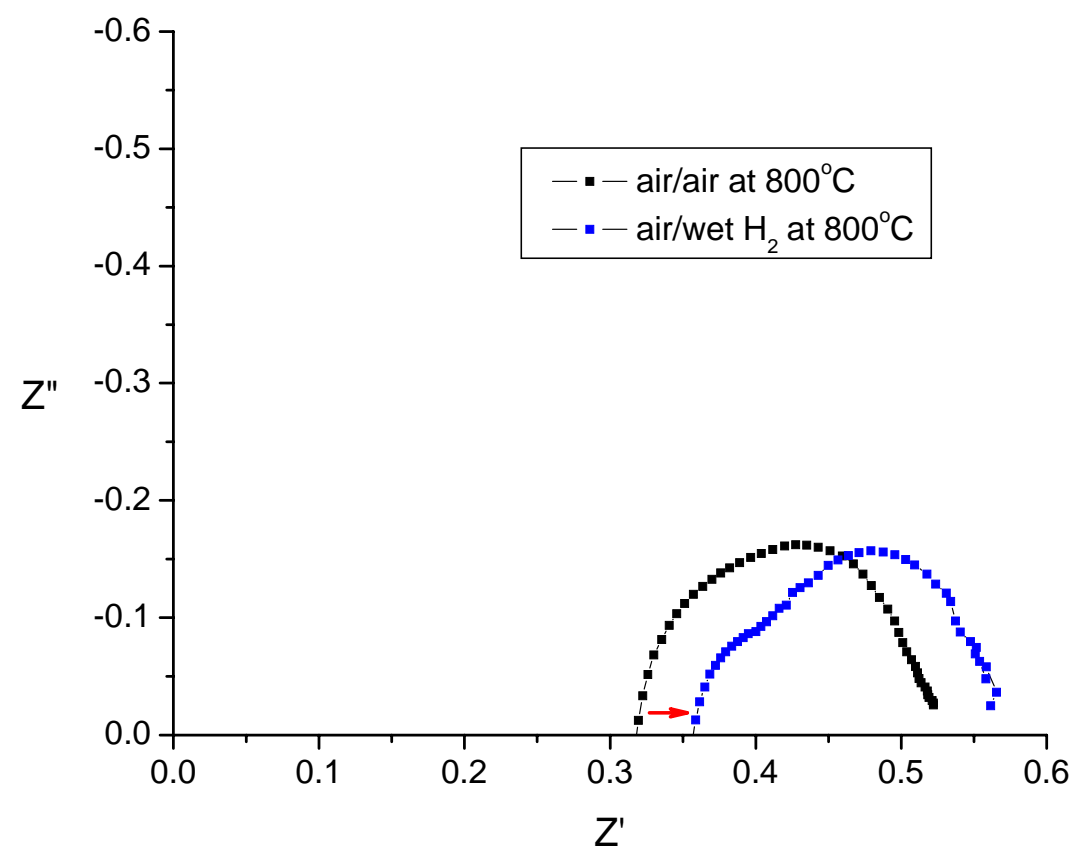

Figure 12. Impedance spectroscopy of a symmetric cell with LSCM electrodes in air atmosphere on one side and wet $10 \% \mathrm{H}_{2}$ on the other side at $800^{\circ} \mathrm{C}$ (electrode area $=0.3 \mathrm{~cm}^{2}$ ) 
A long-term stability test was carried out using $3 \% \mathrm{H}_{2} \mathrm{O}-10 \% \mathrm{H}_{2}$-balance $\mathrm{N}_{2}$ gas mixtures for about 200 hours, as shown in Figure 13. The test was interrupted several times due to unexpected incidents, such as a broken sample holder and power failures, however as shown in the figure, every time after the current collector was re-applied (at 40,110, and 150 hours), the current density went back to the original value close to $1.6 \mathrm{~A} / \mathrm{cm}^{2}$. This suggests that the $18 \%$ drop in current density be probably due to the contact degradation between the LSCM electrode and the current collector rather than the material itself.

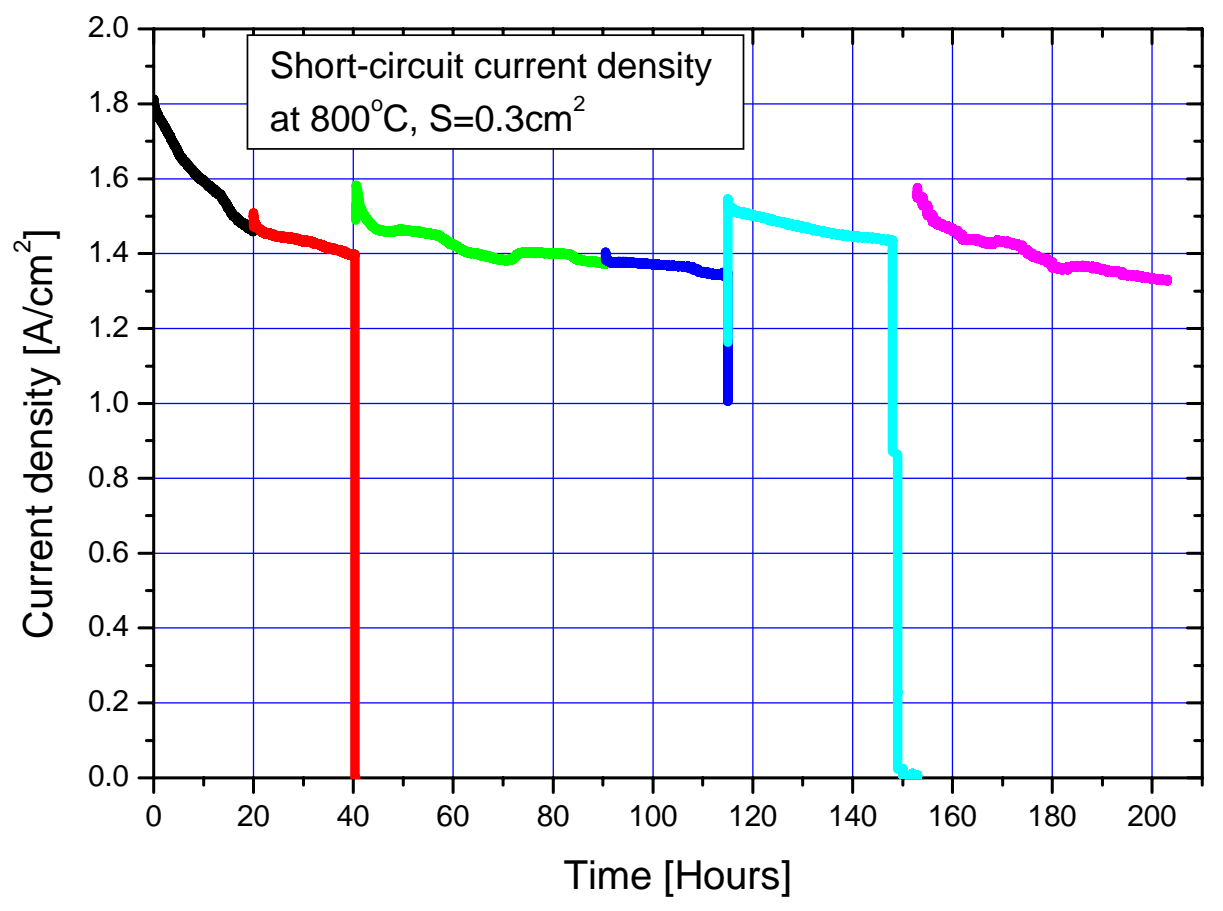

Figure 13. Long-term stability test of LSCM electrodes using short-circuit current density measurement in $3 \% \mathrm{H}_{2} \mathrm{O}-10 \% \mathrm{H}_{2}$-balance $\mathrm{N}_{2}$ gas mixture at $800^{\circ} \mathrm{C}$

During the long-term test, six impedance spectra were measured. As shown in Figure 14, the ASR defined as the intersection between the semicircle and the Z'-axis (at a high frequency range) is about $0.35 \Omega \mathrm{cm}^{2}$ during the initial test (1st test), increasing to $0.48 \Omega \mathrm{cm}^{2}$ after 150 hours, amounting to a degradation of $35 \%$. The Pt current collector was re-applied on the surface of the LSCM electrode before the last impedance test (6th test), after which the ASR returned to $0.35 \Omega \mathrm{cm}^{2}$. This suggests that the major source of degradation is the contact between the current collector and the LSCM electrode. 


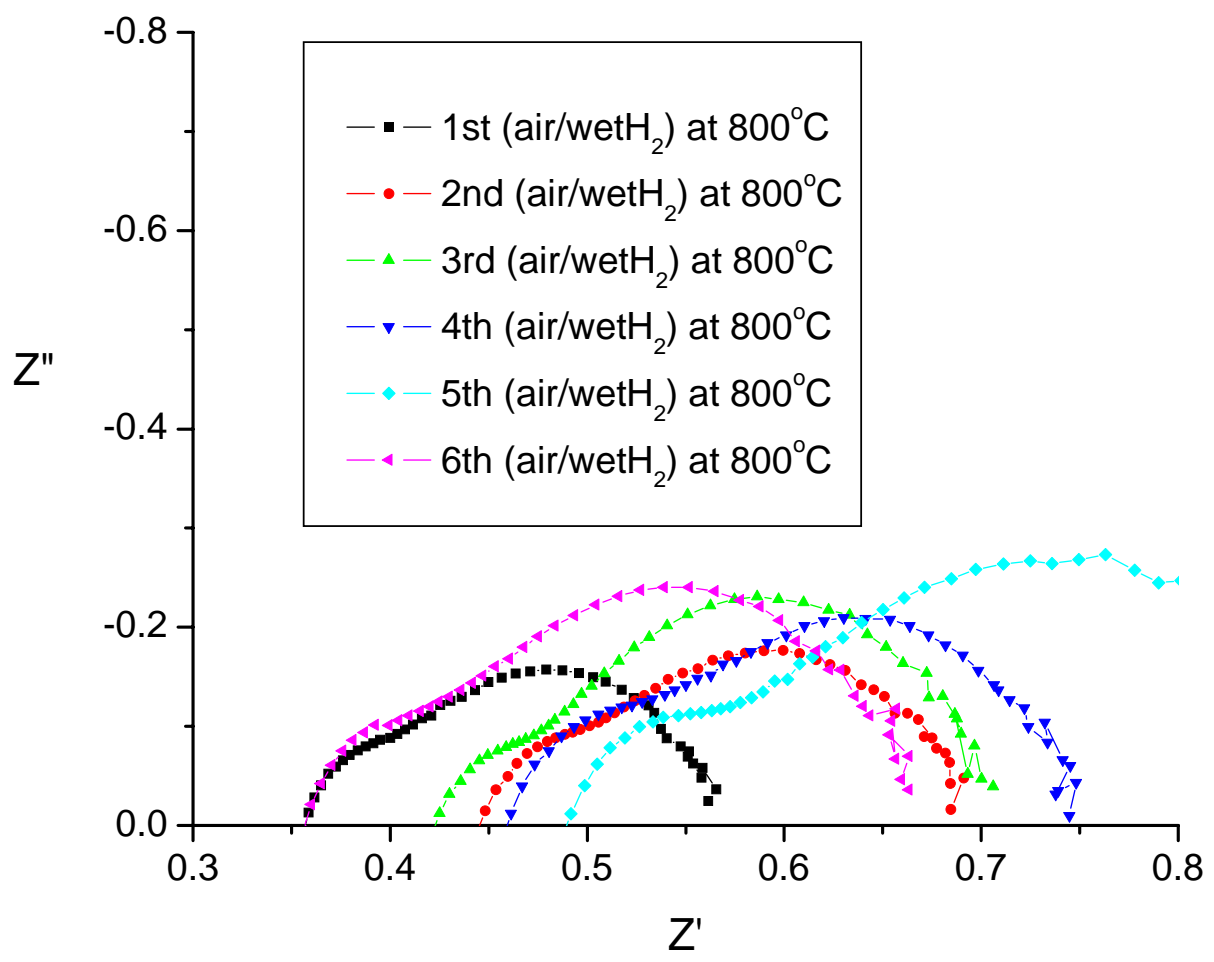

Figure 14. Impedance spectroscopy of LSCM electrodes for the fuel cell test in air and wet $10 \% \mathrm{H}_{2}-$ balance $\mathrm{N}_{2}$ at $800^{\circ} \mathrm{C}$ (electrode area $=0.3 \mathrm{~cm}^{2}$ )

An interesting change in the ASR of the LSCM cell occurred when wet $\mathrm{H}_{2}$ fuel was replaced by $50 \% \mathrm{CO} / 50 \% \mathrm{CO}_{2}$. As shown in Figure 15, a large semi-circle is observed in the low frequency range when the $\mathrm{CO} / \mathrm{CO}_{2}$ fuel is used, corresponding to an ASR of $1.2 \Omega \mathrm{cm}^{2}$. However, the same cell's ASR is $0.56 \Omega \mathrm{cm}^{2}$ when wet hydrogen is used as the fuel. The oxygen activity at $800^{\circ} \mathrm{C}$ of the two gas mixtures is very close, for example, $3.8 \times 10^{-19}$ and $4.9 \times 10^{-20}$ atm for the wet $\mathrm{H}_{2}$ and $\mathrm{CO} / \mathrm{CO}_{2}$, respectively. Therefore, the difference of ASR does not appear to be related to the difference of the oxygen activity. It is suspected that this difference is either due to the gaseous reaction kinetics: (1) between oxygen and $\mathrm{CO} / \mathrm{CO}_{2} ;(2)$ between oxygen and hydrogen, or due to the difference in the gas/solid reaction kinetics occurring at the surface of the YSZ and/or LSCM. Current-voltage characteristics of the cell plotted in Figure 16 show the evidence supporting this conclusion. As is observed, the slope of the current-voltage curves is much steeper when $\mathrm{CO} / \mathrm{CO}_{2}$ (slope $=-1.55$ at $0-0.3 \mathrm{~A} / \mathrm{cm}^{2} ;-0.7$ at $0.3-0.9 \mathrm{~A} / \mathrm{cm}^{2}$ ) is used than under wet hydrogen (slope $=-0.54$ at $0-1.8 \mathrm{~A} / \mathrm{cm}^{2}$ ). This is consistent with slower reaction kinetics occurring for $\mathrm{CO} / \mathrm{CO}_{2}-\mathrm{YSZ}$ than for $\mathrm{H}_{2} \mathrm{O} / \mathrm{H}_{2}-\mathrm{YSZ}$. Further investigation may be needed to elucidate this phenomenon. 


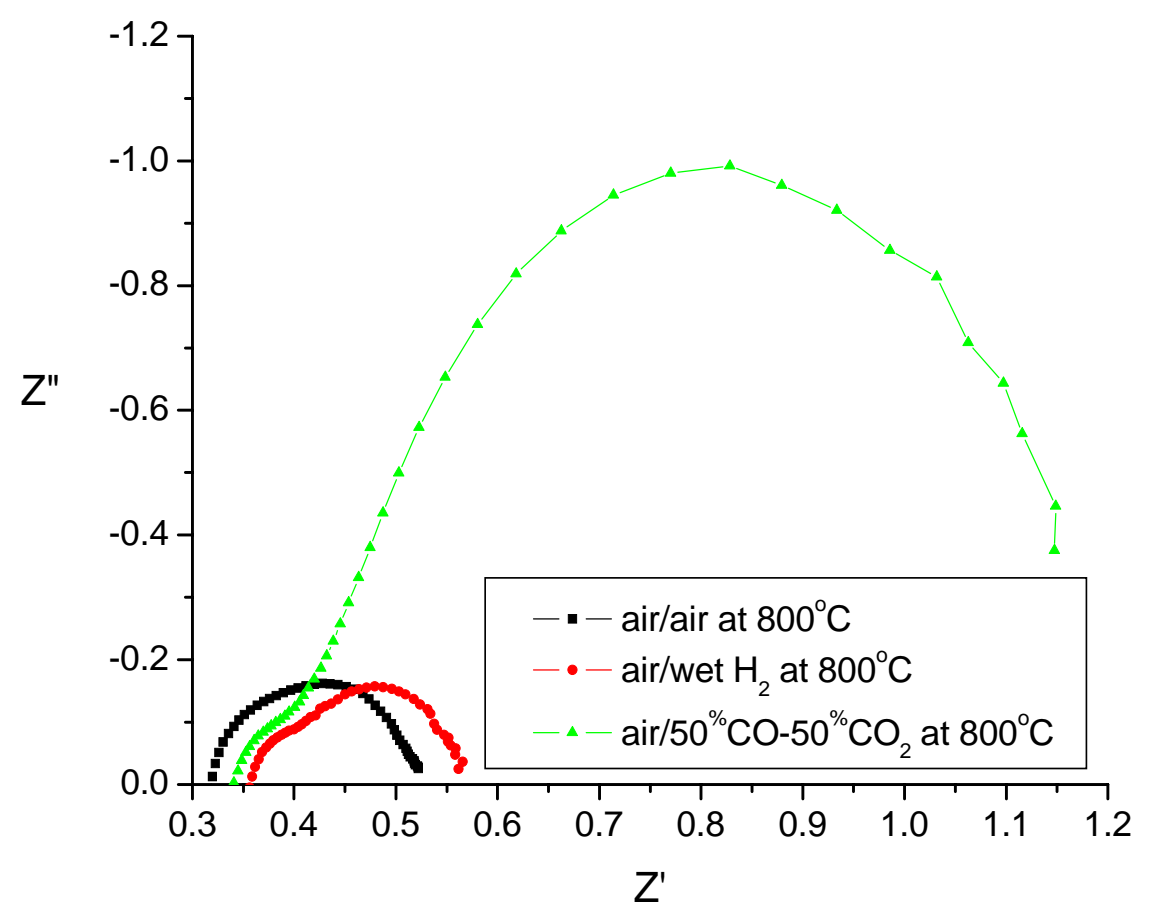

Figure 15. Impedance spectroscopy of LSCM for the fuel cell test in air, wet hydrogen $\left(3 \% \mathrm{H}_{2} \mathrm{O}-10 \%\right.$ $\mathrm{H}_{2}$-balanced with $90 \% \mathrm{~N}_{2}$ ) and $50 \% \mathrm{CO}-50 \% \mathrm{CO}_{2}$ at $800^{\circ} \mathrm{C}$ (surface area $=0.3 \mathrm{~cm}^{2}$ )

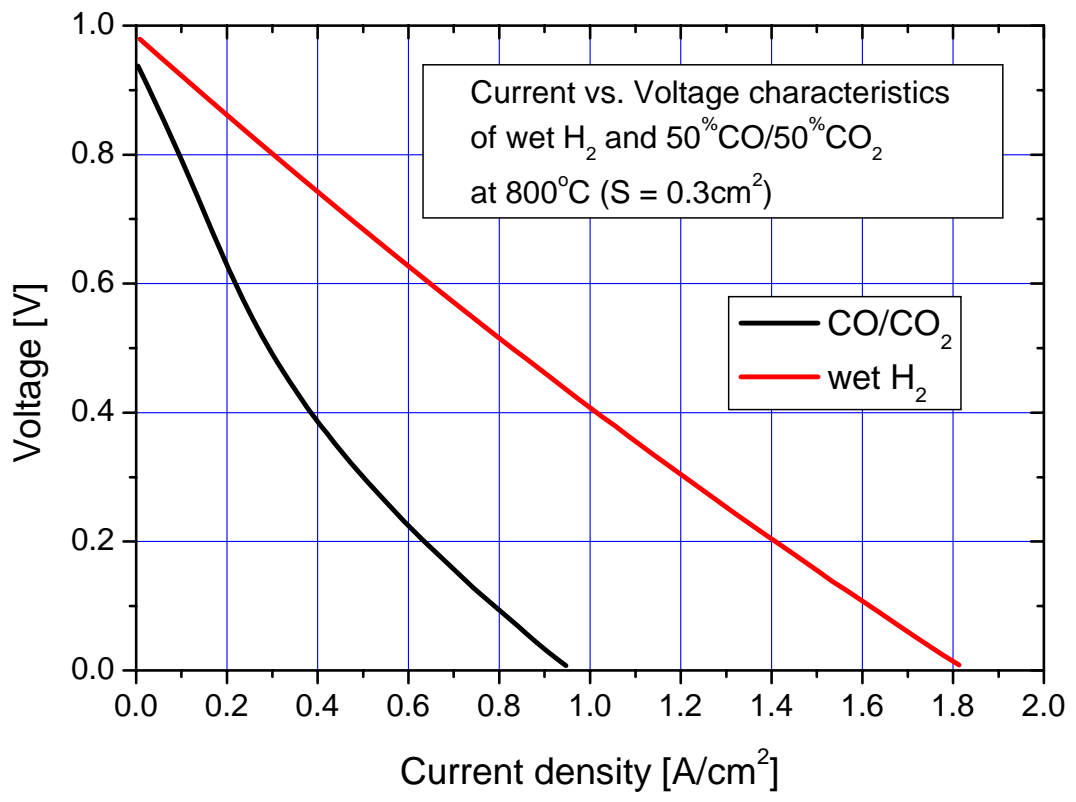

Figure 16. Current vs. voltage characteristics of a cell with LSCM electrodes in air on one side and in wet hydrogen $\left(3 \% \mathrm{H}_{2} \mathrm{O}-10 \% \mathrm{H}_{2}\right.$-balanced $\left.90 \% \mathrm{~N}_{2}\right)$ or $50 \% \mathrm{CO}-50 \% \mathrm{CO}_{2}$ on the other side at $800^{\circ} \mathrm{C}$ 


\section{$\underline{\text { Task } 2 \text { Efficiency Modeling of Stack and System }}$}

The efficiency modeling of a hybrid stack and system has been completed at MSRI. A performance model was developed to simulate the hybrid stack characteristics, including the polarization of the stack when operating in the SOFC and SOFEC modes. A cost analysis of the hybrid system was also contained in the performance model of the hybrid stack and performed for a forecourt hydrogen production application.

\section{Task 2.1 Hybrid Stack Performance Model}

The performance model used a detailed analysis of gas species and equilibrium along the length of the cell as well as the equilibrium partial pressures of oxygen in either chamber to compute the Nernst voltage across the cell at each point. The metallic interconnect was assumed to have an equipotential surface so that the current density at each point could be computed using a linear current-voltage correlation. The linear model was coupled with an iterative solution to correlated functions for the activation polarization and concentration polarization in the porous electrodes of each cell.

Table 1. Hybrid stack modeling parameters

\begin{tabular}{|l|c|}
\hline Number of Cells & 40 \\
\hline Active Cell Area & $100 \mathrm{~cm}^{2}$ \\
\hline Stack Temperature & $800^{\circ} \mathrm{C}$ \\
\hline Stack Pressure & $1 \mathrm{~atm}$ \\
\hline Fuel Inlet Composition & $70 \% \mathrm{H}_{2}, 22 \% \mathrm{CO}, 3 \% \mathrm{CO}_{2}, 5 \% \mathrm{H}_{2} \mathrm{O}$ \\
\hline Steam Inlet Composition & $3 \% \mathrm{H}_{2}$, balance of $\mathrm{H}_{2} \mathrm{O}$ \\
\hline Fuel Utilization & $40 \%$ \\
\hline Air Utilization & $40 \%$ \\
\hline Steam Utilization & $\mathrm{Co-Flow}$ \\
\hline SOFC Flow Configuration & $\mathrm{Co-Flow}$ \\
\hline SOFEC Flow Configuration & $0.40 \Omega \mathrm{cm}^{2}$ \\
\hline SOFC Area Specific Resistance & $0.40 \Omega \mathrm{cm}^{2}$ \\
\hline SOFEC Area Specific Resistance & $0.199 \mathrm{~cm}^{2} / \mathrm{s}$ \\
\hline Anode Effective Diffusivity & $0.117 \mathrm{~cm}^{2} / \mathrm{s}$ \\
\hline Cathode Effective Diffusivity & \\
\hline
\end{tabular}

A $1 \mathrm{~kW}$ stack was set up in the model, which predicted the performance of a 40-cell hybrid stack with per-cell active areas of $100 \mathrm{~cm}^{2}$. The variable in the calculations was the number of SOFCs and SOFECs in the stack. The stack temperature was held constant at $800^{\circ} \mathrm{C}$. The utilizations of 
fuel, air, and steam were held fixed at $70 \%, 40 \%$, and $40 \%$, respectively. The fuel inlet composition was $70 \% \mathrm{H}_{2}, 22 \% \mathrm{CO}, 3 \% \mathrm{CO}_{2}$, and $5 \% \mathrm{H}_{2} \mathrm{O}$, an approximate composition of a methane steam reformate with an initial steam to carbon ratio of $1 / 1$. The steam inlet composition on the SOFEC cathode side was fixed at $3 \% \mathrm{H}_{2}$ with a balance of $\mathrm{H}_{2} \mathrm{O}$. Other parameters for simulations are listed in Table 1 as a reference.

Figure 17 presents the computed values for the gas species distributions for an SOFC under load at $0.7 \mathrm{~V}$, while the oxygen partial pressures in both anode and cathode chambers along the length of the cell are presented in Figure 18. In the simulation, an assumption was made that at any position along the cell, all species are under equilibrium at the working temperature. Figure 19 shows the resulting Nernst potential distribution along with the activation overpotential, and current density. As can be seen in the plot, the Nernst potential varies along the length of the cell due to the changes of the species concentration. It decreases from $1.05 \mathrm{~V}$ at the inlet to $0.85 \mathrm{~V}$ at the outlet. A polarization curve for the cell at the defined utilization was computed, and is presented in Figure 20. It must be noted, however, that under practical operation the current will not exceed 50 A because of ohmic heating constraints.

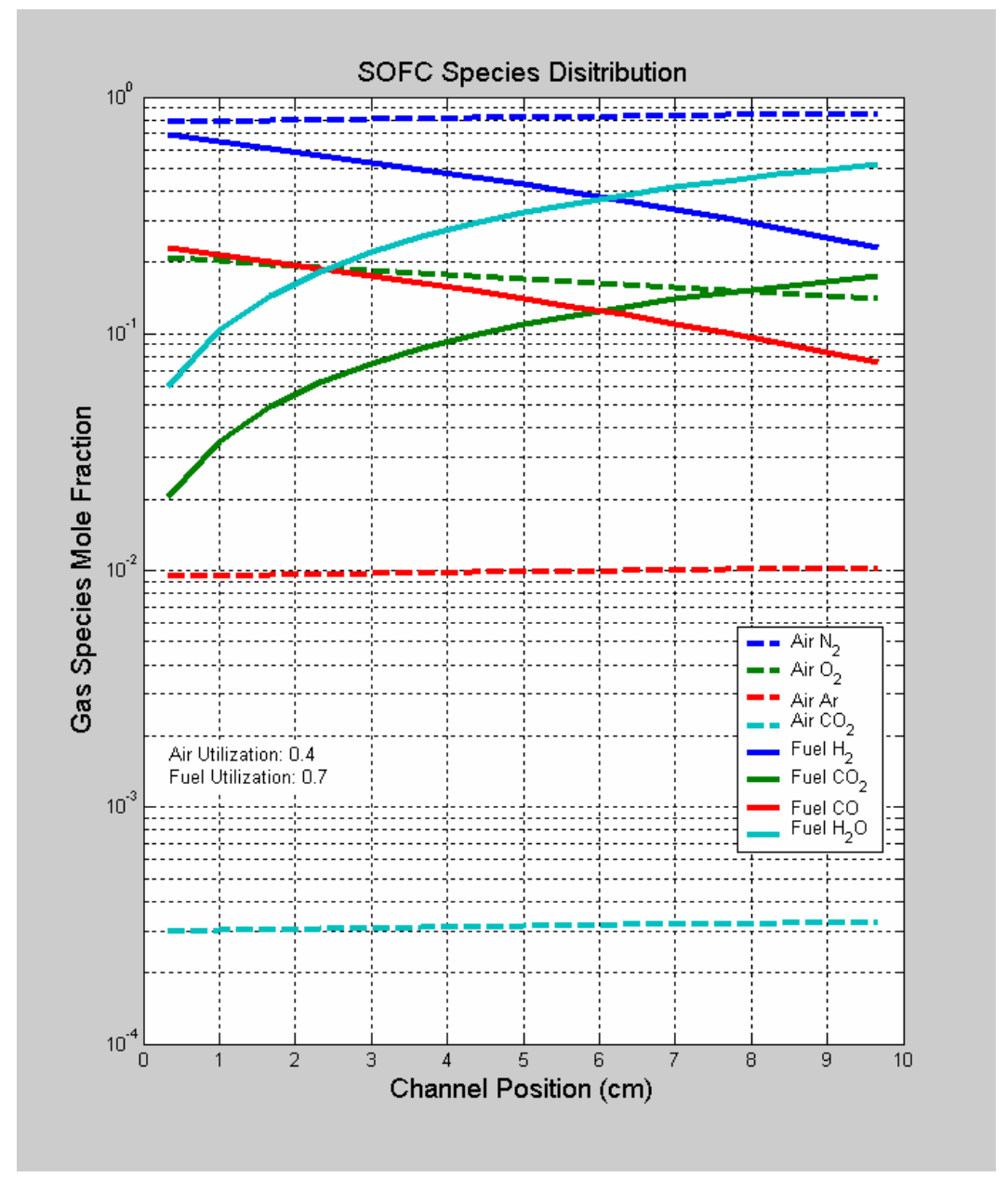

Figure 17. Gas species distributions along the anode and cathode chambers for a SOFC cell operated at $0.7 \mathrm{~V}$ with air and fuel utilizations at $40 \%$ and $70 \%$, respectively. All species are assumed to be at equilibrium at $800^{\circ} \mathrm{C}$. 


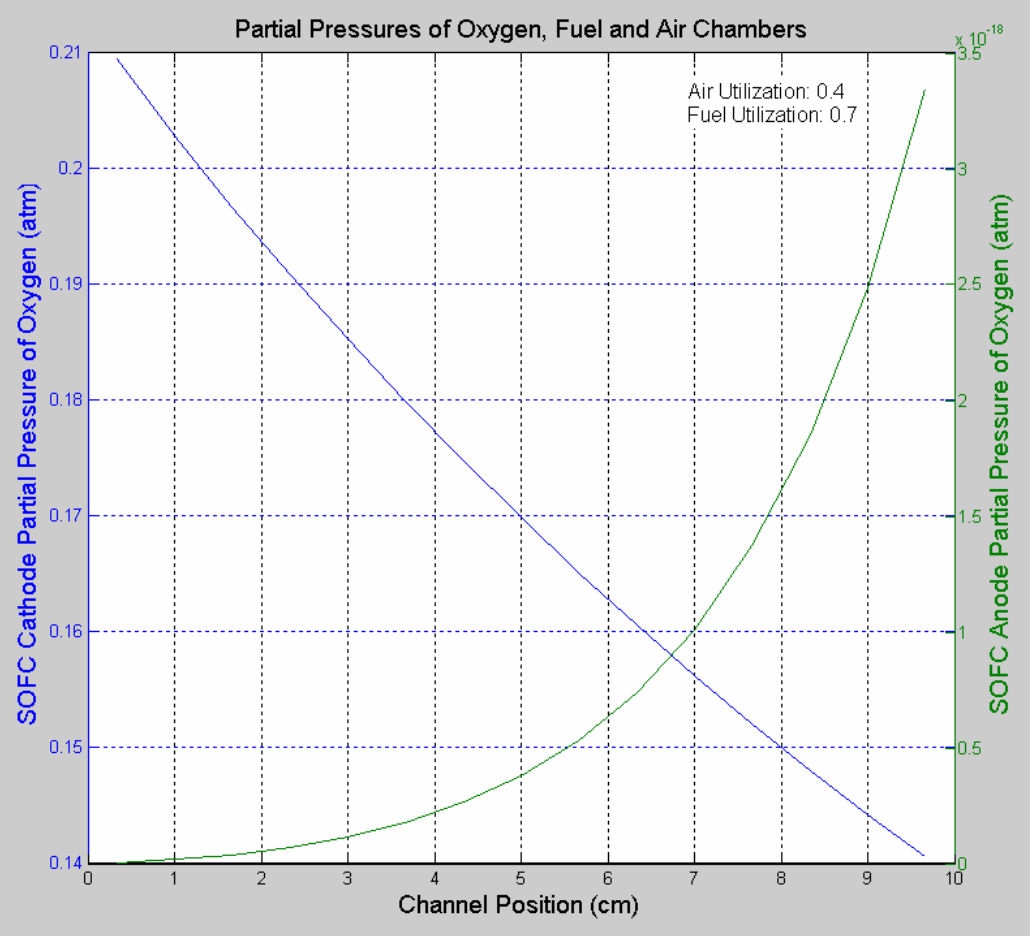

Figure 18. Variation of oxygen partial pressures in the anode and cathode chambers along the length of the SOFC at a cell voltage of $0.7 \mathrm{~V}$

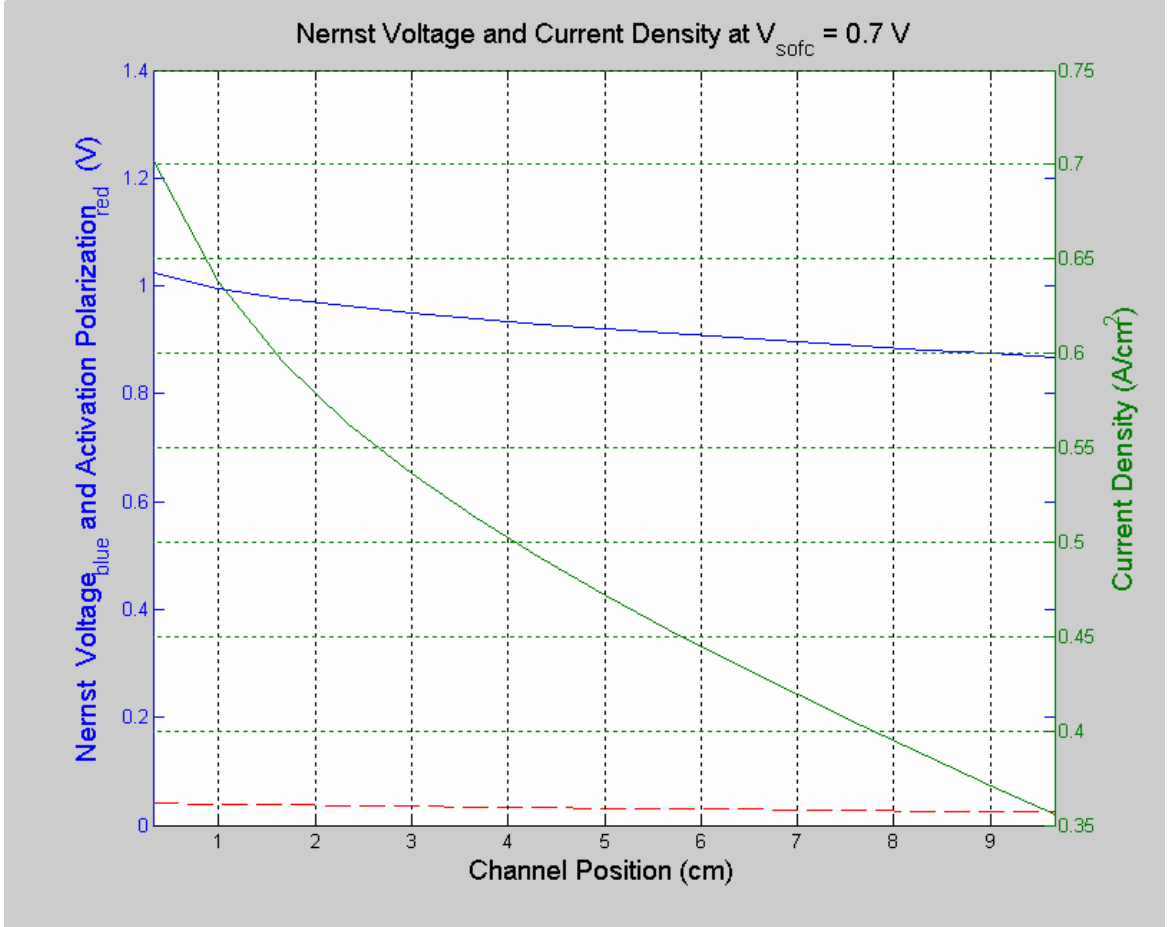

Figure 19. Nernst potential, activation overpotential, and current density at $0.7 \mathrm{~V}$ along the length of the SOFC 


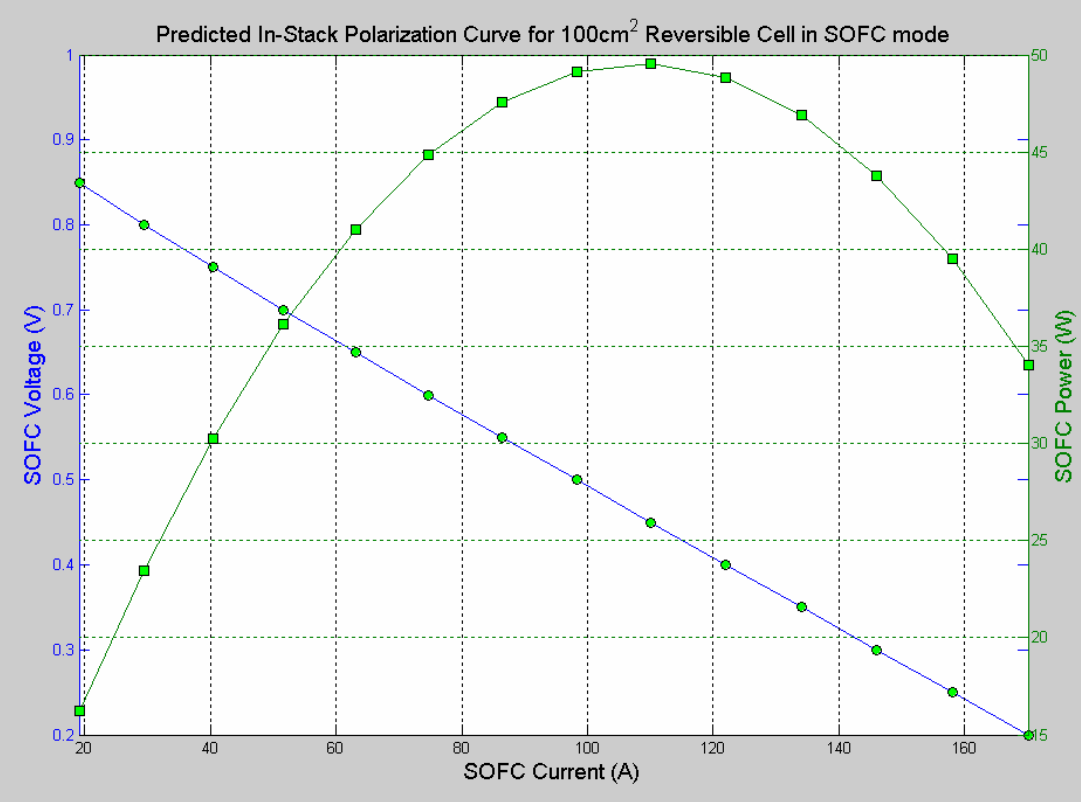

Figure 20. A polarization curve for a reversible cell operated in the SOFC mode on methane steam reformate at $\mathrm{U}_{\text {Fuel }} / \mathrm{U}_{\text {Air }}=70 \% / 40 \%$ and $\mathrm{T}=800^{\circ} \mathrm{C}$

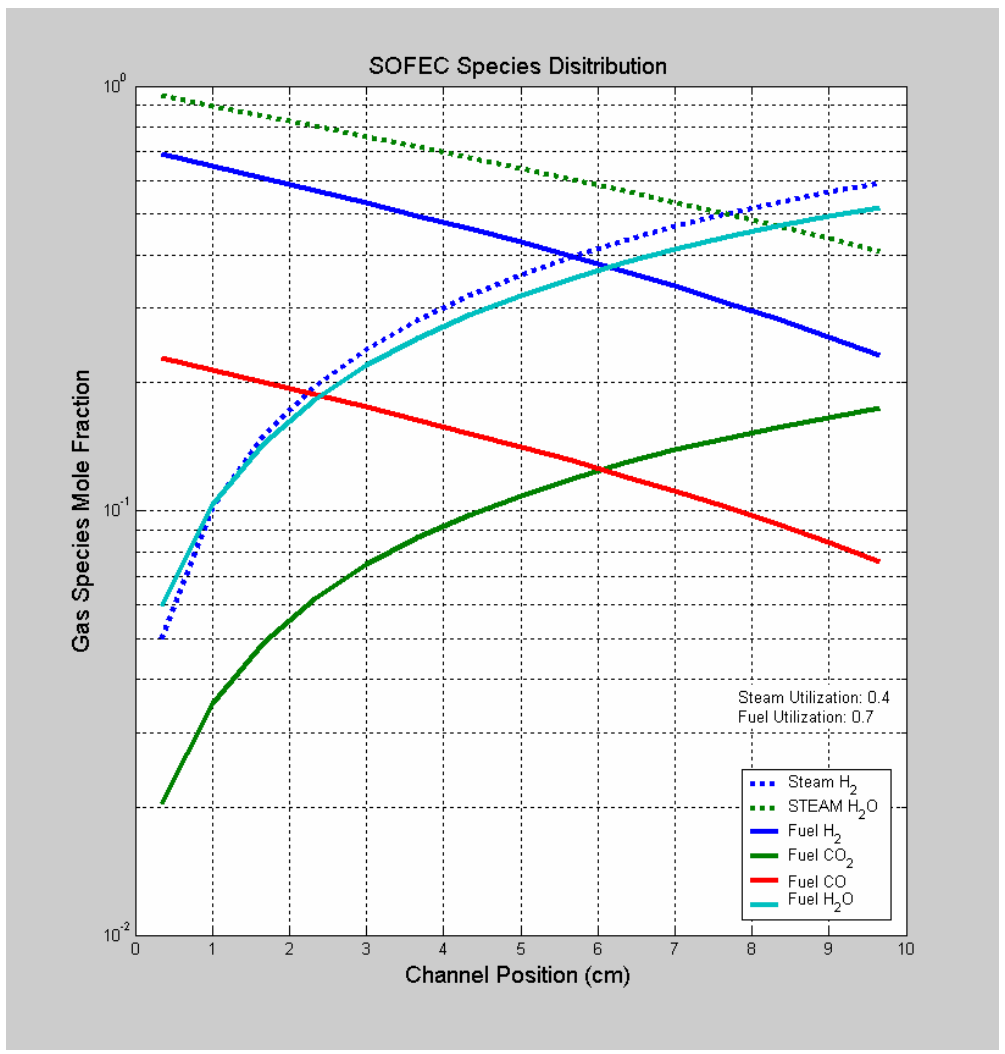

Figure 21. Gas species distributions along the anode and cathode chambers for a SOFEC cell operating at $-0.4 \mathrm{~V}$ with steam and fuel utilizations at $40 \%$ and $70 \%$, respectively. All species are assumed to be in equilibrium at $800^{\circ} \mathrm{C}$. 
A similar analysis was also conducted of the cell operated in the fuel-assisted electrolysis mode, or SOFEC mode. The simulation results are presented in Figure 21 - Figure 23, with the corresponding cell polarization curve shown in Figure 24. Species distributions were calculated at a voltage of $-0.4 \mathrm{~V}$, which is the approximate maximum voltage that can be sustained without introducing degradation of the electrolyte.

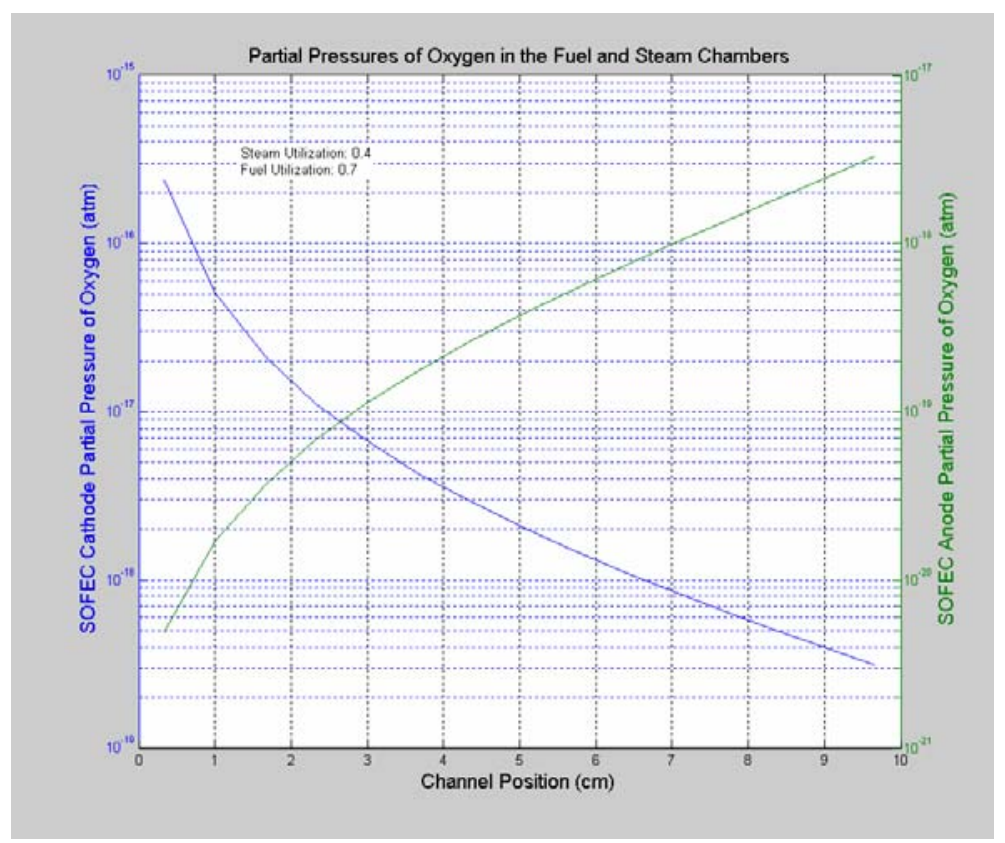

Figure 22. Variation of oxygen partial pressures in the anode and cathode chambers along the length of the SOFEC. The cell voltage is $-0.4 \mathrm{~V}$.

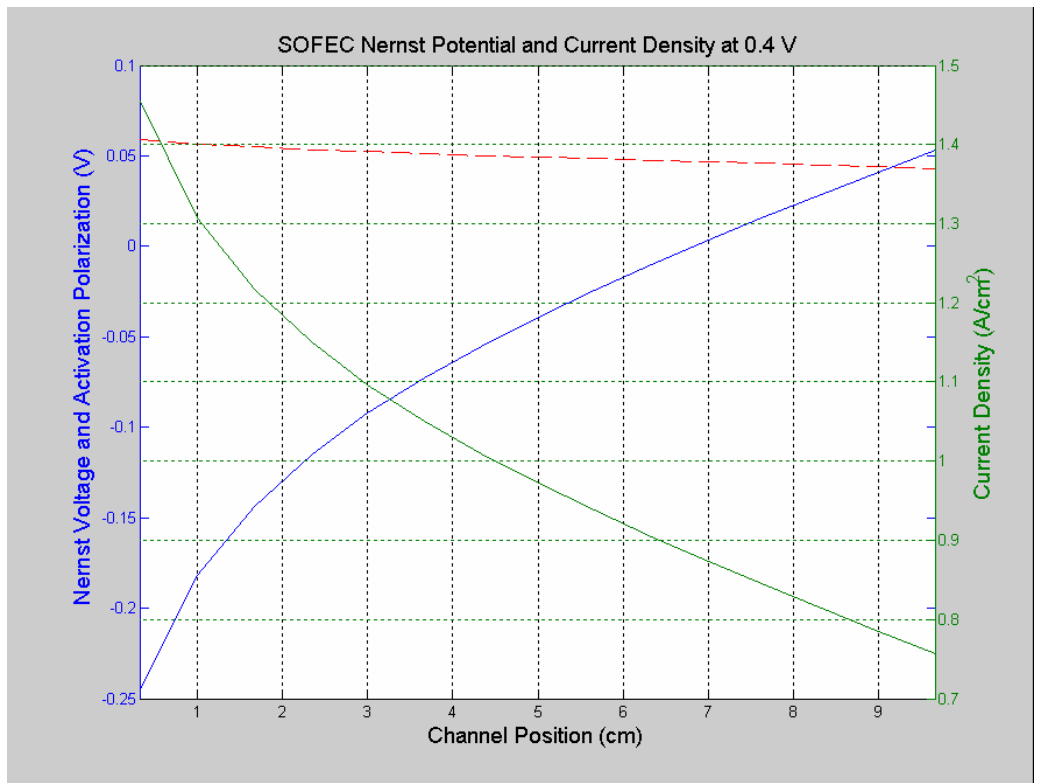

Figure 23. Nernst potential, activation overpotential, and current density at $-0.4 \mathrm{~V}$ along the length of the SOFEC. 


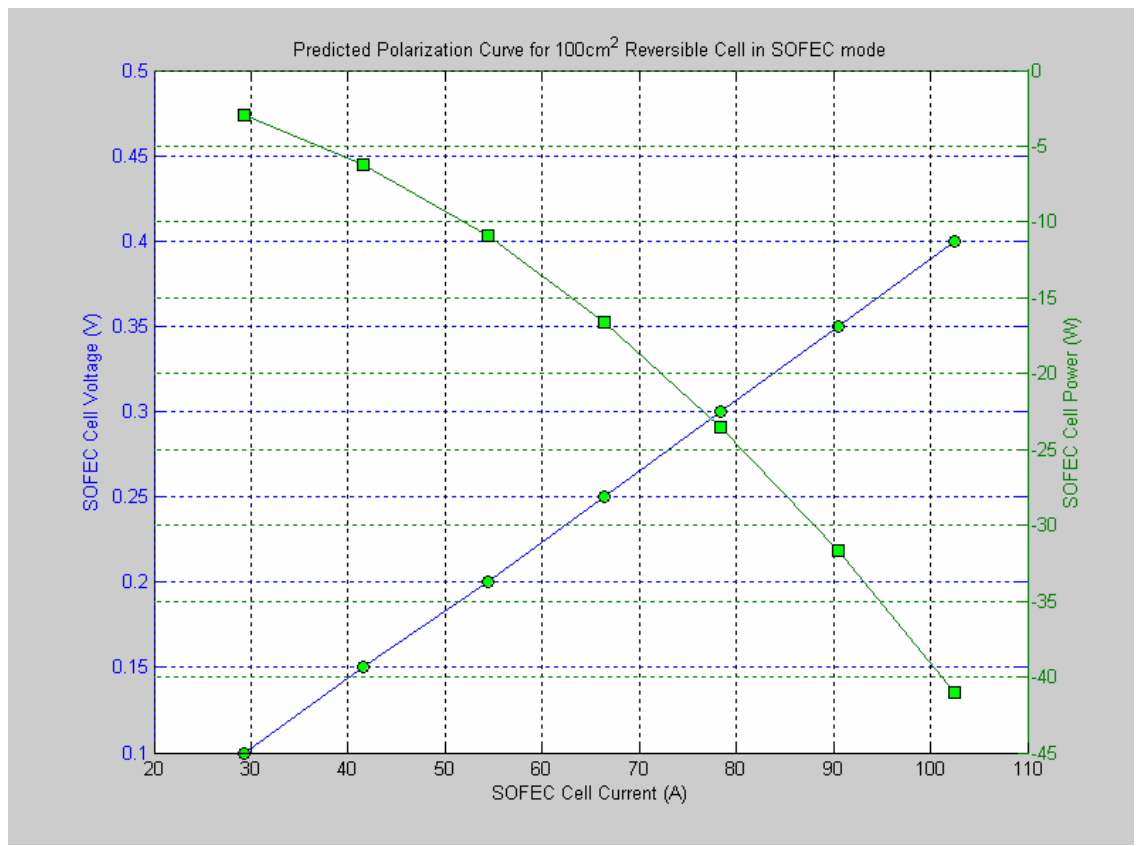

Figure 24. A simulated polarization curve for a reversible SOFC/SOFEC operated in the SOFEC mode on methane steam reformate at $\mathrm{U}_{\text {Fuel }} / \mathrm{U}_{\text {Steam }}=70 \% / 40 \%$ and $\mathrm{T}=800^{\circ} \mathrm{C}$.

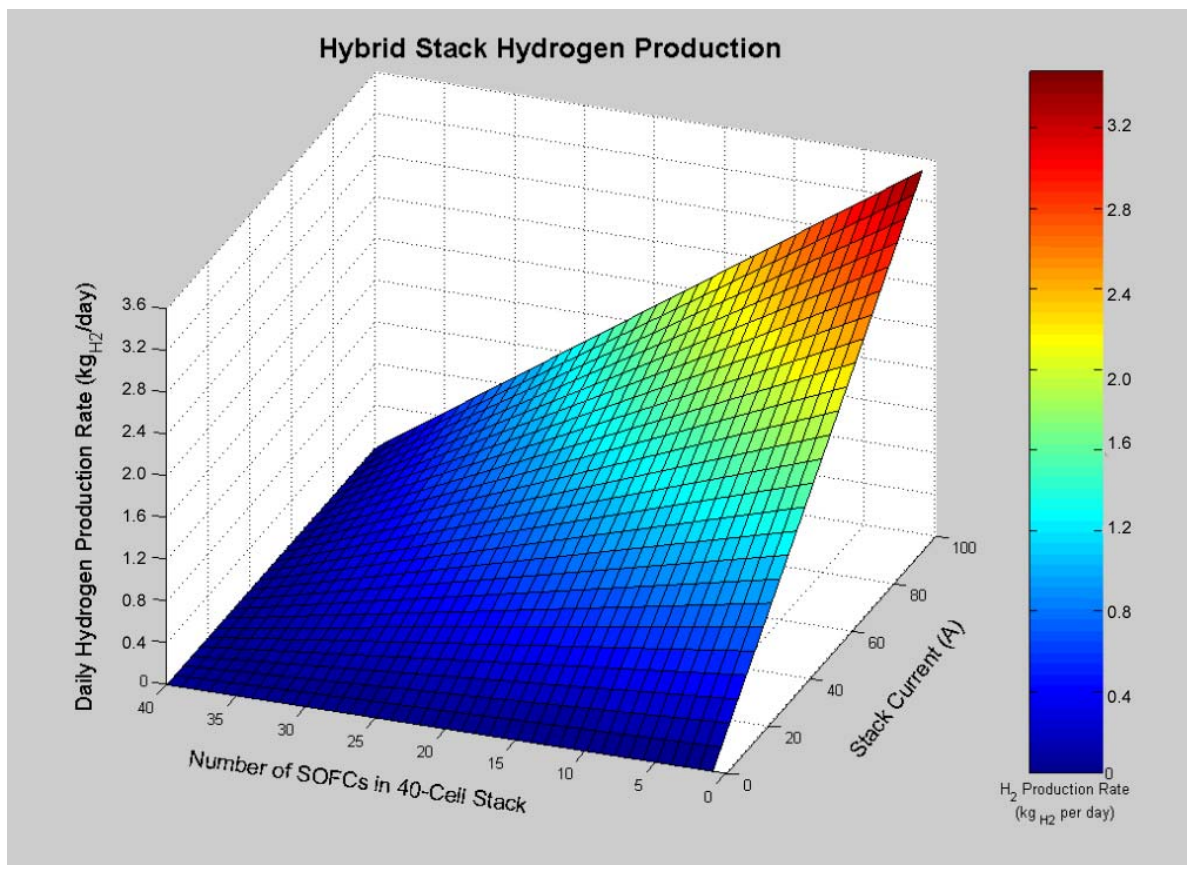

Figure 25. Predicted daily hydrogen production rate for the hybrid stack as a function of discharge current and stack configuration.

The simulated power curves in Figure 20 and Figure 24 were used to predict the performance of a hybrid stack with varying numbers of SOFCs and SOFECs. The predicted hydrogen production and power output of the stack as a function of stack configuration and stack current are given in Figure 25 and Figure 26, respectively. However, the operation must be constrained within these parameters so that the voltage of the individual SOFCs will not be less than $\sim 0.68$ 
$\mathrm{V} /$ cell. Based on current performance of the reversible cell in SOFC mode, this limited the discharge current to $\sim 65 \mathrm{~A}$. Therefore, within the operating constraints, the maximum power output with no hydrogen production was estimated to be $\sim 1.5 \mathrm{~kW}$. Hydrogen production rates scale with the cell active area, which can be adjusted to meet the production goals of the project.

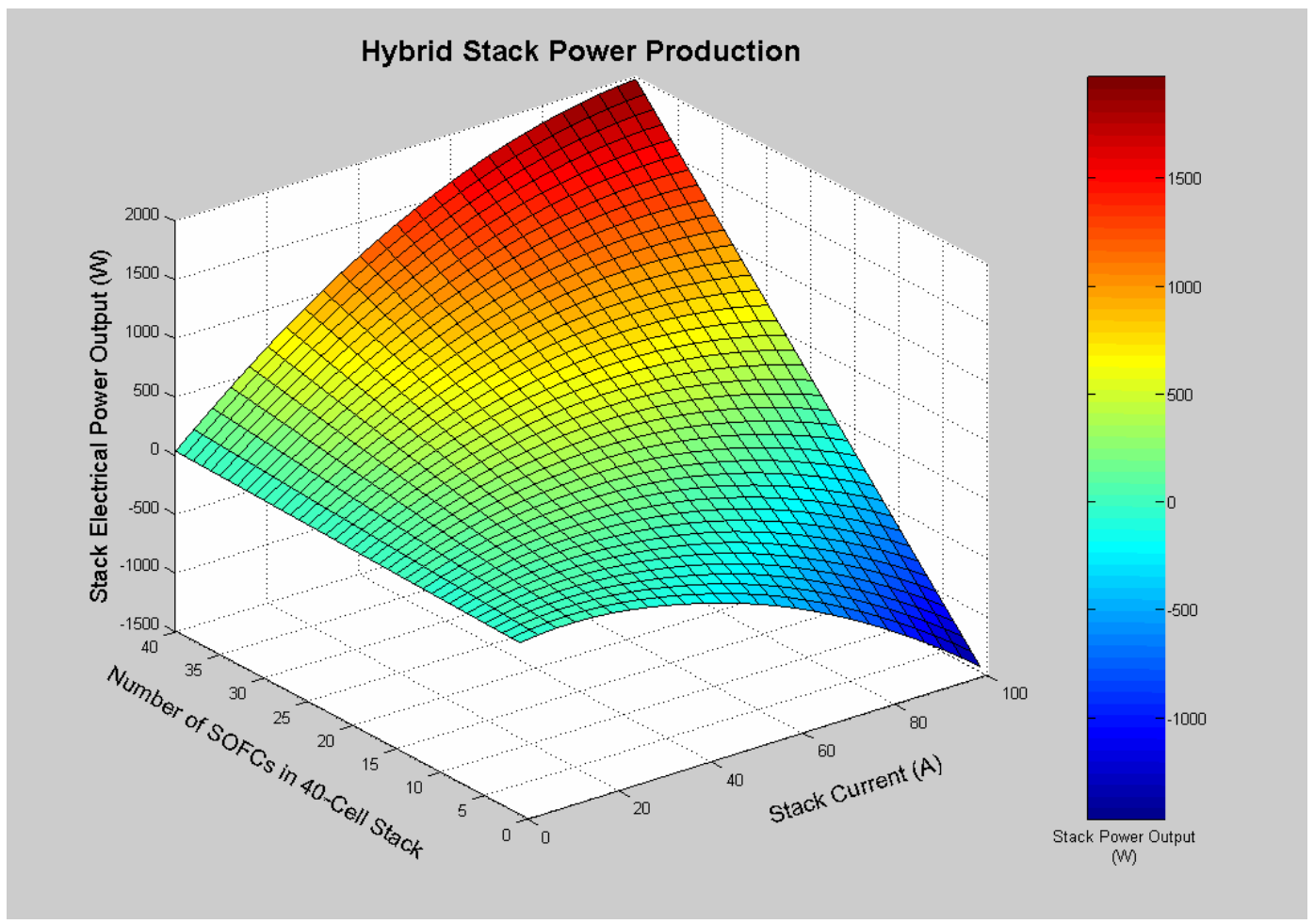

Figure 26. Predicted electrical power output for the hybrid stack as a function of discharge current and stack configuration

\section{Task 2.2 Hydrogen Cost Analysis}

Since hydrogen cost is a vital metric anytime, SOFEC-SOFC hybrid technologies are examined in this task. The cost analysis of the hybrid system was incorporated in the hybrid stack performance model and optimized for a forecourt hydrogen production application. Since the focus of this project has been the development of the hybrid SOFEC-SOFC stack technology and providing a solid proof of concept, as apposed to a system design or integration, the preliminary economic assessment of the cost of hydrogen production using the targeted hybrid technology is a prediction based on current economic conditions and expected future system performance.

A simplified process flow diagram was generated for the cost model of a hybrid SOFEC-SOFC system to produce hydrogen under an electrically self-sustaining condition, as shown in Figure 27. In this cost mode, the hydrogen production cost was considered as a function of capital costs for fabricating the hybrid stack and BOP components, variable costs for the feedstock fuel and energy consumption, and fixed operating expenses including maintenance and the cost of money. Capital costs have taken account of the current status of analogous technologies with regards to manufacturing costs. The variable costs were estimated based on the performance of the SOFCs and SOFECs, combined with established guidelines for feedstock and energy consumption. 
Performance of a $1 \mathrm{~kW}$ hybrid stack, which will be discussed in Task 9, was incorporated in the model. The fixed costs varied significantly with the scale and usage of a given installation, and the computation of these was beyond the scope of the current analysis.

\section{Process Flow Sheet for Hybrid SOFC/SOFEC System Producing Only Hydrogen With No Electricity Input}

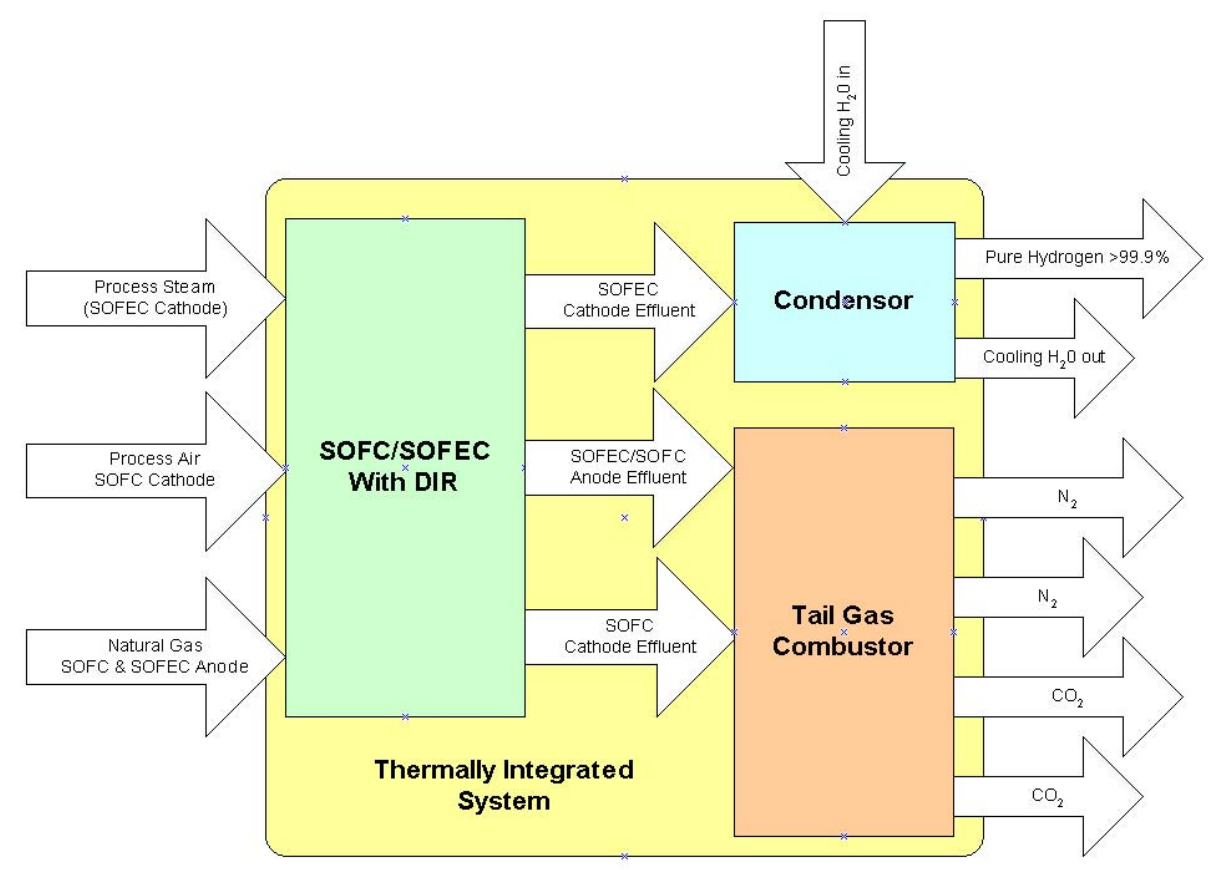

Figure 27. Process flow chart for a hybrid SOFEC-SOFC system to produce hydrogen under an electrically self-sustaining condition

The hybrid stack short-circuit current density and the variable and fixed costs all vary as functions of the ratio of SOFCs to SOFECs. For a given set of input parameters including the performance and operating characteristics of the system, as well as the fuel cost and area-specific stack cost, there is an ideal stack configuration that minimizes the production cost of hydrogen. Therefore, a numerical optimization was conducted to determine this configuration for the input parameters. The results indicate that for a stack having an average cell performance equal to that described by the experimental data, which is to be discussed in Task 9, the optimum stack configuration for the cost effective hydrogen production has a very small ratio of SOFCs to SOFECs, approximately equal to 0.04 . This is markedly different, and it is the result of two factors. First, the stack costs have been adjusted to reflect the advances in cost reduction in the manufacture of analogous SOFC technologies, and second, the performance of the SOFECs has improved significantly over the course of the project. As an example, the short circuit current for a SOFEC is approximately $0.18 \mathrm{~A} / \mathrm{cm}^{2}$, without any additional driving force from either SOFCs or an externally applied electrical potential. Though the low current density would require a significant increase in stack size, the cost tradeoff is minimized by efficient mass customization of the manufacturing process. The variation of stack cost with the stack configuration is shown in Figure 28, along with the contributions of the fixed and variable cost factors. In order to 
highlight the energy savings made possible by MSRI's fuel-assisted electrolysis cells, the electricity cost for ideal water electrolysis is also shown in Figure 28 as a comparison. Though the results indicate that a dedicated SOFEC system could produce hydrogen very efficiently even without the additional driving force from SOFCs, it should be noted that for a distributed production facility, in particular at the residential, commercial, or forecourt (hydrogen refilling station) scales, there are many advantages to having a hybrid SOFEC-SOFC system. The first is the ability to produce distributed electrical power, which depending on the local infrastructure may provide a competitive alternative to centralized power generation. The second advantage is that SOFCs allow for grid-independent hydrogen generation, a boon to both reliability and energy security. And finally, the addition of an increased number of SOFCs allows for flexibility in the hydrogen production rate. Thus a facility would have the flexibility to increase production rates to meet fluctuating demand, which would provide for intermittent periods of high demands and would reduce the required capacity of the on-site storage equipment.

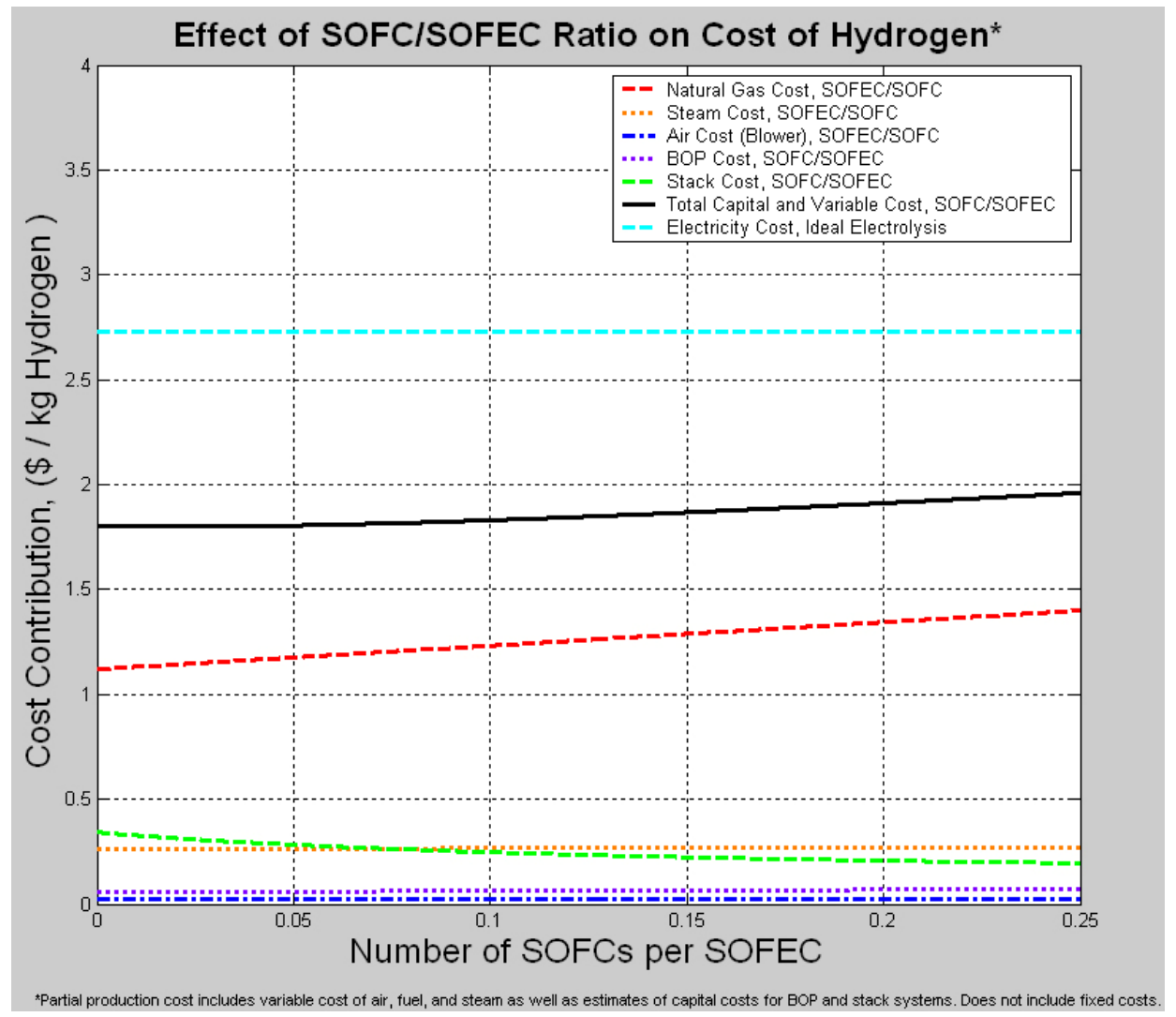

Figure 28. Variation in the contributing factors to the cost of hydrogen production using MSRI's hybrid SOFEC-SOFC technology as a function of the stack configuration.

It is likely that for the distributed power generation, the ideal stack configuration will be tailored for individual locations or types of installations. This may be accomplished efficiently by fabricating stack modules of SOFCs and SOFECs that may be assembled in different ratios to fit each application. In this way, the cost savings of mass customization will be maintained.

Throughout the course of this program, significant gains have been made in the performance of both the SOFCs and SOFECs in hybrid stacks. The improvements have been the result of 
optimizations of both cell materials and structure and of enhanced sealing and cell/stack designs. Increasing the cell performance allows the stack to operate at a higher current density, reducing the stack size and associated capital costs, and also reduces variable costs by requiring fewer SOFCs to drive the electrolysis. Figure 29 shows the effect on the production cost of changes in cell performance, as characterized by the linearized ASR of the SOFCs and SOFECs. The instack cell performance gains that have been demonstrated throughout the project are identified along with a theoretical limit for the current material set based on single cell testing. Closing the gap between the current performance and the theoretical limit requires both cell components and some fine-tuning of primarily non-cell stack components (such as contact aids, gaskets, and interconnects) as well as improved uniformity with regards to flow distribution and the temperature. Such improvements are beyond the scope of this program, and further improvements should be performed in the future as needed to reduce the cost of hydrogen generation.

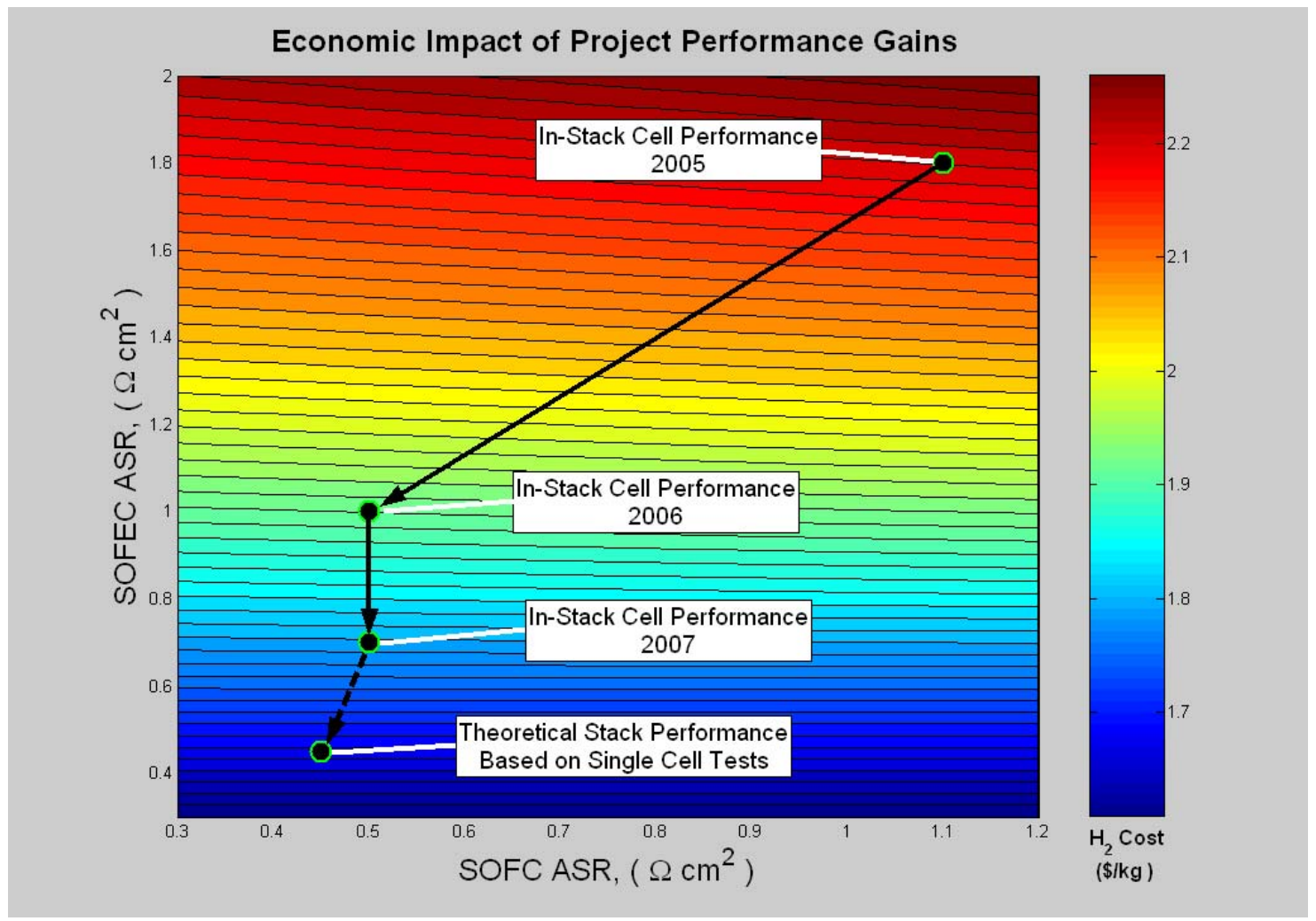

Figure 29. In-stack cell performance gains expressed in terms of the cost of hydrogen production computed using the previously described model

The results presented above indicate that the combined costs of stack, BOP, and feedstock are less than the electricity cost associated with traditional water electrolysis, even with current instack performance levels yielding a hydrogen production cost of $\$ 1.80 / \mathrm{kg}^{*}$. Clearly, there is a

\footnotetext{
${ }^{*}$ Value indicates partial production cost including variable cost of air, fuel, and steam as well as estimates of capital costs for BOP and stack systems. Cost assumes production at STP, and does not include expenses associated with hydrogen compression, storage, or delivery, or fixed costs of operation and maintenance of the system or production facility.
} 
definite potential application for this technology as a method of producing pure hydrogen for PEM fuel cell applications or other hydrogen applications using the existing natural gas pipeline network.

\section{Task 3 Cell, Stack, and Manifold Design and Development}

Design and development of the SOFC/SOFEC cells, stack and manifolding was carried out at MSRI successfully. The composite/hybrid design was based on MSRI's proprietary proven technology developed for SOFC power modules, but with changes to allow for the coupled SOFC and SOFEC operation. The concept for an internally manifolded cell geometry for the hybrid SOFEC-SOFC stack has been developed that provides steam and air to the cathode sides of SOFECs and SOFCs, respectively, and fuel to the anode sides of both SOFECs and SOFCs simultaneously. Use of the internal gas manifold offered many advantages to composite systems including ease of fabrication, low cost, and compliant seals to relieve internal stresses.

Unlike the SOFC, the operation of the SOFEC cells presents an important design constraint on the stack configuration requiring that the steam side of the SOFEC cells be hermetically sealed. In the case of non-hermetic seals, oxygen from the ambient surrounding could leak in and either consume the electrolyzed hydrogen or be pumped across the electrolyte in place of the electrolyzed oxygen, resulting in decreases in hydrogen production. Meanwhile, in the internally manifolded design, there is some gas diffusion through the porous anode supports resulting in limited intermixing of the gas streams between manifolds (cross-leaking) or the outside air. It is estimated that these losses could account for couple percent loss in the total system efficiency. It is therefore desirable to seal the edges of the cell anode support and the interior edges of the gas manifolds to limit these losses. Increasing the cell border width also reduces gas diffusion, which was explored in this project.

MSRI's SOFC technology employs a compliant gasket with an interfacial sealing aid at the mating surfaces. With the proper interfacial aids, sealing efficiencies in excess of $98 \%$ have been achieved between the surfaces of electrolyte and interconnect, and between the electrode and interconnect. The seal tests to be described in Task 6 have indicated that diffusion is occurring through the body of the compliant gasket, though the leakage is small for air in an SOFC where this seal is typically used. However, in the SOFEC cells, the cathode gas is a mixture of hydrogen and steam and since the diffusivity of hydrogen is much higher than that of air, the resulting losses would likely be more significant. Because of this, a modified gasket configuration was used to seal the cathode gasses in which a hermetic, flowable glass seal is constrained between two compressible compliant seals. Implementing the new seal concept necessitates a larger sealing border. Figure 30 shows the modified seals for the composite SOFEC-SOFC stack. 


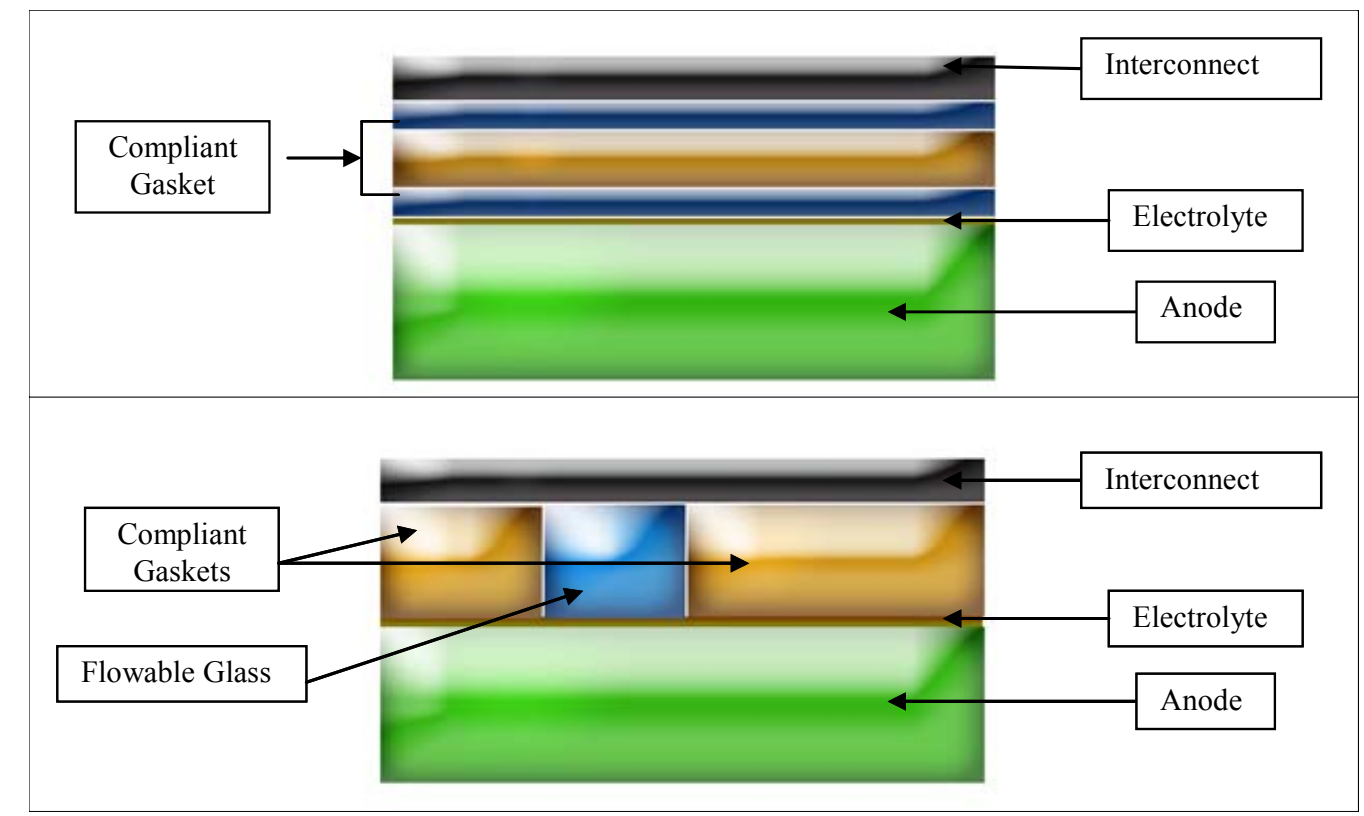

Figure 30. Old (Top) and new (Bottom) compliant-hermetic seal for the composite/hybrid SOFEC-SOFC stack.

In addition to the stringent sealing demands, the need to switch between the fuel-assisted hydrogen production (SOFEC mode) and the electricity production (SOFC) mode introduces further complexity to the design. In the internally manifolded SOFC stack, the air manifolds are integral to the anode support so the region directly surrounding the manifolds is not reduced to nickel metal by the fuel stream. In the SOFC stack this is not a critical problem, since a reasonably stable equilibrium point can be established between the two gasses. However, in the composite stack the cathode gases of the cells will be switched from air to the steam-hydrogen mixture as the stack mode is changed. This changes the equilibrium point between the oxidizing and reducing atmospheres around the manifold channels, resulting in a destructive phenomenon of redox (reduction and re-oxidation). Similar redox degradation can occur at the outer cell border where the edge of the anode support is exposed to air. To prevent redox, the air and steam manifolds must be isolated from the anode support or the cell edges must be sealed. Approaches were explored to solve the aforementioned sealing and redox challenges, by sealing the anode edges and sealing border with an oxygen barrier coated with a layer of $8 \mathrm{YSZ}$, which is similar to the electrolyte deposition process.

The SOFEC interconnect design adapted and modified the MSRI's current cross-flow square SOFC interconnect design. Due to sheet resistance losses, the spacing and width of the interconnect slots can have strong impacts on cell performance, which necessitates the usage of very finely spaced channels. Finely spaced channels, however, introduce a large pressure drop. Therefore, the tradeoff between the sheet resistance and pressure drop was a primary optimization concern during interconnect design procedures.

\section{Task 4 Fabrication of Anode-Supported SOFECs and SOFCs}


In this program, all the SOFCs and SOFECs were fabricated at MSRI. Two approaches were taken to make the anode-supported cells: a die-press method for one-inch button cells, and a tape-casting method for both one-inch button cells and large cells with per-cell active areas of 30 $\mathrm{cm}^{2}$ and $100 \mathrm{~cm}^{2}$. Button cells were used to screen cathode materials and to characterize cell performance. Since it is simple and doesn't require many raw materials, unlike the tape-casting approach, the die-press method is always the first choice to fabricate button cells.

Experiments show that there are three major overpotentials or losses associated with SOFC/SOFEC electrochemical reactions: ohmic losses, concentration overpotential, and activation overpotential. Reducing the ohmic losses, which are contributed from the electrodes (both the anode and cathode) and the electrolyte, can be achieved by reducing the thickness of both the electrodes and the electrolyte. Since the electrolyte has the lowest conductivity, the first action taken was to reduce its thickness. With the implementation of Design of Experiment (DOE) methodology in the fabrication process, the tape quality was iteratively improved with fewer defects while allowing reduced tape thickness at 10 15 $\mu \mathrm{m}$. The defect-free nature of the electrolyte was verified by measuring the range and values of open circuit voltage (OCV) and comparing with theoretical and previous experimental data.

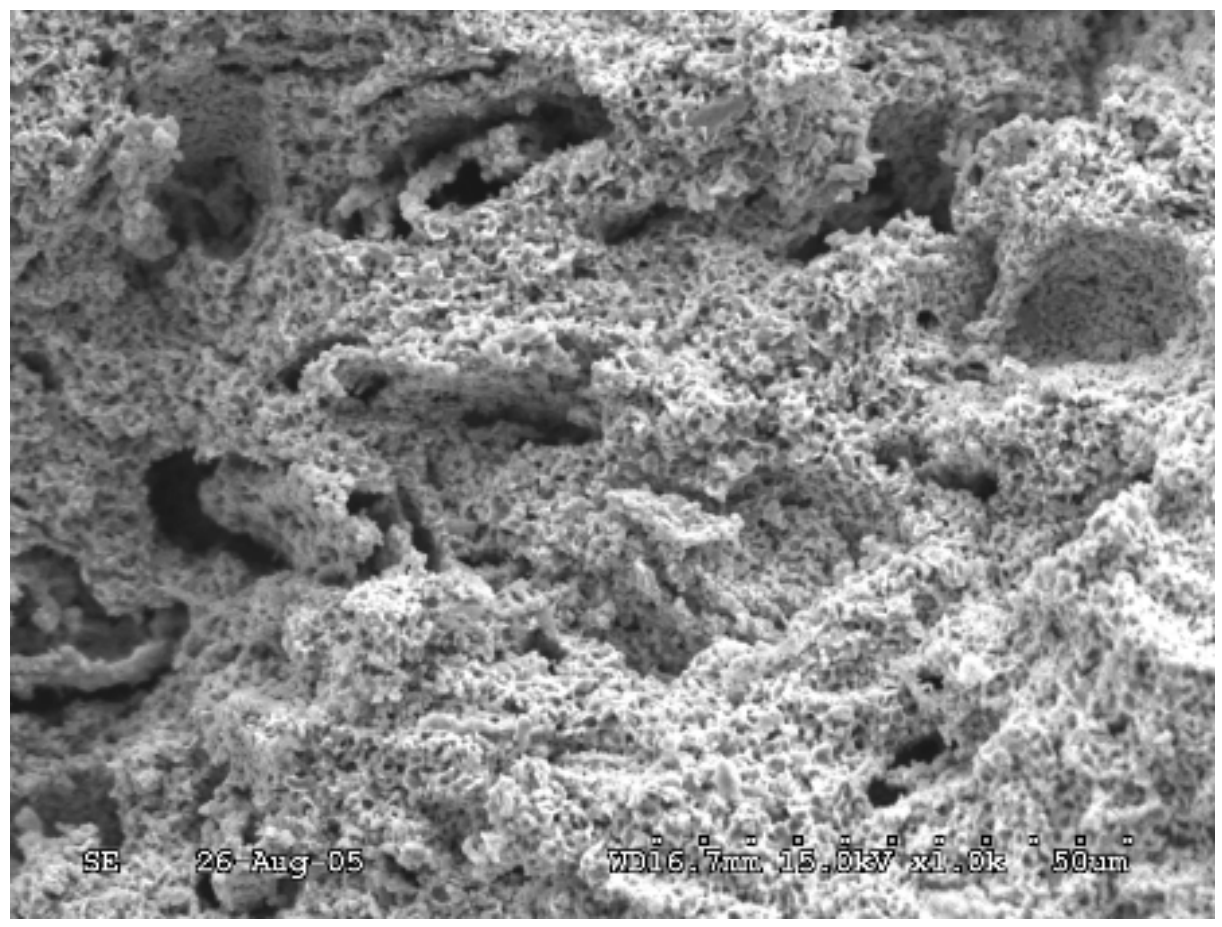

Figure 31. A SEM micrograph of an anode substrate after reduction. This anode substrate used Type A pore former.

Concentration overpotential from the anode side can be reduced by increasing the porosity of the anode support. Pore formers added to the anode support can change the porosity, the number of open pores, and the morphology of the pore structure. The amount of pore former additive should be balanced against the need for cell mechanical strength and green tape sinterbility. Extensive research and development work were completed in this program to optimize the microstructure of anode supports and to scale up cells from one-inch button cells to 2"x2" and 
4" 4 " cells. Different types of pore former additives have been investigated to modify the porosity, the number of open pores, and the morphology of the pore structure of the anode supports. The corresponding solvent system, dispersant and plasticizer were developed for the tape-casting. Figure 31 shows a typical microstructure of an anode substrate using type A pore former. After reduction, Archimedes measurement showed an anode substrate porosity of $42 \%$, significantly higher than anodes without pore former additive.

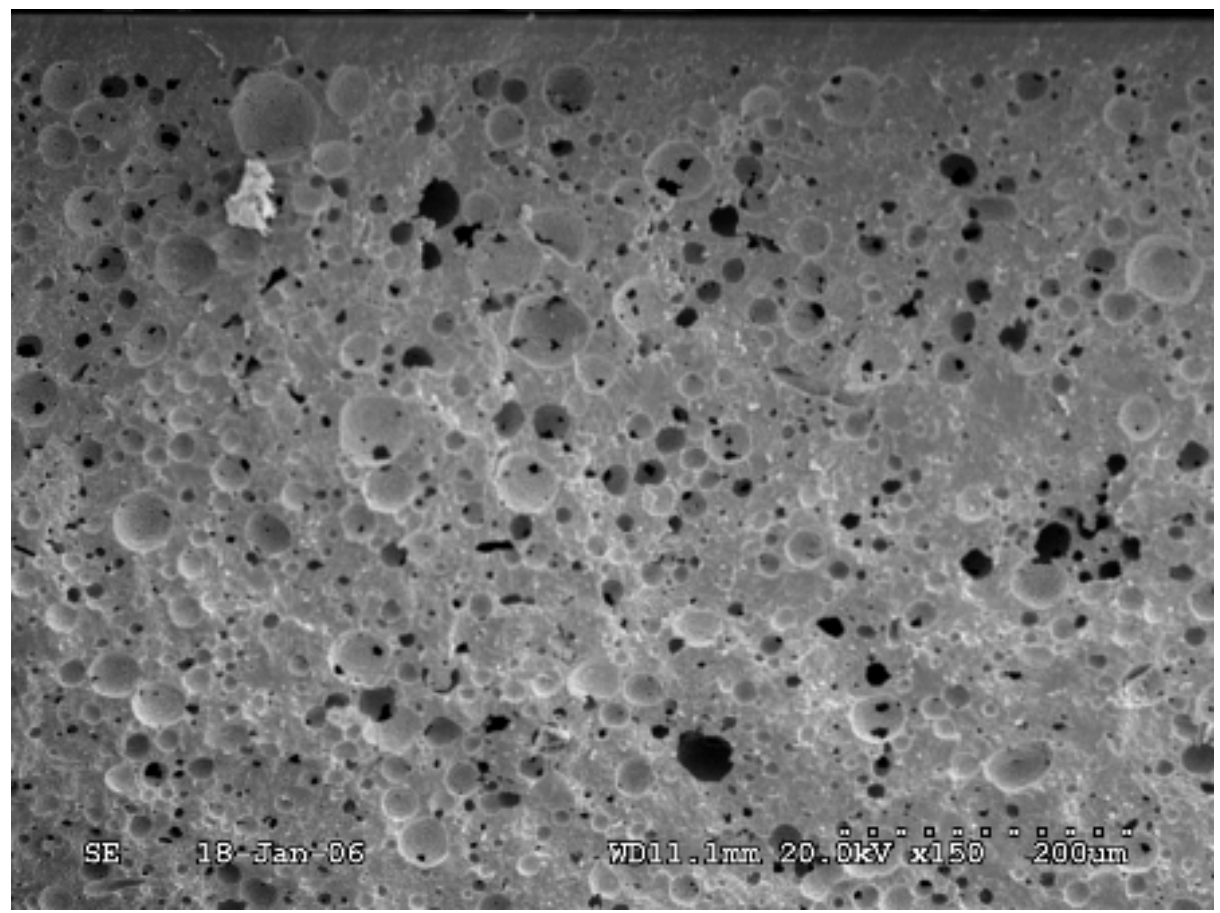

Figure 32. A SEM micrograph of an anode substrate after reduction. This anode substrate used Type B pore former.

A second type of pore former (Type B) was also identified and investigated. Figure 32 is a SEM micrograph of an anode substrate using Type B pore former. Spherical pore structures, sizing from $1 \mu \mathrm{m}$ to $50 \mu \mathrm{m}$ in diameter, were formed after sintering. As measured, the porosity was about $42 \%$ after reduction, close to the anode substrate using Type A pore former. A spherical pore structure is preferred over the layered pore structure from the standpoint of improving mechanical strength and reducing the concentration overpotential. Nevertheless, Type B pore former was not selected due to low yield rates, though efforts of engineering the tape-casting process were made to fabricate large cells.

In addition to the anode optimization, further development work was done to scale cells from one-inch button size cell (with $2 \mathrm{~cm}^{2}$ active area) to 2"x2" cell (with $30 \mathrm{~cm}^{2}$ active area) and 4"x4" (with $100 \mathrm{~cm}^{2}$ active area). The sinterbility and shrinkage were carefully studied. Figure 33 and Figure 34 show the pictures of an internal manifolded 2"x2" cell and an internal manifloded 4"x4' cell, respectively, using Type A pore former. 


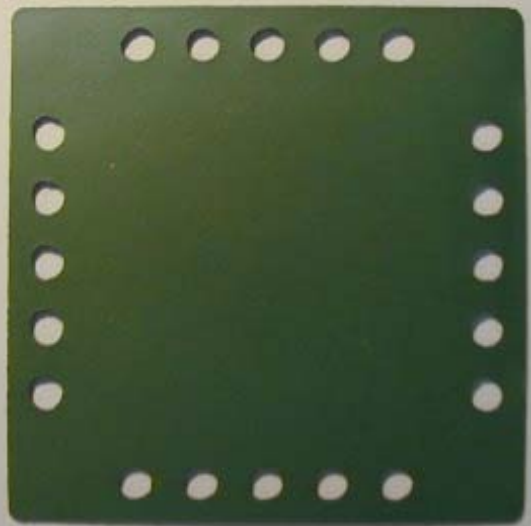

Figure 33. A photograph of an internal manifolded 2"x2" cell with $30 \mathrm{~cm}^{2}$ active areas

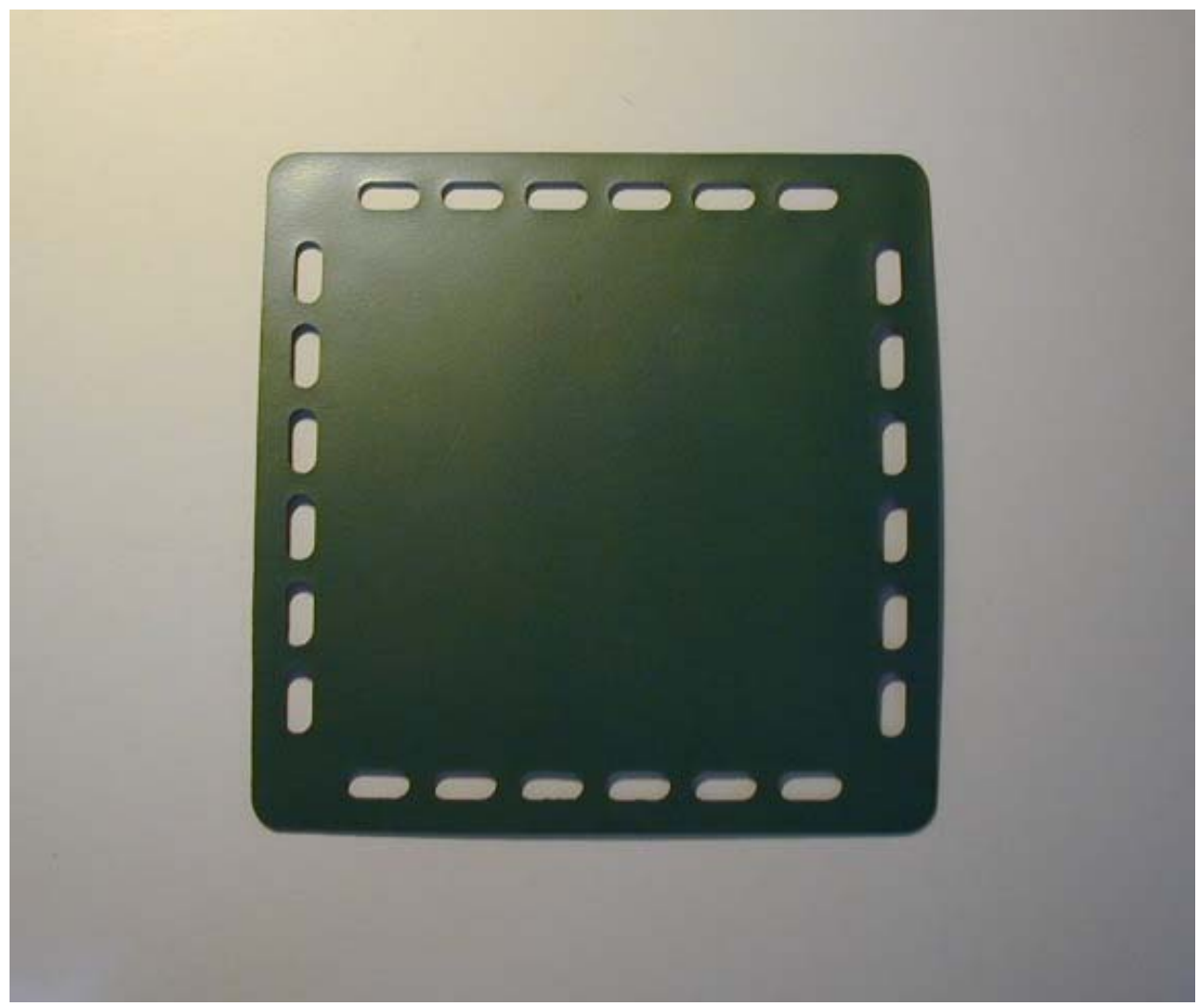

Figure 34. A photograph of an internal manifolded 4" $x 4$ " cell with $100 \mathrm{~cm}^{2}$ active areas 
The cathodes developed in Task 1 were deposited onto the cells by the screen-printing method, followed by firing at optimum temperatures. Figure 35 shows a SEM micrograph of a typical anode-supported cell with a cathode after testing. As shown in the figure, the cell is comprised of five distinct layers: $0.6 \sim 0.8 \mathrm{~mm}$ thick $\mathrm{Ni}+\mathrm{YSZ}$ anode support, a thin $\mathrm{Ni}+\mathrm{YSZ}$ anode interlayer, a thin film YSZ electrolyte $(10 \sim 15 \mu \mathrm{m})$, a composite cathode interlayer, and a cathode current collecting layer. In addition, some cells were fabricated with a sixth distinct layer, a dense barrier film comprised of Sm-doped $\mathrm{CeO}_{2}$ (SDC) located between the dense YSZ electrolyte and the cathode interlayer. The purpose of this barrier layer is to prevent deleterious chemical reactions from occurring between some certain cathodes and electrolyte during the cathoding process.

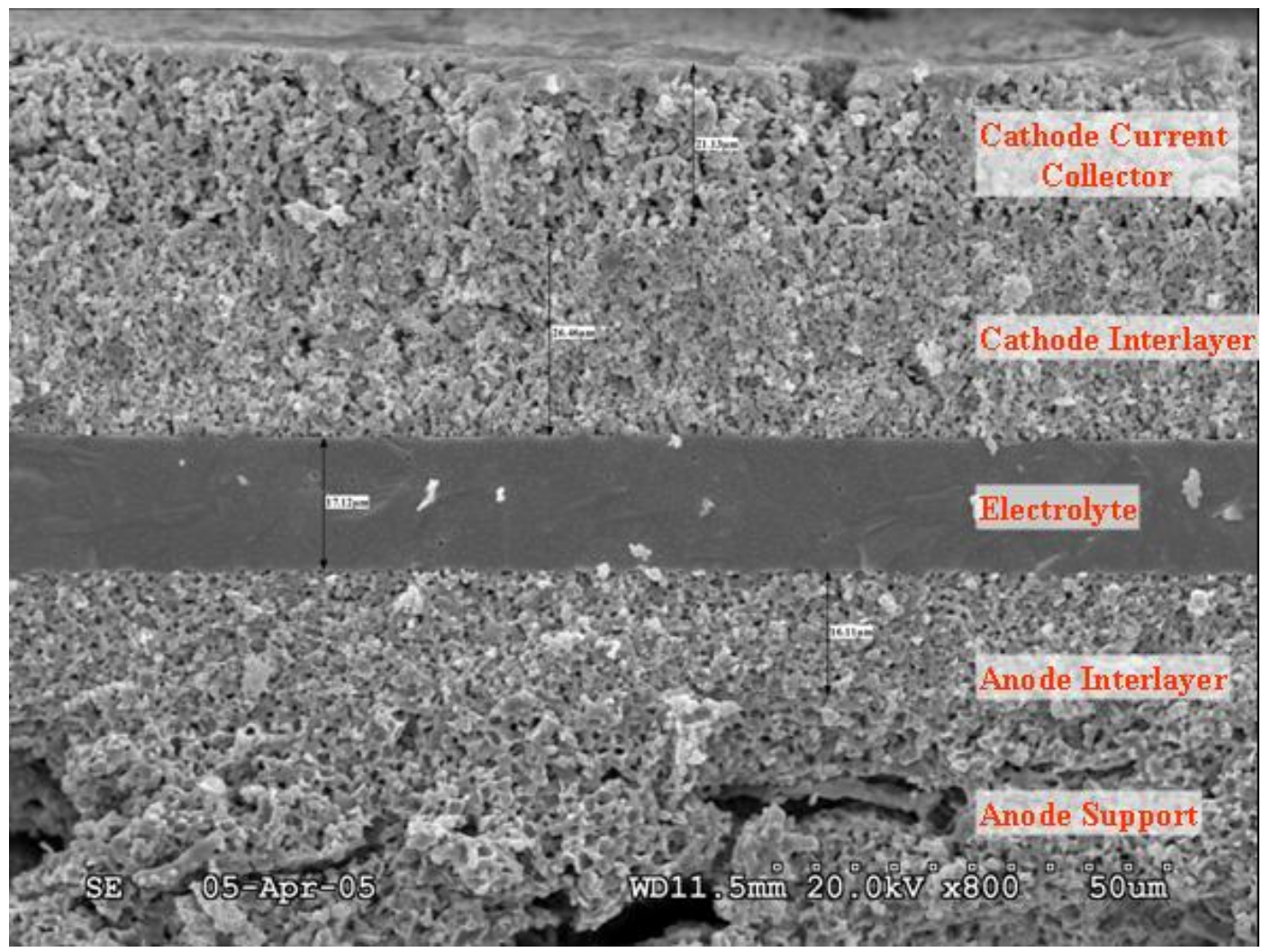

Figure 35. A SEM micrograph of a typical SOFC cell after test. Five distinctive layers are clearly presented in the photo.

\section{$\underline{\text { Task } 5 \text { Single Button Cell Testing in SOFC/SOFEC Mode }}$}

At MSRI, more than a hundred single button-cells were constructed and tested to evaluate electrode characteristics and cell performance operated in three modes: SOFC, SOEC and SOFEC. These results provided the characteristic information for large cells/stacks application, and are to be discussed in the following subsections.

Task 5.1 Button Cell Test Fixture Construction 


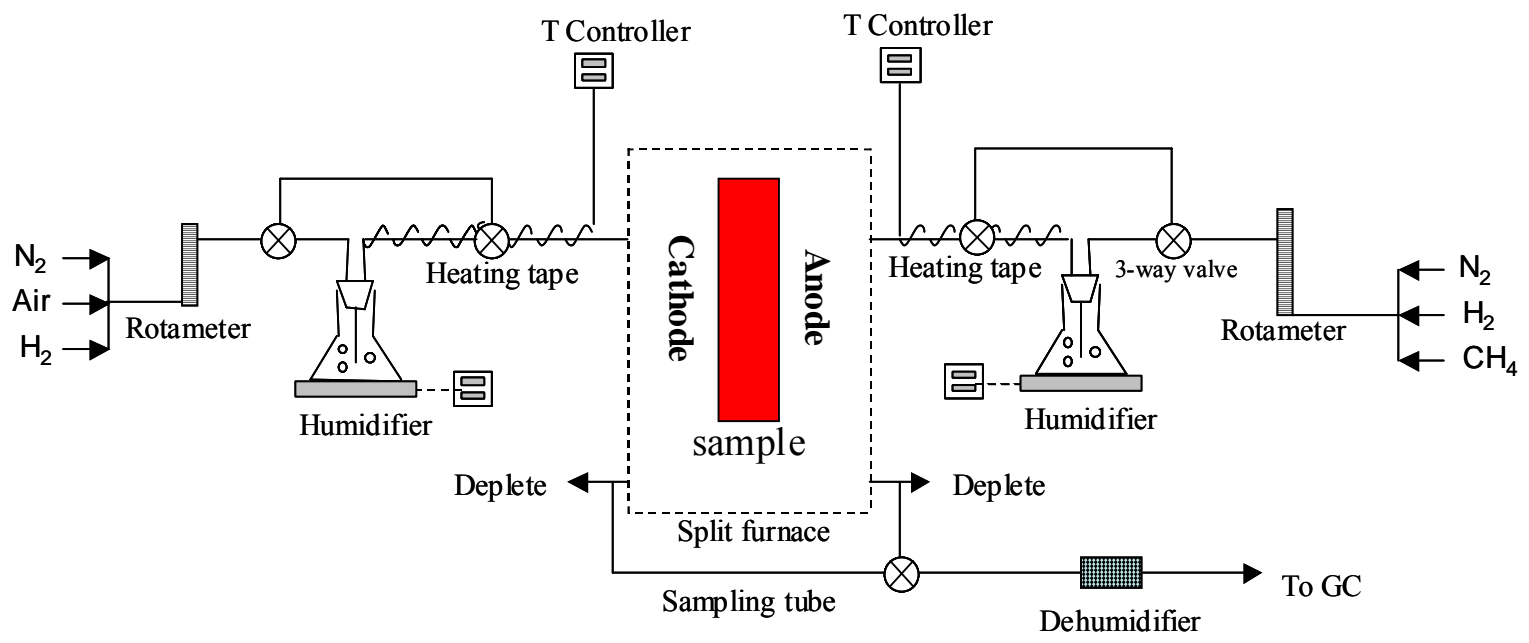

Figure 36. Diagram of a test fixture setup for the SOFC/SOEC/SOFEC testing

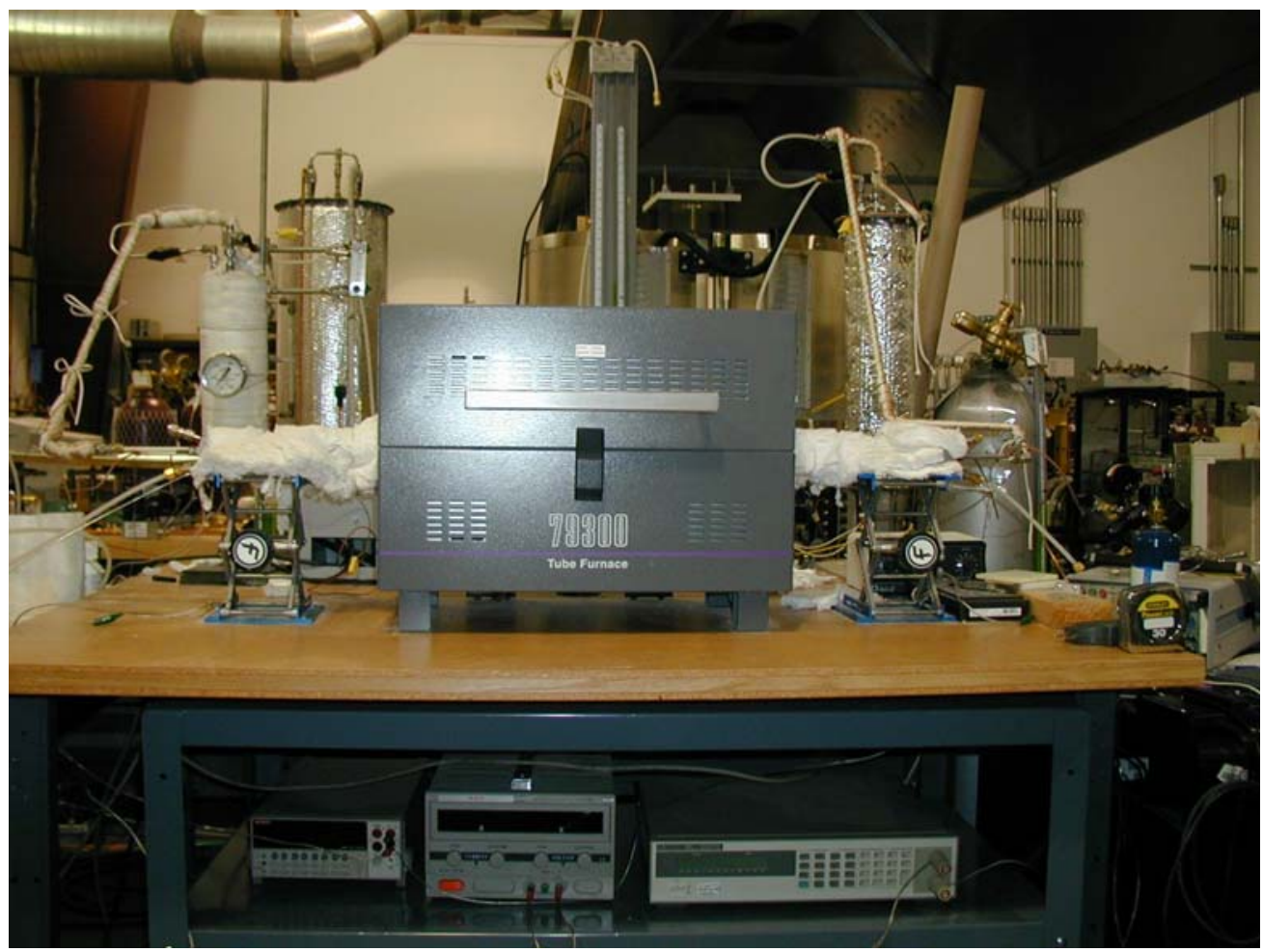

Figure 37. Picture of the modified test rig, capable of operating in the SOFC, SOEC, and SOFEC modes

One-inch button cell test rigs, which were routinely used at MSRI to evaluate SOFCs, were modified to be capable of operating in SOFC, SOEC, and SOFEC modes. Figure 36 is a diagram of the SOFC/SOEC/SOFEC test rig setup. Flexible gas supply options were setup for both the anode and cathode feed, which were controlled by two rotameters. Two specially designed humidifiers were added to both the anode and cathode sides. Humidity was controlled precisely by controlling the humidifier temperature. An Agilent Micro-Gas Chromatograph was connected to the test rig for analyzing the depleted gas composition. Figure 37 is a picture of the button-cell test fixture modified for cells tested in the SOFC, SOEC and SOFEC modes. 
Task 5.2 LSCM Cathode Optimization

As it was discussed in Task 1, LSCM has been identified as the candidate for the SOFEC application. Though studies of the LSCM material properties and stability characterizations were conducted in Task 1 in both oxidizing and reducing environments, the application of the material as the cathode was performed in this task.

One-inch button cells were constructed with the optimized anode substrates, 8 YSZ electrolyte, and the prospective LSCM-based cathode. The cathode for SOFECs was comprised of the composite cathode functional interlayer (CIL) and cathode current collector layer (CL). The CIL was prepared by combining the requisite amounts of the LSCM powder and SDC powder. Both the CIL and CL were screen-printed onto the anode substrate, air-dried, and followed by firing in air separately. Optimizations of the CIL were conducted, taking into account of the powder particle size, which affected the triple phase boundary length (or electrochemical reaction sites ERS), and sheet resistance, which was a matter of the material compositions and degree of sintering. Similar to the CIL, the CL was also optimized by taking into account of the porosity (gas diffusion) and sheet resistance (degree of sintering). A parametric study of optimizing both CIL and CL is described below.

In the study, the relative composition of LSCM+SDC for CIL and LSCM+pore former for CL, sintering temperatures, and sintering time for an optimized cathode microstructure, were all taken into consideration. Typically, the compositions of LSCM+SDC varied from 50\% to $60 \%$ by weight for CIL. The sintering temperatures varied from $1050^{\circ} \mathrm{C}$ to $1200^{\circ} \mathrm{C}$. Certain amounts of pore former (up to $20 \%$ by weight) were added to the CL to reduce concentration overpotential. Cathode firing time varied from 1 hour to 2 hours. Infiltration with different electrocatalytic metal nitrates was also investigated to reduce the activation overpotential. Button cells screen-printed with $2 \mathrm{~cm}^{2}$ active areas with desired CIL and CL were then tested in the SOFC mode at $800^{\circ} \mathrm{C}$. Results of the parametric study of the LSCM-based composite cathodes are summarized in Table 2. For each test, ohmic resistances were measured via applying the current interruption technique. The measured ohmic ASR, cell ASR and activation ASR were also included in Table 2 for comparisons. Corresponding to the 15 samples listed in the table, the power density, peak power density and various ASR measured are also plotted in Figure 38.

Table 2. Parametric studies of the LSCM-based cathode (tested at $800^{\circ} \mathrm{C}$ in SOFC mode)

\begin{tabular}{|c|c|c|c|c|c|c|c|c|}
\hline & Anode & $\mathbf{C I L} \mathbf{( 5 0 / 5 0 )}$ & $\mathbf{C A T}(\mathbf{9 0})$ & $\mathbf{p} \_\mathbf{m a x}\left(\mathbf{w} / \mathbf{c m}^{\mathbf{2}} \mathbf{)}\right.$ & $\mathbf{p} \_\mathbf{0 . 7}\left(\mathbf{w} / \mathbf{c m}^{\mathbf{2}} \mathbf{)}\right.$ & Cell ASR & Ohmic ASR & Act ASR \\
\hline 1 & Std & 1150 & 1050 & 0.225 & 0.17 & 0.88 & 0.39 & 0.49 \\
\hline 2 & Std & 1200 & 1050 & 0.3059 & 0.23 & 0.68 & 0.33 & 0.35 \\
\hline 3 & Std & 1250 & 1050 & 0.2975 & 0.234 & 0.7 & 0.349 & 0.351 \\
\hline 4 & Std & 1300 & 1050 & 0.208 & 0.16 & 0.93 & 0.33 & 0.6 \\
\hline 5 & Std & 1200 & 1100 & 0.27 & 0.16 & 0.63 & 0.49 & 0.14 \\
\hline 6 & Std & 1200 & 1150 & 0.23 & 0.16 & 0.91 & 0.55 & 0.36 \\
\hline 7 & Std & $1200(\mathrm{Pd})$ & 1050 & 0.44 & 0.34 & 0.53 & 0.33 & 0.2 \\
\hline 8 & Std & $1200(\mathrm{Ru})$ & 1050 & 0.18 & 0.14 & 1.064 & 0.74 & 0.324 \\
\hline 9 & Std & 1200 & $1050(\mathrm{CAT}-\mathrm{Pt})$ & 0.37 & 0.23 & 0.552 & 0.357 & 0.195 \\
\hline 10 & Std & 0 & 1050 & 0.21 & 0.14 & 0.867 & 0.381 & 0.486 \\
\hline 11 & Std & 1200 & $1050(\mathrm{pt})$ & 0.4 & 0.3 & 0.576 & 0.286 & 0.29 \\
\hline 12 & Std & 1200 & $1050($ w/o Pd) & 0.5 & 0.39 & 0.47 & 0.225 & 0.245 \\
\hline 13 & Std & 1200 & $1050($ w/ Pd) & 0.34 & 0.25 & 0.632 & 0.33 & 0.302 \\
\hline 14 & Std & $1200(60 / 40)$ & 1050 & 0.295 & 0.207 & 0.656 & 0.493 & 0.161 \\
\hline 15 & Std & $1200(60 / 40)$ & 1050 & 0.28 & 0.204 & 0.654 & 0.435 & 0.219 \\
\hline
\end{tabular}


As can be seen in Figure 38, the sintering temperatures of the CIL and the CL were the most critical parameters affecting the cell performance. Any over-sintering resulting in a reduction of porosity, or under-sintering resulting in poor bonding to the electrolyte or poor particle necking, will cause large losses from large concentration overpotential, large activation overpotential, or/and sheet resistance. From the experiments, it was concluded that the firing temperature of $1200^{\circ} \mathrm{C}$ was the optimum for the composite CIL to achieve good necking and bonding to the electrolyte, while $1100^{\circ} \mathrm{C}$ and $1150^{\circ} \mathrm{C}$ were good for LSCM-based CL. Figure 39 is a microstructure of a button-sized cell printed with the LSCM cathode after testing. Six distinctive layers are clearly presented in the SEM photo. The investigation on electrocatalysts showed that infiltration of metal nitrate as the electrocatalyst helped the cell performance. The peak power density increased nearly $40 \%$ for cells impregnated with a small amount of $\mathrm{Pd}$ solution. Performance improvements were confirmed by the current interruption method, which was applied to each test to measure the ohmic losses and activation overpotentials.

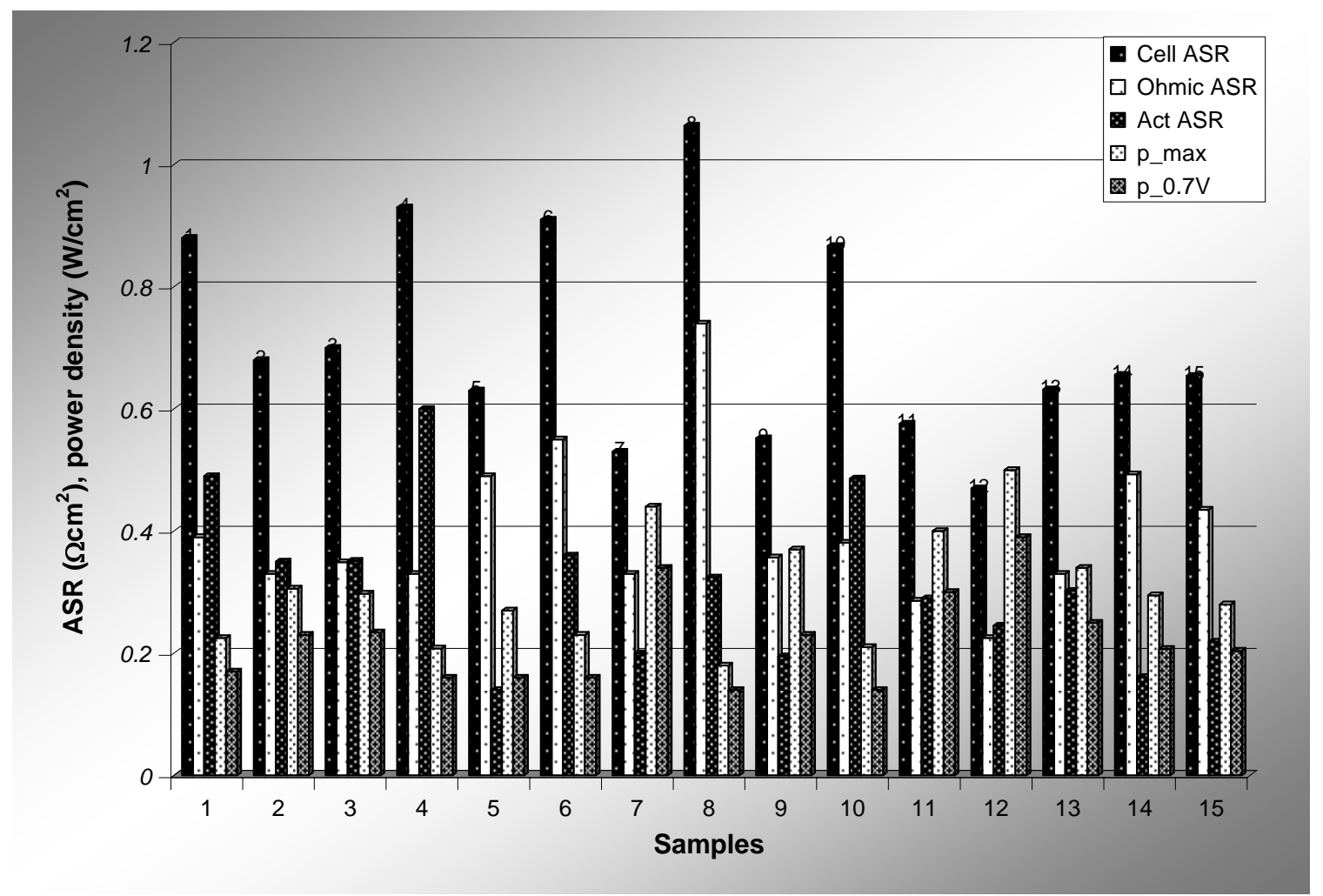

Figure 38. Parametric studies of the LSCM-based CIL and CL. All results were obtained in the SOFC mode at $800^{\circ} \mathrm{C}$. 


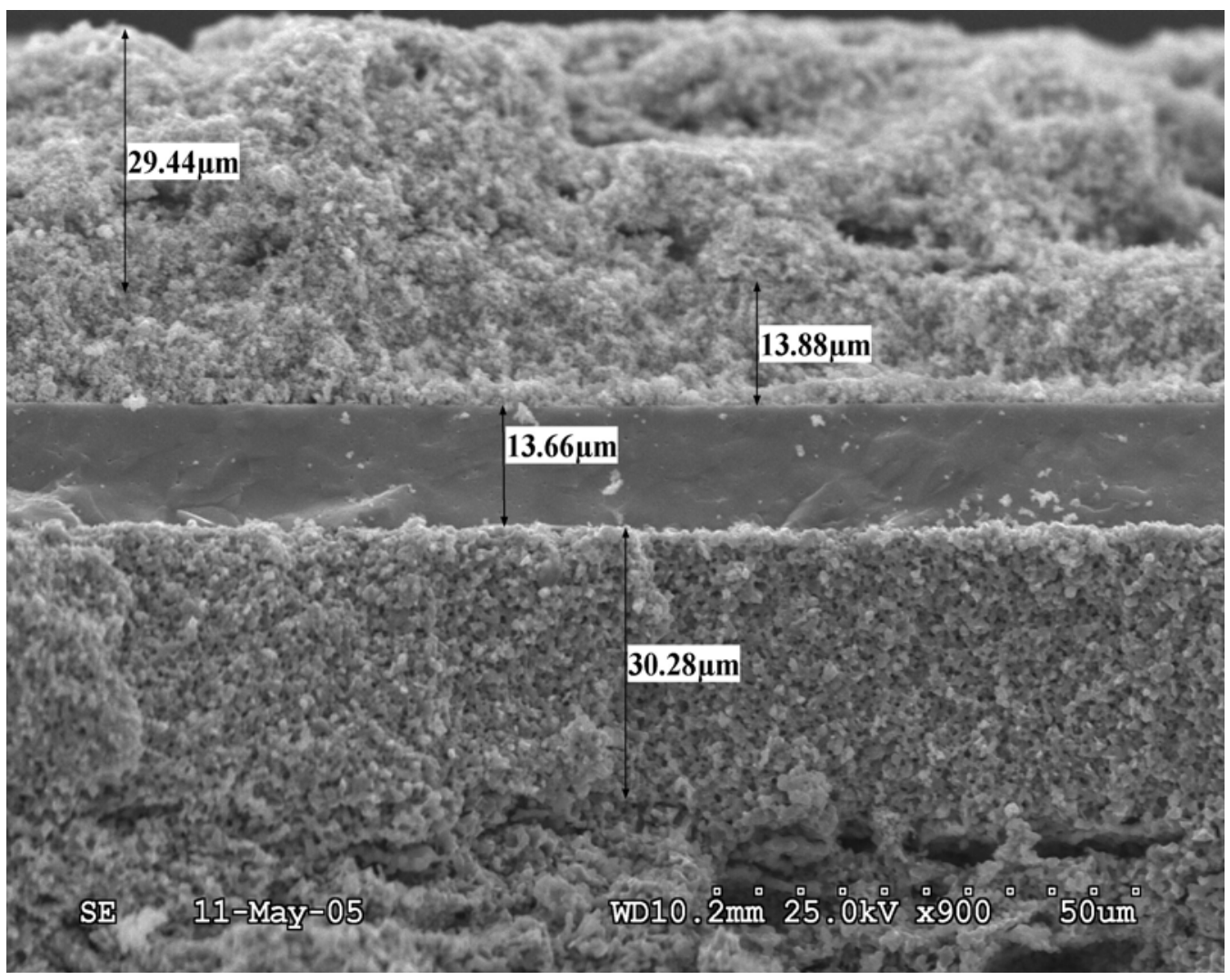

Figure 39. A SEM micrograph of an anode supported button cell with the LSCM-based cathode

\section{Task 5.3 Button Cell Testing in the SOFC, SOEC, and SOFEC Modes}

In general, button cells deposited with the LSCM-based composite cathode were tested in both the SOFC and SOFEC modes at $800^{\circ} \mathrm{C}$. Three kinds of fuels: hydrogen, methane, and syngas comprised of $77 \% \mathrm{H}_{2}, 15 \% \mathrm{CO}$, and $8 \% \mathrm{CO}_{2}$, were used as the fuel to either generate power or to assist in steam electrolysis to produce hydrogen. In every test, cells were first operated in the SOFC mode with dry air as the oxidant as a baseline. In order to prevent carbon deposition, both methane and syngas fuels were humidified. Figure 40 presents performance characteristics of a typical button cell operated in the SOFC mode using three kinds of fuels. The steam/carbon ratio was set to 1 when the methane was used. As shown in the figure, the cell performed the best when hydrogen was used as the fuel. The peak power density is about $0.22 \mathrm{~W} / \mathrm{cm}^{2}$ at the current density $0.5 \mathrm{~A} / \mathrm{cm}^{2}$. The performance of the wet syngas was close to that of methane. 


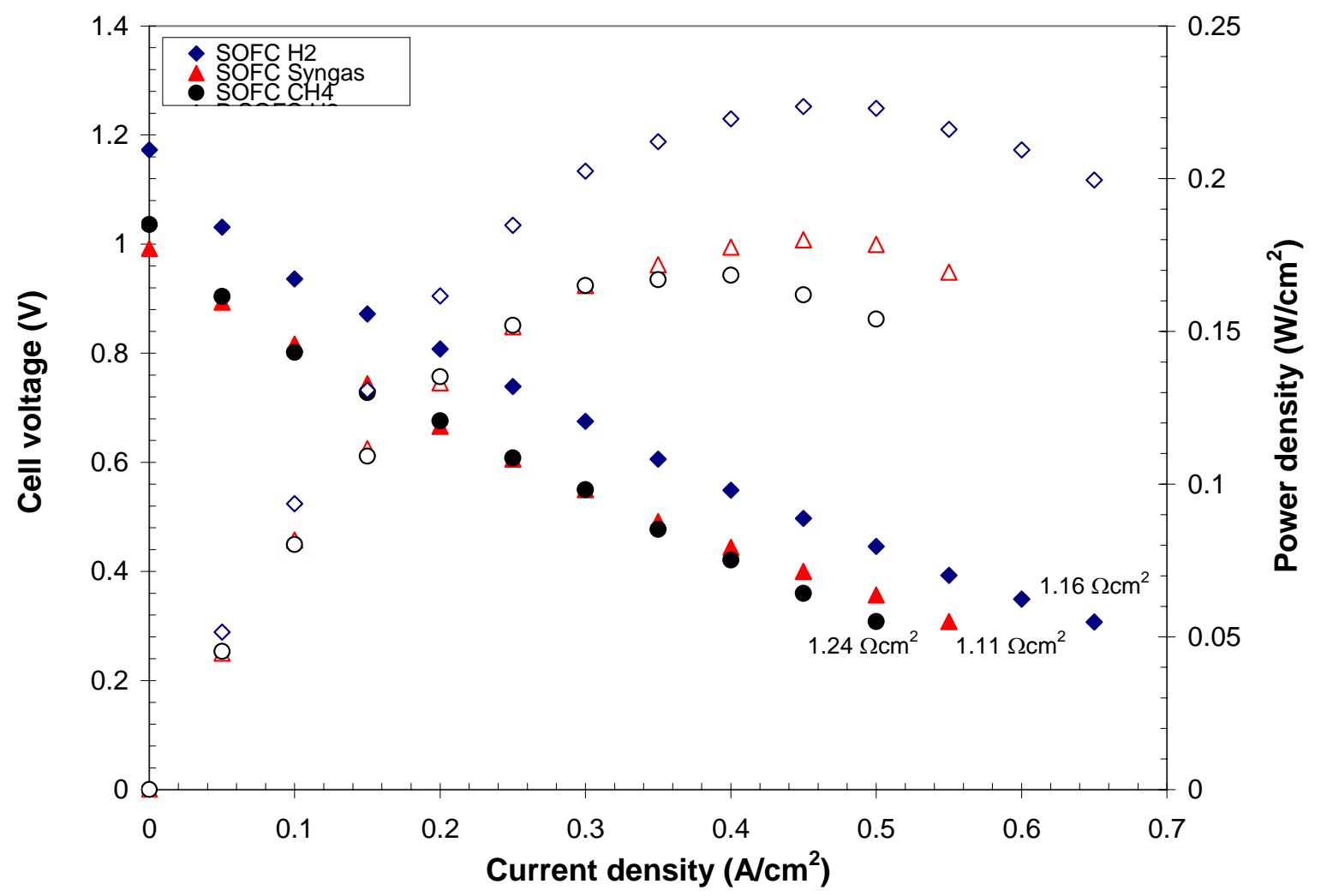

Figure 40. Performance of a button cell tested in the SOFC mode at $800^{\circ} \mathrm{C}$. Hydrogen, syngas with $27 \%$ humidity, or methane with $50 \%$ of humidity was the fuel; dry air was the oxidant.

The same button cells were then operated in the SOFEC mode under the same fuel condition as in the SOFC mode, except that a mixture of $90 \%$ steam with hydrogen was used as the oxidant, in place of air on the cathode. Typical performances of the current density curve and the power density curve are shown in Figure 41 and Figure 42, respectively. Again, when hydrogen was used as the fuel, performance was higher than when using methane or syngas. For instance, at the same hydrogen production rate of $4.5 \mathrm{SCCM} / \mathrm{cm}^{2}$ (standard cubic centimeter of hydrogen per minute per square centimeter), the external electrical energy needed to split steam was only 0.34 $\mathrm{V}$ ( or $0.2 \mathrm{~W} / \mathrm{cm}^{2}$ ) for the $\mathrm{H}_{2}$-assisted SOFEC, comparing to $0.4 \mathrm{~V}$ (or $0.24 \mathrm{~W} / \mathrm{cm}^{2}$ ) for the $\mathrm{CH}_{4^{-}}$ assisted SOFEC. When the current density was less than $0.15 \mathrm{~A} / \mathrm{cm}^{2}$, as shown in Figure 42, the cell was under a self-driven mode with net power output. No external energy was needed to electrolyze the steam. 


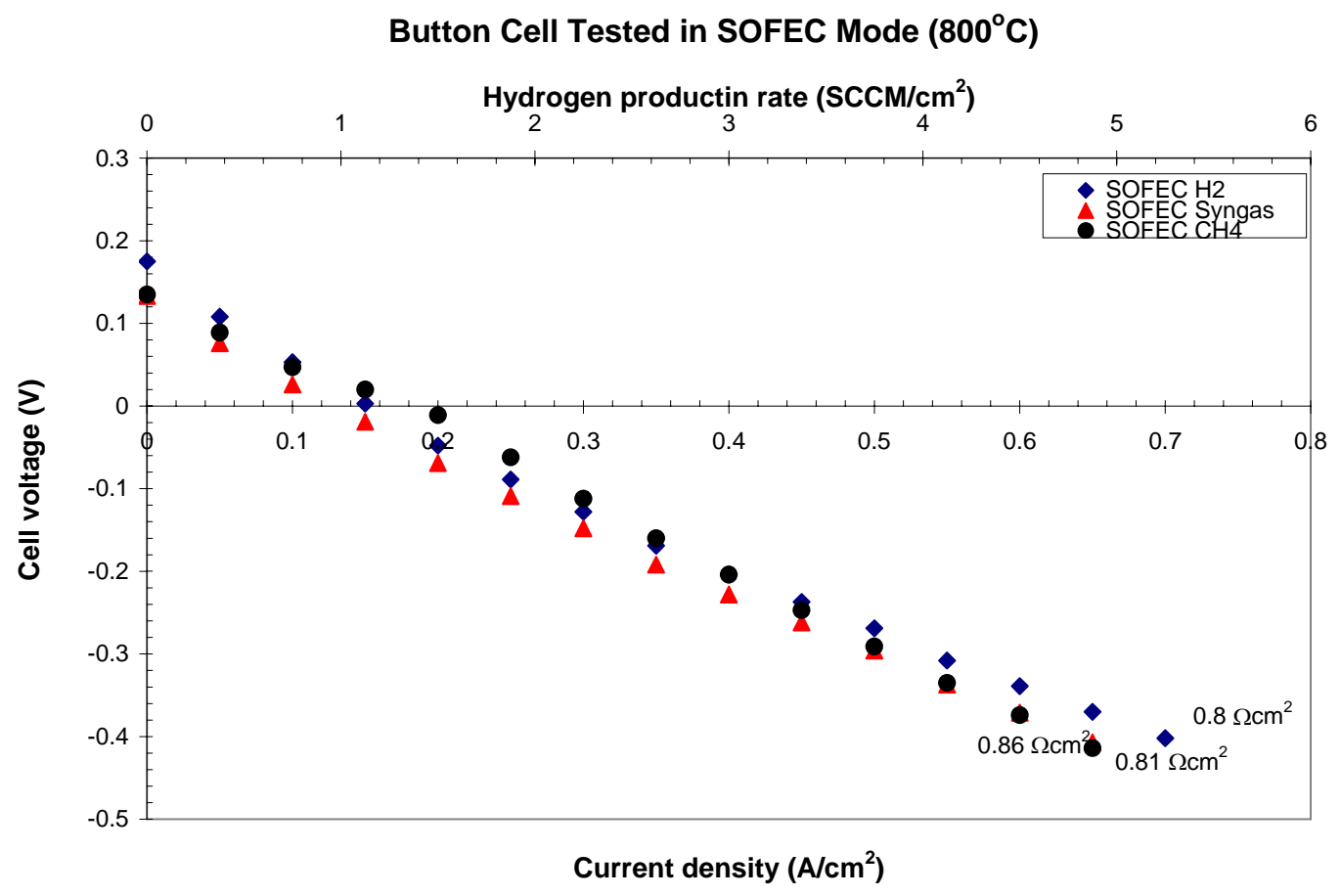

Figure 41. Current density vs. cell voltage curve of a button cell tested at $800^{\circ} \mathrm{C}$ in the SOFEC mode. A mixture of steam (10\%) with hydrogen, steam (27\%) with syngas, or steam $(50 \%)$ with methane was the fuel; and a mixture of steam (90\%) and hydrogen (carry gas) was an oxidant.

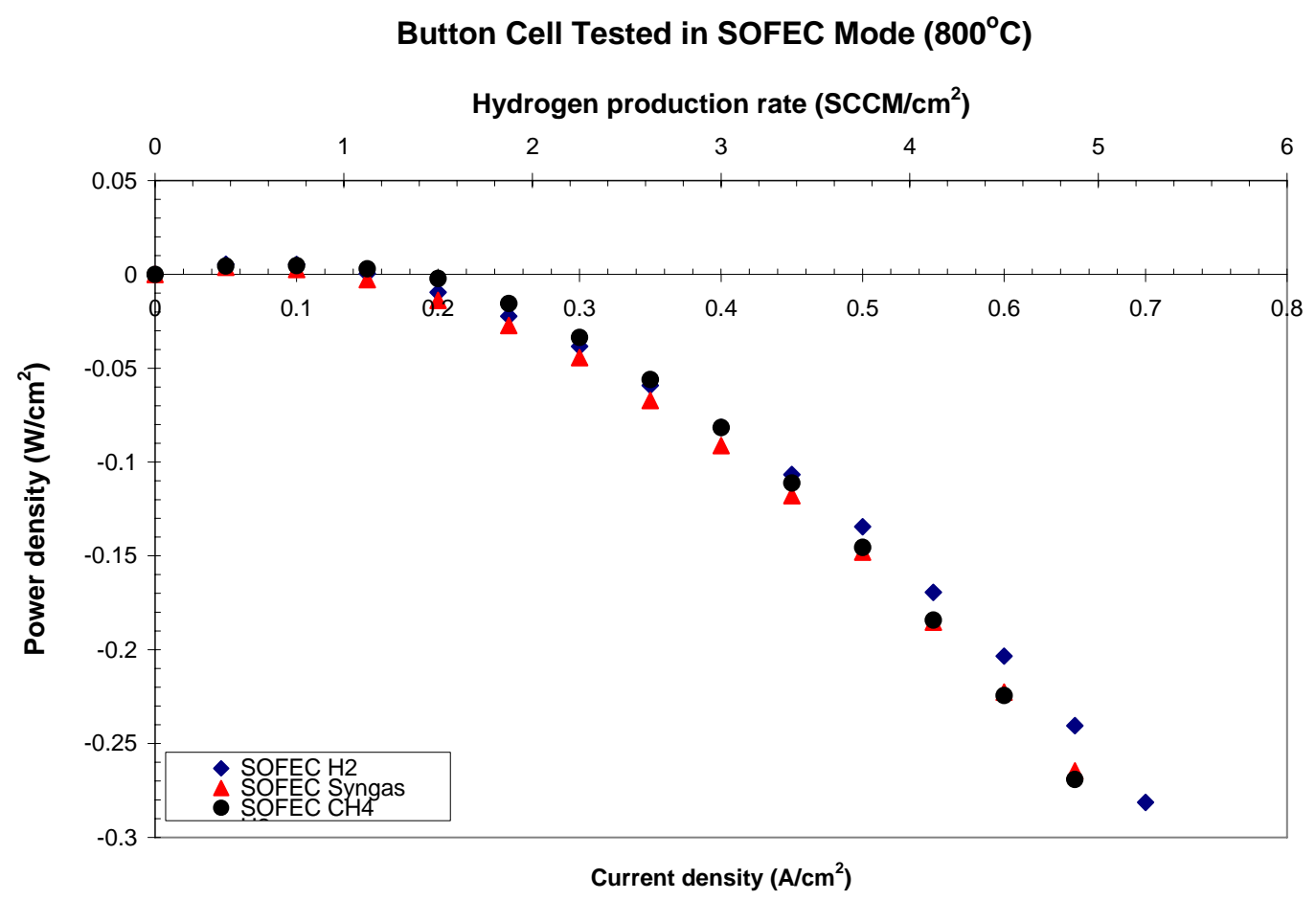

Figure 42. Current density vs. power density curve of a button cell tested at $800^{\circ} \mathrm{C}$ in SOFEC mode. A mixture of steam $(10 \%)$ with hydrogen, steam $(27 \%)$ with syngas, or steam $(50 \%)$ with methane was the fuel; a mixture of steam (90\%) and hydrogen (carry gas) was an oxidant. 
The performance comparison (current density vs. cell voltage) was made between the SOFC mode and the SOFEC mode, as plotted in Figure 43. Quadrants were applied to characterize the cell performance. In the first quadrant, the cell is operated in the SOFC mode, which consumes a fuel to produce electricity. The SOFEC mode is located across the first and fourth quadrants where the current flows in the same direction as in the SOFC mode. When the performance curve sits in the first quadrant, the SOFEC co-generates hydrogen and electricity simultaneously. External power is required to increase the hydrogen production rate, what makes the V-I curve locate in the fourth quadrant. In convenience, SOFEC performance is transposed and redrawn along the negative current direction located across the third and second quadrants. As shown in the plot, the performance was quasi-symmetric. The area specific resistance of the hydrogen assisted SOFEC was lower than that of the methane assisted SOFEC. Nevertheless, the ASR of the cell with the LSCM-based cathode operated in both the SOFC mode and SOFEC mode was higher than that of a typical SOFC cell with a doped-cobaltite $\left(\mathrm{La}_{0.8} \mathrm{Sr}_{0.2} \mathrm{CoO}_{3}\right)$ cathode, which was on the order of $0.3 \Omega \mathrm{cm}^{2}$.

\section{Cell w/LSCM Cathode Operated in SOFC \& SOFEC Modes}

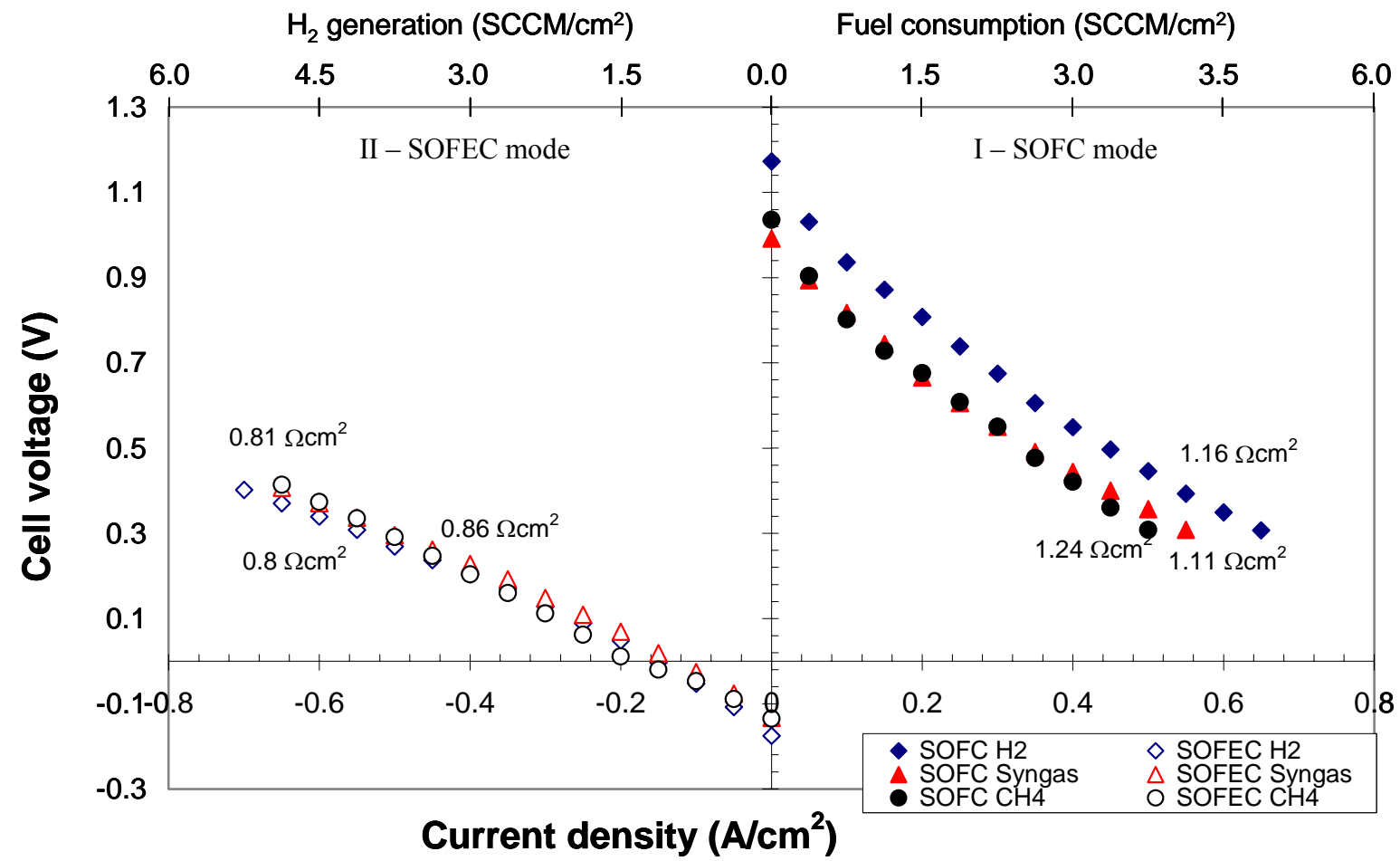

Figure 43. Performance comparison operated at $800^{\circ} \mathrm{C}$ in the SOFC and SOFEC modes. Mixture of steam $(10 \%)$ with hydrogen, steam $(27 \%)$ with syngas, or steam $(50 \%)$ with methane was used as the fuel. Either a dry air was used as the oxidant in the SOFC mode, or a mixture of steam (90\%) with hydrogen was used as an oxidant in the SOFEC mode.

As was discovered from the optimization tests of the LSCM cathode, infiltration of a small quantity of Pd nitrate solution can significantly improve cell performances, thanks to the reduction of activation overpotential. Those button cells were evaluated in SOFC, SOEC, and 
SOFEC modes. As usual, the cells were tested in the SOFC mode first as a baseline using three types of fuels: hydrogen, wet methane, and wet syngas. Figure 44 shows the performance characteristics obtained at $800^{\circ} \mathrm{C}$. The cell had similar performance characteristics for both the $\mathrm{H}_{2}$ and syngas fuel, while a starvation condition was observed for $\mathrm{CH}_{4}$ due to lack of directinternal-reforming (DIR) of $\mathrm{CH}_{4}$. $\mathrm{GC}$ measurement confirmed that only a small portion of $\mathrm{CH}_{4}$ was reformed.

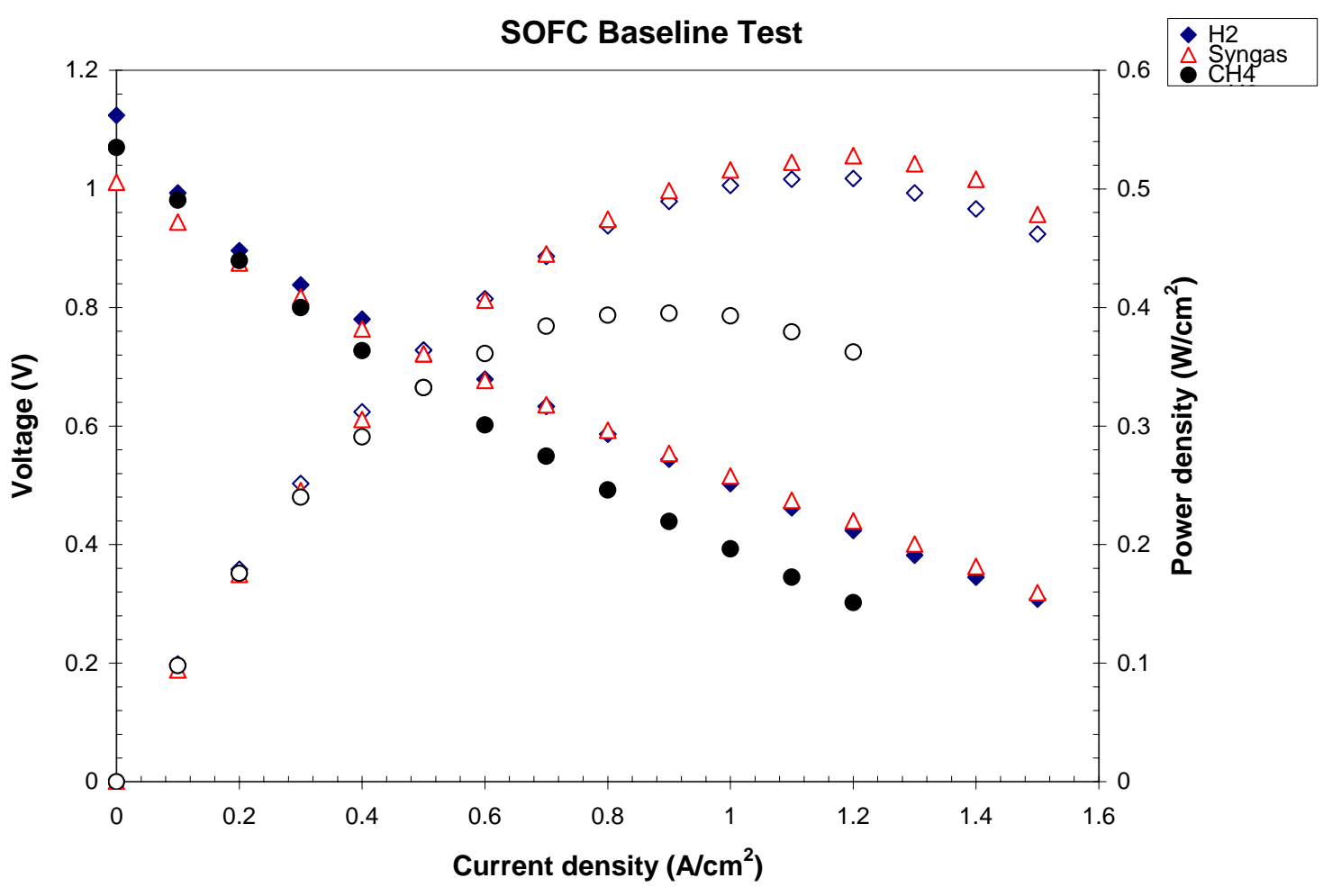

Figure 44. A typical performance of a button cell, tested at $800^{\circ} \mathrm{C}$ in the SOFC mode as a baseline test. Cathode was the LSCM+SDC composite with Pd infiltration. Hydrogen, a mixture of steam (27\%) with syngas, or steam $(50 \%)$ with methane was the fuel; and air was the oxidant.

The reversible SOFC/SOEC mode was also tested at various steam and $\mathrm{H}_{2}$ compositions, at which varied from $10 \%$ to $90 \%$. Figure 45 shows the voltage-current performance comparisons in the SOFC and SOEC modes. The cell generated electrical power by consuming chemical energy in the first quadrant of the figure, while it consumed electrical energy to produce hydrogen from the steam in the second quadrant. It is observed in the figure that at a lower steam concentration, a higher performance is achieved in the SOFC mode; conversely, this causes a lower performance in the SOEC mode. The cell showed the symmetric characteristics for the SOFC and SOEC operations against the y-axis as the steam concentration was above $60 \%$ with a balance of $\mathrm{H}_{2}$. Cell starvation existed as the steam concentration was either less than $30 \%$ in the SOEC mode or more than $90 \%$ in the SOFC mode. 


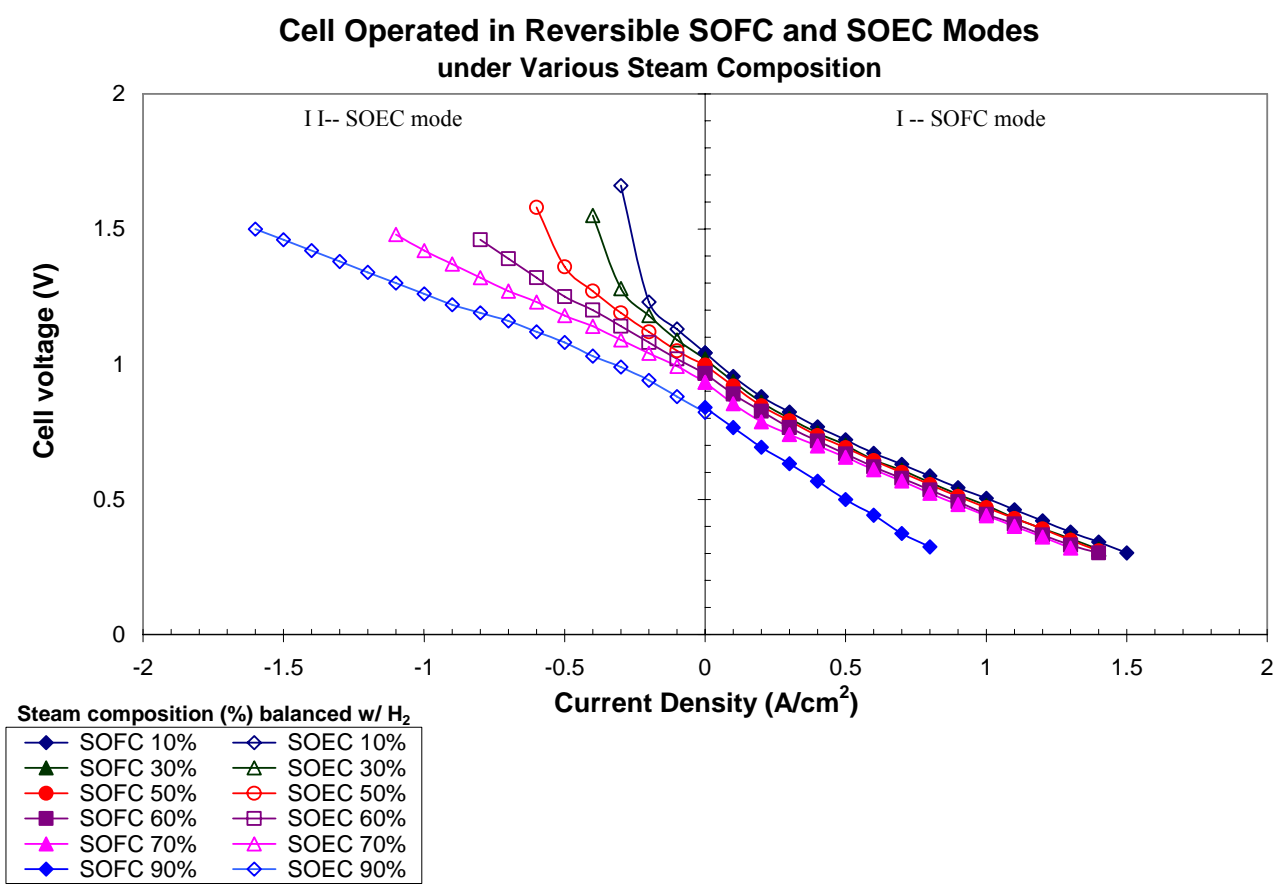

Figure 45. Reversible SOFC/SOEC tests. In the SOFC mode, mixtures of $\mathrm{H}_{2}$ and steam were the anode gas, while dry air was the cathode gas. In the SOEC mode, mixtures of $\mathrm{H}_{2}$ and steam were the cathode gas, while dry air was the anode gas. The steam composition on the anode varied from $10 \%$ to $90 \%$.

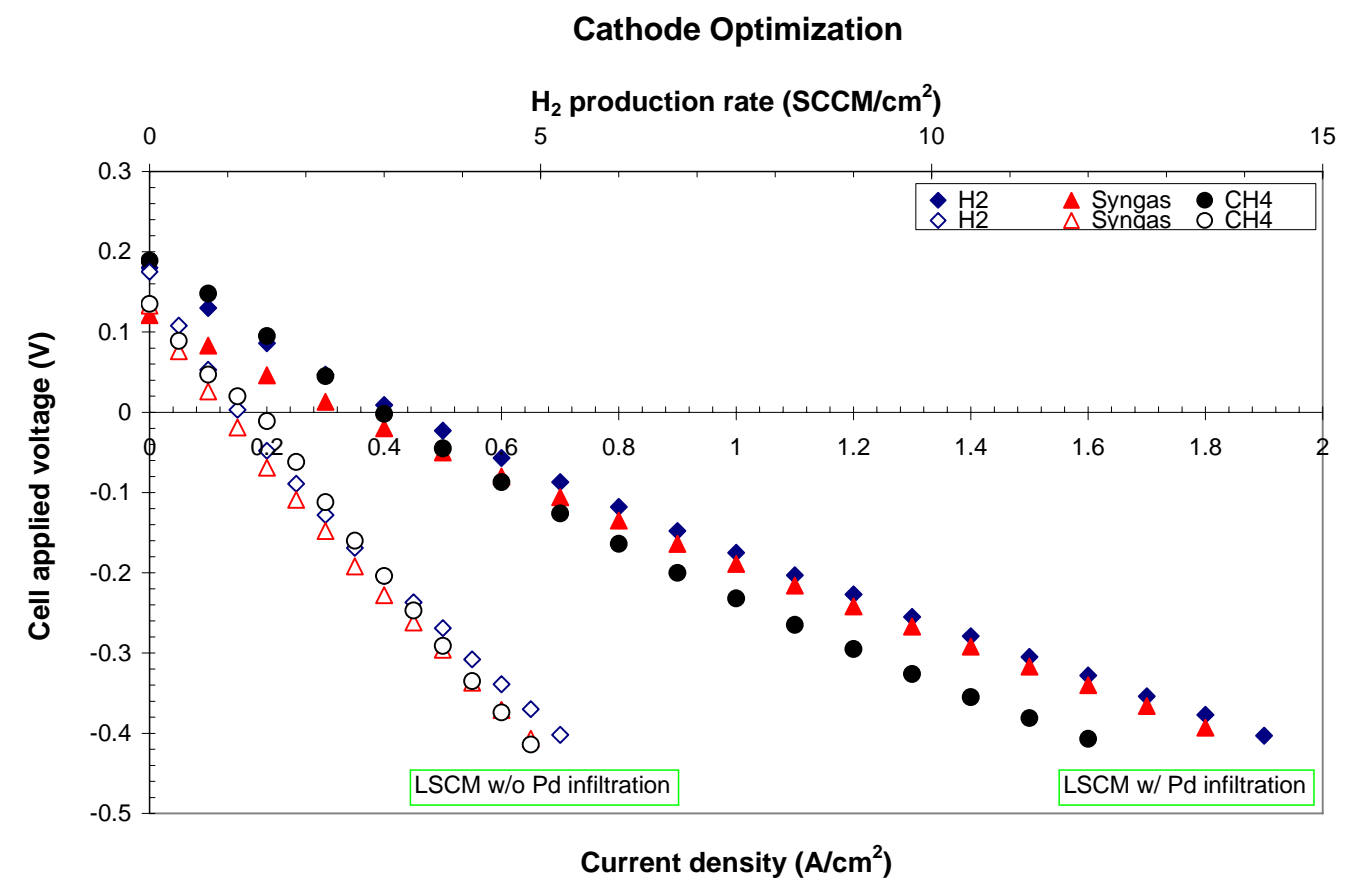

Figure 46. LSCM-based cathode optimizations. Button cells were tested at $800^{\circ} \mathrm{C}$ in the SOFEC mode. Unfilled symbols represent the button cell with LSCM cathode only, while the filled symbols are the button cell with LSCM cathode infiltrated with Pd. A mixture of steam (10\%) with hydrogen, steam $(27 \%)$ with syngas, or steam $(50 \%)$ with methane was the fuel; and a mixture of steam $(90 \%)$ as the oxidant with $10 \%$ hydrogen as a carrier gas. 
After the SOFC and SOEC operation, the same cell was tested in the SOFEC mode, with hydrogen-, syngas- or methane- assisted on the anode, while steam replaced air on the cathode. Figure 46 presents the performance characteristics, which are very similar to the performance shown in Figure 41. In order to show the improvement made by the Pd infiltration, the performance of a LSCM-based cell without a catalyst infiltration was also plotted in Figure 46. The improvement made by Pd infiltration was obviously significant. As shown in the plot, at the same applied voltage for the two cells to drive the steam dissociation, for instance, at $0.4 \mathrm{~V}$, the hydrogen production rate in the $\mathrm{H}_{2}$-assisted SOFEC mode reached $14.25 \mathrm{SCCM} / \mathrm{cm}^{2}$ for the cell with the Pd infiltration; by contrast, it was only $5.25 \mathrm{SCCM} / \mathrm{cm}^{2}$ for the cell without the $\mathrm{Pd}$ infiltration. This is approximately a $170 \%$ improvement. Similar improvements were also achieved for the syngas-assisted and $\mathrm{CH}_{4}$-assisted SOFEC operations. The ASRs were estimated to be around $0.3 \sim 0.4 \Omega \mathrm{cm}^{2}$ and $0.8 \sim 0.9 \Omega \mathrm{cm}^{2}$, for the cell with Pd infiltration and the cell without infiltration, respectively. It can be predicted that such substantial reduction of ASR resulted from the activation overpotential reduction by the electrocatalyst infiltration. That is consistent with the results obtained from the current interruption measurement in the SOFC tests performed in the subtask 5.2.

\section{Cell Operated in SOFC, SOEC and SOFEC Modes}

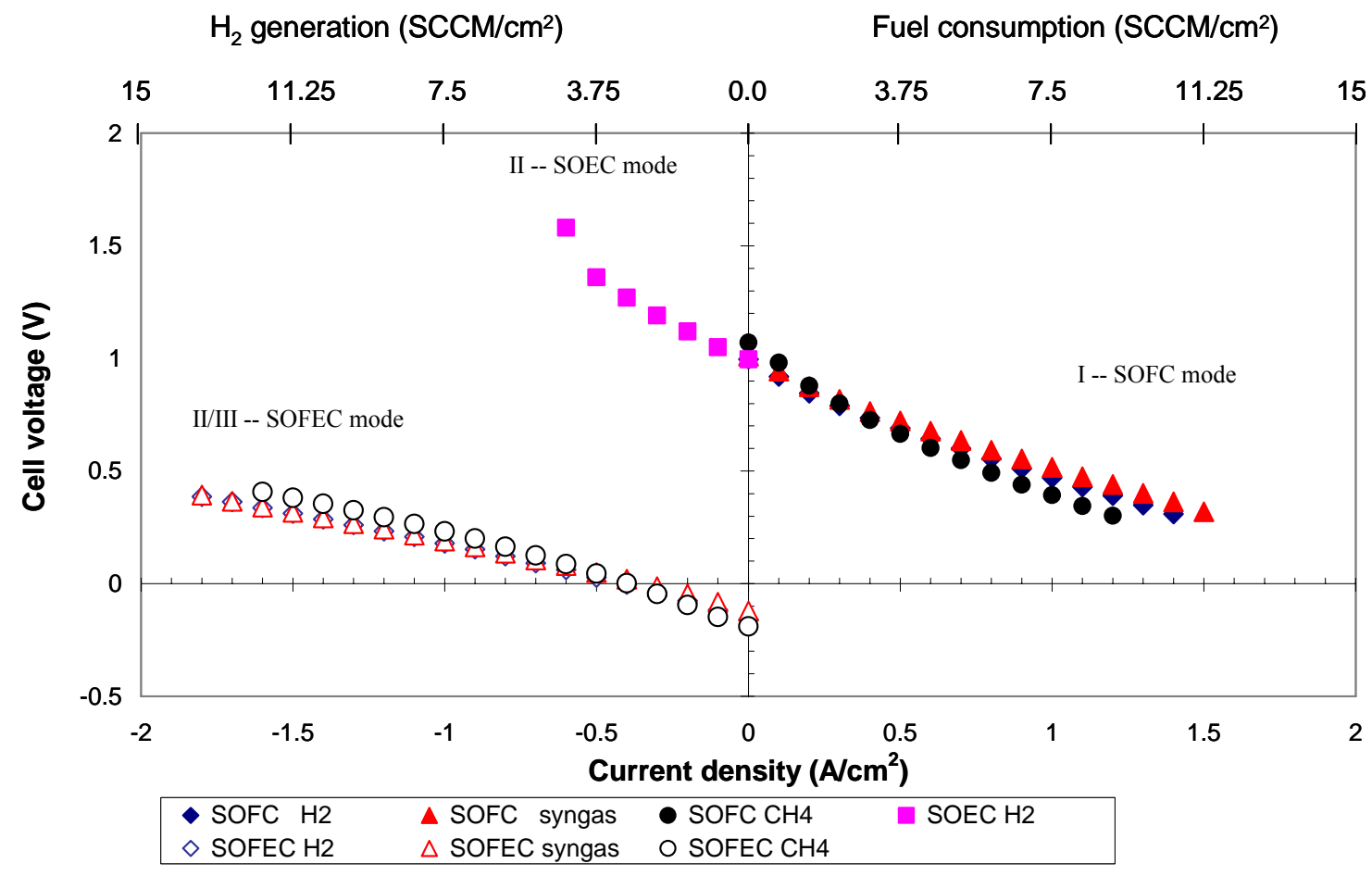

Figure 47. Performance comparison operated at $800^{\circ} \mathrm{C}$ in the reversible SOFC, SOEC, and SOFEC modes. Button cell was made from MSRI standard tape. Cathode was the LSCM-based composite infiltrated with $\mathrm{Pd}$. In the SOFC mode, a mixture of steam $(50 \%)$ with $\mathrm{H}_{2}$, steam $(27 \%)$ with syngas, or steam (50\%) with $\mathrm{CH}_{4}$ was the on the anode, and air was on the cathode. In the SOEC mode, a mixture of steam $(50 \%)$ with $\mathrm{H}_{2}$ was on the cathode, and air was on the anode. In the SOFEC mode, a mixture of steam $(50 \%)$ with $\mathrm{H}_{2}$, steam $(27 \%)$ with syngas, or steam $(50 \%)$ with $\mathrm{CH}_{4}$ was the on the anode, and a mixture of steam $(90 \%)$ with $\mathrm{H}_{2}$ was on the cathode. 
Figure 47 summarizes the typical performances tested in the reversible SOFC, SOEC, and SOFEC modes. Similarly, the first quadrant represents the SOFC mode, which consumes a fuel $\left(\mathrm{H}_{2}\right.$, syngas, or $\left.\mathrm{CH}_{4}\right)$ to produce the electricity. The second quadrant represents cells operating in the conventional electrolyzer mode (SOEC) without fuel assist to produce hydrogen from steam. In order to compare the fuel-assisted electrolysis with the traditional electrolysis, the SOFEC performance was again transposed and plotted along the negative current direction, which is in the same direction as the SOEC in the second/third quadrant. At a current density $0.6 \mathrm{~A} / \mathrm{cm}^{2}$, or equivalent to a $4.5 \mathrm{SCCM} / \mathrm{cm}^{2}$ hydrogen production rate, the electrical energy required to electrolyze steam is $1.58 \mathrm{~V}$ and $0.087 \mathrm{~V}$ for the SOEC and SOFEC, respectively. Subsequently, for the electrochemical devices, it can save a significant amount of electricity when operated in the SOFEC mode instead of in the SOEC mode.

Other than the precious metal infiltration to improve the LSCM-based cathode performance, work was also done to develop non-precious metal catalysts to decrease the materials cost without sacrificing cell performance for hydrogen generation. Several catalysts were identified and evaluated in both the reducing (hydrogen generation mode) and the oxidizing atmospheres (electricity generation mode). Figure 48 presents the performance of a button cell tested at $800^{\circ} \mathrm{C}$ on a MSRI standard SOFC test bed with seals on the anode side. This cell was applied with LSCM-based composite cathode and infiltrated with catalyst A. In test, hydrogen and air were fuel and oxidant, respectively. As shown in the figure, this cell achieved $1 \mathrm{~W} / \mathrm{cm}^{2}$ power density, and the ASR was $0.25 \Omega \mathrm{cm}^{2}$, very comparable to the cells infiltrated with Pd catalyst.

SOFC Baseline Test (LSCrM-based CA infiltrated w/ A)

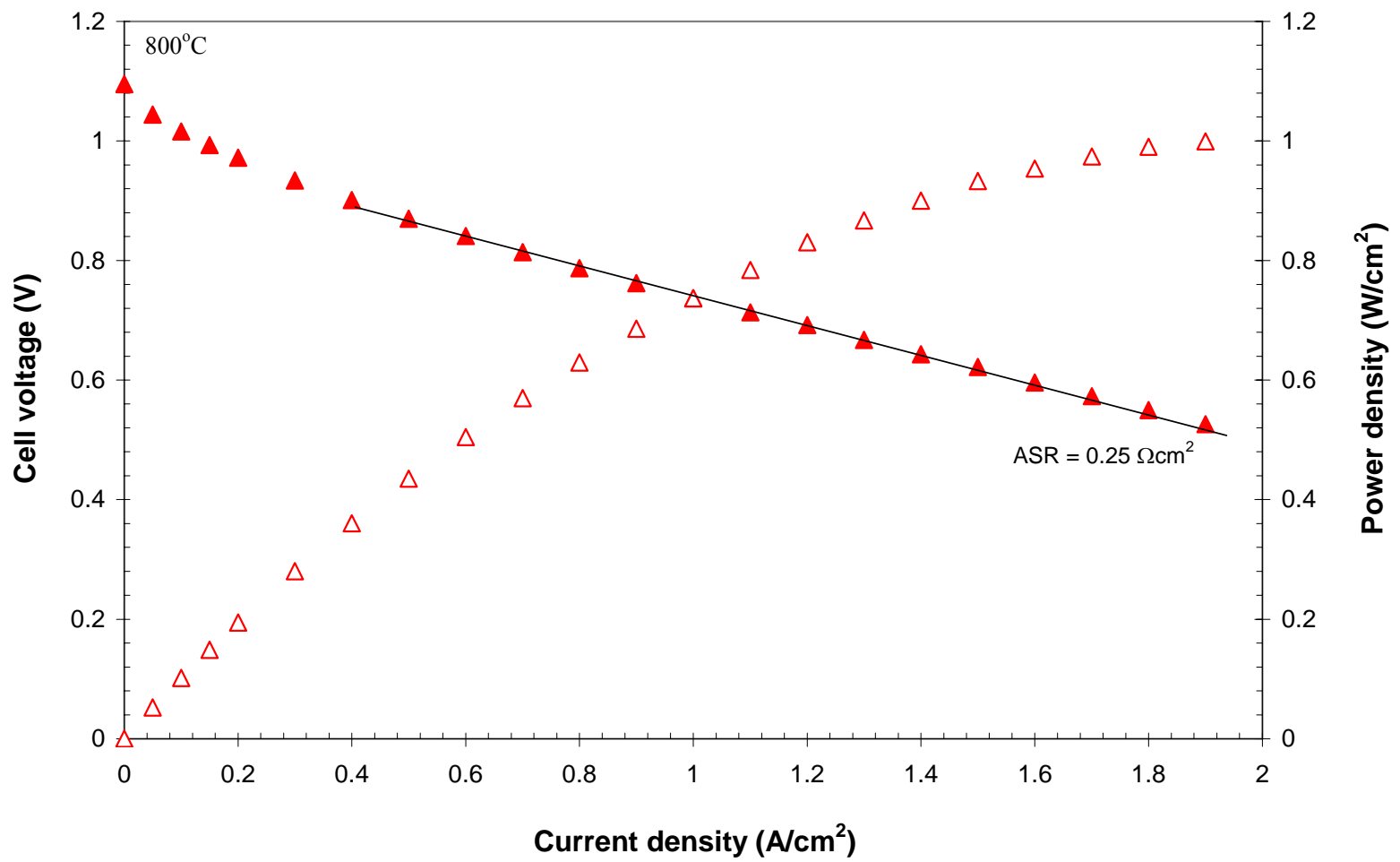

Figure 48. Performance of a button cell tested in the SOFC mode as the baseline at $800^{\circ} \mathrm{C}$. Cathode was the LSCM+SDC composite infiltrated w/ catalyst A. Hydrogen was the fuel; and air was the oxidant. 
In parallel, cells infiltrated with the same catalyst A were tested in the SOFC/SOEC/SOFEC test bed with hermetic seals on both anode and cathode sides, first in the SOFC mode as the baseline, then in the SOEC mode followed in the SOFEC mode to produce hydrogen. Figure 49 shows the test results operated in the SOFC mode using three types of fuels: hydrogen, wet syngas, and wet methane. The cell showed the best performance for the $\mathrm{H}_{2}$ fuel.

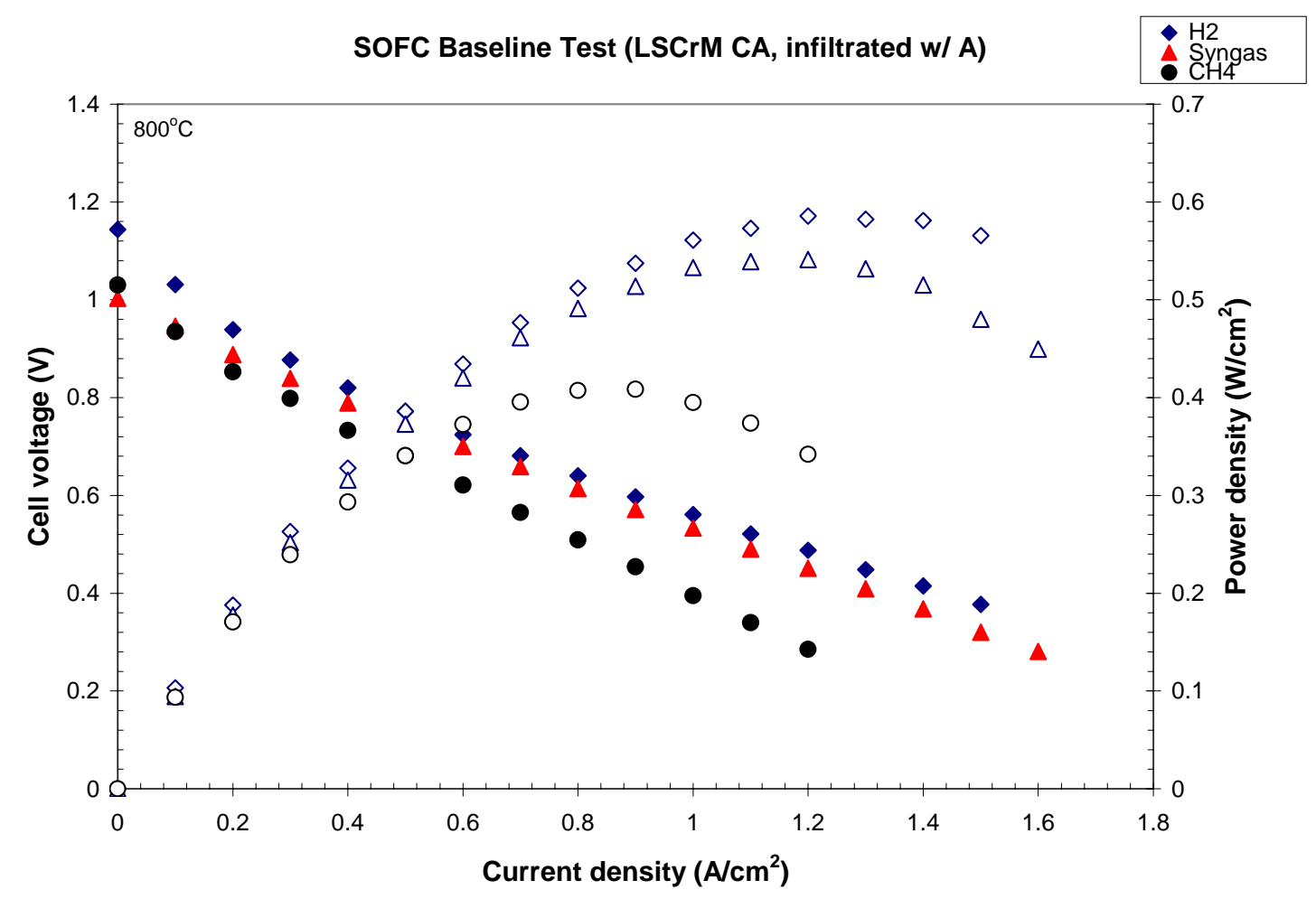

Figure 49. Performance of a button cell infiltrated with catalyst $\mathrm{A}$ and tested at $800^{\circ} \mathrm{C}$ in the SOFC mode. Cathode was the LSCM+SDC composite. Hydrogen, a mixture of steam (27\%) with syngas, or steam $(50 \%)$ with methane was the fuel; and air was the oxidant.

Following the SOFC baseline test, some cells were operated in the reversible SOFC mode, i.e., SOEC mode, by feeding steam to the anode and air to the cathode. The compositions of steam and carrier gas $\left(\mathrm{H}_{2}\right)$ varied from $20 \%$ steam to $90 \%$ steam. Figure 50 presents a typical SOEC performance. It is observed that as the steam concentration is less than $40 \%$, a low performance is obtained due to high concentration overpotentials, indicating more external electrical energy is required to split steam. The performances are almost identical as the steam concentration is higher than $60 \%$. This observation is consistent with what was obtained from those cells with the infiltrated Pd solution. 


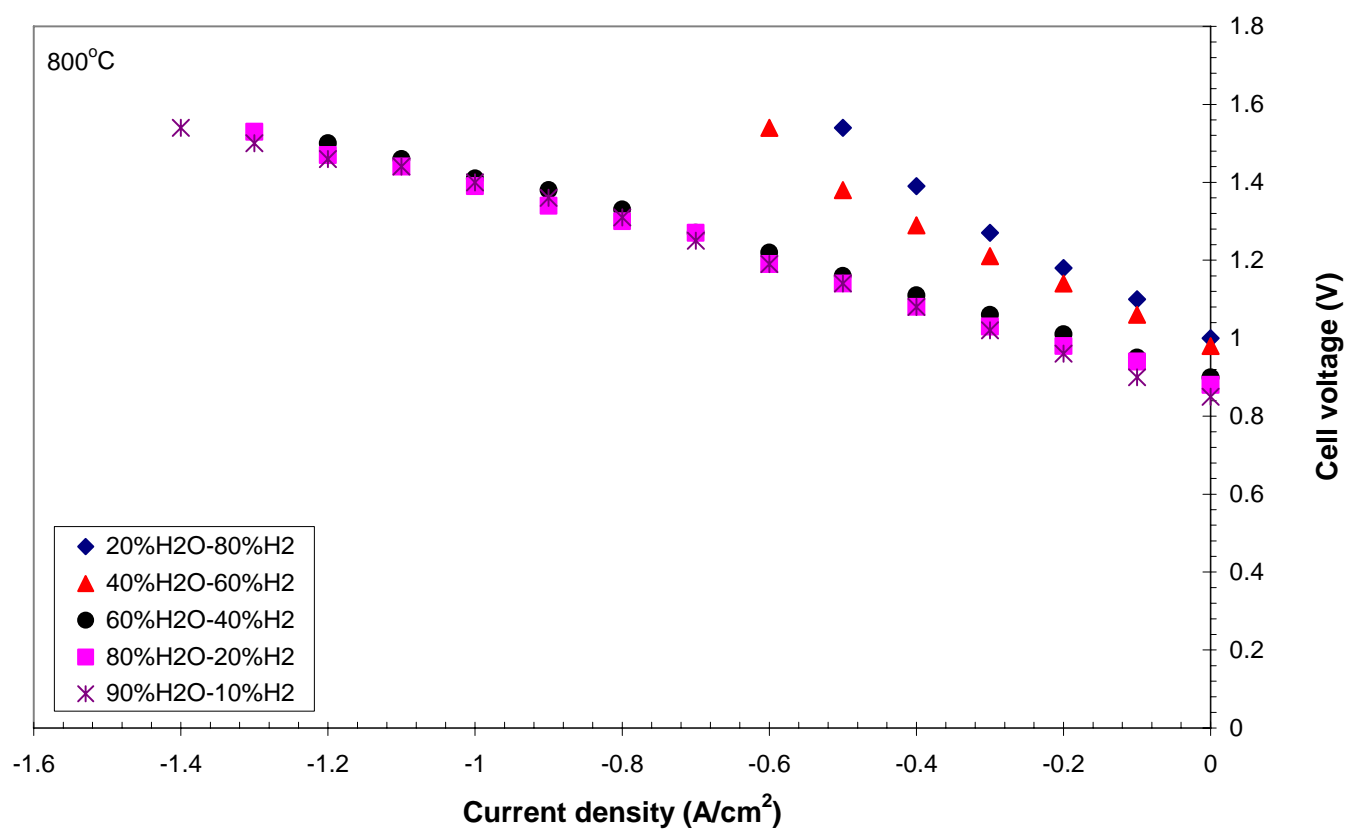

Figure 50. Same cell operated in the SOEC mode to generate hydrogen from steam on the anode. A mixture of $\mathrm{H}_{2}$ and steam was fed to the anode, and dry air was fed to the cathode. The steam composition varied from $20 \%$ to $90 \%$.

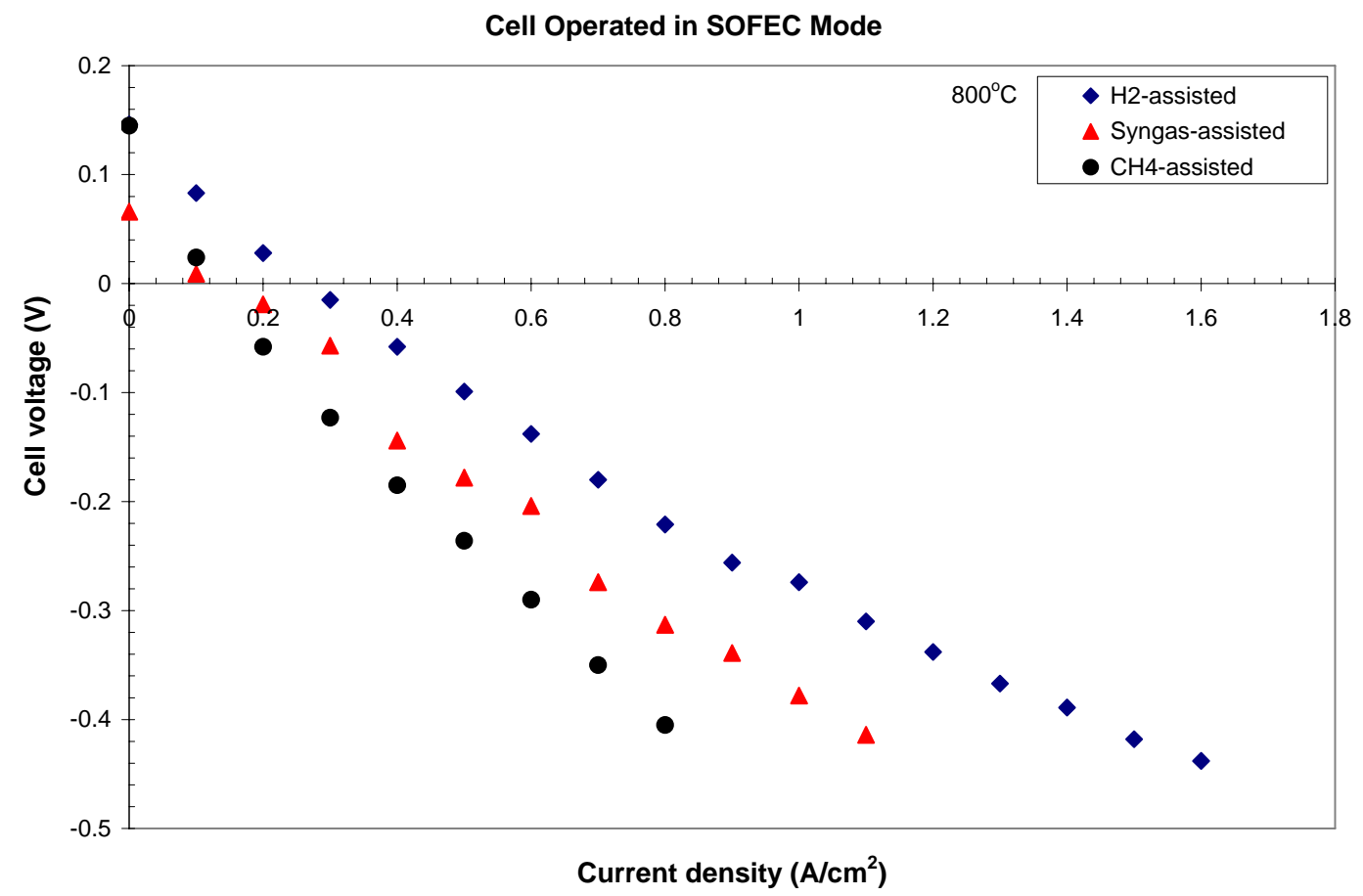

Figure 51. Cell performance operated at $800^{\circ} \mathrm{C}$ in the SOFEC mode with three different types of fuel assisted on the anode. A mixture of steam (10\%) with hydrogen, steam (27\%) with syngas, or steam $(50 \%)$ with methane was the fuel; and a mixture of steam (90\%) with hydrogen was the oxidant. 
The same cell thereafter was operated in the SOFEC mode, with hydrogen-, syngas- or methaneassisted on the anode, and steam on the cathode. The performance characteristics in the SOFEC mode are shown in Figure 51. The cell has the best performance when hydrogen is supplied to the anode. At the same applied cell voltage, the hydrogen production rate with the syngas assist is more than $40 \%$ higher than that with the methane assist.

\section{Task 5.4 Long-Term Stability Test of Cells with LSCM-Based Cathode}

In order to evaluate the stability of both the anode and the cathode and to determine the amount of degradation over time, a long-term test of button cells was initiated and conducted at MSRI. The long-term test in the SOFC mode started in September 2005, and was completed in April 2006, in excess of 5000 hours (under a constant current load). Figure 52 summarizes the longterm test results. In this test, hydrogen was the fuel and air was the oxidant. The cell was constructed from the MSRI standard anode substrate with Type A pore former and LSCM-based cathode with infiltration of the catalyst A. The active areas were $2 \mathrm{~cm}^{2}$. Various tests were performed in initial 100 hours, including V-I characteristic tests and burn-in tests to stabilize the performance. The cell was then applied with a continuously constant load at a current density $0.7 \mathrm{~A} / \mathrm{cm}^{2}$. The cell voltage was recorded by a PC, and the cell temperature was also monitored closely by a thermocouple installed near the cathode. This long-term test was terminated due to the loss of the current-collection wire at the second time after the 5000-hour test. During the test, it was also interrupted several times due to unexpected power outages happened at MSRI facility, subsequently the cell experienced several unplanned thermal cycles. As was observed in the test, the effects of thermal cycles on the cell performance were small. However, reconnecting current-collection wires did impair performance. In the same plot, three regions, I, II and III, were identified, corresponding to the first 2500 hours, 3600 hours, and 5004 hours of operation, respectively. In region I (2500 hrs), it was observed that no degradation occurred. There was less than $1.5 \%$ per 1000 hours degradation rate in region II. Afterwards, in region III, the cell extended its degradation rate to $5.6 \%$ per 1000 hour over 1370 hours. At 4335 hours operation time, the current conducting wire on the cathode side was broken again and reconnected, which caused a significant degradation. The test was terminated at the end of 5004 operational hours due to a broken wire on the cathode current-collector. The cell broke into pieces upon removal from the fixture. Post mortem analysis was performed to investigate any potential issues leading to the degradation, and will be discussed in the Task 8 section of this report. 


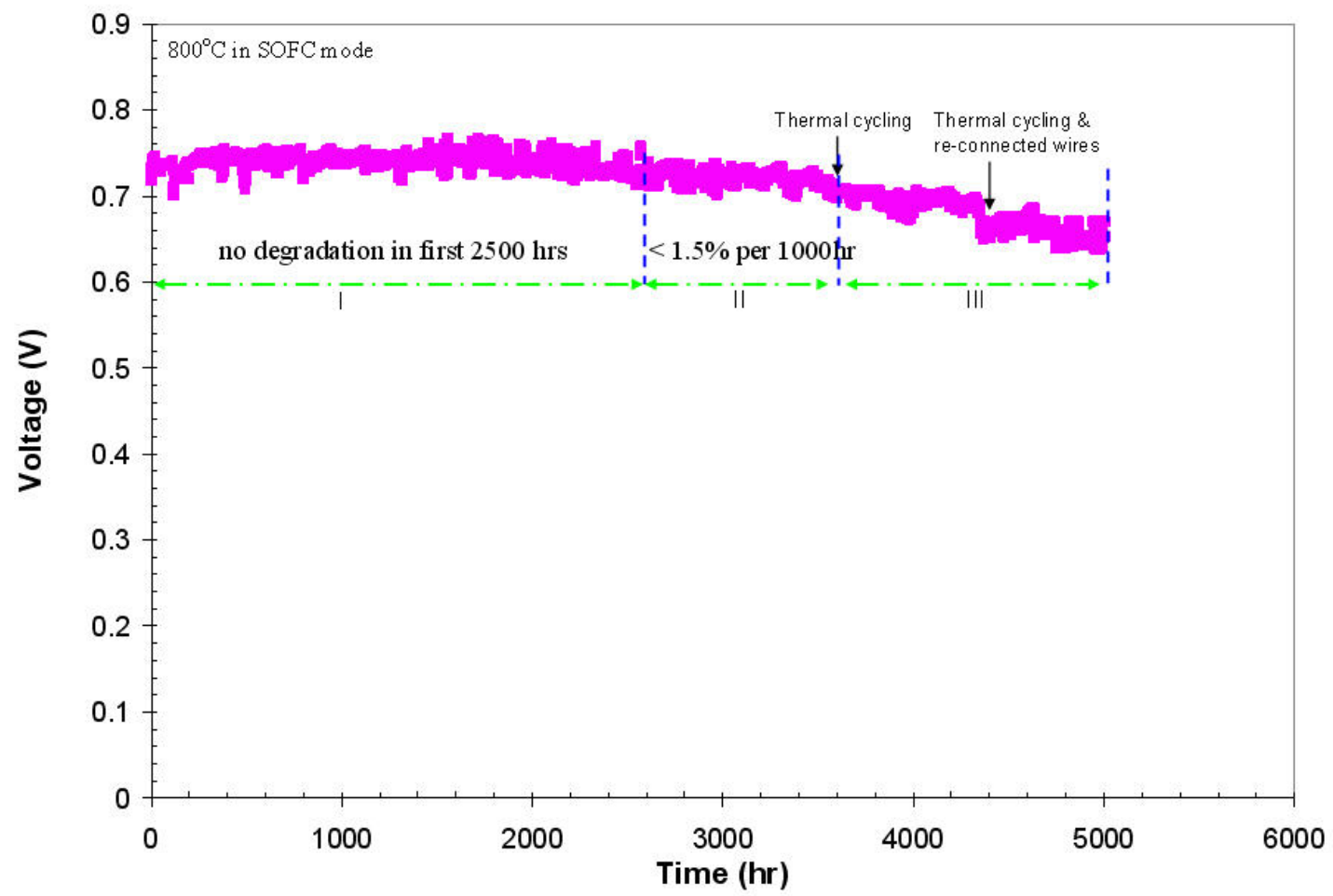

Figure 52. Long-term degradation test in the SOFC mode at $800^{\circ} \mathrm{C}$. Hydrogen was the fuel and air was the oxidant.

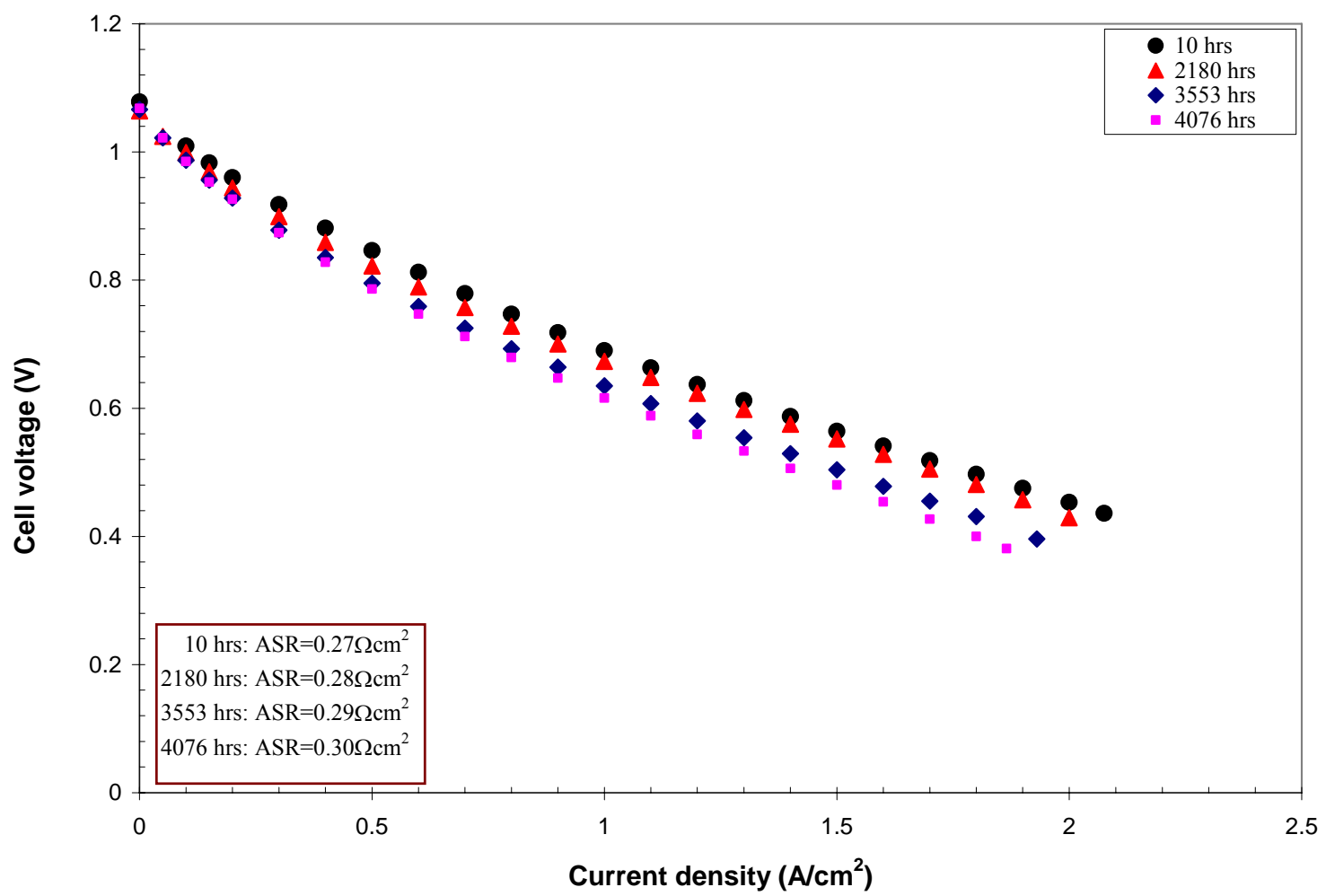

Figure 53. Current-voltage curves measured at different time 
Periodically, throughout this long-term test, measurements of the polarization curves were conducted along with IR losses (via the current-interruption method) to investigate the degradation mechanisms. Figure 53 summarizes the V-I characteristic curves measured at different time. The cell performance after 2180 hours of operation time was almost identical to its initial performance. However, performance drops were recorded at 3553 and 4076 hours. In order to identify the degradation mechanisms, the current-interruption method was applied to measure various resistances at scheduled times, and the results are plotted in Figure 54. The bars in different colors show the normalized ASRs, including the cell overall resistance (in periwinkle), ohmic resistance (in plum), activation overpotentials (in bright green). An assumption was made that the concentration overpotentials were negligible or lumped into the activation overpotentials. The maximum power density (in light turquoise), and power density (in red) at cell voltage $0.7 \mathrm{~V}$ were also shown in the same plot. Polarization data were consistent with V-I characteristic curves in which both the maximum power density and power density at $0.7 \mathrm{~V}$ decreased along with increasing the cell ASR. As shown in the plot, the degradation of the cell performance could be attributed from an increase of ohmic ASRs comprised of electrodes, electrolyte and contact resistances, which were also investigated during the postmortem analysis.

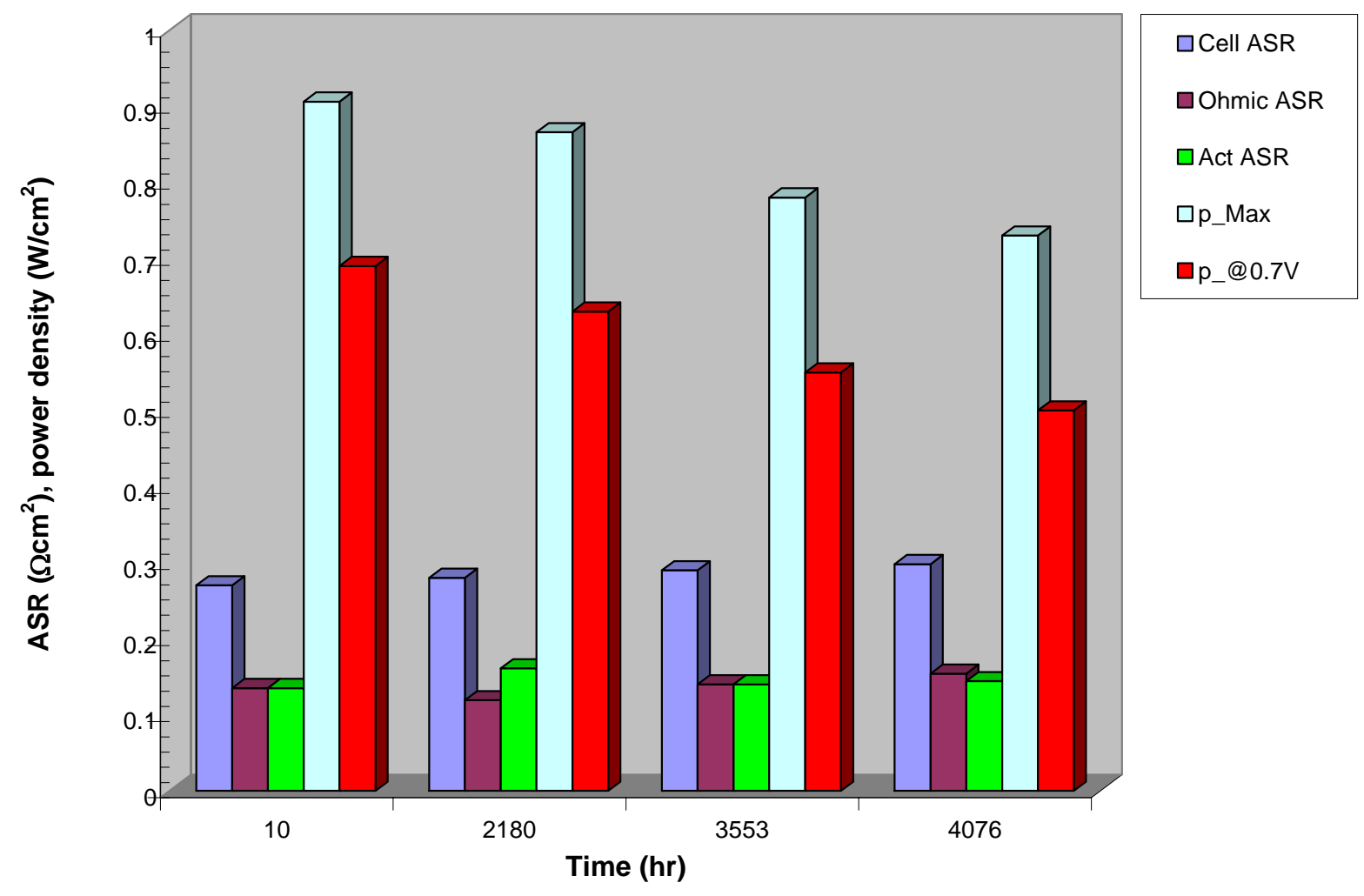

Figure 54. IR measurements at a scheduled time. The bars in different color show the normalized cell resistance-ASR (in periwinkle), ohmic resistance (in plum), activation overpotentials (in bright green), maximum power density (in light turquoise), and power density at cell voltage $0.7 \mathrm{~V}$ (in red). 
Task 6 Fabrication of Non-cell Components and Seals

The design of the hybrid stack described in Task 3 was performed and finalized by MSRI. Noncell repeat components of the SOFEC-SOFC hybrid stack, including the ferritic stainless steel interconnects and endplates, were fabricated at designated machine shops. Current collectors/dry contact aids were cut in-house to desired dimensions.

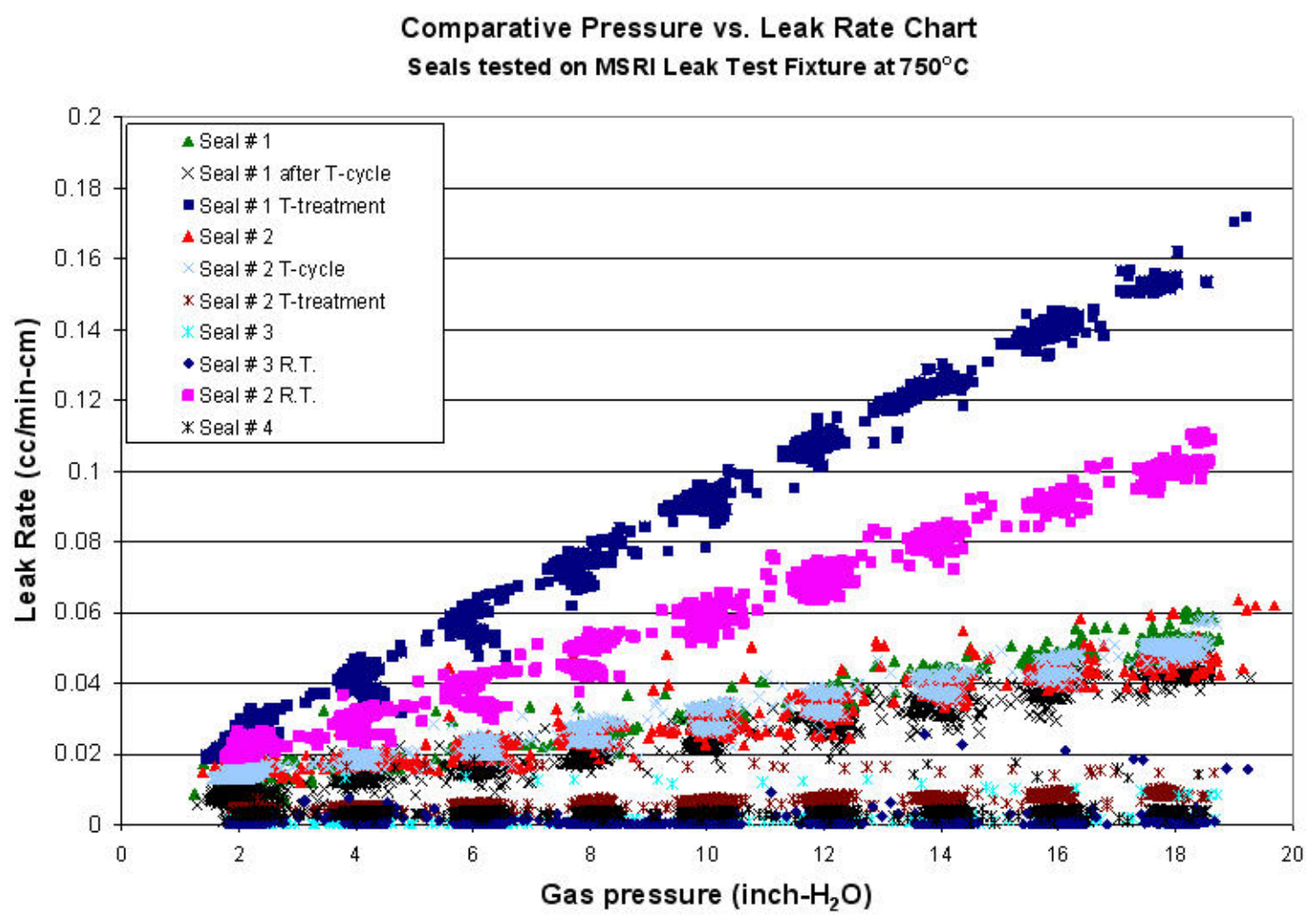

Figure 55. Leak rate comparisons of different seals tested at different gas pressures. Leak rate tests were performed in helium atmosphere on the MSRI leak-test fixture.

In order to achieve the hermetic seals required to prevent oxygen leakage from negating hydrogen production, MSRI has developed and evaluated different types of seals, including the rigid glass seals and compliant seals. A new glass-ceramic composition was also evaluated to form a basis for a thermochemically stable glass-ceramic hermetic seal for high temperature electrochemical devices (HTED). The glass was based on unusual silicate compositions that possessed 'invert' molecular structures and thus possessed the required viscosity characteristics to seal at relatively low temperatures, but facilitated crystallization to form a thermally stable sealing material. Figure 55 summarizes the leak-rate test results of various types of seals performed at MSRI on a leak-test fixture. Helium gas was used as the testing media. The sealing materials were sandwiched between two flat plates and heated up to the desired firing temperature. A spring-load was applied during the tests. Pressure transducers were used to measure the He leak rate. For the sealing tests, a minimum sealing gap was maintained using metal screens, allowing for the mimicking of fuel cell sealing gaps necessitated by cathode thicknesses and current collection screens. As plotted in the leak-rate figure, it clearly shows 
that the leak rate increases with increasing the gas pressure. Thermal pre-treatment may enhance the sealing for certain types of seal materials, particularly for the invert glass, though it is not conclusive observation.

The leak-rate test results of the invert glass were magnified and presented in Figure 56. At the seven inch-water pressure (or equivalent to $0.25 \mathrm{psi}$ ), which is a typical pressure drop over a 20cell 4"x4" SOFC stack, the normalized leak rate is less than $0.0015 \mathrm{SCCM} / \mathrm{cm}$. The leak rate increases slightly when the helium gas pressure doubles to the 15 inch water pressure (or equivalent to $0.54 \mathrm{psi}$ ).

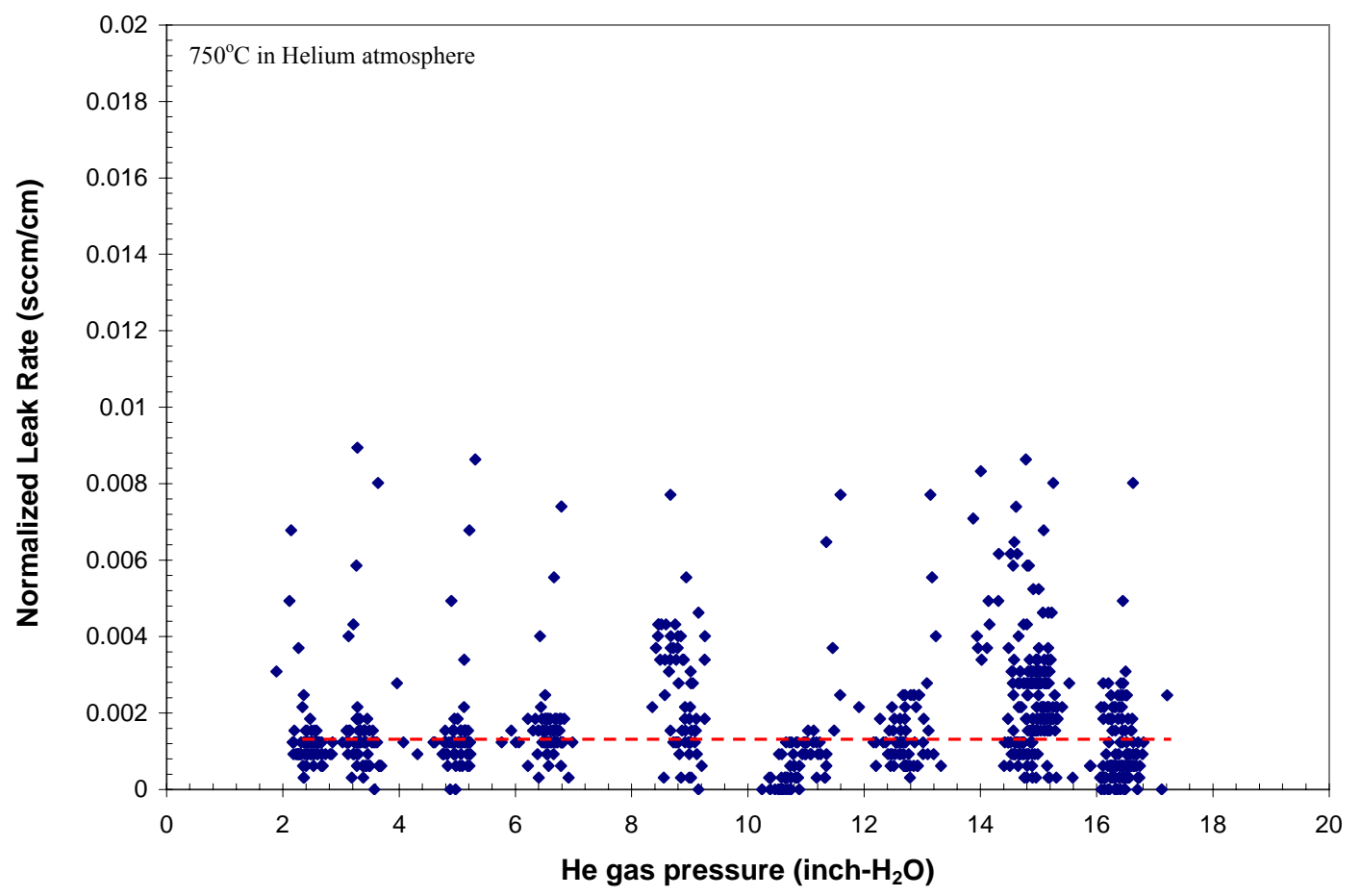

Figure 56. "Invert” glass gasket leak-rate test

In order to apply the sealing materials to stacks, MSRI developed the tape-casting technique to fabricate glass tapes with desired thickness. A binder system was developed and the amount of plasticizer was adjusted to improve the flexibility of glass tapes. Ball-milling time was also optimized to help breaking agglomerates. A de-air system equipped with twin propellers was developed to remove air trapped in the glass slurry after the ball-mill. Figure 57 shows a glasstape, which is very flexible and can be bent and rolled without cracking. Glass gaskets were then cut from the glass tapes to make gasket seals fitting for stacks geometries. 


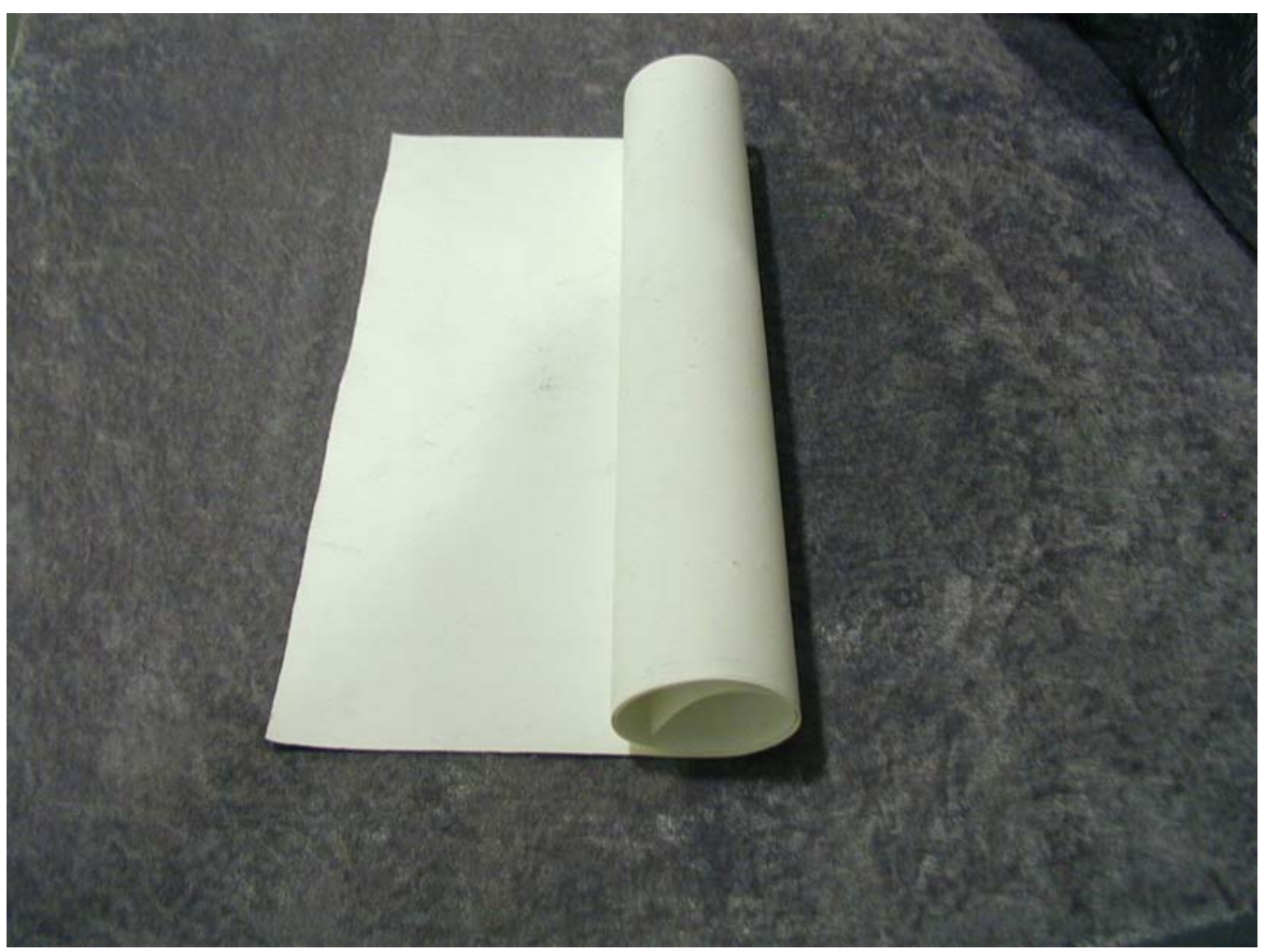

Figure 57. A flexible glass tape cast at MSRI facility

\section{Task 7 Proof of Concept, Short SOFEC/SOFC Stacks Testing}

In order to prove the concept of the hydrogen generation approach based on the fuel-assisted electrolyzer technology, short stacks, comprised of 2 to 10 cells per stack, have been built and evaluated at MSRI. Again, the SOFC mode was tested first as a baseline, followed by operation in the SOFEC mode. Each cell had per-cell active areas of either $30 \mathrm{~cm}^{2}$ or $100 \mathrm{~cm}^{2}$, and was made from the MSRI standard anode-supports with pore former Type A. The cells were screenprinted with the optimized composite cathode, which was developed in Task 5. The process and equipment applied to deposit the cathode interlayer (CIL) and cathode layer (CL) onto the larger cells were identical to that used for the button cells described in Task 5. Short stacks tested were capable of either generating up to 200 watts power or producing up to 1.7 standard liter of hydrogen per minute, in the SOFC mode and the SOFEC mode, respectively. Hydrogen, wet syngas, and wet methane were used as the fuel in both modes. Air and steam were used as the oxidant for the SOFC and SOFEC, respectively. In order to demonstrate the capacity of the electricity savings by applying the SOFEC technology, some stacks were also tested in the SOEC mode to produce hydrogen from steam without a fuel assist. Experimental results were analyzed and used for stack design and optimization of the $1 \mathrm{~kW}$ class hybrid stack.

\section{Task 7.1 Catalyst Effects on Stack Performance}

Effects of the catalyst infiltration on large cell performance were investigated at a stack level. A short stack comprised of seven (7) identical 2"x2" cells were assembled and tested in the SOFC mode. Figure 58 shows the V-I characteristic curves of each single cell out of the 7-cell stack. 
These seven cells, which were constructed from the same batch of the anode substrate, were screen-printed with the standard LSCM+SDC based cathode with $30 \mathrm{~cm}^{2}$ per-cell active areas. Cell \#2, \#3, and \#4 were infiltrated with catalyst A, B, and C, respectively. There was no infiltration of any catalyst for Cell \#1,6, and 7. Cell \# 5 was not infiltrated with any catalyst either, but instead had a contact aid applied, which was stable at redox atmospheres. As shown in the figure, cells with catalyst infiltration outperform cells without infiltration. Catalyst A shows the best performance, which is consistent with the results obtained from the button cell tests described in Task 5. The performance of Cell \# 5 is very close to Cell \#6, implying that under the current test condition, the contact resistance (loss) is negligible comparing to other losses, such as activation overpotentials and/or concentration overpotentials. Cell \# 7 and \#1, which were located on the top and bottom of the stack, respectively, showed lower performance than others. It is suspected that the heat loss of the cells, consequently low cell temperatures, led to a lower performance.

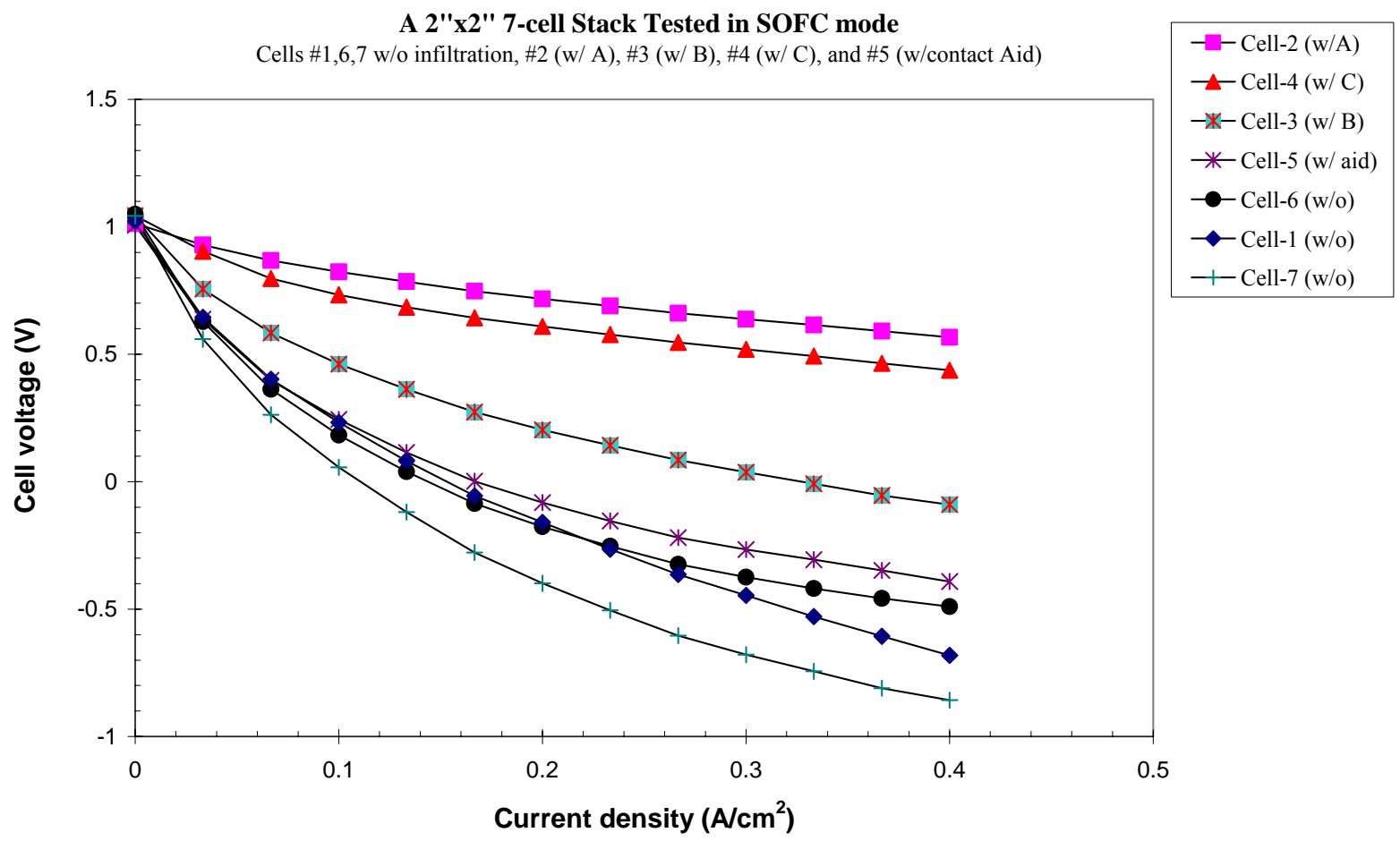

Figure 58. Cell performance comparisons of a 7-cell 2"x2" stack. The seven cells were constructed from the same batch of the anode substrate and screen-printed with the same cathode. Some cells were infiltrated with catalysts while others were not.

\section{Task 7.2 SOFEC Concept Validation on 2"x2" Short Stacks}

The concept of hydrogen generation using the SOFEC technology was validated on 2"x2" short stacks. Dozens of short stacks comprised of multiple 2"x2" cells have been assembled and tested in the SOFC, SOEC, and SOFEC modes, providing fundamental data and critical experience needed for developing $1 \mathrm{~kW}$ stacks. Each 2" 2 2" cell was made from the MSRI standard anode substrate and screen-printed with the LSCM+SDC cathode. The catalyst, which demonstrated the best catalytic characteristics over other catalysts during previous tests of button cells and 
short stacks, was applied to the cathode to improve stack performance. Glass seals developed in Task 6 were used at stack sealing interfaces, including both the interfaces between interconnects and cells, and the interfaces between interconnects and endplates.

Figure 59 shows the burn-in test results of a 2"x2" 2-cell stack infiltrated with catalyst A. After the burn-in, a baseline test was conducted in the SOFC mode at $800^{\circ} \mathrm{C}$. Hydrogen and air were used as the fuel and oxidant at flow rates corresponding to $40 \%$ utilizations for both fuel and air. As shown in the plot, in a three-day test, the stack current density at $0.7 \mathrm{~V} /$ cell decreases by $30 \%$, and the corresponding stack ASR increases from $0.506 \Omega \mathrm{cm}^{2}$ to $0.561 \Omega \mathrm{cm}^{2}$.

2"x2" 2-cell Stack Baseline Test -- SOFC Mode

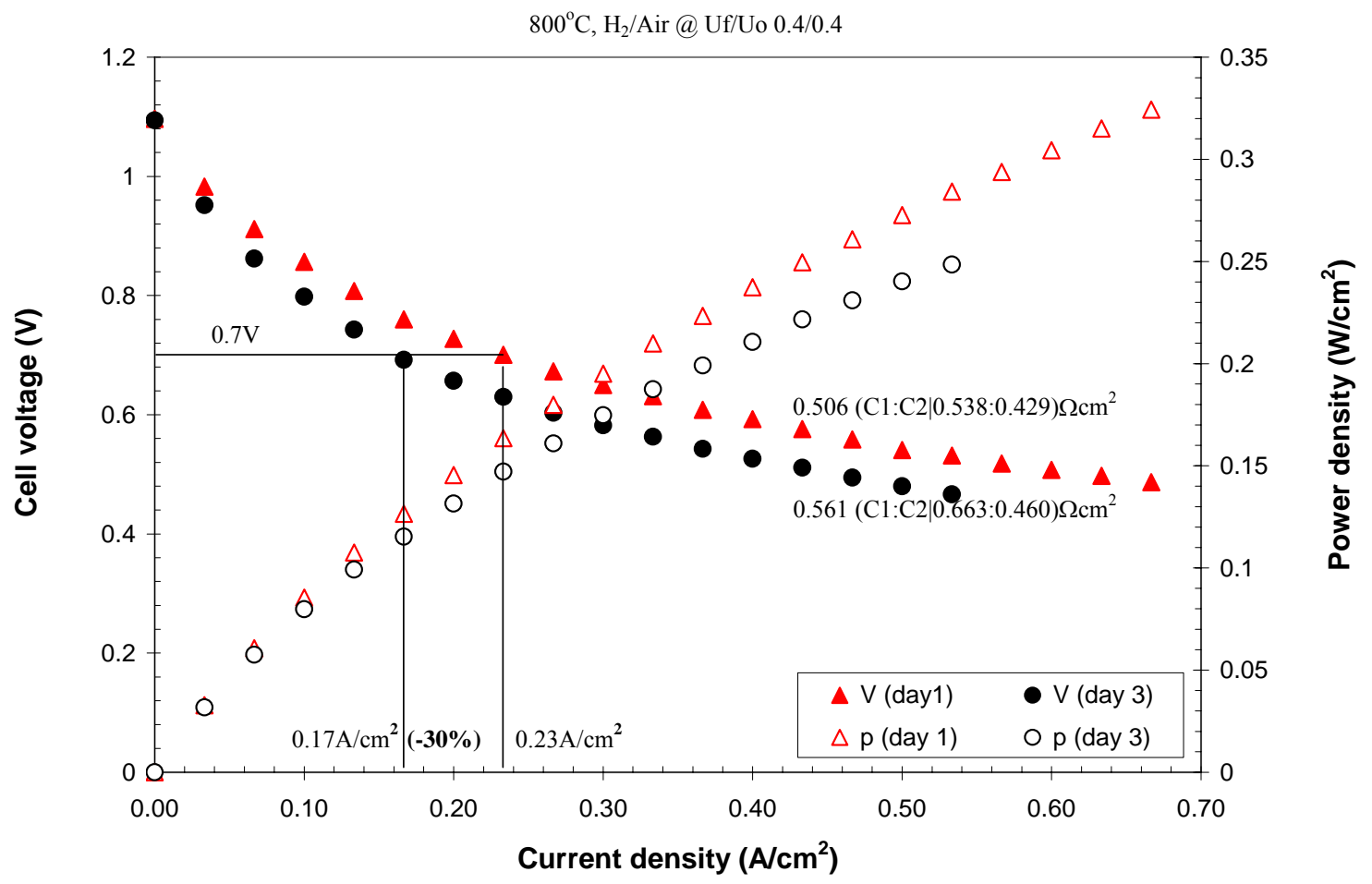

Figure 59. Burn-in test of a 2"x2" 2-cell stack running in the SOFC mode in two different days

In order to reduce the cost of BOP and the cost of hydrogen production, high fuel/oxidant utilizations are desired. However, the performance might then be sacrificed because of the increase of concentration overpotentials at high utilizations. Figure 60 shows the effects of fuel/oxidant utilizations on the stack performance in the SOFC mode. When the current density is low (less than $0.25 \mathrm{~A} / \mathrm{cm}^{2}$ ), high utilizations (up to $80 \%$ fuel utilization) do not affect the stack performance. This result stems from the domination of stack losses by the activation overpotentials at low current densities. However, when the current density increases, the effects of concentration overpotentials on the performance increase. As shown in the figure, at 0.5 $\mathrm{A} / \mathrm{cm}^{2}$, the stack voltage drops about $15 \%$ when the fuel utilization doubles from $40 \%$ to $80 \%$. 


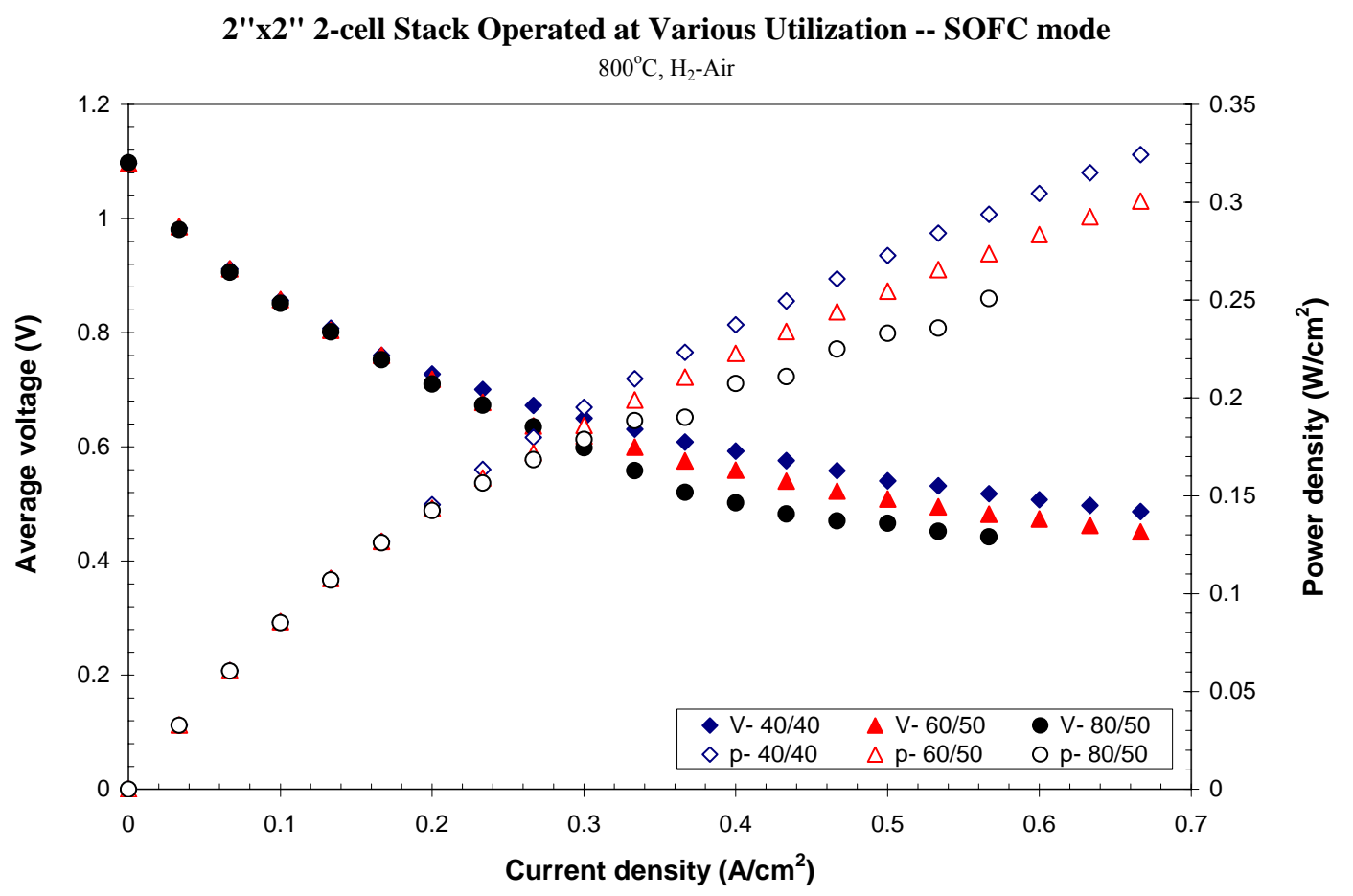

Figure 60. Performance of a 2"x2" 2-cell stack tested at different utilizations of the fuel/oxidant

2"x2" 2-cell Stack -- SOFC vs. SOEC

$800^{\circ} \mathrm{C}$, @ Uf/Uo 40/40

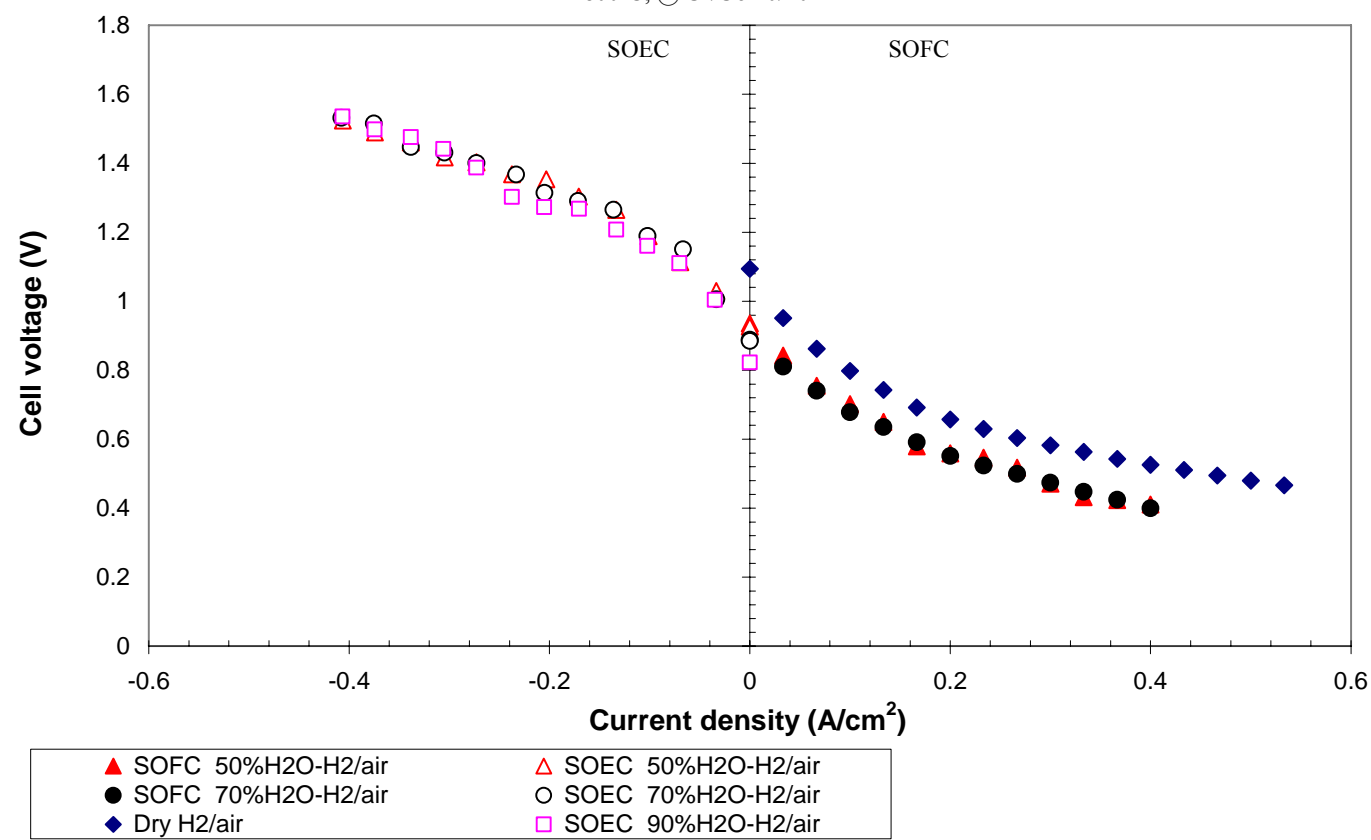

Figure 61. Performance comparisons of the 2"x2" 2-cell stack operated in the reversible SOFC/SOEC modes. In the SOFC mode, dry air was fed to the cathode, and a mixture of $\mathrm{H}_{2}$ and steam was fed to the anode. The steam composition on the anode varied from 0 to $70 \%$. Same gas compositions were used for the SOEC test, except that $90 \%$ steam with hydrogen was also test in the SOEC mode. 
Following the SOFC baseline test, the stack was operated in the reversible SOFC/SOEC modes at $800^{\circ} \mathrm{C}$. Figure 61 summarizes the performance comparison of the stack tested in both modes. In the SOFC mode, dry air was fed to the cathode, and a mixture of $\mathrm{H}_{2}$ and steam was fed to the anode. The steam flow rate was controlled by a precision water pump, which regulated the water flow rate. The vaporizer temperature was set to $600^{\circ} \mathrm{C}$ to ensure that the water entering the vaporizer was evaporated thoroughly. The steam composition on the anode varied from 0 to $70 \%$. The same gas compositions were used for the SOEC test, except that $90 \%$ steam with hydrogen was also tested in the SOEC mode. The performance shows very consistent results. Pseudo-symmetric VI curves were observed when it was operated in the SOFC mode and the SOEC mode at the same gas compositions.

Following the SOFC and SOEC tests, the same 2-cell stack was tested in the SOFEC mode. Figure 62 shows the performance characteristics with the hydrogen fuel assisted on the anode and steam on the cathode with hydrogen as the carrier gas. In order to investigate the effects of a steam concentration on the stack performance, the steam composition on the cathode varied from $40 \%$ to $70 \%$. As shown in the figure, a high steam concentration yields a high OCV. This result is consistent with the Nernst potential estimation that a high steam concentration gives a high oxygen partial pressure thus a high OCV. Nevertheless, no significant performance changes were observed at high hydrogen production rates for different steam concentrations.

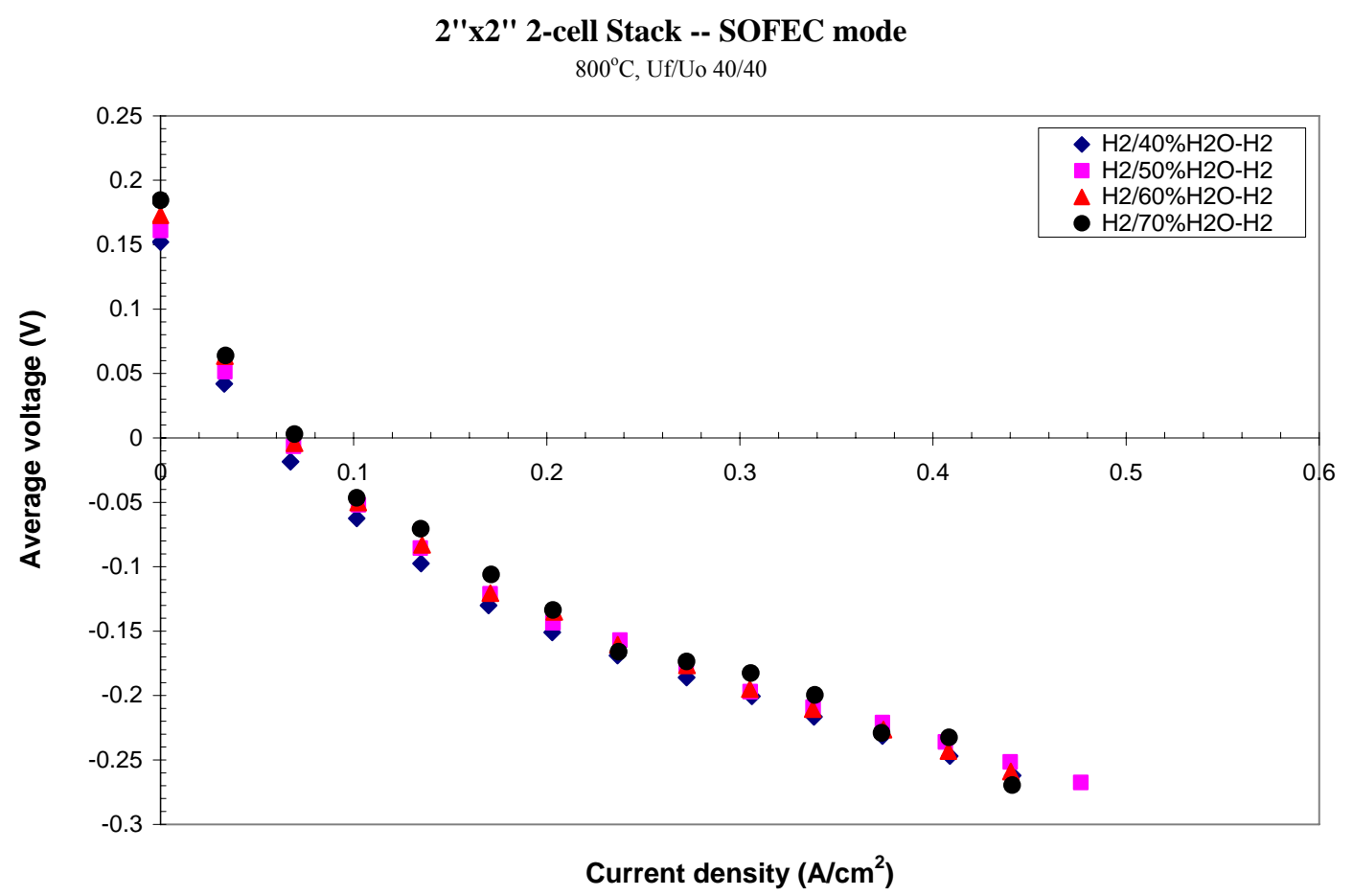

Figure 62. Performance characteristics of a 2"x2" 2-cell stack operated in the SOFEC mode with hydrogen assisted on the anode to generate hydrogen from the cathode steam. Wet hydrogen at various steam concentration was fed to the cathode. The steam composition varied from $40 \%$ to $70 \%$. 
2"x2" 2-cell Stack -- SOFEC mode

$800^{\circ} \mathrm{C}, \mathrm{Uf} / \mathrm{Uo} @ 40 / 40$ in various fuel-assisted electrolyzer mode

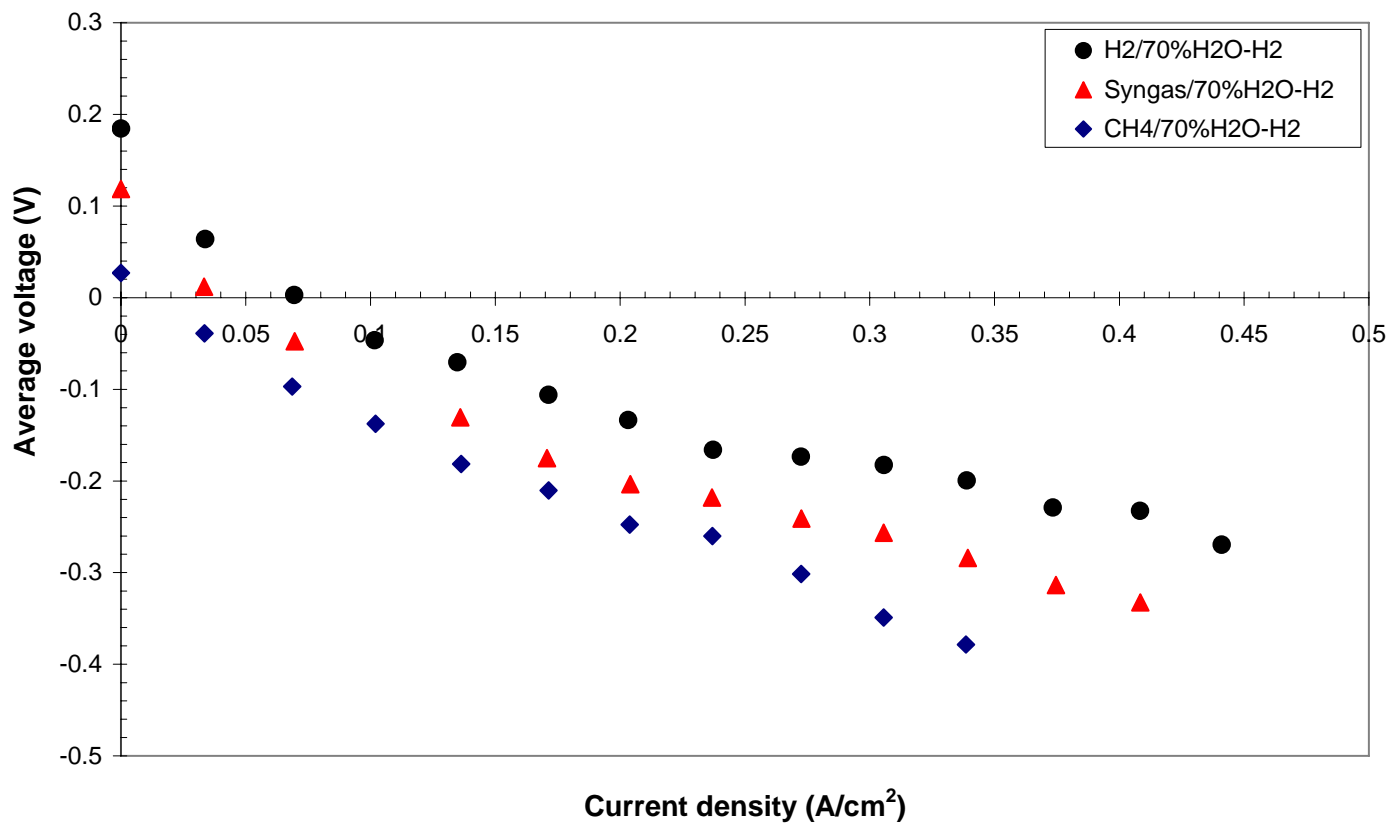

Figure 63. Performance comparisons of a 2"x2" 2-cell stack operated in the SOFEC mode with hydrogen-, syngas-, or $\mathrm{CH}_{4}$ - assisted on the anode to generate hydrogen from the cathode steam.

Other than the hydrogen fuel-assisted on the anode, various fuels assisted SOFEC were also evaluated on the same stack, including the syngas and $\mathrm{CH}_{4}$. In the case of the syngas and methane fuel, $27 \%$ steam and 50\% steam were added to the fuel for preventing from the carbon deposition issue, respectively. The steam flow rate was controlled by the second precision water pump, and the corresponding vaporizer temperature was set to $600^{\circ} \mathrm{C}$ to ensure a complete evaporation process. The performance comparisons of these three types of fuel-assisted SOFEC are shown in Figure 63. While the hydrogen assisted SOFEC shows the best performance, the syngas assisted SOFEC outperforms the $\mathrm{CH}_{4}$-assisted SOFEC by a large margin, the result consistent with those obtained from button-cell tests. At $0.34 \mathrm{~A} / \mathrm{cm}^{2}$, (or $2.59 \mathrm{SCCM} / \mathrm{cm}^{2}$ hydrogen production rate), the external voltage required to electrolyze steam is only $0.28 \mathrm{~V}$ for the syngas assisted SOFEC, rather than $0.38 \mathrm{~V}$ for the $\mathrm{CH}_{4}$ assisted SOFEC.

Figure 64 summarizes the performances of the 2-cell stack operated in three modes: SOFC, SOEC, and SOFEC. The performance characteristics in three modes were presented in the same manner as button cells shown in Figure 47. The first quadrant represents the SOFC operation, which consumes a fuel $\left(\mathrm{H}_{2}\right.$, syngas, or $\left.\mathrm{CH}_{4}\right)$ to generate the power. The second quadrant represents the stack operated in the conventional electrolyzer mode without a fuel assist to the anodes to produce hydrogen. In this quadrant, the stack simply consumes electrical energy to produce hydrogen from steam. The current in the SOEC stack flows in the opposite direction to that flowing in the SOFC stack. In order to compare the fuel-assisted electrolyzer (SOFEC) with the conventional electrolyzer (SOEC), the SOFEC performance is transposed from the first/fourth quadrant to the second/third quadrant and is plotted along the negative current direction, which is in the same direction as the SOEC. As the comparison, at the same hydrogen 
production rate (for instance, $2.59 \mathrm{SCCM} / \mathrm{cm}^{2}$ or $0.34 \mathrm{~A} / \mathrm{cm}^{2}$ ), the voltage need is $1.45 \mathrm{~V}$ and $0.28 \mathrm{~V}$ for the SOEC operation and the SOFEC syngas-assisted SOFEC operation, respectively, indicating significant electricity savings by using the SOFEC technology over the traditional electrolysis technologies for the hydrogen generation.

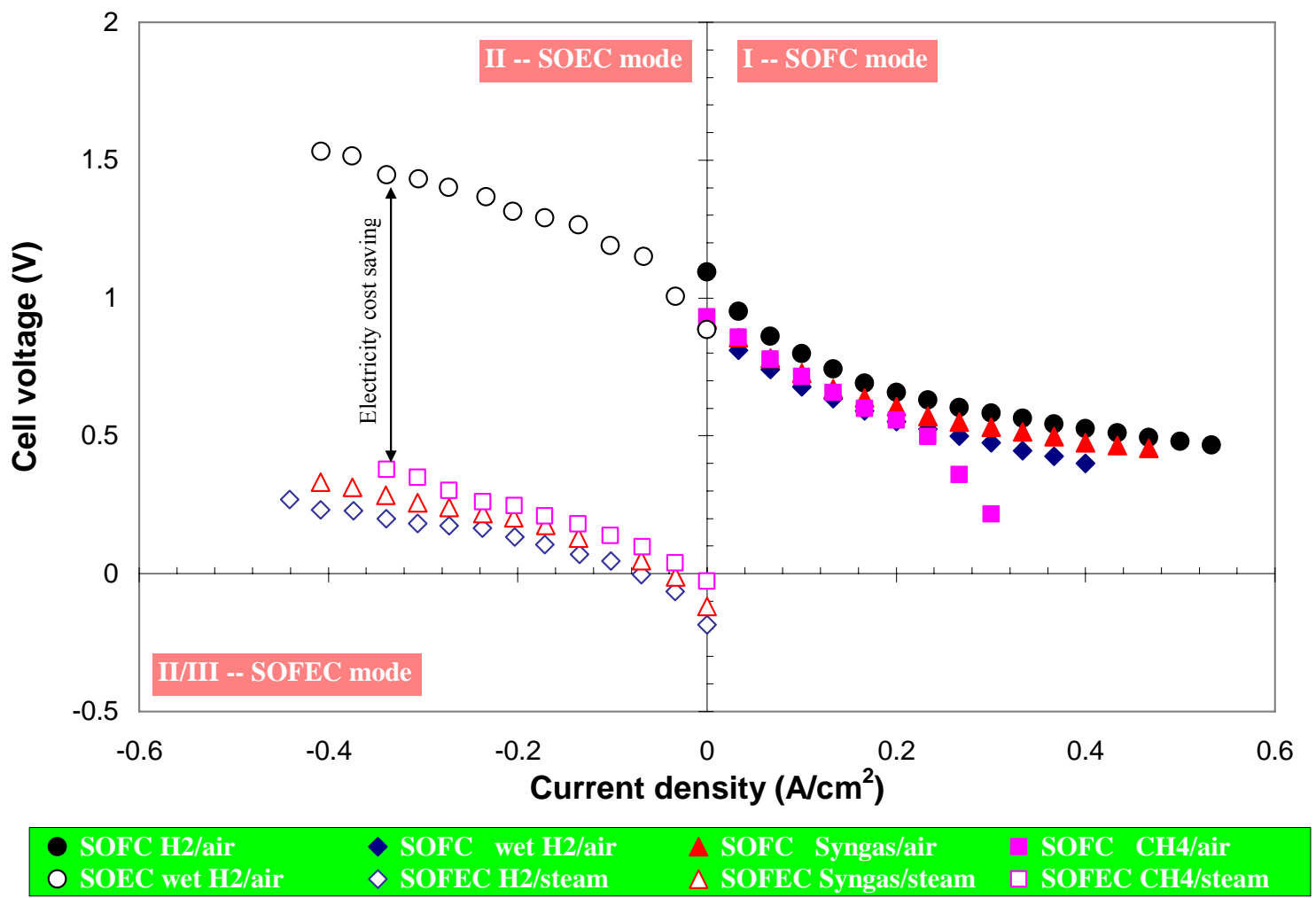

Figure 64. Stack performance comparisons in the reversible SOFC, SOEC, and SOFEC modes. In the SOFC mode, hydrogen, steam $(27 \%)$ with syngas, or steam $(50 \%)$ with $\mathrm{CH}_{4}$ was the on the anode, and air was on the cathode. In the SOEC mode, steam (70\%) carried with hydrogen was on the anode, and air was on the cathode. In the SOFEC mode, hydrogen, steam $(27 \%)$ with syngas, or steam $(50 \%)$ with $\mathrm{CH}_{4}$ was the on the anode, and steam (70\%) carried with hydrogen was on the cathode.

Hydrogen produced on the cathode of the stack was measured using a Horiba film flow meter. Production measurements were taken after the steam in the downstream flow had been condensed. Figure 65 shows the measured hydrogen flow rate produced by the short stack. The theoretical value based on the mass/electron conservation theory is also plotted in the same figure as a comparison. It is noticed that two set of data match very well, though a datum point at a low current density deviates from the theoretical value due to a flow meter scale limitations. 


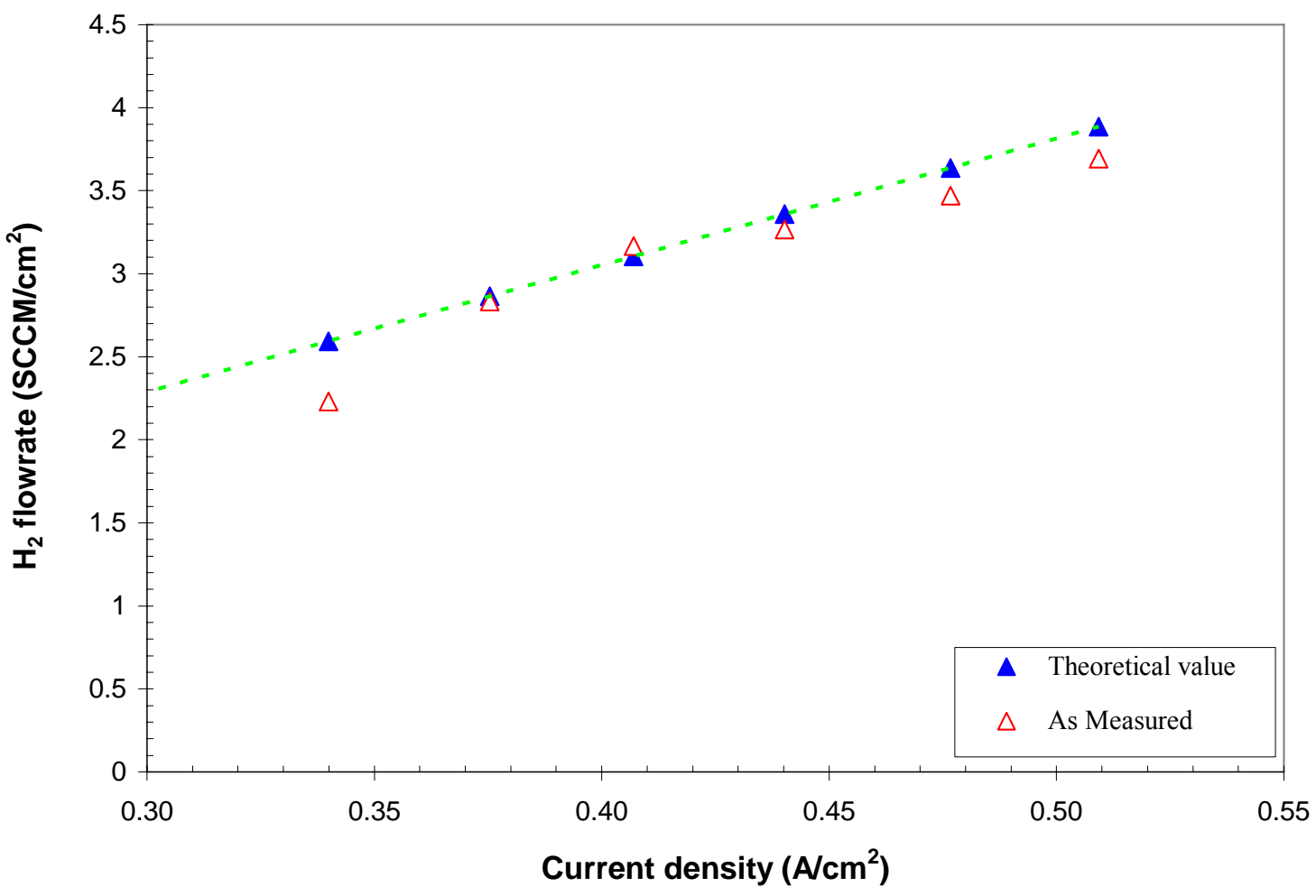

Figure 65. Flow rate measurement to quantify the hydrogen production rate on the cathode.

\section{Task 7.3 SOFEC Concept Validation on 4"x4" Short Stacks}

Beyond 2"x2" short stacks, validation of the concept of hydrogen generation using the SOFEC technology was carried out on 4"x4" short stacks, which were to be used for construction of the 1 $\mathrm{kW}$ class hybrid stack. Short stacks, comprised of 2 to 10 cells per stack with $100 \mathrm{~cm}^{2}$ per-cell active areas, were tested to generate up to $200 \mathrm{~W}$ electricity or to produce up to 1.7 standard liter of hydrogen per minute, in the SOFC mode or the SOFEC mode, respectively. Figure 66 is a picture of a 10-cell 4"x4" stack assembly. Each cell voltage was measured through a metal tab attached to the contacting interconnects. Multiple thermal couples (TC) were embedded in the stacks at various locations to trace the stack internal temperature profiles. Similar to the tests of 2" 2 " short stacks delineated above, the 4"x4" stacks were first evaluated in the SOFC mode as a baseline with different utilizations of the fuels and the oxidant (air). Before being switched to the hydrogen production mode, stack seal efficiency was measured to ensure hermetic seals, particularly on the cathode side. The purity of the generated hydrogen and the composition of the depleted fuel gas were measured using the gas chromatography. 


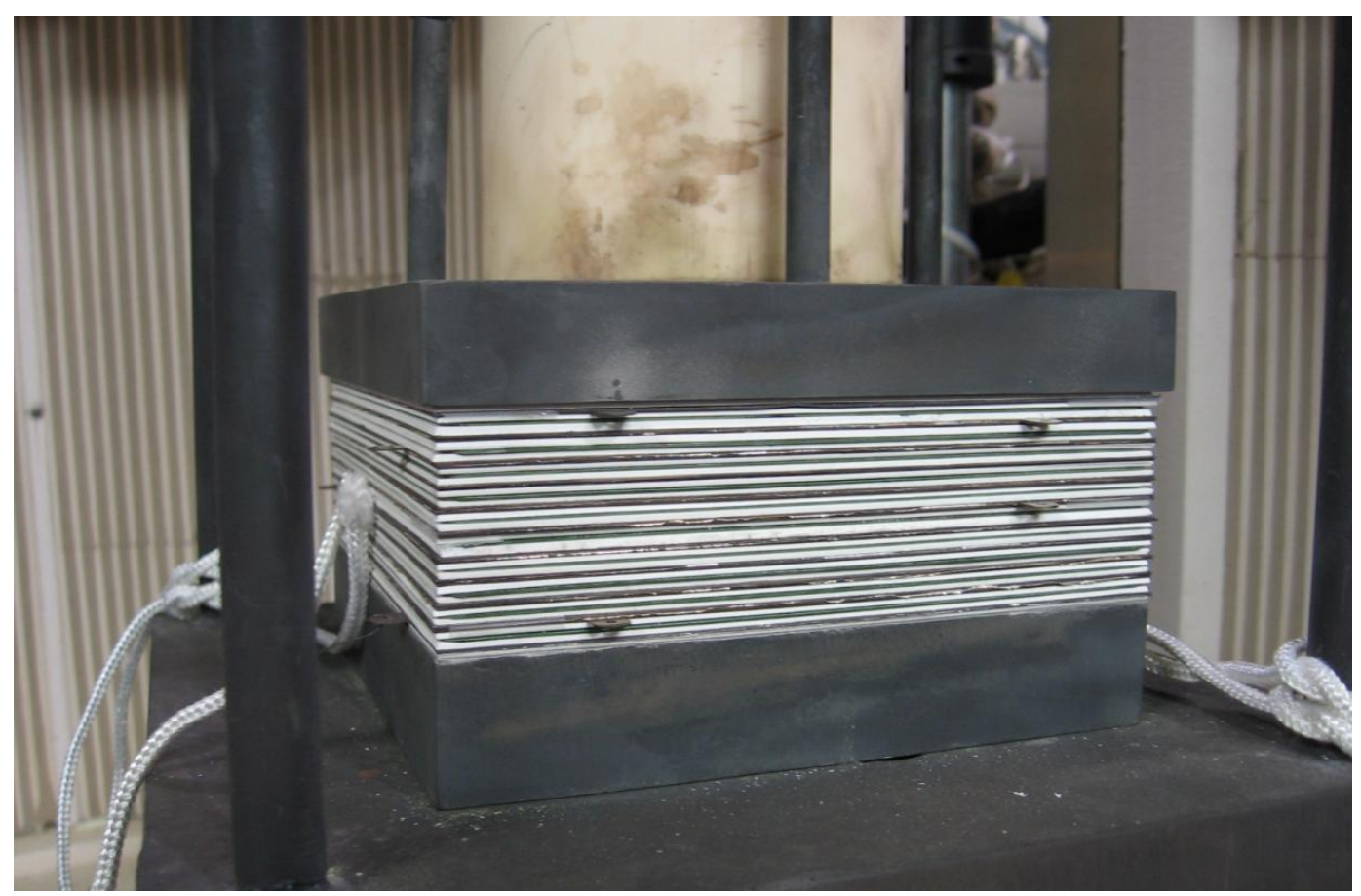

Figure 66. A 4”x4”10-cell stack assembly ready for testing

4"x4" 5-cell Stack Baseline Test in SOFC Mode

$800^{\circ} \mathrm{C}$, Syngas/Air, $\mathrm{U}_{\mathrm{f}} / \mathrm{U}_{0} @$ various utilization

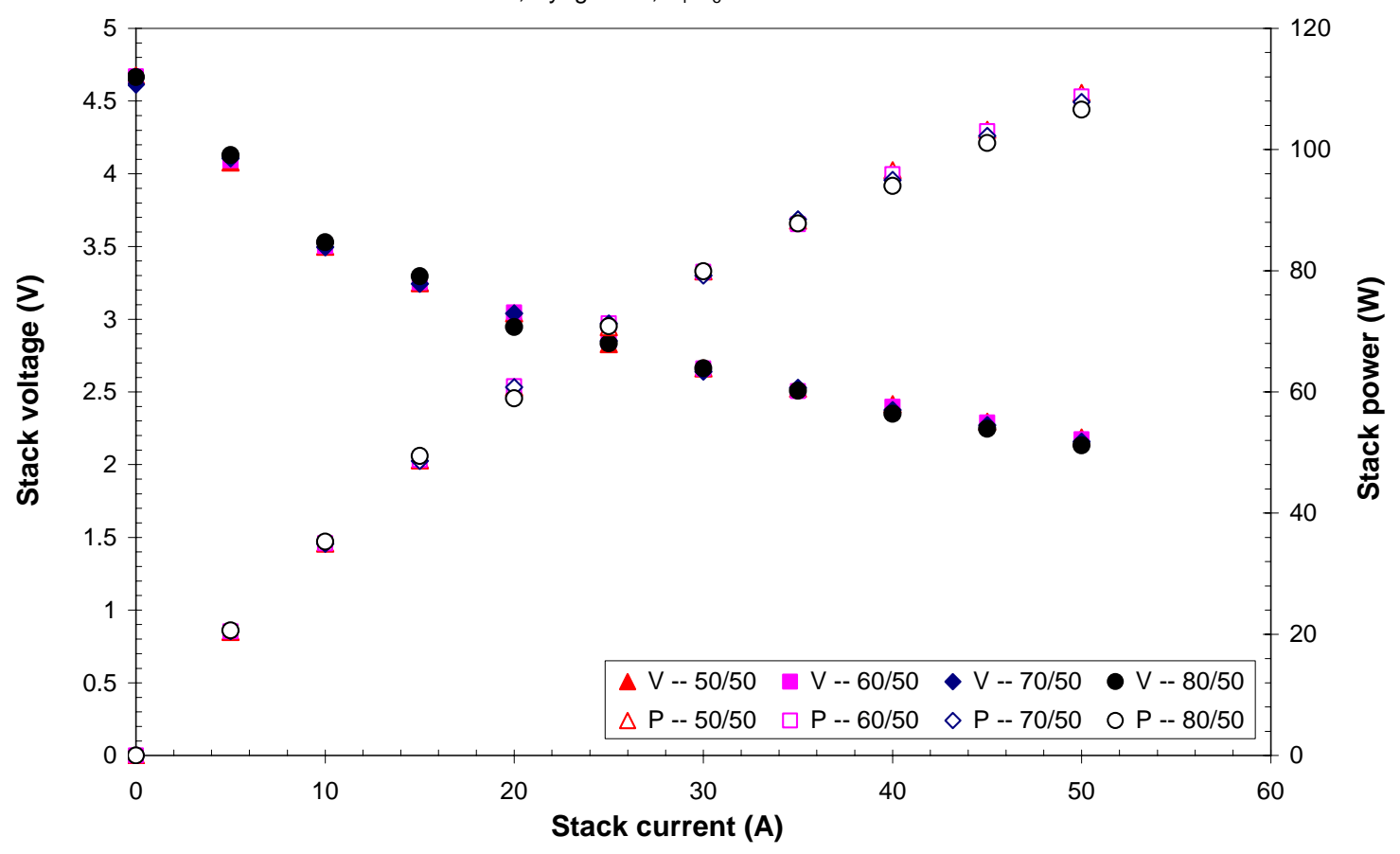

Figure 67. Performance characteristics of a 4" $\mathrm{x} 4$ " 5-cell stack baseline test at $800^{\circ} \mathrm{C}$ at different fuel utilizations. Wet Syngas (30\% steam) was the fuel and air was the oxidant. The syngas utilization increased from $50 \%$ to $80 \%$ at $10 \%$ each step. 
Figure 67 details the performance of a 4"x4" 5-cell stack operated in the SOFC baseline mode at various fuel utilizations. Wet syngas with $30 \%$ steam was used as the fuel and air was used as the oxidant. The furnace temperature was set to $800^{\circ} \mathrm{C}$. As shown in the figure, the effects of the fuel utilization, increasing from $50 \%$ to $80 \%$, on the stack performance are negligible, thanks to the optimized anode microstructure and the leak-tight seals. At $50 \mathrm{~A}$, this 5-cell stack outputted $140 \mathrm{~W}$ power. Other than wet syngas, hydrogen and wet $\mathrm{CH}_{4}$ were also tested at various fuel utilizations, results were similar to those of the syngas.

The SOFEC performance with hydrogen assist on the anode is shown in Figure 68. The stack cathode was fed with hydrogen and steam, with the proportional composition ranging from $50 \%$ to $90 \%$. The utilizations of both the cathode steam and anode hydrogen were fixed at $50 \%$. As shown in the figure, the higher the cathode steam concentration, the lower the voltage (or less energy) required to produce hydrogen from the cathode steam. This effect is due to reduced concentration overpotential at the high steam concentration.

4"x4" 5-cell Stack in SOFEC mode at Various Steam Composition

$800^{\circ} \mathrm{C}, \mathrm{H}_{2} / \mathrm{H}_{2} \mathrm{O}, \mathrm{U}_{\mathrm{f}} / \mathrm{U}_{\mathrm{o}}$ at $50 / 50$

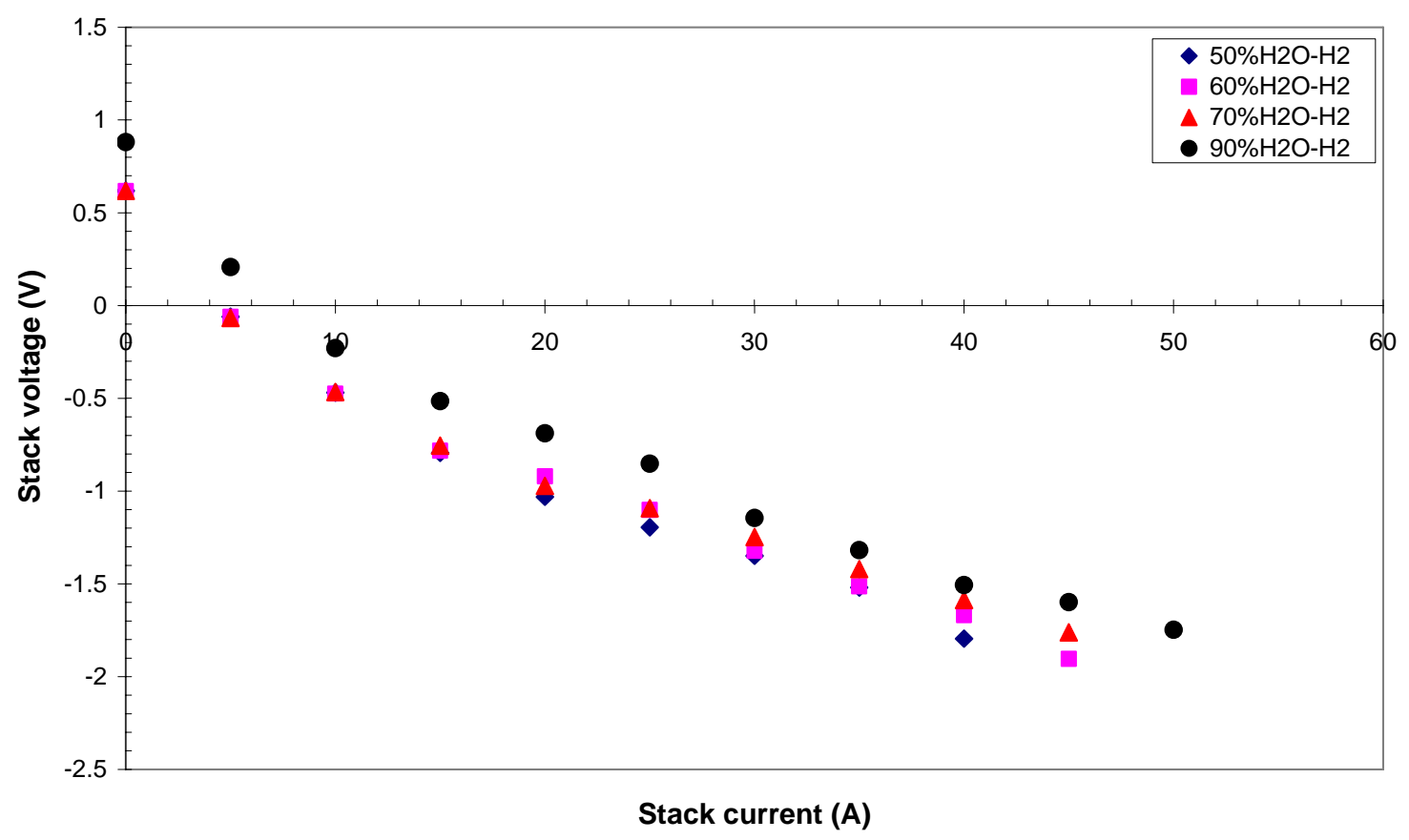

Figure 68. Performance characteristics of a 4" $x 4$ " 5-cell stack operated in the SOFEC mode with hydrogen-assisted on the anode. Each cell had $100 \mathrm{~cm}^{2}$ active areas. Composition of the cathode steam varied from $50 \%$ to $90 \%$.

After the hydrogen-assisted SOFEC test, tests of the syngas-assisted and $\mathrm{CH}_{4}$-assisted SOFEC were performed on the same stack with a $90 \%$ steam cathode flow carried by hydrogen. In order to make a good comparison, the utilizations of both the cathode steam and the anode fuel were fixed at 50\%, which were the same utilizations used in the previous SOFC test. Figure 69 shows the performance comparison. As predicted, hydrogen-assisted SOFEC shows the best performance, consistent with the previous results obtained from button-cells and 2"x2" stacks. 
4"x4" 5-cell Stack in SOFEC Mode

$800^{\circ} \mathrm{C}, \cup_{f} / \cup_{0} 50 / 50$ various fuel-assisted electrolyzer

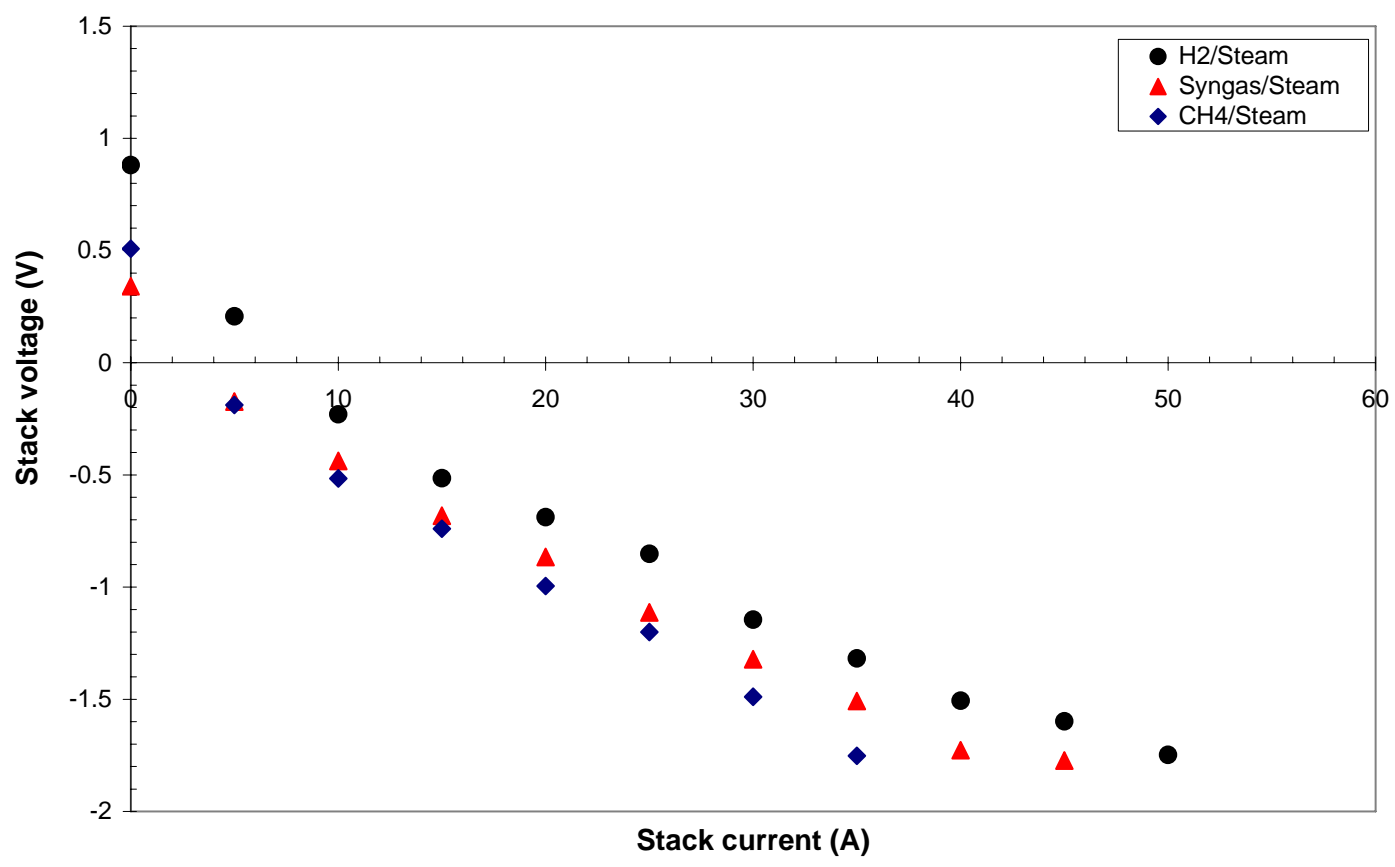

Figure 69. Performance characteristics of a 4" $x 4$ " 5-cell stack operated in the SOFEC mode with hydrogen-, syngas-, or $\mathrm{CH}_{4}$ - assisted at the anode. The cathode gas was a mixture of steam (90\%) with hydrogen carry gas. The utilizations of both the cathode steam and anode fuel were fixed at $50 \%$.

Figure 70 summarizes the comparisons of the stack voltage-current characteristics obtained in both the SOFC and SOFEC modes. It is very similar to the plots for button cells and 2"x2" short stacks. The first quadrant represents the SOFC performance, which consumes a fuel $\left(\mathrm{H}_{2}\right.$, Syngas, or $\mathrm{CH}_{4}$ ) to produce electricity. The fuel assisted electrolyzer mode is located across the first and fourth quadrants to generate hydrogen at a lowered external electricity requirement, because in the SOFEC mode the electrical current flows from the anode to the cathode (or oxygen ions flow from the cathode to the anode), what is in the same direction as that in the SOFC mode. The VI curve of the SOFEC is transposed to the negative current direction for the performance comparisons of the SOFEC and SOEC. Corresponding to the voltage-current characteristics shown in Figure 70, Figure 71 presents the power-current curve comparisons. In the SOFC mode, this 5-cell stack generated $\sim 100 \mathrm{~W}$ at $45 \mathrm{~A}$ current, while in the SOFEC mode, the stack produced over 100 standard liters hydrogen per hour while consuming just $80 \mathrm{~W}$ of electrical power. This electrical energy consumption is significantly lower than what is needed for the traditional SOEC to produce the same amount of hydrogen from steam (the minimum electrical energy required is $247.5 \mathrm{~W}$ to produce the same amount of hydrogen by using the SOEC technology). 
4"x4" 5-cell Stack Voltage Curve Comparison in SOFC and SOFEC Modes $800^{\circ} \mathrm{C}, \mathrm{Uf}, \mathrm{U}$ o or $\mathrm{Uf}, \mathrm{UH}_{2 \mathrm{O}} @ 50 / 50$

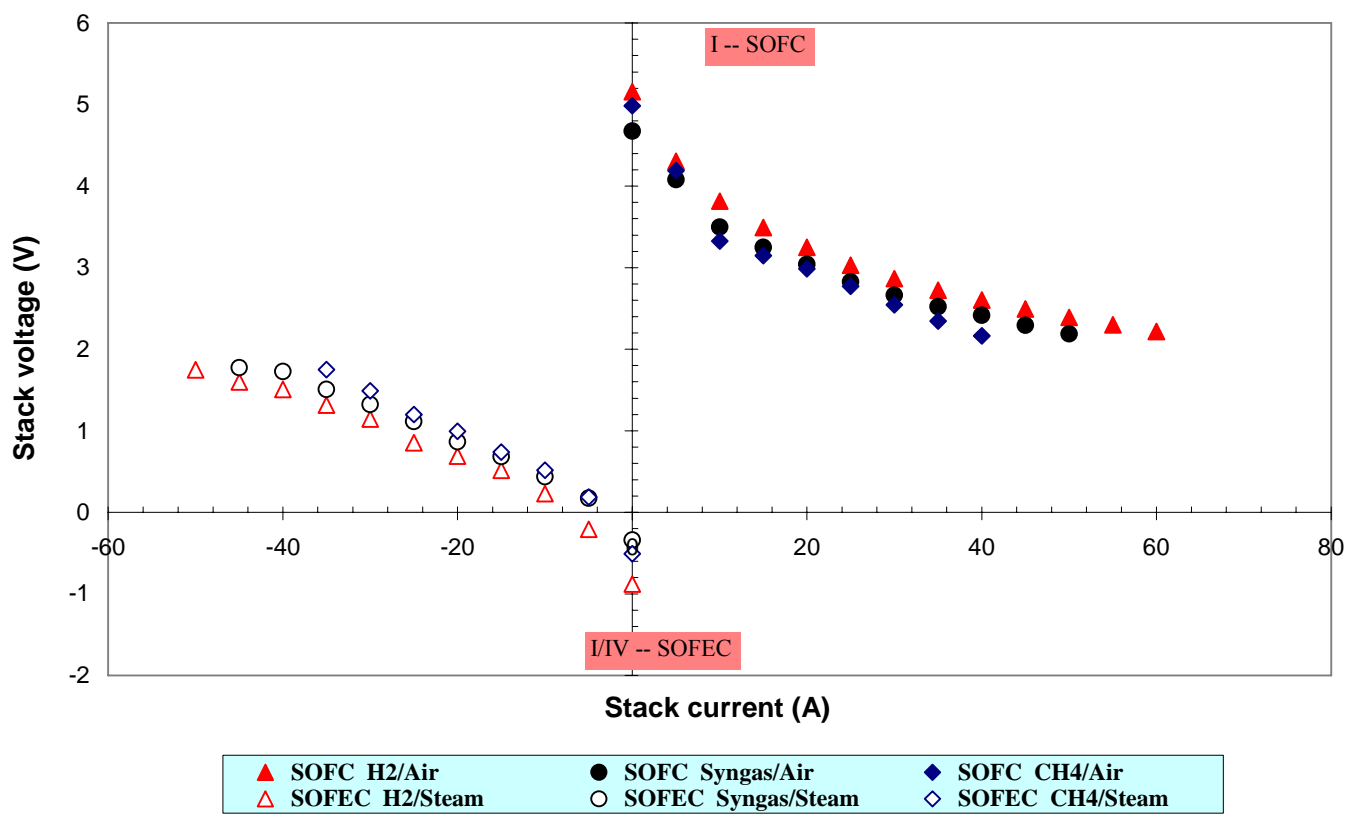

Figure 70. Stack voltage-current characteristics comparisons obtained in the SOFC and the SOFEC modes at $800^{\circ} \mathrm{C}$. In the SOFC mode, hydrogen, a mixture of steam $(27 \%)$ with syngas, or a mixture of steam (50\%) with $\mathrm{CH}_{4}$ was fed to the anode, and air was fed to the cathode. In the SOFEC mode, the same fuel that was used in SOFC tests was used to feed the anode, and a mixture of steam (90\%) with hydrogen was fed to the cathode.

4"x4" 5-cell Stack Power Curve Comparison in SOFC and SOFEC Modes $800^{\circ} \mathrm{C}, \mathrm{U}_{\mathrm{f}} / \mathrm{U}_{\mathrm{O}}$ or $\mathrm{U}_{\mathrm{f}} / \mathrm{U}_{\mathrm{H} 2 \mathrm{O}} @ 50 / 50$

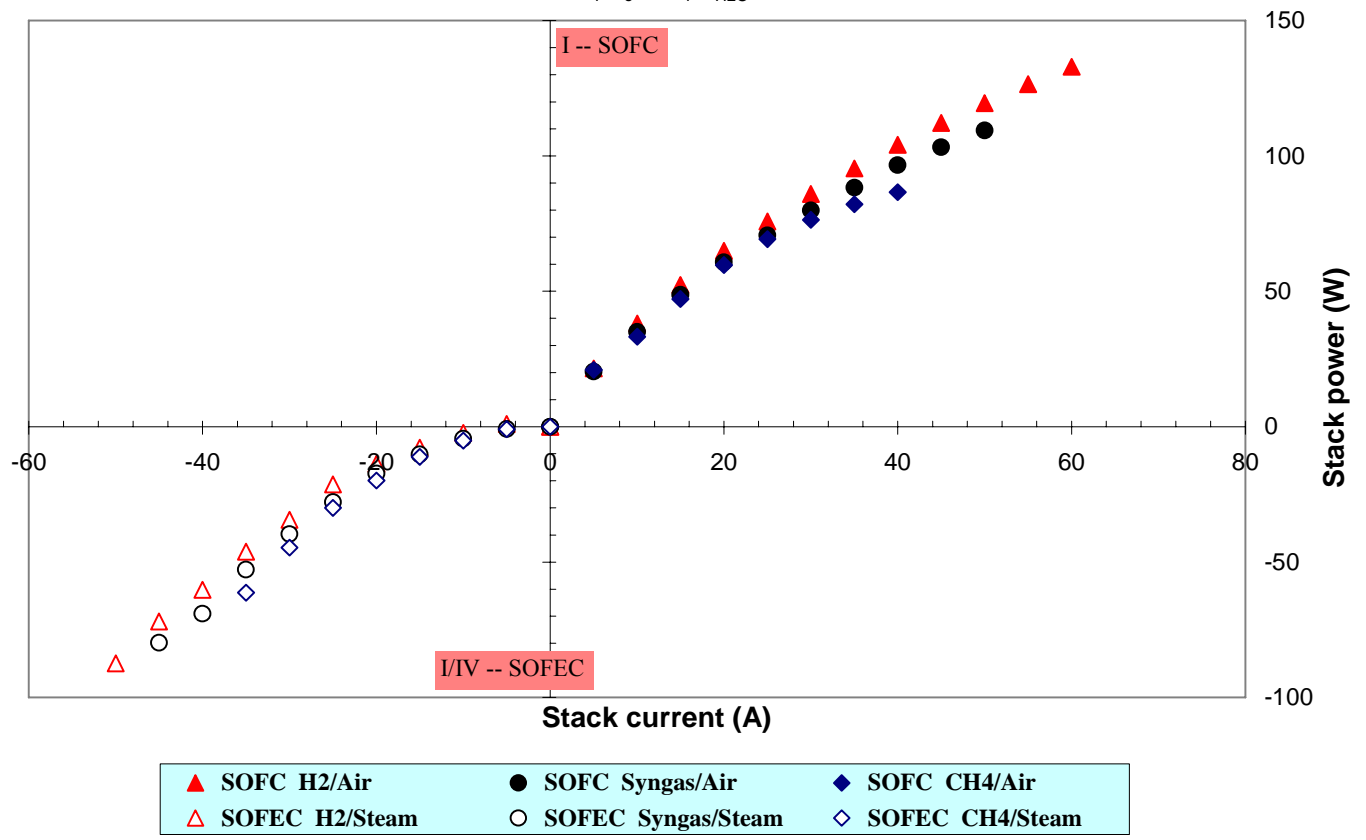

Figure 71. Stack power-current characteristics comparisons obtained in SOFC and SOFEC modes at $800^{\circ} \mathrm{C}$. Same operation conditions were used as what is shown in Figure 70. 
Characterization tests in the SOFC and SOFEC modes have been repeated using multiple sets of 5-cell 4"x4" stacks, providing sufficient data for the design of $1 \mathrm{~kW}$ hybrid stack. Figure 72 shows the test results of another set of 4" $\mathrm{x} 4$ " 5-cell stack operated at $800^{\circ} \mathrm{C}$ in the SOFC mode using different fuels and at various fuel/air utilizations. As shown in the figure, the effects of the fuel or air utilization on the stack performance are negligible, thanks to the optimized porous anode microstructure and the leak-tight seals. This result is consistent with what were obtained from the previous stack shown in Figure 67. As always, the stack showed a little bit higher performance using the hydrogen fuel than using the syngas fuel. At $40 \mathrm{~A}$, this 5-cell stack generated $120 \mathrm{~W}$ electric power when the utilizations of both the syngas fuel and air were fixed at $60 \%$.

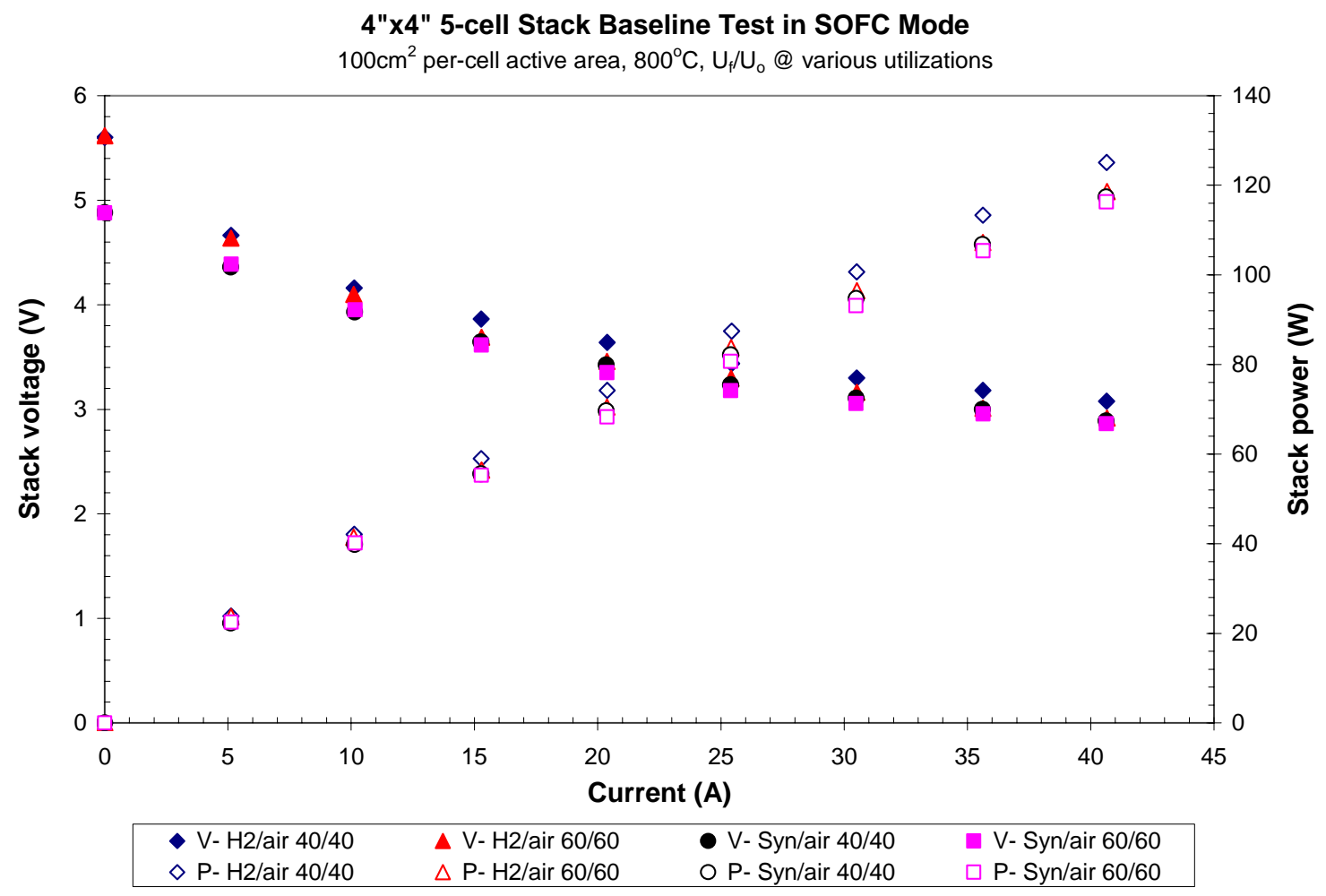

Figure 72. Performance characteristics of a 4"x4" 5-cell stack tested at $800^{\circ} \mathrm{C}$ at different utilizations. In this baseline test in SOFC mode, hydrogen and wet syngas (mixed with $30 \%$ steam) were used as the fuels and air was the oxidant. Both the fuels and air utilizations were increased from $40 \%$ to $60 \%$.

Figure 73 is the performance of the same stack operated in the SOFEC mode with hydrogen and wet syngas fuels on the anode to assist in the generation of hydrogen from the cathode steam. Both the fuel and steam utilizations varied from $40 \%$ to $60 \%$. As shown in the figure, at the $40 \%$ fuel (hydrogen or wet syngas) and steam utilizations, the stack reached $45 \mathrm{~A}$, which is equivalent to 1.712 SLPM (or 103 standard liter of hydrogen per hour) hydrogen production rate. The average applied voltage per-cell was about $0.2 \mathrm{~V}$. When the utilizations were increased to $60 \%$, the average cell voltage at the same current (or hydrogen production rate) increased by $20 \%$ to $0.24 \mathrm{~V}$, because of the increased concentration losses. This result is different from what was obtained when the stack was operated in the SOFC mode. As shown in the Figure 72, there is no 
performance drop in SOFC mode when the utilizations go up from $40 \%$ to $60 \%$. The only difference between the two operation modes is that the oxidant on the cathode is either air or steam for the SOFC mode or the SOFEC mode, respectively. This prompts that the two oxidants (air and steam) may have different characteristics on the LSCM based composite cathode, such as the diffusivity, adsorptivity, activity, etc. This difference is a trait that warrants further examination in future work.

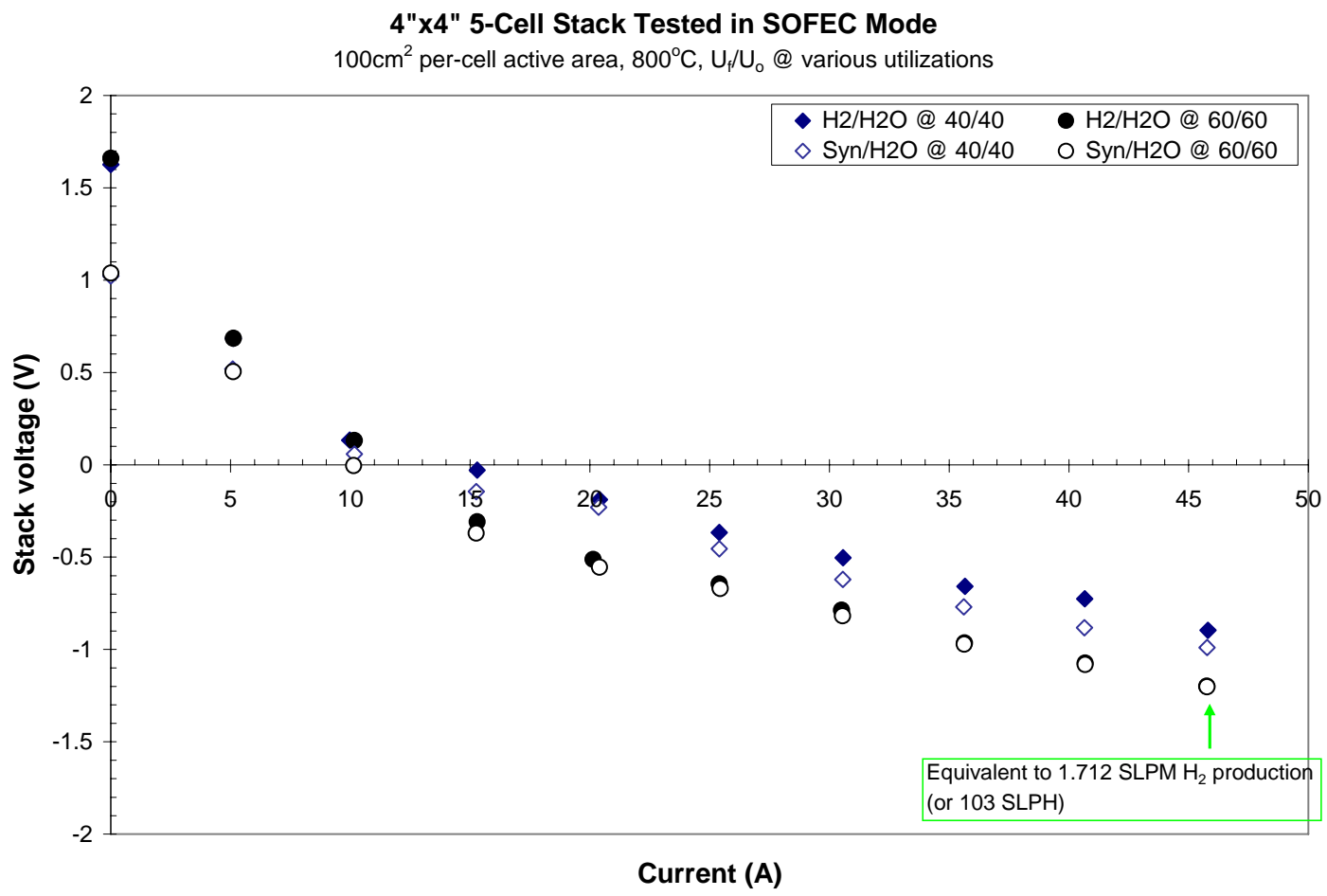

Figure 73. Performance characteristics of a 4" 4 4" 5-cell stack operated in the SOFEC mode assisted with either hydrogen or syngas flow on the anode to produce hydrogen from the cathode steam. Both fuels and steam utilizations varied from $40 \%$ to $60 \%$. Each cell had $100 \mathrm{~cm}^{2}$ active areas.

In order to predict the co-generation performance of a hybrid stack comprised of a number of SOFCs and SOFECs electrically connected in series, the power-current characteristics operated in the SOFC mode and in the SOFEC mode were added together and presented in Figure 74. In the plot, the filled but unconnected symbols represent the experimental results obtained from the SOFC operation, shown in Figure 72. The unfilled and unconnected symbols are data obtained from the same stack but operated in SOFEC mode, shown in Figure 73. The filled symbols connected with solid lines are the projected power output for this pseudo-hybrid 10-cell stack. As it is outlined in Figure 74, at 40 A, this hybrid stack is projected to produce 1.521 SLPM hydrogen, and to co-generate net power output $95 \mathrm{~W}$ simultaneously for a fixed hydrogen utilization at $40 \%$. When wet syngas fuel is used at $60 \%$ utilization, at the same hydrogen production rate (i.e. $40 \mathrm{~A}$ ), this pseudo-hybrid stack is projected to generate $72 \mathrm{~W}$ net power output simultaneously. In order to maximize the hydrogen production capacity per stack with the fixed total cell numbers under the electrically self-sustaining condition (zero net power output), the hybrid stack can either be operated at a high current or increase the numbers of SOFECs per SOFC. In the first option, higher current operation may introduce a higher ohmic 
heating effect, resulting in an accelerated degradation of the stack performance. Consequently, a large ratio of SOFECs per SOFC is preferred for the hybrid stack.

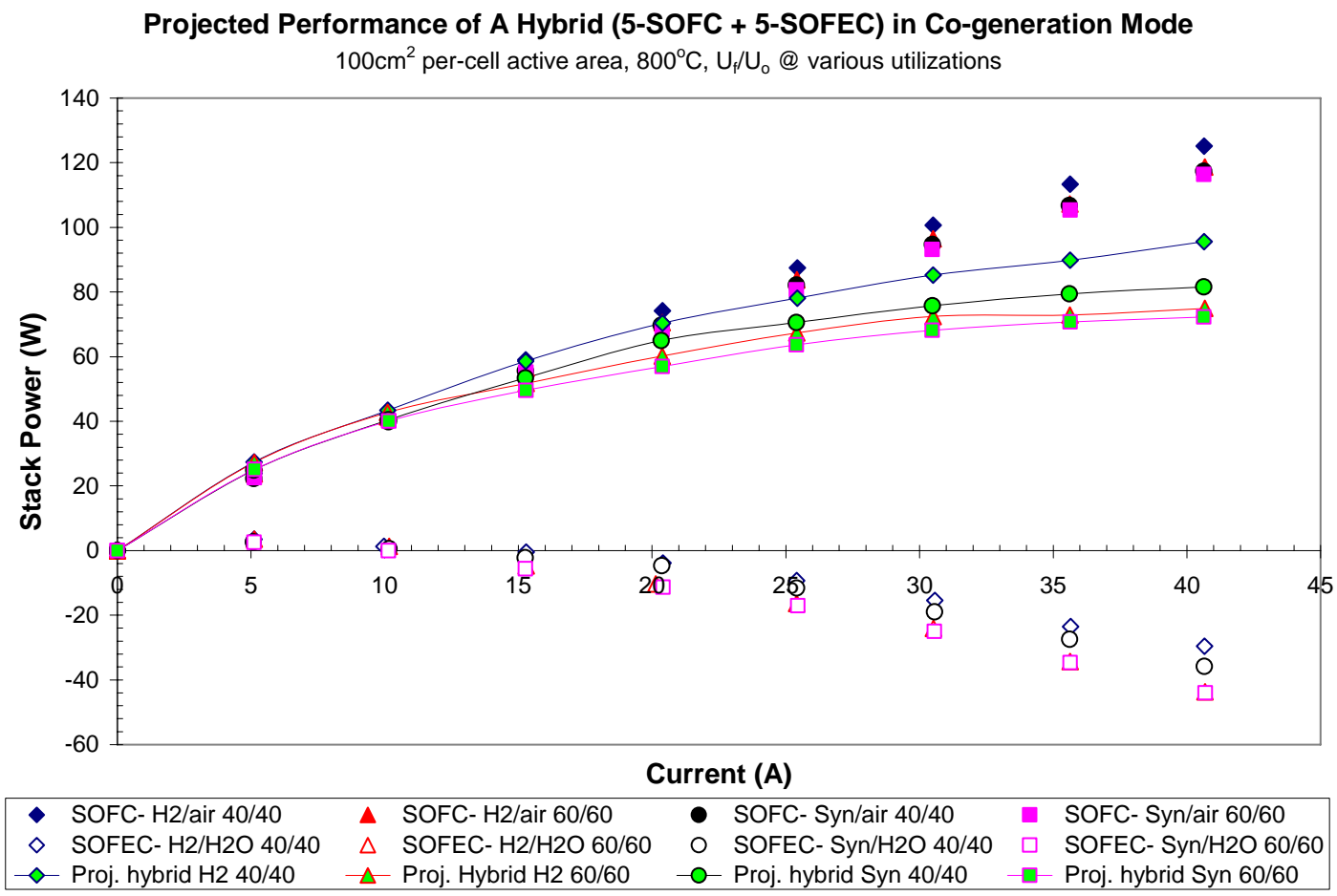

Figure 74. Projected power-current characteristics of a hybrid 10-cell stack comprised of 5 SOFCs and 5 SOFECs connected in series.

After a series of cycling operations between the SOFC and the SOFEC modes with different fuels and utilizations, the same stack underwent a continuous test operating in the syngasassisted SOFEC mode to continuously produce hydrogen from the cathode steam. Figure 75 shows the 150-hour test results. The continuous test started from the initial 300 operation hours of cycling tests described above, and ended at 500 operation hours. The green line is the stack current, and other four lines are voltage of Cell \#1 through Cell \#4. The voltage of Cell \#5, which is the top cell of the stack encountering the inlet gases, is not shown in the plot. That cell failed in the previous 300 hours cycling test due to mistakes made by the operator, who accidentally ran the stack under a starvation condition without attention. As plotted in the figure, the first 80 hours of the continuous test shows a stable performance without noticeable degradation, even though the test was interrupted by the power supply, which did not provide enough voltage to drive the electrolyzer. After the initial 80 hours continuous test, the stack was set to the OCV condition in the SOFC mode over the weekend for the maintenance. Every single cell showed the OCVs above $1.08 \mathrm{~V}$ in the SOFC mode. Cross leak tests and GC composition tests did not show leakage of the stack. The long-term test was terminated after another 30 hours under the load test, due to large performance degradations caused by Cell \#3 and \#4. The posttest inspection of the stack showed occurrences of delamination of cathode interlayers. 
4"x4" 5-Cell Stack Long-term Test in SOFEC Mode

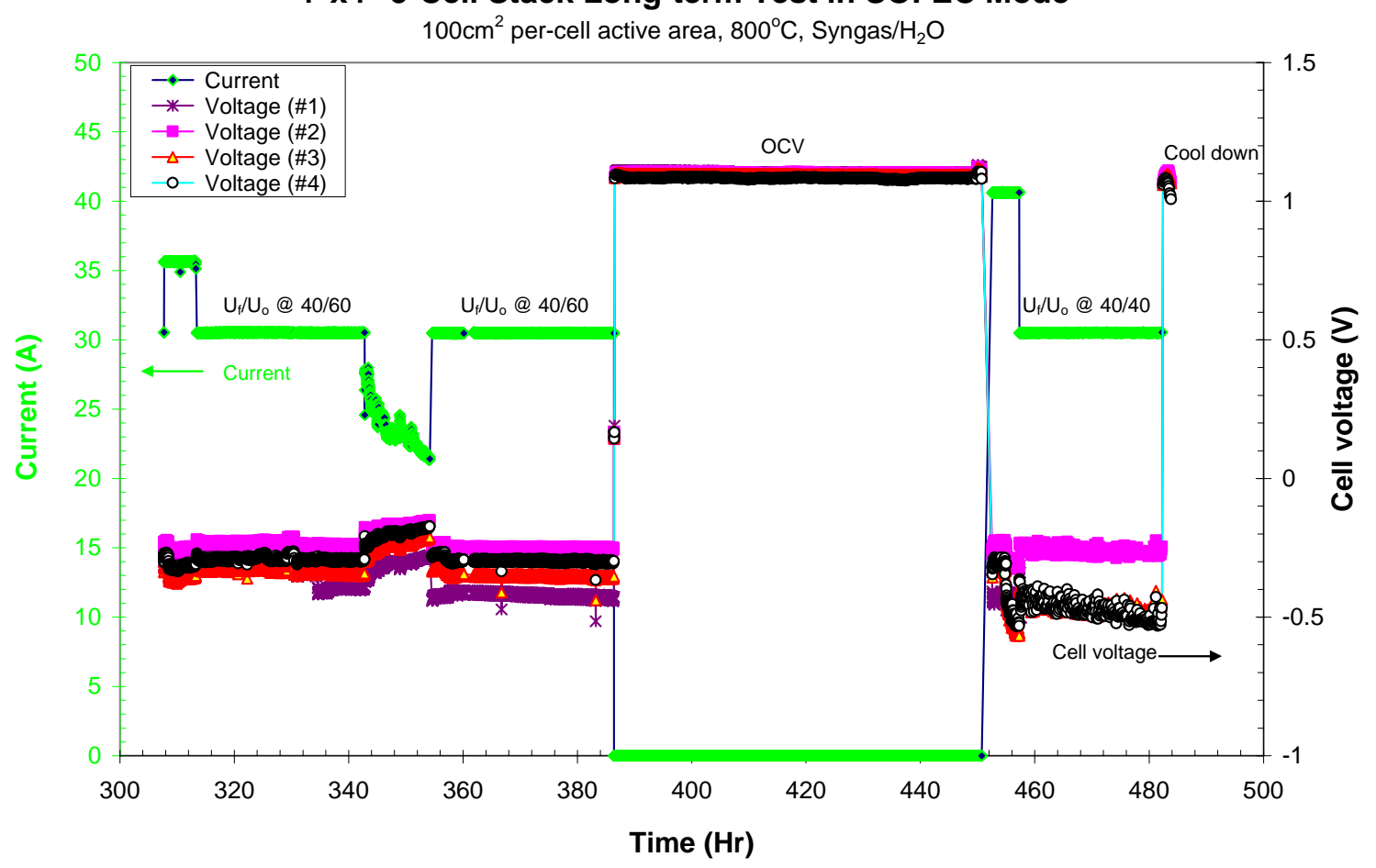

Figure 75. A 4" $\times 4$ " 5-cell stack long-term test in the syngas-assisted SOFEC mode to produce hydrogen from the cathode steam. Each cell has $100 \mathrm{~cm}^{2}$ active areas. The syngas fuel utilization was fixed at $40 \%$, while the steam utilization was initially set to $60 \%$, but then lowered to $40 \%$.

\section{Task 8 Post Test Characterization of SOFECs and SOFCs}

After tests, button cells or stacks were inspected visually before being moved out of the furnace. Any signs of cracks, lost of seals, burning images on edges, etc. were recorded. Figure 76 shows a picture of a 4 "x4" 10 -cell stack after testing. No external cracks or burning images were observed.

Button cells or stacks were then dissembled and each cell was marked and inspected. Signs of cracks, burning, SDC barrier layer delamination, cathode interlayer/cathode delamination and reduction, anode redox, lost of dry contact aids, etc. were recorded. Any physical changes of the cell were recorded for further investigation and optimization. Cathode sheet resistance of each cell was measured using a four-probe instrument and recorded before and after testing. The ohmic resistance across the cell was also measured before and after testing to ensure no electric shorts occurred during testing. Selected cells were cross sectioned and examined with SEM and XRD. 


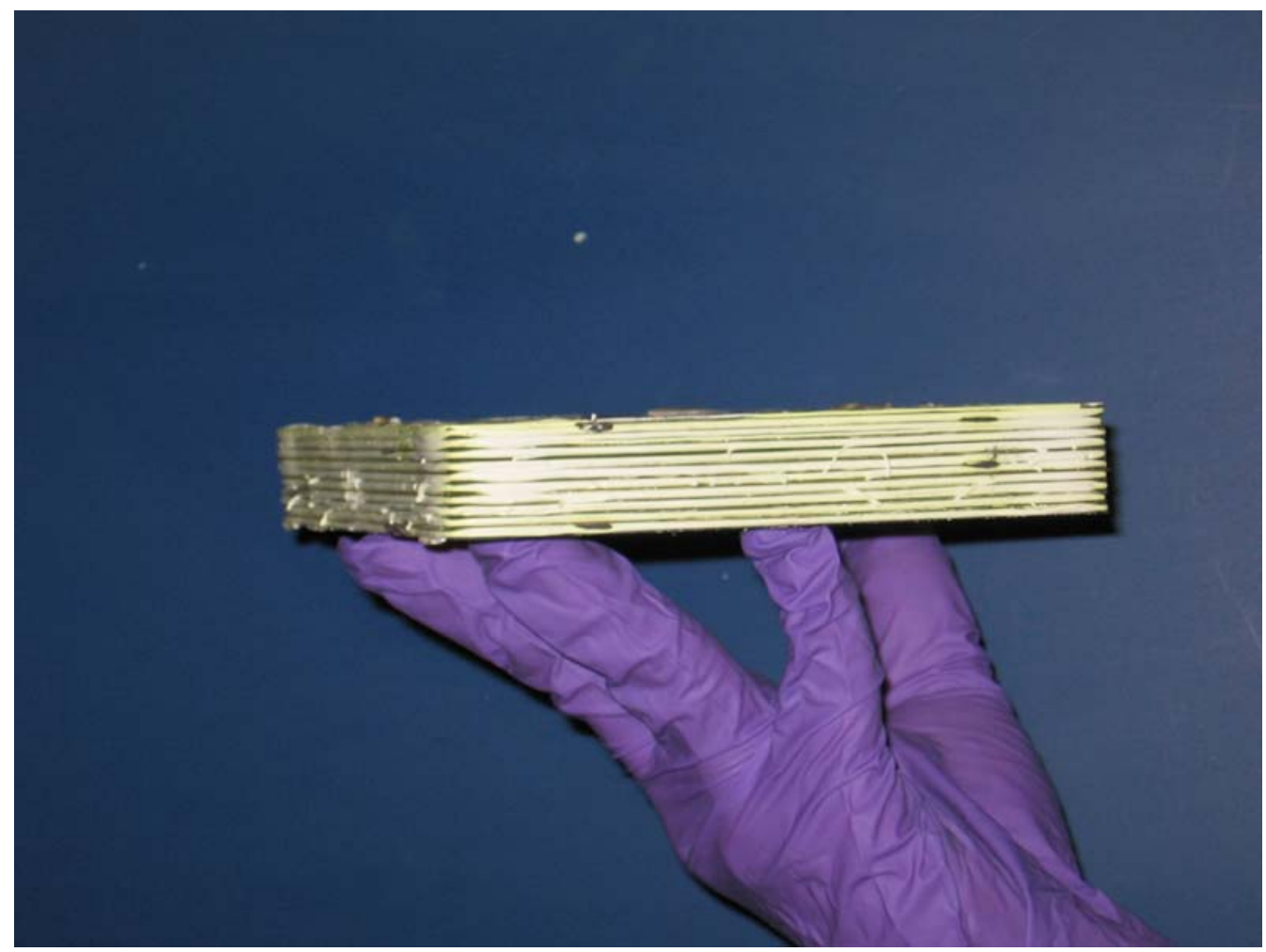

Figure 76. A picture of a 4"x4" 10-cell stack after testing

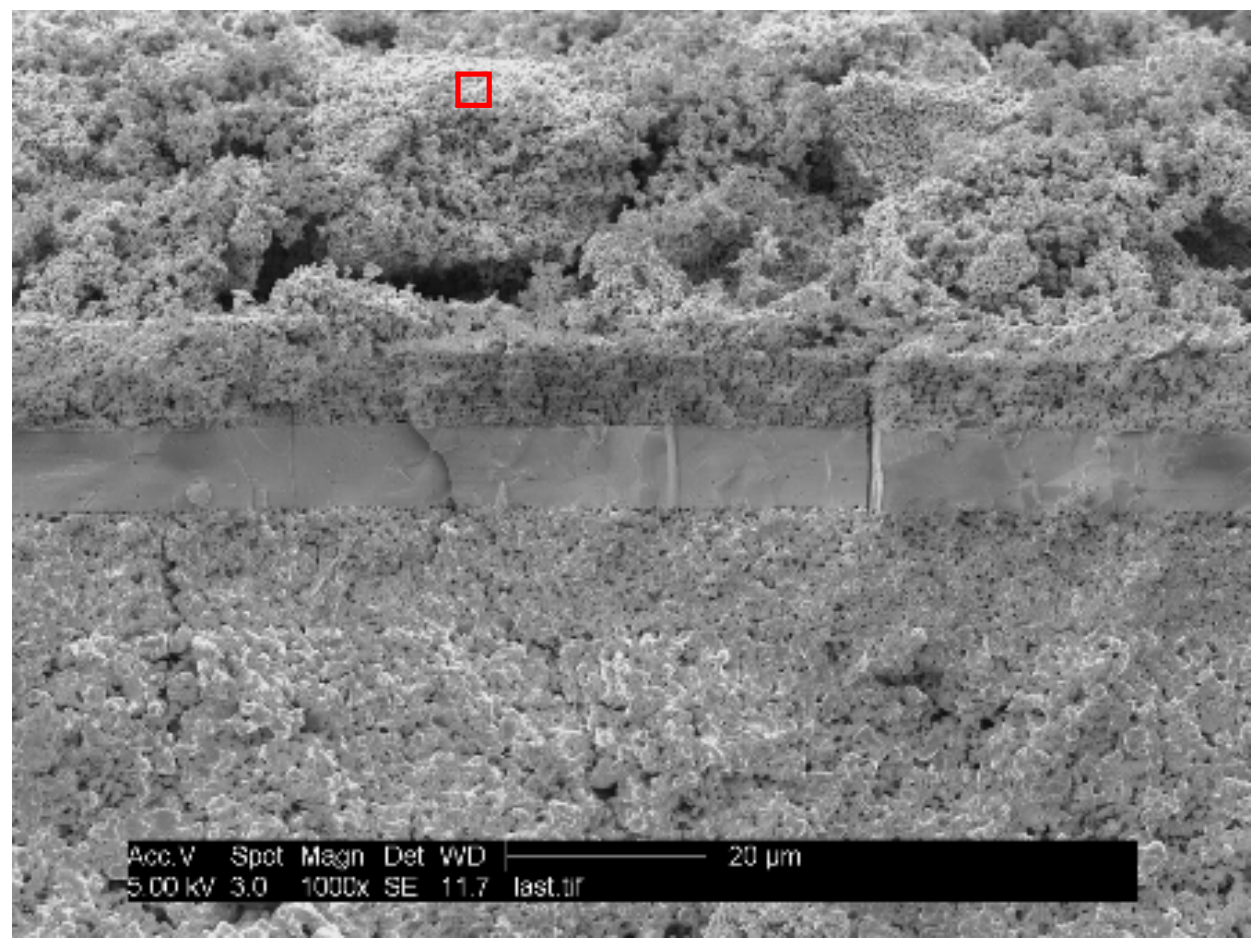

Figure 77. A SEM micrograph of the button cell after a 5000 hours long-term test operated in the SOFC mode. 
Figure 77 is a SEM micrograph of a button cell, which was tested continuously over 5000 hours in the SOFC mode. As was discussed in the subtask 5.4, the cell made from the MSRI standard anode support (with pore former Type A) and LSCM-based cathode showed exceptionally stable performance in the first 3600 hours of testing, but showed measurable degradation during the last 1360 hours of the test. The ohmic ASR, measured periodically by the current interruption method, increased by $11 \%$, suggesting possible electrode delamination or electrode microstructure changes. Nevertheless, when examining the micrographs of the cell shown in Figure 77, no apparent delaminations of the anode and cathode were observed. Micrographs of the cathode barrier layer and the cathode function layer were also studied. Both layers bonded satisfactorily, as shown in Figure 78.

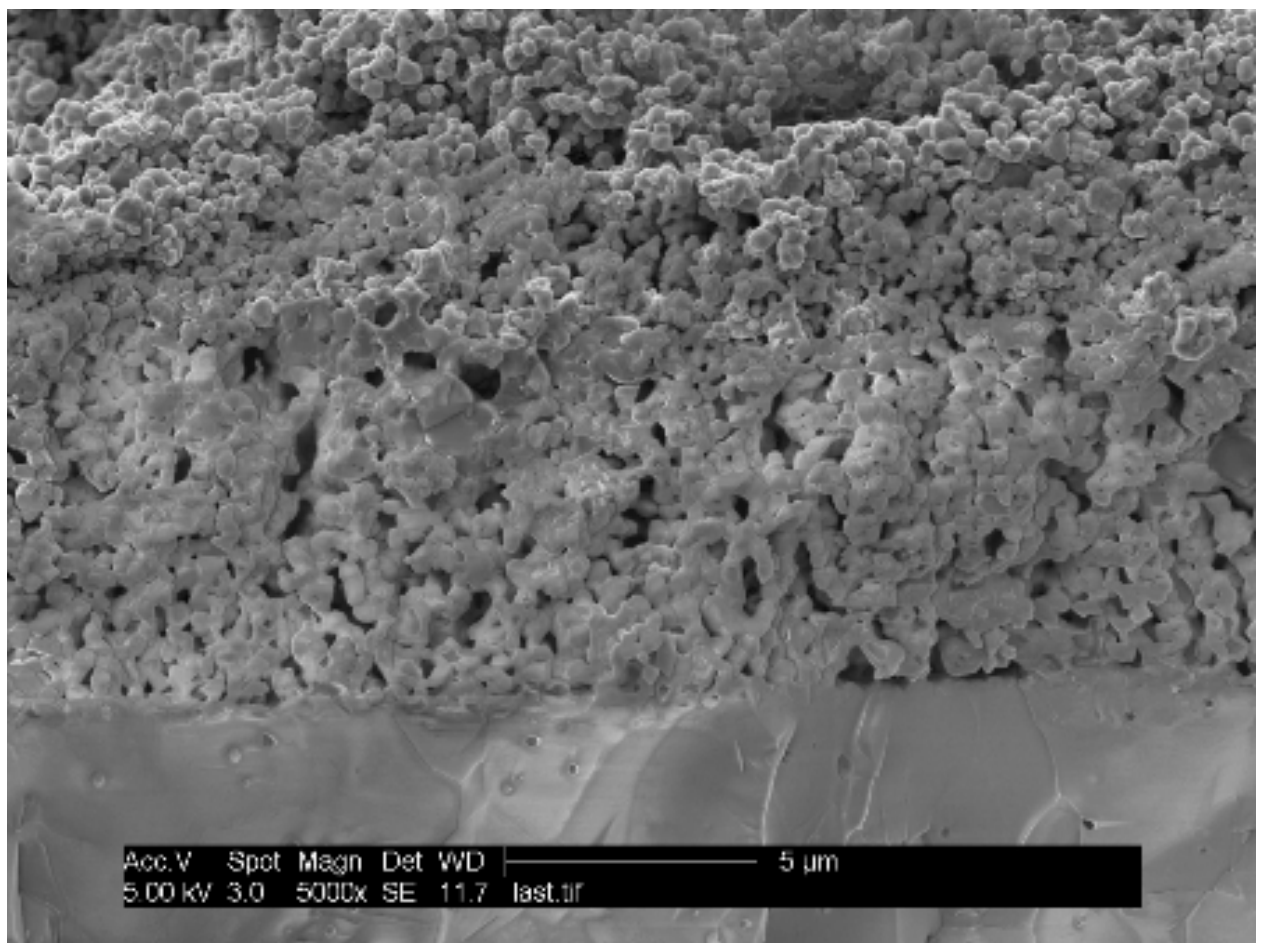

Figure 78. A SEM micrograph of the button cell showing the barrier layer and cathode functional layer. This cell was tested over 5000 hours in the SOFC mode.

Combined with the SEM study of the button cell, an Energy Dispersive X-Ray analysis (EDAX) was also performed to investigate the elemental composition. Even though EDAX technique does not provide precise information of the material's composition, it provides information about the compositional variation in the target materials. Figure 79 shows the EDAX spectrum of the highlighted area, shown in Figure 77, on the cathode side of the button cell. The corresponding elemental compositions are listed in Table 3. It is interesting to notice that besides the elements of the cathode (LSCM), a small amount of Ag (about $0.3 \mathrm{wt} \%$ ) was also detected, though no $\mathrm{Ag}$ was added to the cathode of the pristine cell before testing. This Ag contaminant was from the deposition of the Ag-based current collector on its cathode, since Ag has relatively low melting temperature and high vapor pressure at $800^{\circ} \mathrm{C}$. After the 5000 hours long-term test, the majority of the bulk of the cathode contact aids remained. No other contaminant was detected. 


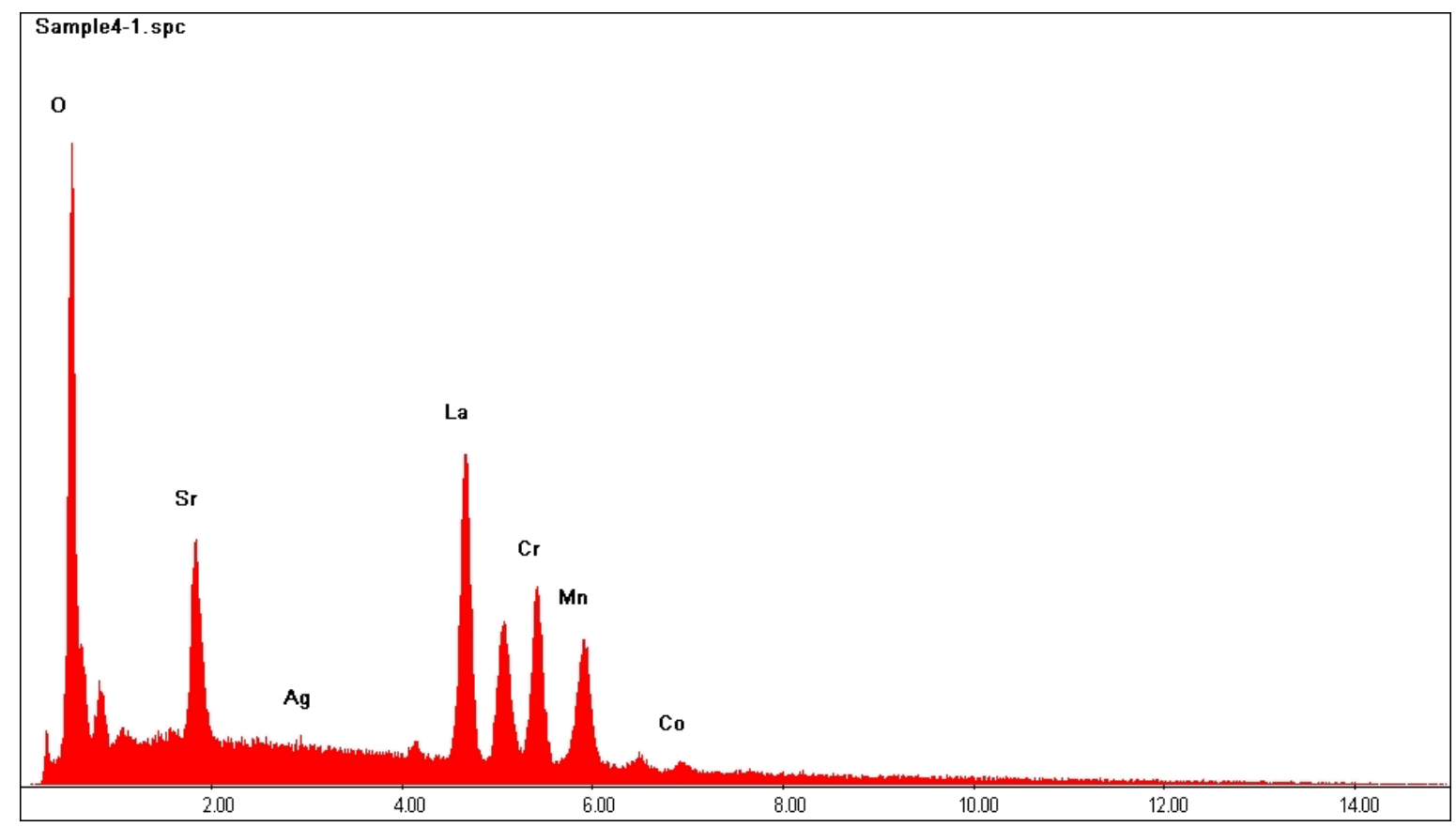

Figure 79. EDAX spectrum of the highlighted area of the button cell shown in Figure 77.

Table 3. Elemental compositions of the button cell cathode

\begin{tabular}{|c|c|c|}
\hline Element & Wt \% & At \% \\
\hline O K & 15.61 & 51.61 \\
\hline SrL & 9.55 & 5.76 \\
\hline $\mathrm{AgL}$ & 0.3 & 0.15 \\
\hline $\mathrm{LaL}$ & 51.07 & 19.45 \\
\hline $\mathrm{CrK}$ & 9.89 & 10.06 \\
\hline $\mathrm{MnK}$ & 11.94 & 11.5 \\
\hline CoK & 1.64 & 1.47 \\
\hline Total & 100 & 100 \\
\hline
\end{tabular}

Figure 80 shows a cross section view of a 4"x4" cell after testing. It distinctly displayed 6 layers: part of the anode support, anode functional layer, thin but dense electrolyte layer, SDC barrier layer, cathode functional layer, and cathode layer. A fraction of delamination could be observed between the cathode internal layer and the cathode layer, this could result in a performance drop. It also shows that the SDC barrier layer was too thick $(\sim 20 \mu \mathrm{m})$ and should be reduced. EDAX line scanning was performed to investigate the chemical elements profiles and to identify any contaminants. Figure 81 is the EDAX spectrum of a highlighted area shown in Figure 80 on the top of the cathode. Besides the cathode elements, Si and Ca were detected, indicating the presence of contaminants from the glass seal. 


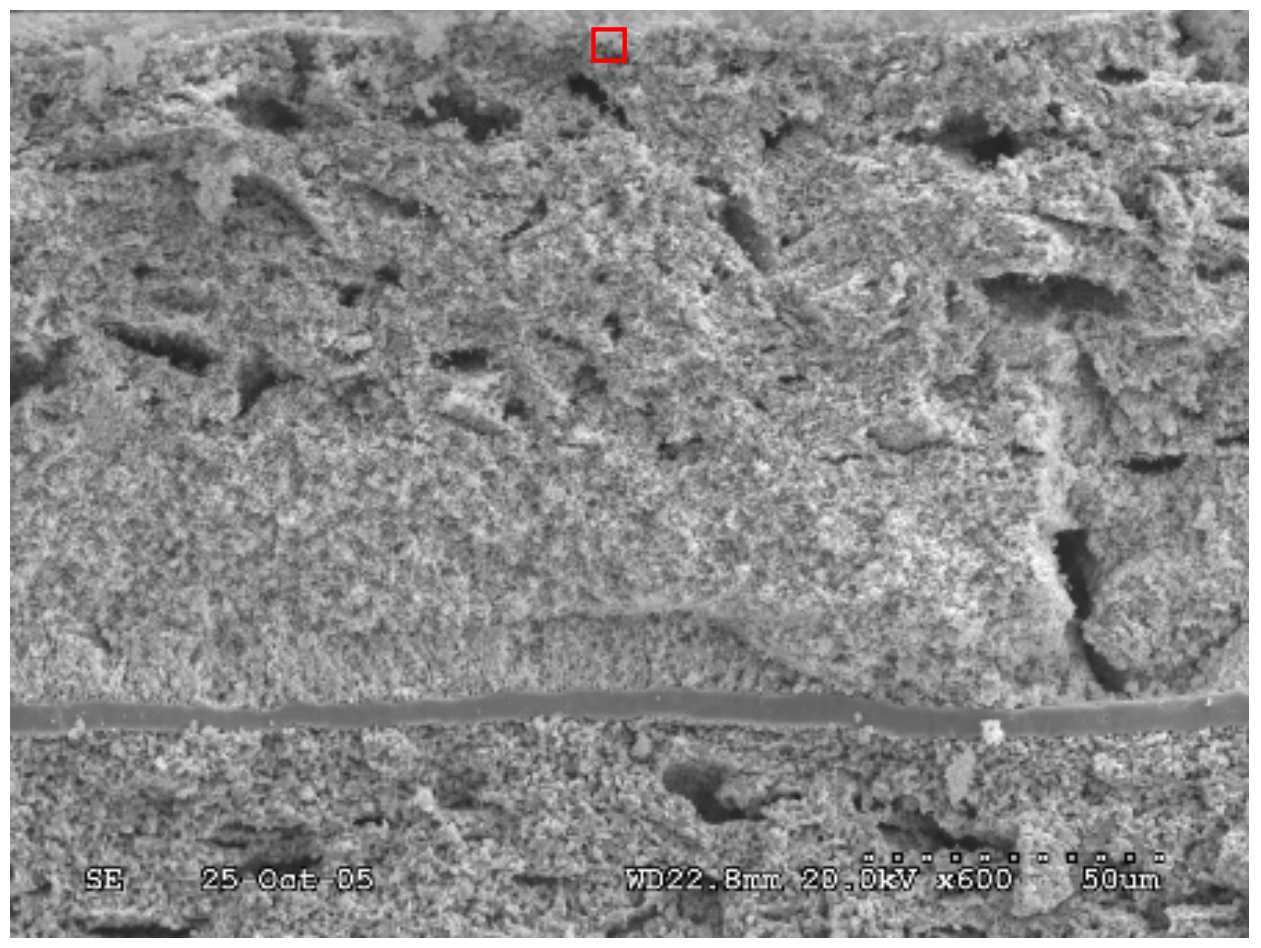

Figure 80. A SEM micrograph of a 4"x4" cell after testing

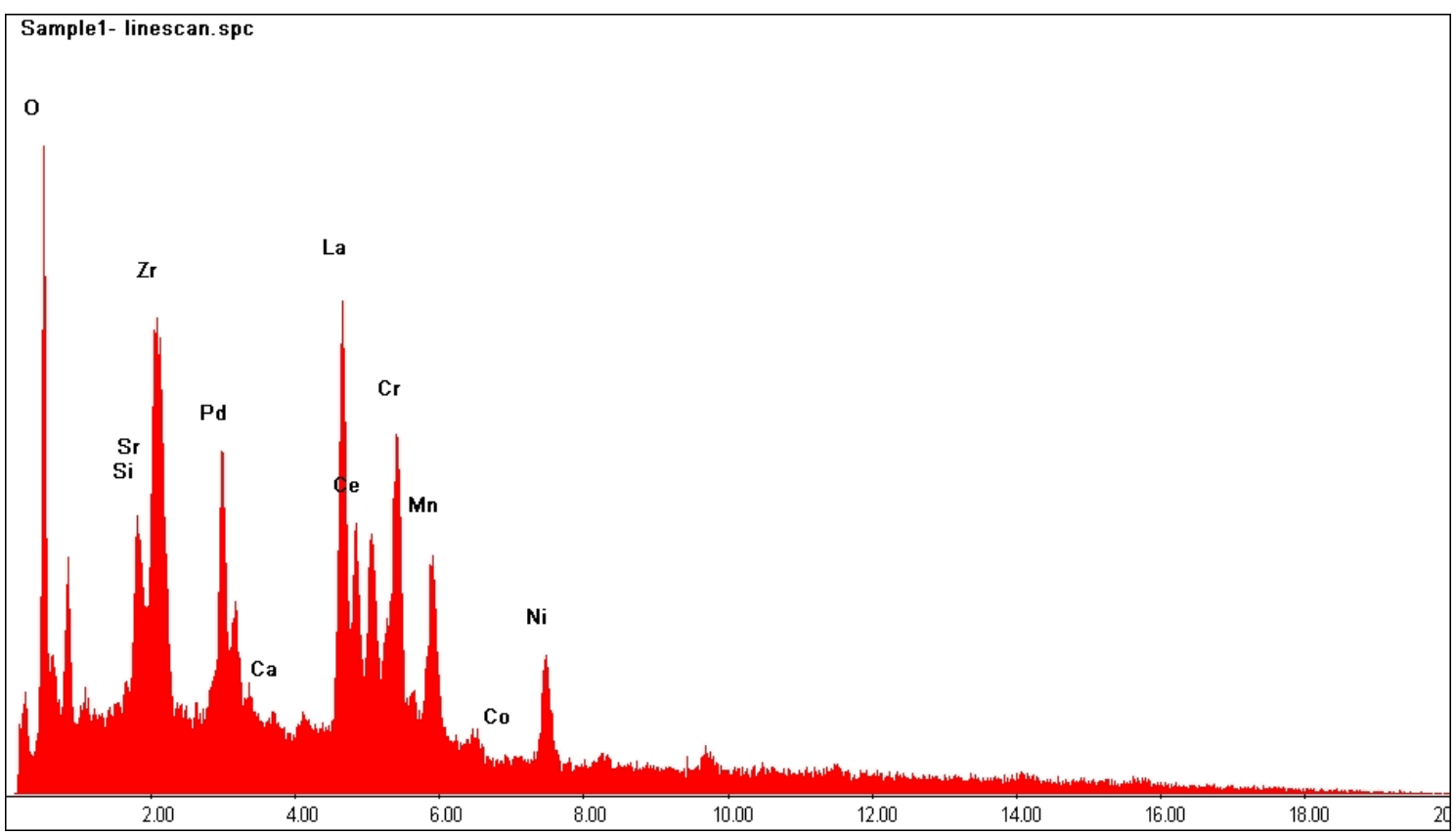

Figure 81. EDAX spectrum of the highlighted area of the 4"x4" cell shown in Figure 80

Task 9 Assembly and Test of SOFEC-SOFC $1 \mathrm{~kW}$ Stacks

Hybrid stacks comprised of multiple SOFCs and SOFECs were constructed and tested to demonstrate the viability of the hydrogen and electricity co-generation technology at a $1 \mathrm{~kW}$ 
scale. In previous analyses performed in Task 7.3, the projected power-current characteristics of a hybrid stack suggested that a large ratio of SOFECs per SOFC is preferred to maximize the hydrogen production capacity for the fixed total cell numbers per stack. Instead of having the same numbers of SOFECs and SOFCs, the construction of a hybrid stack started with 10SOFECs and 7-SOFCs connected in series. Both SOFECs and SOFCs were made from the same anode substrate with Type A pore former, but SOFECs were printed with the LSCM-based cathode while SOFCs were printed with LSCF-based cathode. The active areas of each cell were $100 \mathrm{~cm}^{2}$. Since the LSCM-based cathode developed was electrochemically stable under both reducing and oxidizing atmospheres, but not the LSCF-based cathode, the 10-SOFECs were reversible and capable of operating either in the SOFEC mode for hydrogen generation or in the SOFC mode for power generation. The SOFCs were not reversible so that the power generated was either consumed by the SOFECs or became a stack product. The SOFECs shared the same fuel with the SOFCs. During tests, polarization and power data were recorded for a range of stack current settings.

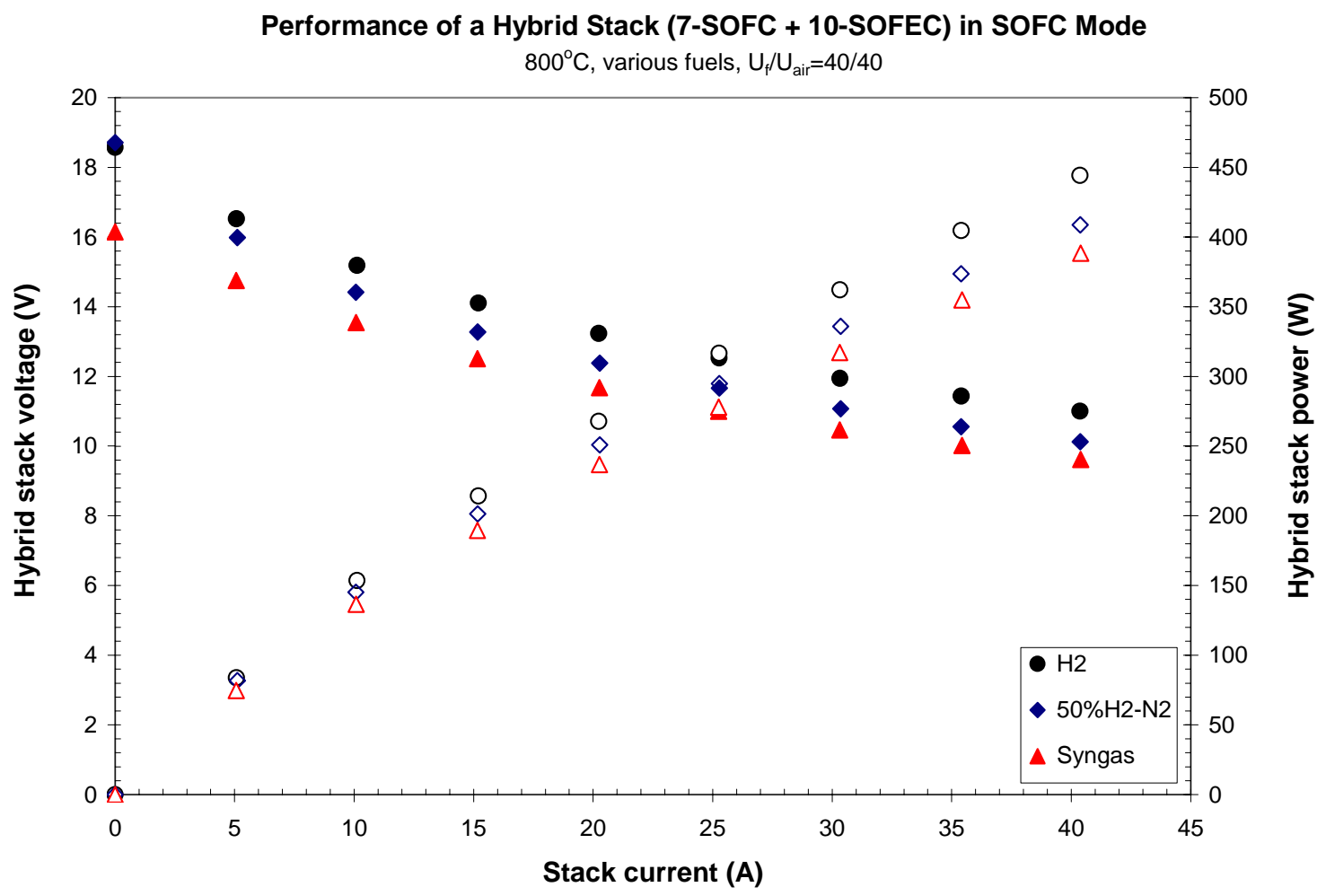

Figure 82. 17-cell hybrid stack baseline test operated in SOFC mode. The hybrid was comprised of 10SOFECs and 7-SOFCs connected in series. A fuel, which was $\mathrm{H}_{2}$, mixture of $\mathrm{H}_{2}(50 \%)$ and $\mathrm{N}_{2}$, or wet syngas (with $30 \%$ steam), was fed to the anode of SOFECs and SOFCs simultaneously. Air was the oxidant for both SOFECs and SOFCs.

As usual, characterizations of the 17-cell hybrid began with a baseline SOFC test to generate electricity, followed by tests in the hybrid mode (SOFEC-SOFC) co-generating hydrogen and electricity. Three different fuels were tested: hydrogen, a mixture of hydrogen (50\%) with nitrogen, and wet syngas (with $30 \%$ steam). Figure 82 shows the performance of the 17-cell hybrid stack operated at $800^{\circ} \mathrm{C}$. At the fixed fuel/air utilizations of $40 / 40$, the entire 17 -cell stack generated $440 \mathrm{~W}$ electricity for the hydrogen fuel and $390 \mathrm{~W}$ electricity for the syngas fuel. 
Performance of the 7-SOFC in SOFC Mode

$800^{\circ} \mathrm{C}$, various fuels, $U_{f} / \cup_{\text {air }}=40 / 40$

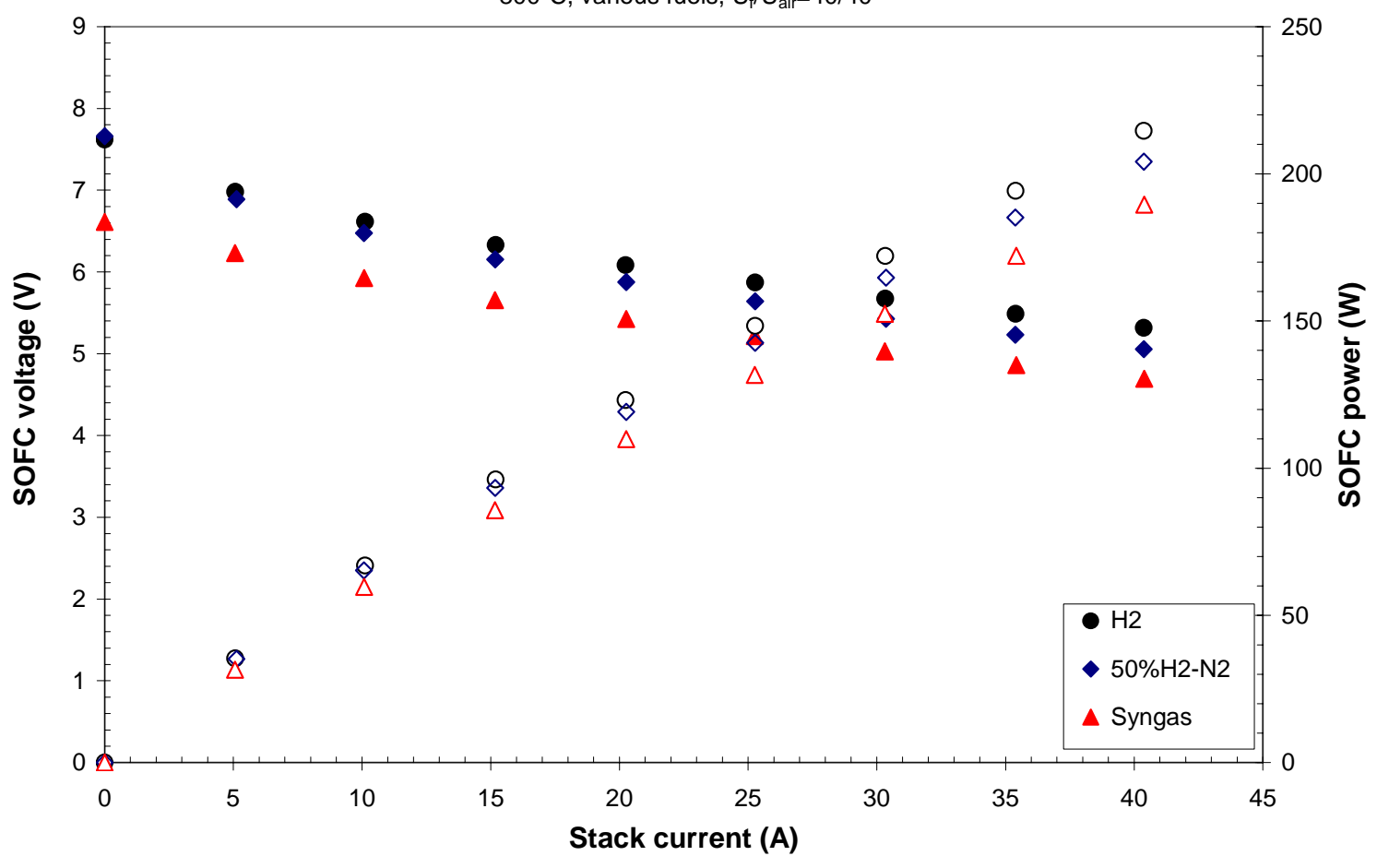

(a)

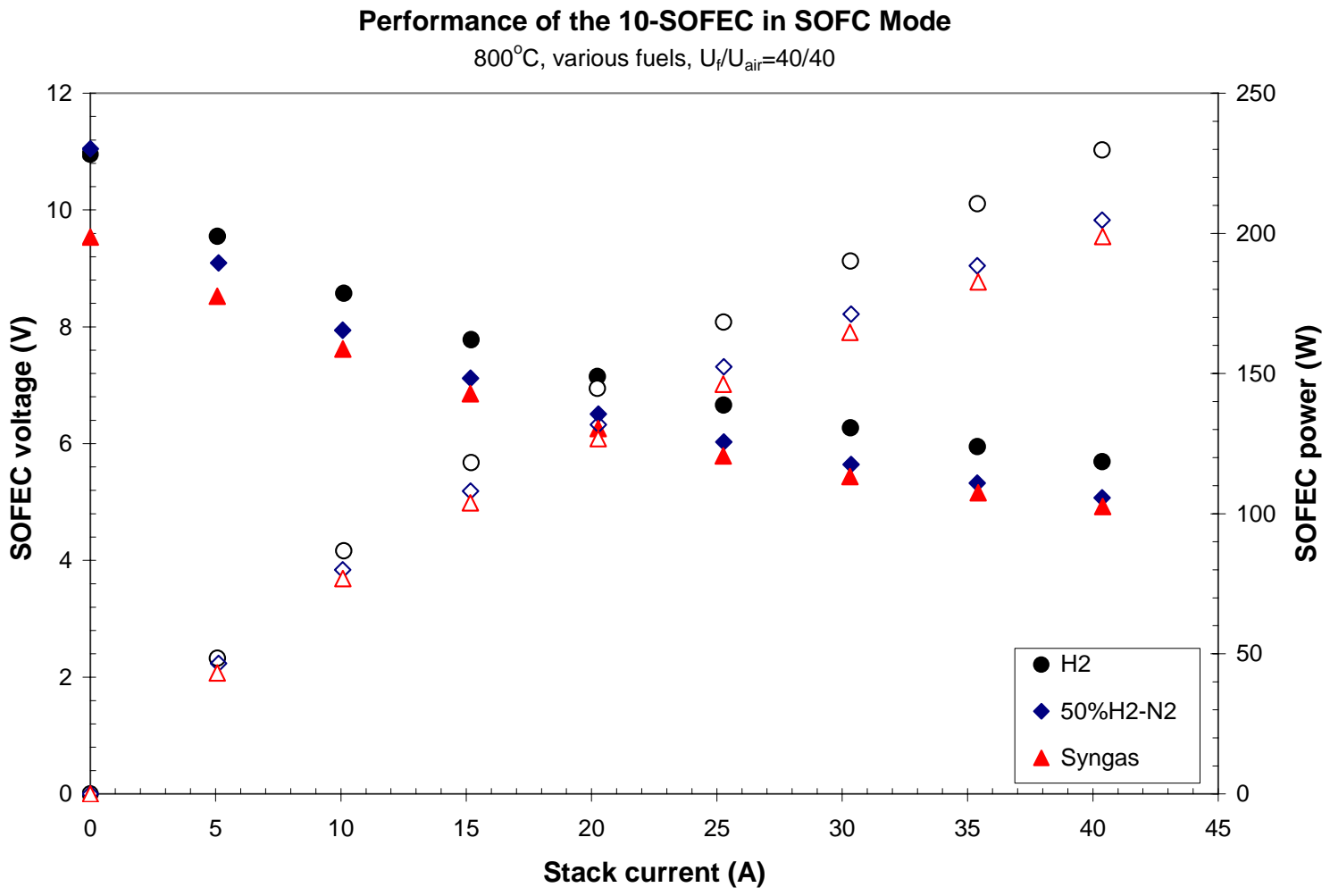

(b)

Figure 83. Hybrid stack performance breakdown for the 7-SOFCs and 10-SOFECs 
Figure 83 provides a side-by-side performance comparison of the 7-SOFC (a) and 10-SOFEC (b). For the syngas fuel at $40 \mathrm{~A}$, the 7-SOFC and 10-SOFEC generated $190 \mathrm{~W}$ and $199 \mathrm{~W}$ power, respectively. As expected, the LSCF-based cathode, which was developed only for the SOFC application, showed higher catalytic activity and higher conductivity than the LSCMbased cathode, though it cannot be used for the SOFEC operation because of its chemical instability under a reducing environment.

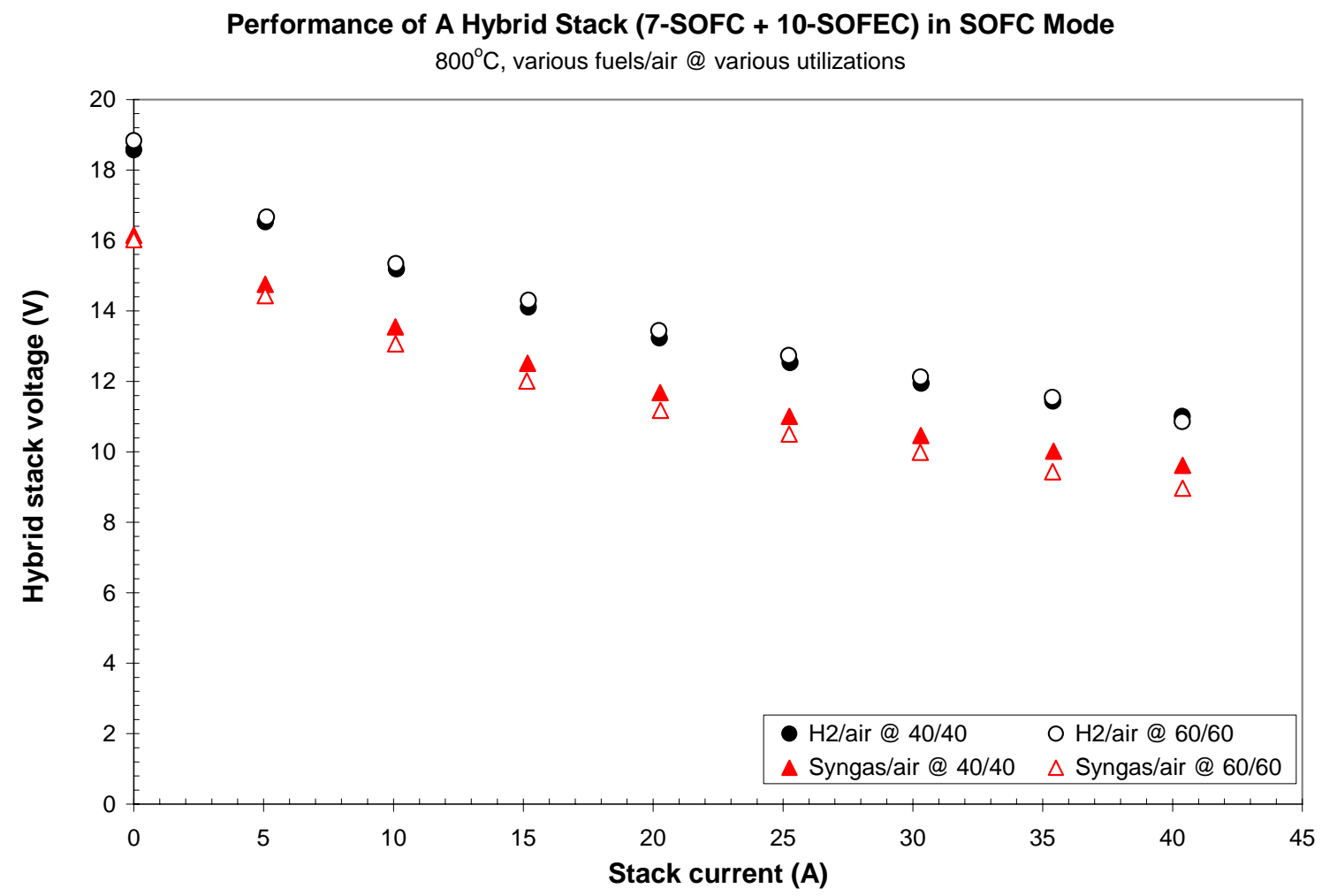

Figure 84. Fuel/air utilizations effects on the hybrid stack performance tested in SOFC mode

The effects of both the fuel and oxidant utilizations on hybrid stack's performance were investigated by changing the utilizations from $40 \%$ to $60 \%$. Figure 84 shows the SOFC test results. For the hydrogen fuel, high utilization didn't affect the stack performance. However, when the syngas fuel was used with the utilization increasing from $40 \%$ to $60 \%$, the power generated by the hybrid decreased from $388 \mathrm{~W}$ to $362 \mathrm{~W}$, a $7 \%$ performance drop. In order to identify the sources of the drop, which could be either from the 10-SOFEC or from the 7-SOFCs, the performances of these two types of cells were plotted in Figure 85 (a) and (b). By the sideby-side comparisons, both types of cells showed an equal drop when the syngas utilization increased to $60 \%$. 
Performance of the 7-SOFC in SOFC Mode

$800^{\circ} \mathrm{C}$, various fuels/air @ various utilizations

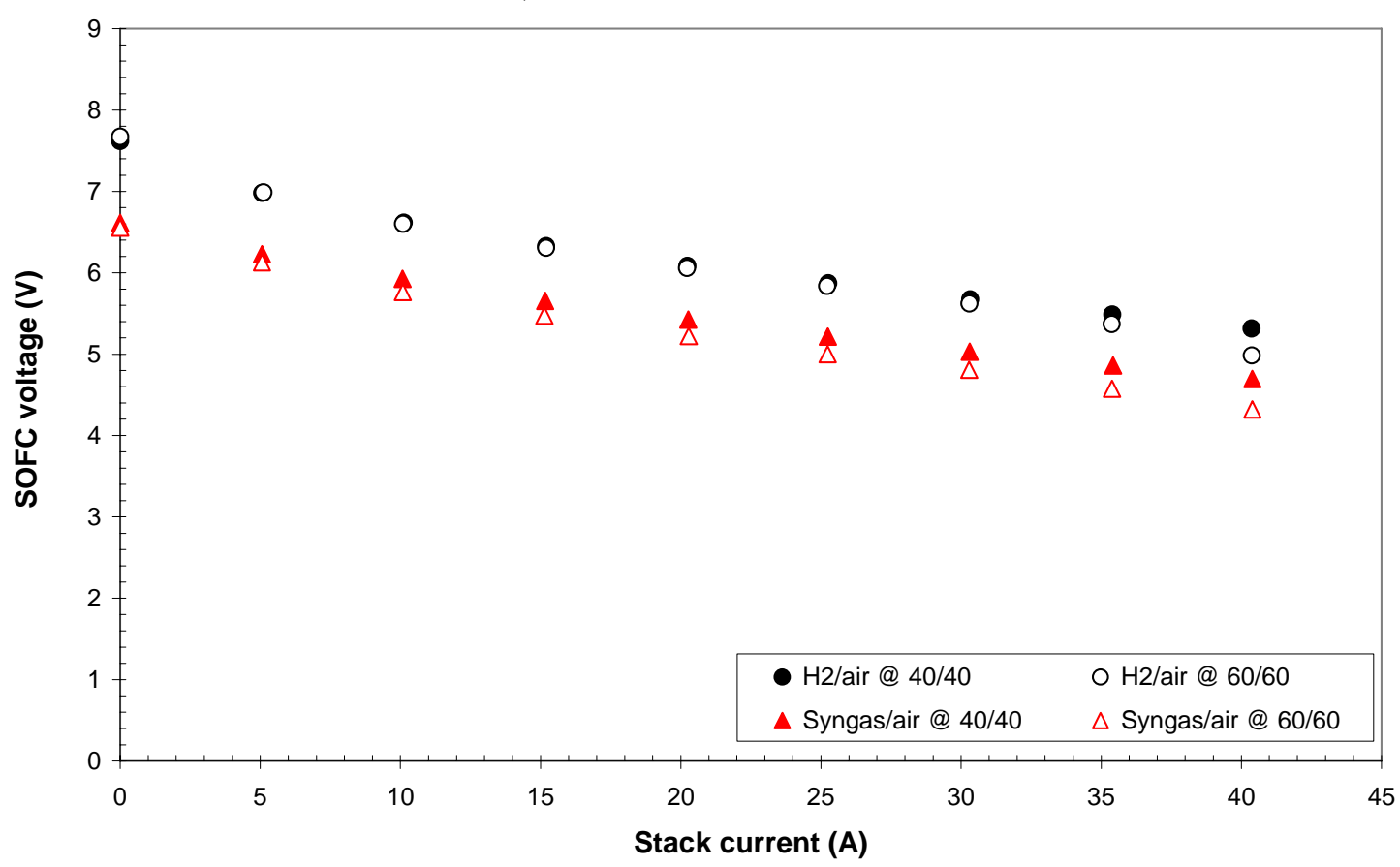

(a)

Performance of the 10-SOFEC in SOFC Mode

$800^{\circ} \mathrm{C}$, various fuels/air @ various utilizations

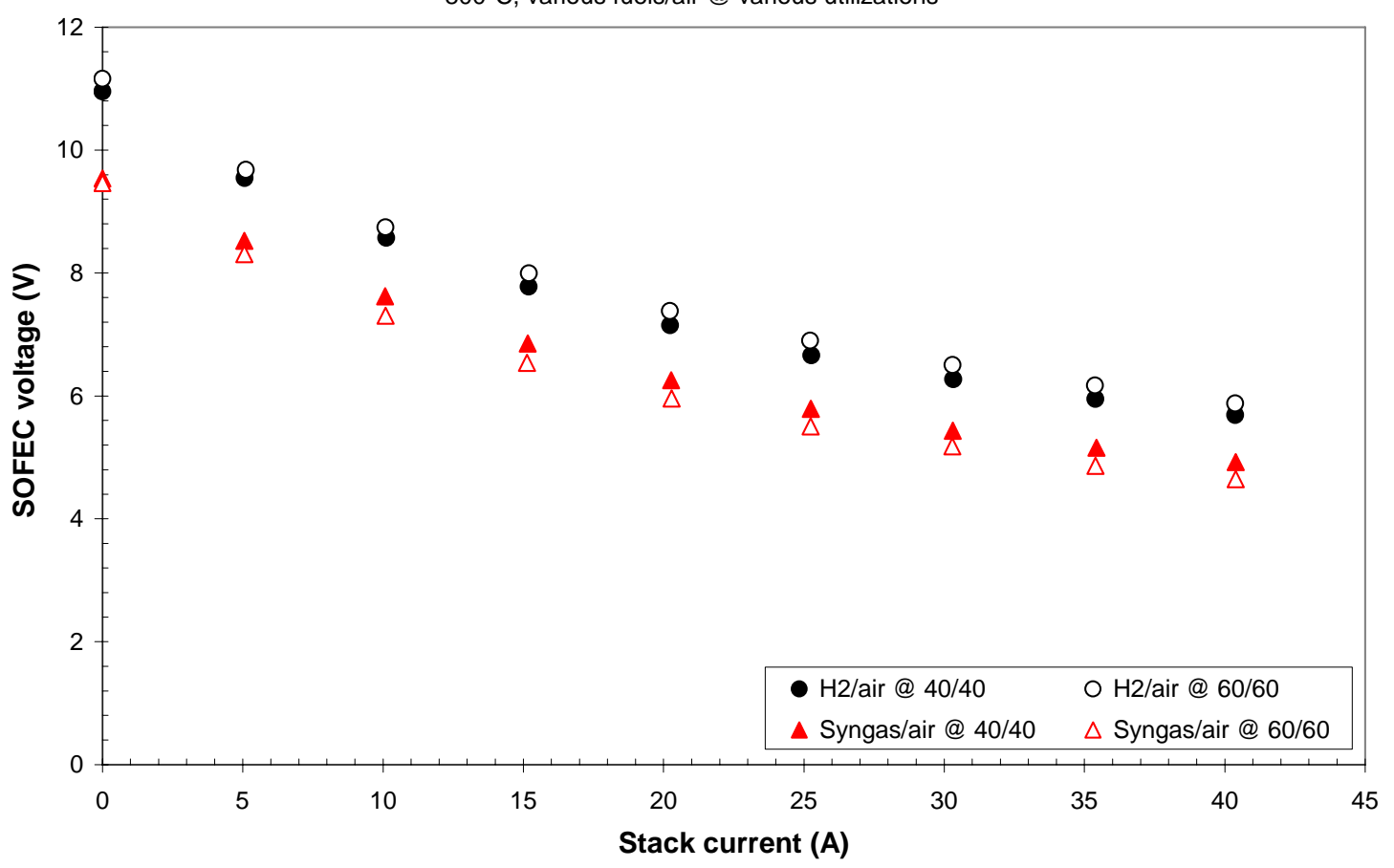

(b)

Figure 85. SOFC performance comparisons between the 7-SOFCs and 10-SOFECs at various fuel and air utilizations. Both fuel and air utilizations increased from $40 \%$ to $60 \%$. 
Performance of A Hybrid Stack (7-SOFC + 10-SOFEC) in Hybrid Mode wl Syngas

$800^{\circ} \mathrm{C}$, AN: wet syngas; CA1: air; CA2: $\mathrm{H}_{2} \mathrm{O} ; \mathrm{U}_{\mathrm{f}} / \mathrm{U}_{\text {air }} / \mathrm{U}_{\text {steam }}=40 / 40 / 40$

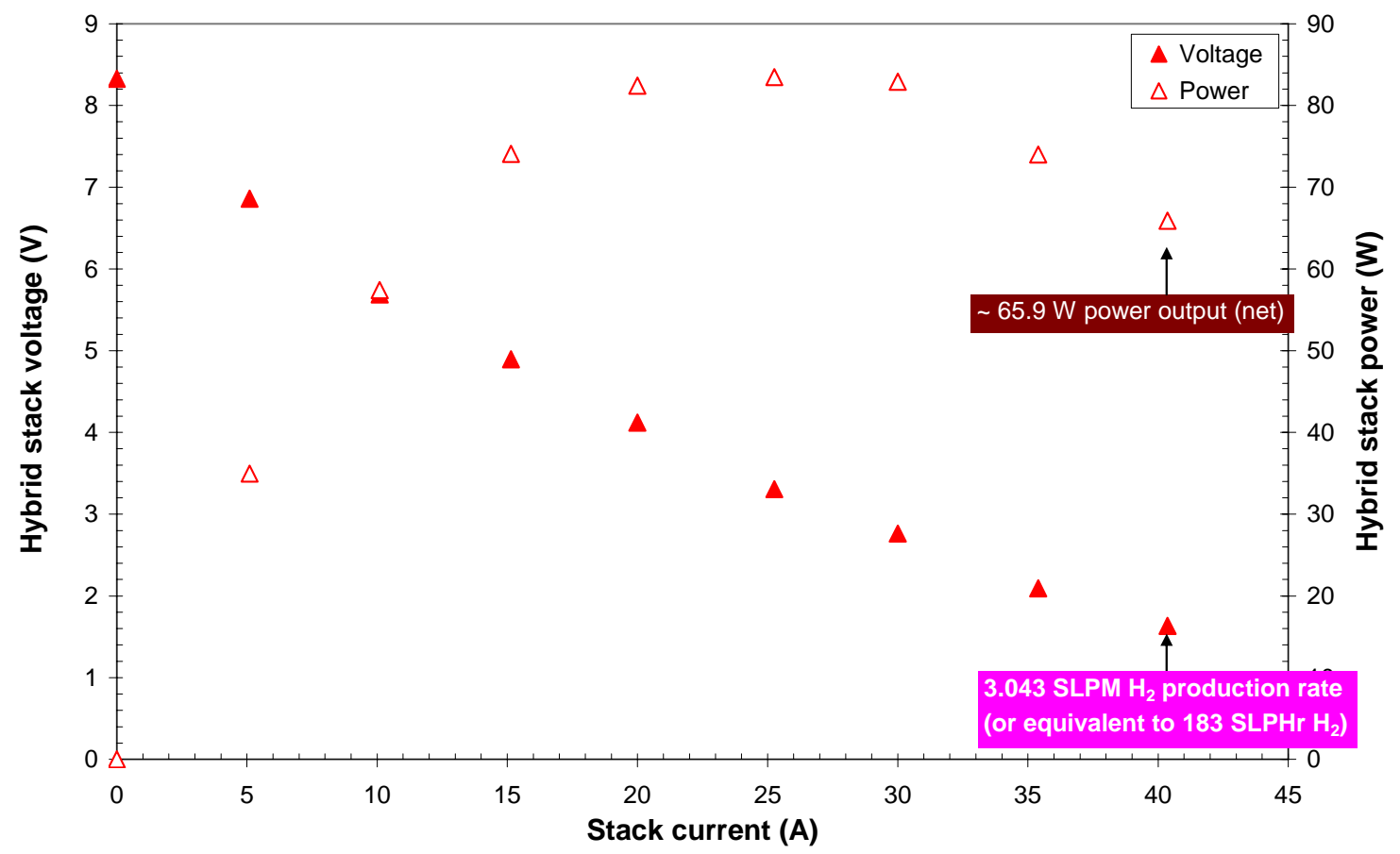

Figure 86. A 17-cell hybrid stack performance in the hybrid mode: 10-SOFECs were in the SOFEC mode to produce hydrogen directly from the steam on the cathode; simultaneously 7-SOFCs were in the SOFC mode to generate electric power to drive SOFECs directly.

Following the baseline test, the 17-cell stack was operated in the hybrid mode under an electrically self-sustaining condition, meaning no external power source is required to electrolyze the steam. In this mode, the 10-SOFECs solely produced hydrogen from the cathode steam while the 7-SOFCs generated electricity from the same anode fuel. Figure 86 presents the hybrid stack overall performance at $800^{\circ} \mathrm{C}$. Wet syngas was fed to the anode sides of SOFECs and SOFCs simultaneously at the fixed $40 \%$ utilization. Air was fed to the cathode side of the 7 SOFCs, and steam was fed to the cathode side of the 10-SOFECs. Both air and steam utilizations were set to $40 \%$. The power generated from 7-SOFCs was partially applied to the 10 -SOFECs directly to increase hydrogen production rate. The remainder was outputted to an electronic load. As shown in the figure, at $40 \mathrm{~A}$, this hybrid generated a net power $65.9 \mathrm{~W}$, and produced 3.043 SLPM hydrogen (equivalent to 183 SLPH hydrogen) simultaneously. Figure 87 is the performance breakdown for the 7-SOFCs vs. 10-SOFECs. At the same current (i.e. 40 A), the 7-SOFCs generated $179 \mathrm{~W}$ electrical power, of which $113 \mathrm{~W}$ was consumed by the 10SOFECs for hydrogen production. 
Performance of A Hybrid Stack (7-SOFC + 10-SOFEC) in Hybrid Mode wl syngas $800^{\circ} \mathrm{C}$, AN: various fuels; CA1: air; $\mathrm{CA} 2: \mathrm{H}_{2} \mathrm{O} ; \mathrm{U}_{\mathrm{f}} / \mathrm{U}_{\text {air }} / \mathrm{U}_{\text {steam }}=40 / 40 / 40$

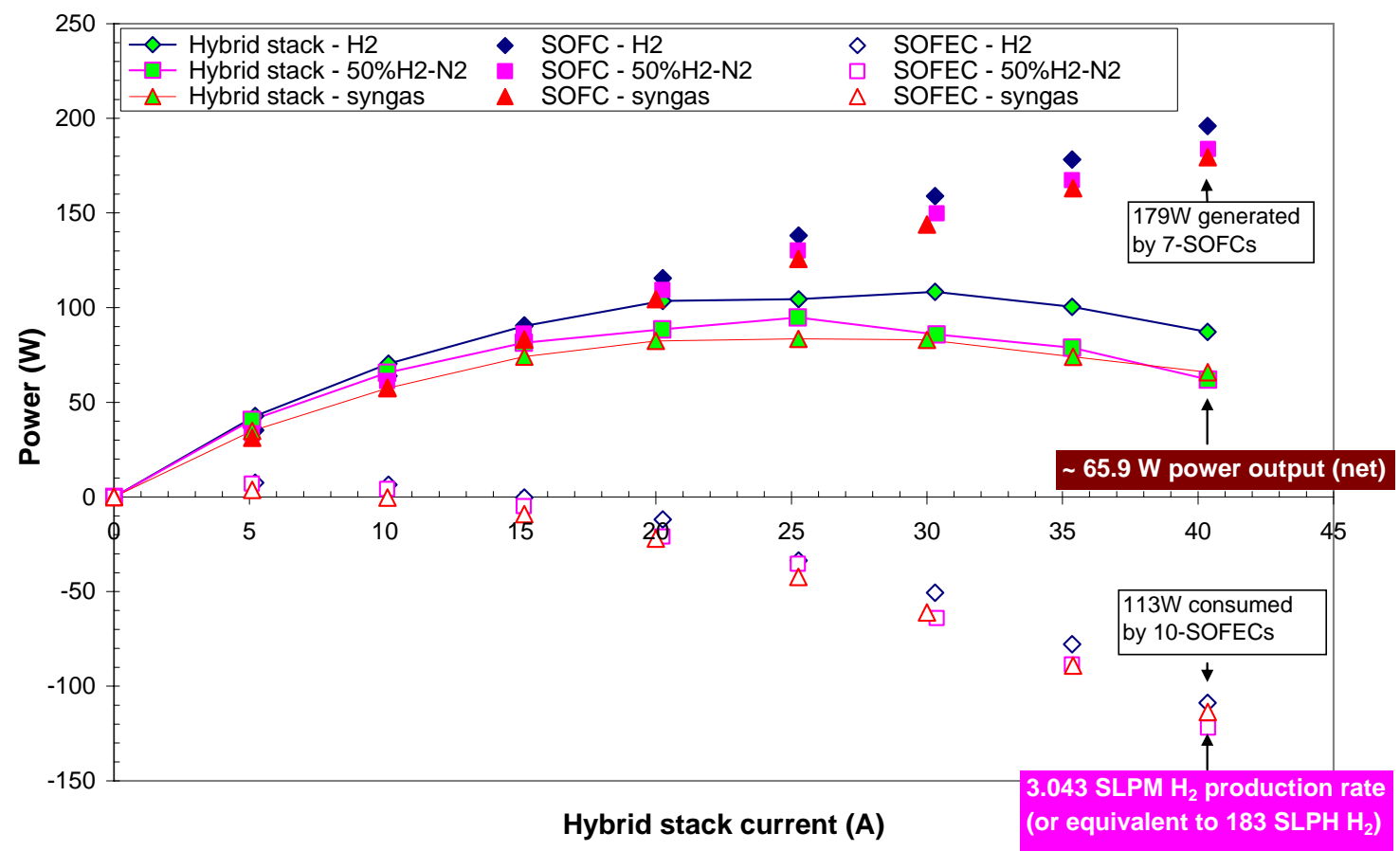

Figure 87. Performance of a 17-cell hybrid stack and the breakdown for 10-SOFECs and 7-SOFCs.

Pure hydrogen and diluted hydrogen with nitrogen were also tested, and the performances are shown in the Figure 87, and are readily compared to the syngas results. As is usual, the stack performance was higher using hydrogen than other types of fuels. At $40 \mathrm{~A}$, the hybrid stack generated $87 \mathrm{~W}$ power for the hydrogen fuel, comparing to $65.9 \mathrm{~W}$ power for the syngas fuel.

Effects of fuel/air/steam utilizations on stack performance in the hybrid mode were investigated by increasing the fuel/oxidants (both air and steam) utilizations from $40 \%$ to $60 \%$. The test results of the 17-cell hybrid stack, and breakdowns of the 10-SOFECs and 7-SOFCs, are shown in Figure 88 for the syngas fuel at different utilizations. When the utilizations increased from $40 \%$ to $60 \%$, at $40 \mathrm{~A}$, the hybrid net power output decreased from $65.9 \mathrm{~W}$ to $29.5 \mathrm{~W}$, a $55 \%$ drop. Among the $36.4 \mathrm{~W}$ power drop due to high utilizations, $14.5 \mathrm{~W}$ was from the SOFCs while $21.9 \mathrm{~W}$ was from the SOFECs. It indicates that the steam may have low activity on the cathode. This observation is consistent with what was observed in short SOFEC stacks tests performed in Task 7. Further investigation will be needed to improve the steam characteristics on the LSCM-based cathode. 
Performance of A Hybrid Stack (7-SOFC + 10-SOFEC) in Hybrid Mode wl syngas $800^{\circ} \mathrm{C}$; AN: wet syngas; CA1: air; CA2: $\mathrm{H}_{2} \mathrm{O} ; \mathrm{U}_{\mathrm{f}} / \mathrm{U}_{\text {air }} / \mathrm{U}_{\text {steam }} @$ various utilizations

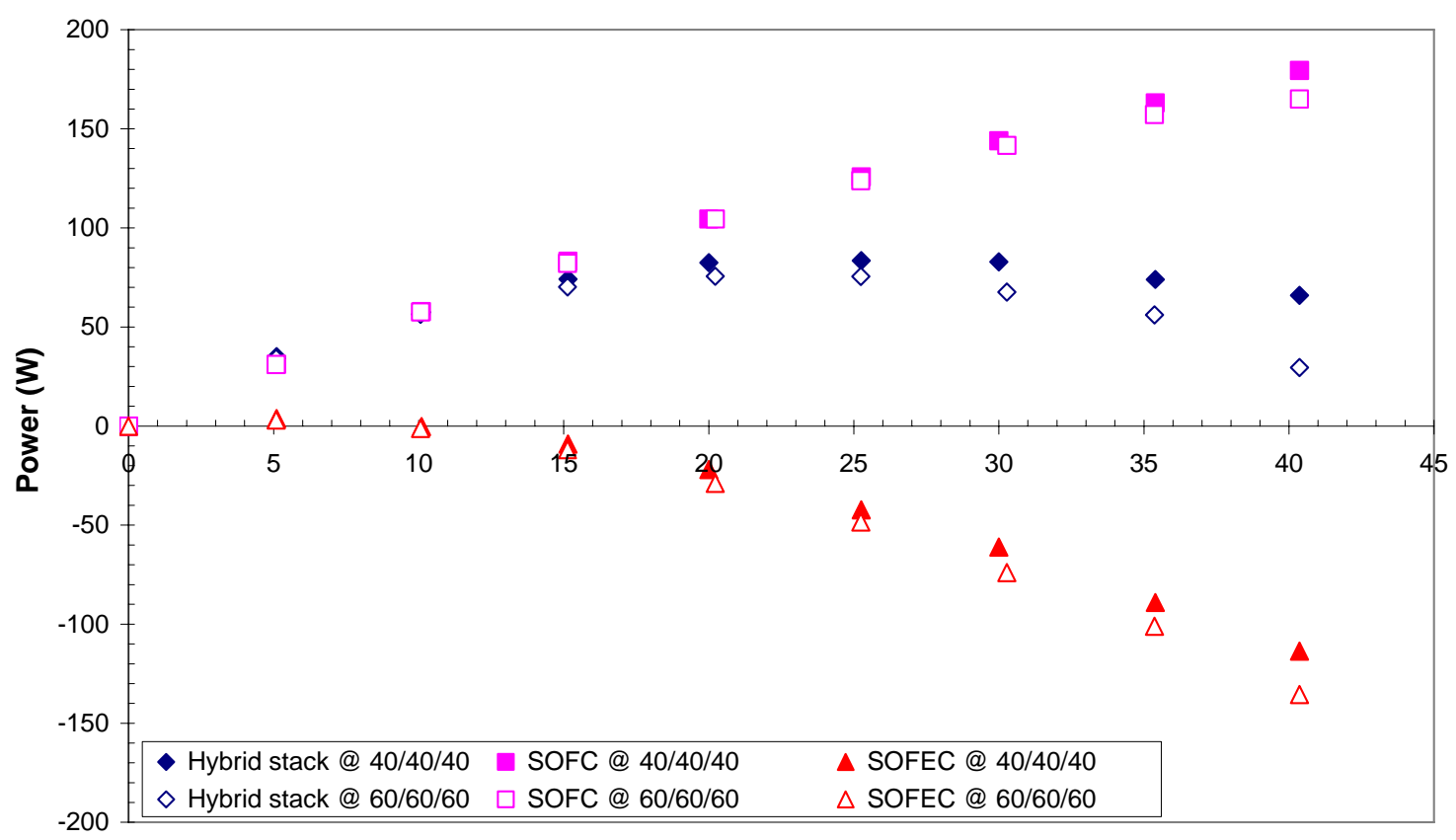

Hybrid stack current (A)

Figure 88. Effects of fuel and oxidant utilizations on the hybrid performance. Wet syngas was the fuel for both SOFECs and SOFCs. Air and steam were the oxidants for the SOFCs and SOFECs, respectively.

Using the results of the aforementioned 17-cell hybrid stack development, stacks at a $1 \mathrm{~kW}$ scale were constructed and evaluated in the co-generation mode to achieve the proposed project goal. With a similar ratio of SOFCs to SOFECs as the previous 17-cell stack, a hybrid having 20 LSCM-based SOFECs and 13 LSCF-based SOFCs was assembled. Both the SOFCs and SOFECs were anode supported-cells using the pore former Type A. The per-cell active areas of both SOFECs and SOFCs were $100 \mathrm{~cm}^{2}$. Construction of the $1 \mathrm{~kW}$ class stack was similar to the 17-cell hybrid stack, except that two thermocouples were embedded on the cathode sides of SOFECs to trace the stack temperature profile during testing. Figure 89 shows the hybrid stack assembly before testing. The bottom half of the hybrid stack was comprised of 20 glass-sealed SOFECs while the top had 13 SOFCs cells with compliant seals. Voltage leads were attached to each cell to monitor the cell voltage during testing. The stack height was near 5" before preconditioning, and shrank to 4" after heatup because of burning away the binder and solvent from the glass gaskets. The final dimension of this $1 \mathrm{~kW}$ class stack was 5.5 "x 5.5" 4 4". 


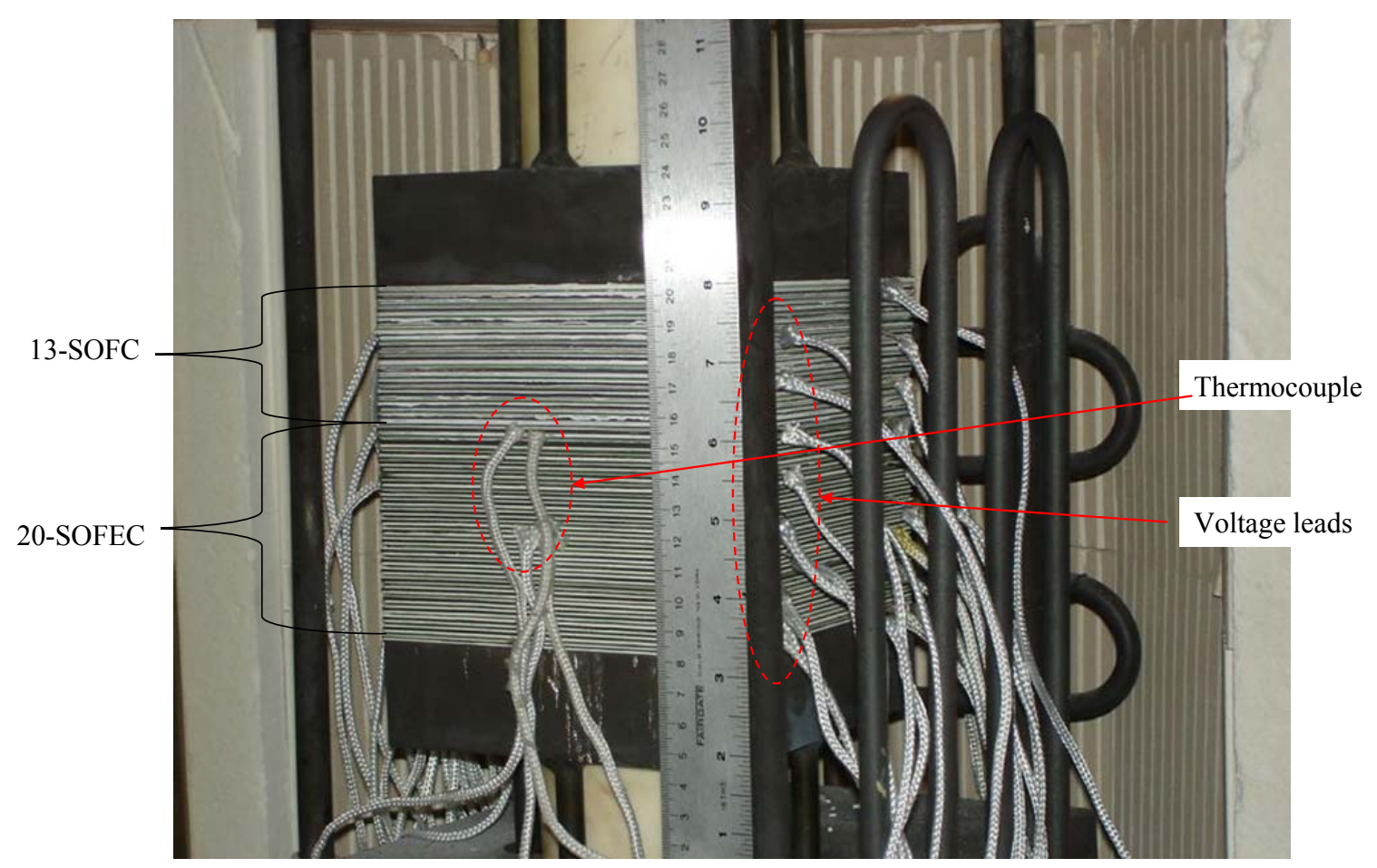

Figure 89. A 33 -cell $1 \mathrm{~kW}$ class hybrid stack assembly before testing

Performance of A kW Class Hybrid Stack (13-SOFC + 20-SOFEC) in SOFC Mode Stack Performance vs. SOFCs \& SOFECs

Furnace temperature $750^{\circ} \mathrm{C}, 50 \% \mathrm{H}_{2}+\mathrm{N}_{2}, \mathrm{U}_{\mathrm{f}} / \mathrm{U}_{\text {air }}=40 / 40$

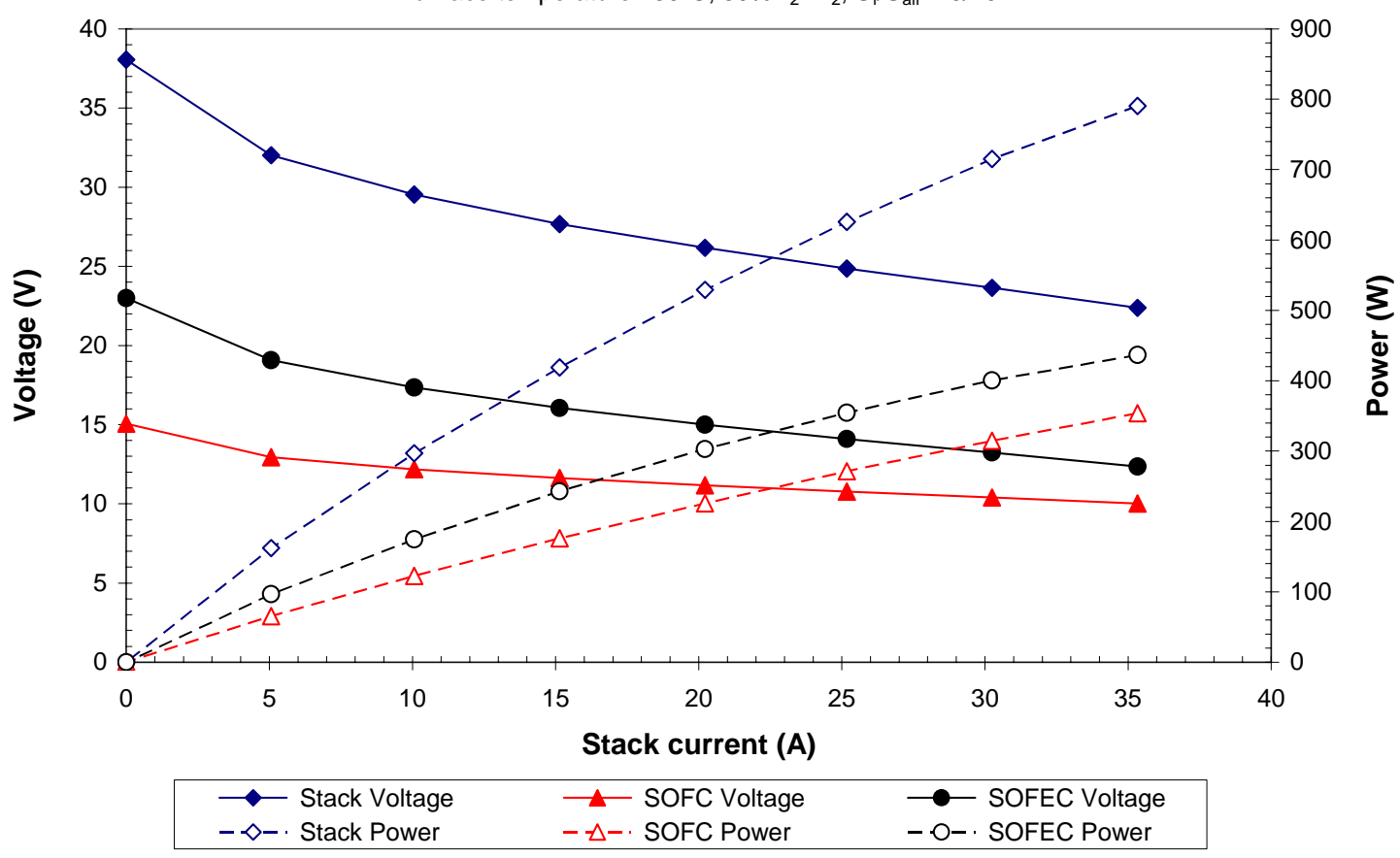

Figure 90. A $1 \mathrm{~kW}$ class hybrid stack baseline test in the SOFC mode at a furnace temperature of $750^{\circ} \mathrm{C}$. The hybrid was comprised of 20 SOFECs and 13 SOFCs. Diluted hydrogen with $50 \% \mathrm{~N}_{2}$ was used as the fuel for both the SOFCs and SOFECs. Utilizations of the fuel and air were fixed at $40 \%$. 
Following the same procedure developed for stack testing, SOFC baseline tests were first performed with a diluted hydrogen fuel $\left(50 \% \mathrm{H}_{2}-50 \% \mathrm{~N}_{2}\right)$ and a wet syngas fuel. In order to prevent the stack from overheating and constrain the stack temperature close to $800^{\circ} \mathrm{C}$ during discharge, the furnace temperature was adjusted to $750^{\circ} \mathrm{C}$. Figure 90 is the baseline test results, showing that at $35 \mathrm{~A}$, the hybrid stack generated net power of $791 \mathrm{~W}$, of which $437 \mathrm{~W}$ was generated by the 20 SOFECs while $354 \mathrm{~W}$ was generated by the 13 SOFCs. Both the fuel and air utilizations were fixed at $40 \%$.

Figure 91 presents the performance comparison for two types of fuels (diluted hydrogen and wet syngas) used for the baseline tests. The utilizations of both fuels were fixed at $40 \%$. At the furnace temperature of $750^{\circ} \mathrm{C}$, the hybrid stack net power generated $791 \mathrm{~W}$ and $768 \mathrm{~W}$ for the diluted hydrogen fuel $\left(50 \% \mathrm{H}_{2}-50 \% \mathrm{~N}_{2}\right)$ and the wet syngas (with $30 \%$ steam), respectively, at 35 A. A relatively lower OCV was observed for the wet syngas fuel than that for the dilute hydrogen fuel. This is due to a low flow rate of syngas and extra steam presented on the anode. Nevertheless, the hybrid performance was not affected.

Performance of A kW Class Hybrid Stack (13-SOFC + 20-SOFEC) in SOFC Mode furnace temperature $750^{\circ} \mathrm{C}$, various fuels, $\mathrm{U}_{f} / \mathrm{U}_{\text {air }}=40 / 40$

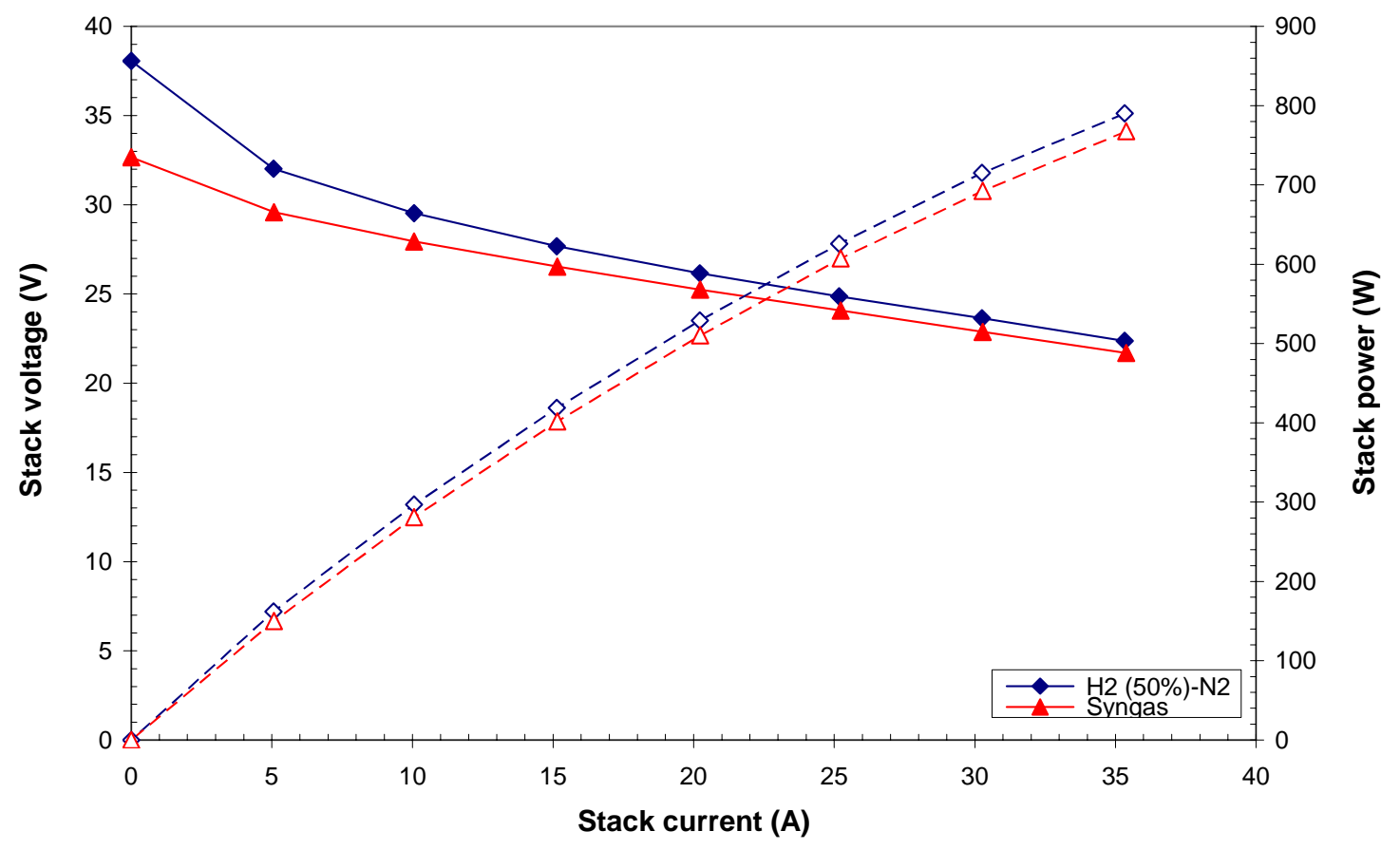

Figure 91. The performance comparison of the 33-cell hybrid stack baseline tests using two different fuels: a mixture of $\mathrm{H}_{2}(50 \%)$ with $\mathrm{N}_{2}$ and wet syngas (30\% steam). The utilizations of both the fuel and air were fixed at $40 \%$. The furnace temperature was set to $750^{\circ} \mathrm{C}$. 


\section{Performance of A kW Class Hybrid Stack (13-SOFC + 20-SOFEC) in Hybrid Mode wl syngas_assist}

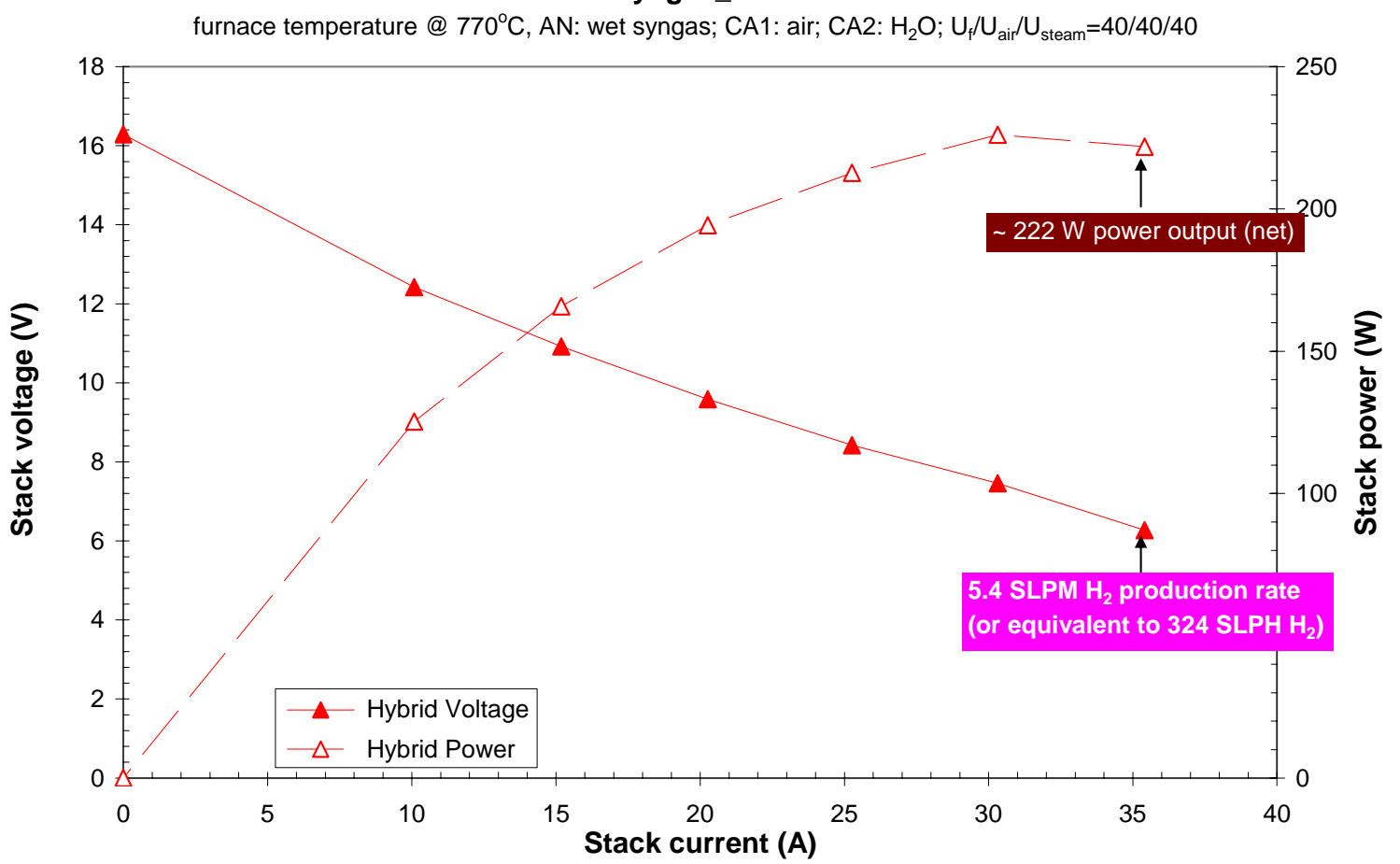

Figure 92. A 33-cell stack performance in the hybrid mode to co-generate hydrogen and electricity: 20 SOFECs were in the syngas-assisted electrolyzer mode, and 13 SOFCs were in the SOFC mode to drive electrolyzers. The furnace temperature was $770^{\circ} \mathrm{C}$.

Following the miscellaneous baseline tests, the 33-cell stack was evaluated in the hybrid mode to co-generate both hydrogen and electricity, again under the electrically self-driven condition without external power sources to electrolyze steam. Figure 92 shows the hybrid stack performance at a furnace temperature of $770^{\circ} \mathrm{C}$, a temperature chosen to maintain the hybrid stack at $800^{\circ} \mathrm{C}$. Wet syngas (with $30 \%$ steam) was fed to the anodes of SOFCs and SOFECs simultaneously at the fixed $40 \%$ utilization. Air was fed to the cathodes of the 13 SOFCs, and steam was fed to the cathodes of the 20 SOFECs. Both air and steam utilizations were set to $40 \%$. The power generated from the 13 SOFCs was directly applied to the 20 SOFECs through the interconnects, allowing the hydrogen to be produced from the steam. Depending on the power consumption of the SOFECs, any unused power can be output as a product for other applications. As shown in the figure, at $35 \mathrm{~A}$, this hybrid generated a net power of $222 \mathrm{~W}$, and produced 5.4 SLPM hydrogen (or equivalent to 324 SLPH hydrogen) simultaneously. Figure 93 is the power breakdown for the SOFCs and SOFECs. At $35 \mathrm{~A}$, the 13 SOFCs generated $346 \mathrm{~W}$ of electrical power, $125 \mathrm{~W}$ of this was used to drive steam electrolysis of the 20 SOFECs. At 30 A (or 4.6 SLPM hydrogen production rate), the hybrid stack reached the maximum net power output at $226 \mathrm{~W}$. Projecting the plot to higher current densities, it would seem that the hybrid can make the maximum hydrogen production around $60 \sim 75 \mathrm{~A}$ with zero net power output, which is equivalent to $550 \sim 690 \mathrm{SLPH}$ of hydrogen production. Therefore, with the flexibility of the hybrid stack, the cogeneration capacity can be adjusted for maximizing either the power generation or hydrogen production to meet market demand. Meanwhile, the hybrid also provides significant electricity savings over the traditional electrolysis technology to produce hydrogen. 
For example, at the same hydrogen production rate of 5.4 SLPM, the minimum electrical power requirement is about $770 \mathrm{~W}$ for a conventional electrolyzer with 20 SOECs without counting any losses introduced from ohmic losses, concentration and activation overpotentials. As a comparison, the power requirement is only $125 \mathrm{~W}$, or $16 \%$ of $770 \mathrm{~W}$, for applying the SOFEC technology at the same hydrogen production rate. It can be projected that a $\mathrm{kW}$ class hybrid is capable of co-generating $0.545 \mathrm{~kg}$ hydrogen and $3.43 \mathrm{kWhr}$ electricity per day.

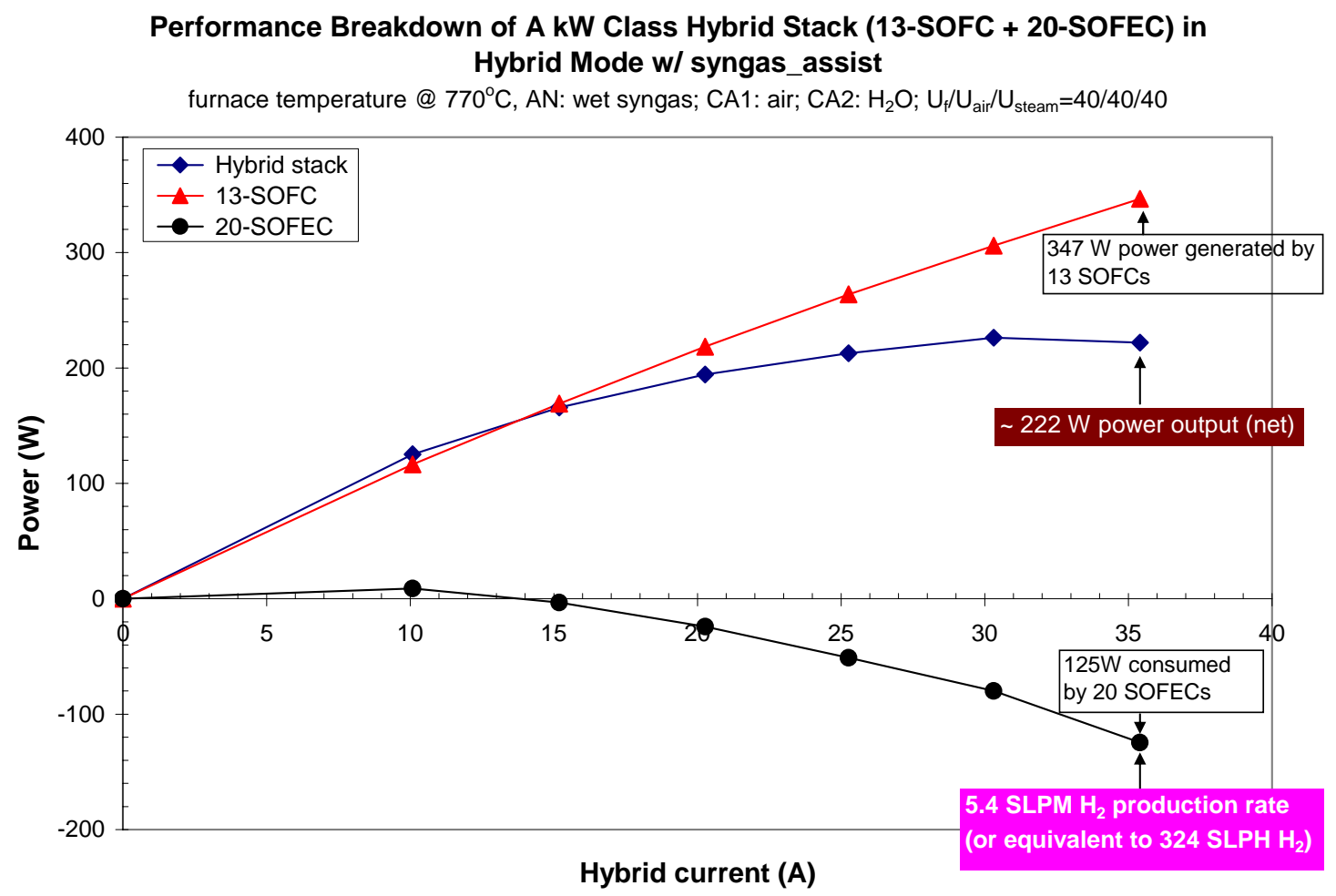

Figure 93. A 33-cell hybrid stack power performance breakdown for the 20 SOFECs and 13 SOFCs.

Figure 94 shows the temperature profiles recorded for the stack during testing in the cogeneration mode. The stack temperatures were presented as Stack Tc-1 and Tc-2, which were located in two adjacent SOFECs: Cell \#10 and Cell \#11. These two thermocouples were in the middle of SOFECs stack, which is typically highest temperature location. As can be seen from the figure, at $35 \mathrm{~A}$, the stack temperature increased by $15^{\circ} \mathrm{C}$. The furnace temperature was kept at $770^{\circ} \mathrm{C}$. Both the steam and fuel inlet temperatures were also recorded for the SOFECs. The steam inlet temperature and the fuel inlet temperature were $606^{\circ} \mathrm{C}$ and $735^{\circ} \mathrm{C}$, respectively, which were significantly lower than the stack temperature and the furnace temperature $\left(770^{\circ} \mathrm{C}\right)$ as well. Such low gaseous inlet temperatures may introduce under-heating effects on the first couple cells adjacent to the inlet gases, leading to lower performance compared to cells distanced from the inlet gases. Better thermal management would be preferred when designing a system to efficiently co-generate hydrogen and electricity. 


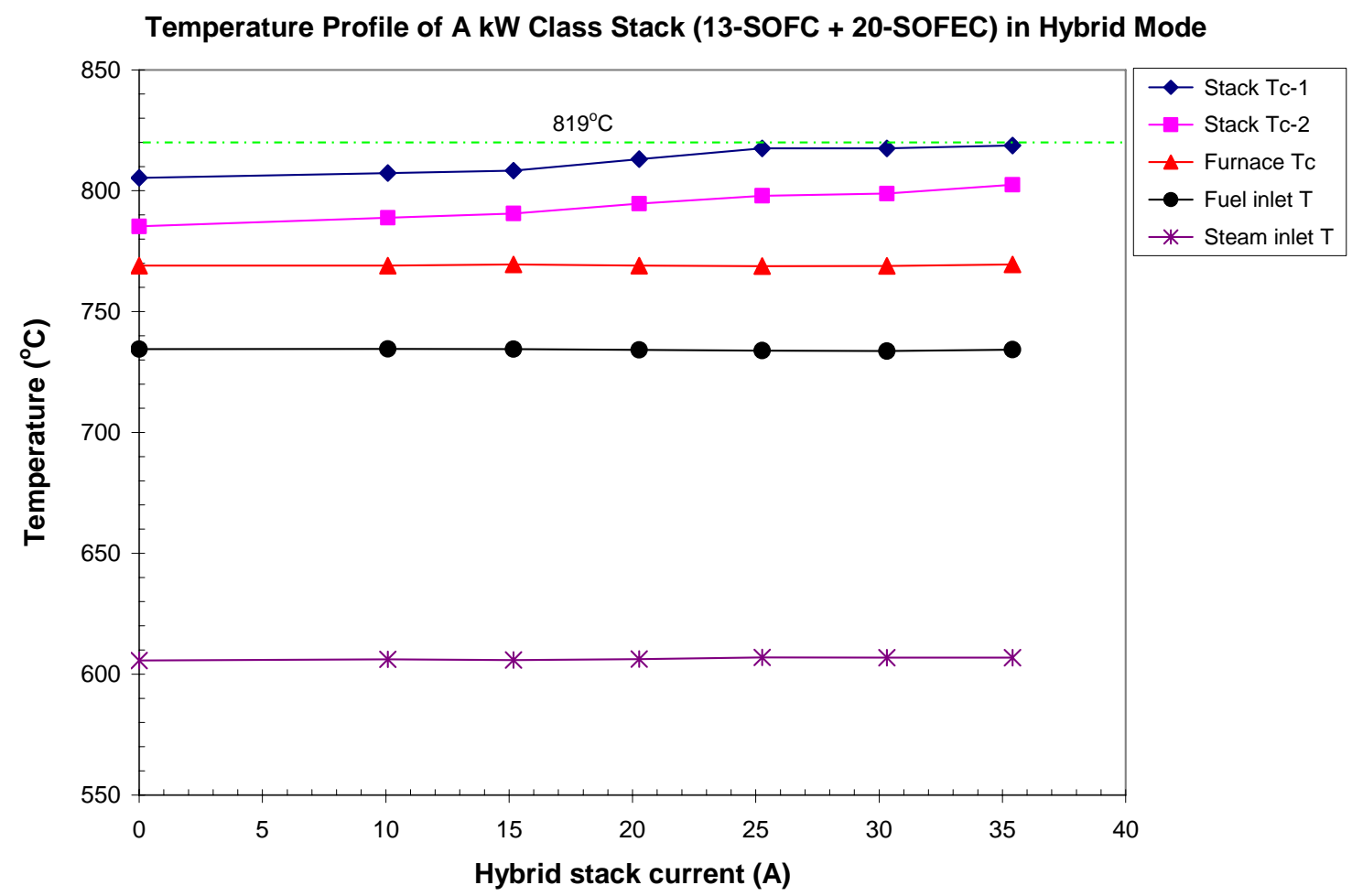

Figure 94. Stack temperature profiles as a function of the current in the hybrid mode: the stack temperatures, fuel and air inlet temperatures, and the furnace temperature.

After the aforementioned tests, the hybrid stack was operated under a constant current load (i.e. 30A) for a continuous hydrogen/electricity co-generation. Figure 95 presents the results of a continuous 72-hour test, including a 52-hour co-generation and 20-hour maintenance under OCV conditions. Again, wet syngas was used as the fuel assist on the anode of SOFECs. Steam was fed to the SOFEC cathode. SOFCs were operated with the same fuel fed to the anode, but air was supplied to the cathode. The utilizations of the fuel and steam were fixed at $50 \%$ and $40 \%$, respectively. The air utilization for the SOFCs started from $60 \%$, but was reduced to $50 \%$ after the first 50 hours of operation. The furnace temperature was maintained at $780^{\circ} \mathrm{C}$. As shown in the figure, over the total 52 hours continuous co-generation test, the 20-SOFECs demonstrated very stable performance showing no performance degradation. An average voltage per SOFECs was about $-0.22 \mathrm{~V}$. On the other hand, the 13-SOFCs experienced a performance drop in the first 50 hours test. In order to maintain the voltage of each SOFCs above $0.7 \mathrm{~V}$, the air utilization was reduced from initial $60 \%$ to $50 \%$. However, the test was terminated after another 22 hours due to the loss of the SOFC cell right adjacent to the SOFECs. After the test, a postmortem analysis was performed, and a delamination of electrolyte layer was observed on the SOFC cell.

During the test, a Horiba STEC film flow meter was used to measure the hydrogen production rate. The measured value was consistent with the theoretical value calculated from mass and electron conservation. Besides the quantification of the hydrogen production rate, the purity of the gas produced from the SOFECs was also verified by repeated sampling of the cathode exhaust from the SOFECs by the GC. The GC measurement showed that the product was $99.1 \%$ 
$\mathrm{H}_{2}$ and the remainder being contamination, primarily $\mathrm{CO}$. The contamination could be caused by a diffusion leak from the anode side through edges of the anode supports. Further investigation is necessary to produce pure hydrogen through SOFECs seal improvement, though this task is beyond the working scope of this program. Approaches may include the development of new sealing materials which better match the CTEs of the electrodes and interconnects, and reducing the gas diffusion effects in the edges of porous anodes. Improvement efforts are already under way on another project.

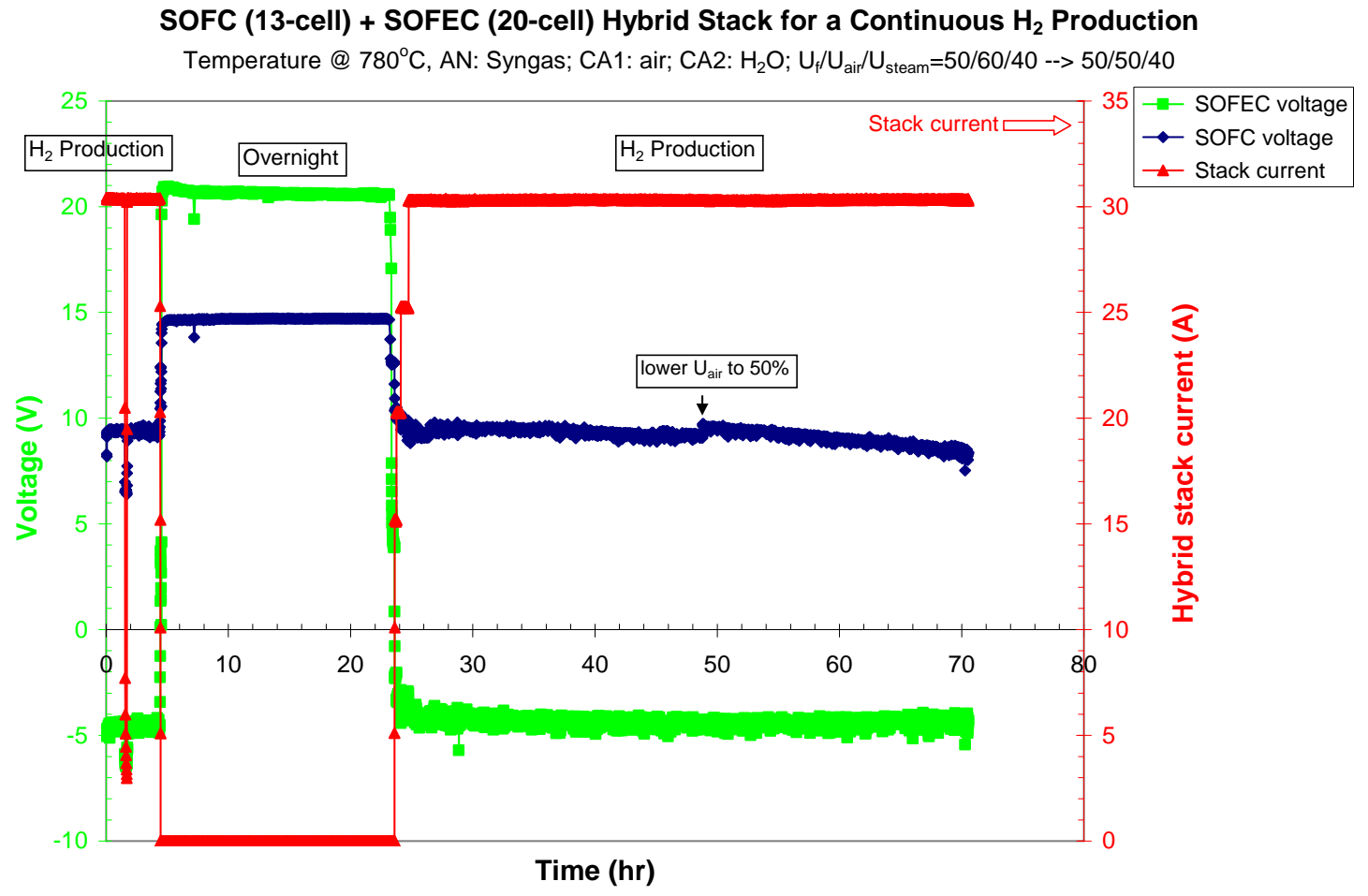

Figure 95. Hybrid stack tests for a continuous hydrogen/electricity co-generation. Wet syngas was the fuel for the hybrid. Steam and air were on the cathode of the SOFECs and SOFCs, respectively. The utilizations of fuel and steam were fixed at $50 \%$ and $40 \%$, respectively, while the air utilization reduced from initial $60 \%$ to $50 \%$ after the first 50 hours test.

\section{Task $10 \quad$ Reporting}

All the quarterly reports, the annual reports, and the final report were completed and submitted as required.

\section{Appendix}

A1

Figure Captions

Figure 1. LSCM using ethylene glycol before sonication (a) and after sonication (b)

Figure 2. XRD patterns of the as-prepared LSCM and the smashed LSCM powders 
Figure 3. Optical micrographs of LSCM powders (a) as-prepared; (b) after milling with a tungsten ball in a vial

Figure 4. Electrical conductivity of LSCr as a function of temperatures and oxygen activities Figure 5. The conductivities of LSCr, LSM, and LSCM as a function of oxygen activity at $800^{\circ} \mathrm{C}$

Figure 6. Electrical conductivity of LSM as a function of oxygen activity and temperature

Figure 7. XRD of LSM quenched in Air, $90 \% \mathrm{CO}-10 \% \mathrm{CO}_{2}$, and treated in $90 \% \mathrm{CO}-10 \% \mathrm{CO}_{2}$ followed by in air at $800^{\circ} \mathrm{C}$

Figure 8. Redox stability test of LSCr as a function of oxygen activity at $800^{\circ} \mathrm{C}$

Figure 9. Electrical conductivity of LSCM as a function of oxygen activity and temperature

Figure 10. The impedance spectra of LSCM symmetrical cells with (a) Ag as the current collector and (b) Pt as the current collector during the symmetrical cell tests

Figure 11. Impedance spectroscopy of a symmetric cell with both LSCM electrodes in air atmosphere at $800^{\circ} \mathrm{C}$ (electrode area $=0.3 \mathrm{~cm}^{2}$ )

Figure 12. Impedance spectroscopy of a symmetric cell with LSCM electrodes in air atmosphere on one side and wet $10 \% \mathrm{H}_{2}$ on the other side at $800^{\circ} \mathrm{C}$ (electrode area $=0.3 \mathrm{~cm}^{2}$ )

Figure 13. Long-term stability test of LSCM electrodes using short-circuit current density measurement in $3 \% \mathrm{H}_{2} \mathrm{O}-10 \% \mathrm{H}_{2}$-balance $\mathrm{N}_{2}$ gas mixture at $800^{\circ} \mathrm{C}$

Figure 14. Impedance spectroscopy of LSCM electrodes for the fuel cell test in air and wet $10 \% \mathrm{H}_{2}$ - balance $\mathrm{N}_{2}$ at $800^{\circ} \mathrm{C}$ (electrode area $=0.3 \mathrm{~cm}^{2}$ )

Figure 15. Impedance spectroscopy of LSCM for the fuel cell test in air, wet hydrogen $\left(3 \% \mathrm{H}_{2} \mathrm{O}\right.$ $-10 \% \mathrm{H}_{2}$-balanced with $90 \% \mathrm{~N}_{2}$ ) and $50 \% \mathrm{CO}-50 \% \mathrm{CO}_{2}$ at $800^{\circ} \mathrm{C}$ (surface area $=0.3 \mathrm{~cm}^{2}$ )

Figure 16. Current vs. voltage characteristics of a cell with LSCM electrodes in air on one side and in wet hydrogen $\left(3 \% \mathrm{H}_{2} \mathrm{O}-10 \% \mathrm{H}_{2}\right.$-balanced $\left.90 \% \mathrm{~N}_{2}\right)$ or $50 \% \mathrm{CO}-50 \% \mathrm{CO}_{2}$ on the other side at $800^{\circ} \mathrm{C}$

Figure 17. Gas species distributions along the anode and cathode chambers for a SOFC cell operated at $0.7 \mathrm{~V}$ with air and fuel utilizations at $40 \%$ and $70 \%$, respectively. All species are assumed to be at equilibrium at $800^{\circ} \mathrm{C}$.

Figure 18. Variation of oxygen partial pressures in the anode and cathode chambers along the length of the SOFC at a cell voltage of $0.7 \mathrm{~V}$

Figure 19. Nernst potential, activation overpotential, and current density at $0.7 \mathrm{~V}$ along the length of the SOFC

Figure 20. A polarization curve for a reversible cell operated in the SOFC mode on methane steam reformate at $\mathrm{U}_{\text {Fuel }} / \mathrm{U}_{\mathrm{Air}}=70 \% / 40 \%$ and $\mathrm{T}=800^{\circ} \mathrm{C}$

Figure 21. Gas species distributions along the anode and cathode chambers for a SOFEC cell operating at $-0.4 \mathrm{~V}$ with steam and fuel utilizations at $40 \%$ and $70 \%$, respectively. All species are assumed to be in equilibrium at $800^{\circ} \mathrm{C}$. 
Figure 22. Variation of oxygen partial pressures in the anode and cathode chambers along the length of the SOFEC. The cell voltage is $-0.4 \mathrm{~V}$.

Figure 23. Nernst potential, activation overpotential, and current density at $-0.4 \mathrm{~V}$ along the length of the SOFEC.

Figure 24. A simulated polarization curve for a reversible SOFC/SOFEC operated in the SOFEC mode on methane steam reformate at $\mathrm{U}_{\text {Fuel }} / \mathrm{U}_{\text {Steam }}=70 \% / 40 \%$ and $\mathrm{T}=800^{\circ} \mathrm{C}$.

Figure 25. Predicted daily hydrogen production rate for the hybrid stack as a function of discharge current and stack configuration.

Figure 26. Predicted electrical power output for the hybrid stack as a function of discharge current and stack configuration

Figure 27. Process flow chart for a hybrid SOFEC-SOFC system to produce hydrogen under an electrically self-sustaining condition

Figure 28. Variation in the contributing factors to the cost of hydrogen production using MSRI's hybrid SOFEC-SOFC technology as a function of the stack configuration.

Figure 29. In-stack cell performance gains expressed in terms of the cost of hydrogen production computed using the previously described model

Figure 30. Old (Top) and new (Bottom) compliant-hermetic seal for the composite/hybrid SOFEC-SOFC stack.

Figure 31. A SEM micrograph of an anode substrate after reduction. This anode substrate used Type A pore former.

Figure 32. A SEM micrograph of an anode substrate after reduction. This anode substrate used Type B pore former.

Figure 33. A photograph of an internal manifolded 2"x2" cell with $30 \mathrm{~cm}^{2}$ active area

Figure 34. A photograph of an internal manifolded 4"x4" cell with $100 \mathrm{~cm}^{2}$ active area

Figure 35. A SEM micrograph of a typical SOFC cell after test. Five distinctive layers are clearly presented in the photo.

Figure 36. Diagram of a test fixture setup for the SOFC/SOEC/SOFEC testing

Figure 37. Picture of the modified test rig, capable of operating in the SOFC, SOEC, and SOFEC modes

Figure 38. Parametric studies of the LSCM-based CIL and CL. All results were obtained in the SOFC mode at $800^{\circ} \mathrm{C}$.

Figure 39. A SEM micrograph of an anode supported button cell with the LSCM-based cathode

Figure 40. Performance of a button cell tested in the SOFC mode at $800^{\circ} \mathrm{C}$. Hydrogen, syngas with $27 \%$ humidity, or methane with $50 \%$ of humidity was the fuel; dry air was the oxidant.

Figure 41. Current density vs. cell voltage curve of a button cell tested at $800^{\circ} \mathrm{C}$ in the SOFEC mode. A mixture of steam (10\%) with hydrogen, steam (27\%) with syngas, or steam (50\%) with methane was the fuel; and a mixture of steam $(90 \%)$ and hydrogen (carry gas) was an oxidant. 
Figure 42. Current density vs. power density curve of a button cell tested at $800^{\circ} \mathrm{C}$ in SOFEC mode. A mixture of steam (10\%) with hydrogen, steam $(27 \%)$ with syngas, or steam $(50 \%)$ with methane was the fuel; a mixture of steam (90\%) and hydrogen (carry gas) was an oxidant.

Figure 43. Performance comparison operated at $800^{\circ} \mathrm{C}$ in the SOFC and SOFEC modes. Mixture of steam (10\%) with hydrogen, steam (27\%) with syngas, or steam $(50 \%)$ with methane was used as the fuel. Either a dry air was used as the oxidant in the SOFC mode, or a mixture of steam $(90 \%)$ with hydrogen was used as an oxidant in the SOFEC mode.

Figure 44. A typical performance of a button cell, tested at $800^{\circ} \mathrm{C}$ in the SOFC mode as a baseline test. Cathode was the LSCM+SDC composite with Pd infiltration. Hydrogen, a mixture of steam $(27 \%)$ with syngas, or steam $(50 \%)$ with methane was the fuel; and air was the oxidant.

Figure 45. Reversible SOFC/SOEC tests. In the SOFC mode, mixtures of $\mathrm{H}_{2}$ and steam were the anode gas, while dry air was the cathode gas. In the SOEC mode, mixtures of $\mathrm{H}_{2}$ and steam were the cathode gas, while dry air was the anode gas. The steam composition on the anode varied from $10 \%$ to $90 \%$.

Figure 46. LSCM-based cathode optimizations. Button cells were tested at $800^{\circ} \mathrm{C}$ in the SOFEC mode. Unfilled symbols represent the button cell with LSCM cathode only, while the filled symbols are the button cell with LSCM cathode infiltrated with Pd. A mixture of steam (10\%) with hydrogen, steam (27\%) with syngas, or steam (50\%) with methane was the fuel; and a mixture of steam $(90 \%)$ as the oxidant with $10 \%$ hydrogen as a carrier gas.

Figure 47. Performance comparison operated at $800^{\circ} \mathrm{C}$ in the reversible SOFC, SOEC, and SOFEC modes. Button cell was made from MSRI standard tape. Cathode was the LSCM-based composite infiltrated with $\mathrm{Pd}$. In the $\mathrm{SOFC}$ mode, a mixture of steam $(50 \%)$ with $\mathrm{H}_{2}$, steam $(27 \%)$ with syngas, or steam $(50 \%)$ with $\mathrm{CH}_{4}$ was the on the anode, and air was on the cathode. In the SOEC mode, a mixture of steam (50\%) with $\mathrm{H}_{2}$ was on the cathode, and air was on the anode. In the SOFEC mode, a mixture of steam (50\%) with $\mathrm{H}_{2}$, steam $(27 \%)$ with syngas, or steam $(50 \%)$ with $\mathrm{CH}_{4}$ was the on the anode, and a mixture of steam $(90 \%)$ with $\mathrm{H}_{2}$ was on the cathode.

Figure 48. Performance of a button cell tested in the SOFC mode as the baseline at $800^{\circ} \mathrm{C}$. Cathode was the LSCM+SDC composite infiltrated w/ catalyst A. Hydrogen was the fuel; and air was the oxidant.

Figure 49. Performance of a button cell infiltrated with catalyst $\mathrm{A}$ and tested at $800^{\circ} \mathrm{C}$ in the SOFC mode. Cathode was the LSCM+SDC composite. Hydrogen, a mixture of steam (27\%) with syngas, or steam (50\%) with methane was the fuel; and air was the oxidant

Figure 50. Same cell operated in the SOEC mode to generate hydrogen from steam on the anode. A mixture of $\mathrm{H}_{2}$ and steam was fed to the anode, and dry air was fed to the cathode. The steam composition varied from $20 \%$ to $90 \%$.

Figure 51. Cell performance operated at $800^{\circ} \mathrm{C}$ in the SOFEC mode with three different types of fuel assisted on the anode. A mixture of steam (10\%) with hydrogen, steam (27\%) with syngas, or steam $(50 \%)$ with methane was the fuel; and a mixture of steam $(90 \%)$ with hydrogen was the oxidant.

Figure 52. Long-term degradation test in the $\mathrm{SOFC}$ mode at $800^{\circ} \mathrm{C}$. Hydrogen was the fuel and air was the oxidant. 
Figure 53. Current-voltage curves measured at different time

Figure 54. IR measurements at a scheduled time. The bars in different color show the normalized cell resistance-ASR (in periwinkle), ohmic resistance (in plum), activation overpotentials (in bright green), maximum power density (in light turquoise), and power density at cell voltage $0.7 \mathrm{~V}$ (in red).

Figure 55. Leak rate comparisons of different seals tested at different gas pressures. Leak rate tests were performed in helium atmosphere on the MSRI leak-test fixture.

Figure 56. "Invert" glass gasket leak-rate test

Figure 57. A flexible glass tape cast at MSRI facility

Figure 58. Cell performance comparisons of a 7-cell 2"x2" stack. The seven cells were constructed from the same batch of the anode substrate and screen-printed with the same cathode. Some cells were infiltrated with catalysts while others were not.

Figure 59. Burn-in test of a 2"x2" 2-cell stack running in the SOFC mode in two different days

Figure 60. Performance of a 2"x2" 2-cell stack tested at different utilizations of the fuel/oxidant

Figure 61. Performance comparisons of the 2"x2" 2-cell stack operated in the reversible SOFC/SOEC modes. In the SOFC mode, dry air was fed to the cathode, and a mixture of $\mathrm{H}_{2}$ and steam was fed to the anode. The steam composition on the anode varied from 0 to $70 \%$. Same gas compositions were used for the SOEC test, except that $90 \%$ steam with hydrogen was also test in the SOEC mode.

Figure 62. Performance characteristics of a 2"x2" 2-cell stack operated in the SOFEC mode with hydrogen assisted on the anode to generate hydrogen from the cathode steam. Wet hydrogen at various steam concentration was fed to the cathode. The steam composition varied from $40 \%$ to $70 \%$.

Figure 63. Performance comparisons of a 2"x2" 2-cell stack operated in the SOFEC mode with hydrogen-, syngas-, or $\mathrm{CH}_{4}$ - assisted on the anode to generate hydrogen from the cathode steam.

Figure 64. Stack performance comparisons in the reversible SOFC, SOEC, and SOFEC modes. In the SOFC mode, hydrogen, steam (27\%) with syngas, or steam $(50 \%)$ with $\mathrm{CH}_{4}$ was the on the anode, and air was on the cathode. In the SOEC mode, steam $(70 \%)$ carried with hydrogen was on the anode, and air was on the cathode. In the SOFEC mode, hydrogen, steam (27\%) with syngas, or steam $(50 \%)$ with $\mathrm{CH}_{4}$ was the on the anode, and steam $(70 \%)$ carried with hydrogen was on the cathode.

Figure 65. Flow rate measurement to quantify the hydrogen production rate on the cathode.

Figure 66. A 4"x4" 10-cell stack assembly ready for testing

Figure 67. Performance characteristics of a 4" 4 4" 5-cell stack baseline test at $800^{\circ} \mathrm{C}$ at different fuel utilizations. Wet Syngas (30\% steam) was the fuel and air was the oxidant. The syngas utilization increased from $50 \%$ to $80 \%$ at $10 \%$ each step.

Figure 68. Performance characteristics of a 4"x4" 5-cell stack operated in the SOFEC mode with hydrogen-assisted on the anode. Each cell had $100 \mathrm{~cm}^{2}$ active areas. Composition of the cathode steam varied from $50 \%$ to $90 \%$. 
Figure 69. Performance characteristics of a 4"x4" 5-cell stack operated in the SOFEC mode with hydrogen-, syngas-, or $\mathrm{CH}_{4}$ - assisted at the anode. The cathode gas was a mixture of steam $(90 \%)$ with hydrogen carry gas. The utilizations of both the cathode steam and anode fuel were fixed at $50 \%$.

Figure 70. Stack voltage-current characteristics comparisons obtained in the SOFC and the SOFEC modes at $800^{\circ} \mathrm{C}$. In the SOFC mode, hydrogen, a mixture of steam (27\%) with syngas, or a mixture of steam $(50 \%)$ with $\mathrm{CH}_{4}$ was fed to the anode, and air was fed to the cathode. In the SOFEC mode, the same fuel that was used in SOFC tests was used to feed the anode, and a mixture of steam $(90 \%)$ with hydrogen was fed to the cathode.

Figure 71. Stack power-current characteristics comparisons obtained in SOFC and SOFEC modes at $800^{\circ} \mathrm{C}$. Same operation conditions were used as what is shown in Figure 70.

Figure 72. Performance characteristics of a 4" $44^{\prime \prime} 5$-cell stack tested at $800^{\circ} \mathrm{C}$ at different utilizations. In this baseline test in SOFC mode, hydrogen and wet syngas (mixed with 30\% steam) were used as the fuels and air was the oxidant. Both the fuels and air utilizations were increased from $40 \%$ to $60 \%$.

Figure 73. Performance characteristics of a 4" 4 " 5-cell stack operated in the SOFEC mode assisted with either hydrogen or syngas flow on the anode to produce hydrogen from the cathode steam. Both fuels and steam utilizations varied from $40 \%$ to $60 \%$. Each cell had $100 \mathrm{~cm}^{2}$ active areas.

Figure 74. Projected power-current characteristics of a hybrid 10-cell stack comprised of 5 SOFCs and 5 SOFECs connected in series.

Figure 75. A 4"x4" 5-cell stack long-term test in the syngas-assisted SOFEC mode to produce hydrogen from the cathode steam. Each cell has $100 \mathrm{~cm}^{2}$ active areas. The syngas fuel utilization was fixed at $40 \%$, while the steam utilization was initially set to $60 \%$, but then lowered to $40 \%$.

Figure 76. A picture of a 4"x4" 10-cell stack after testing

Figure 77. A SEM micrograph of the button cell after a 5000 hours long-term test operated in the SOFC mode.

Figure 78. A SEM micrograph of the button cell showing the barrier layer and cathode functional layer. This cell was tested over 5000 hours in the SOFC mode.

Figure 79. EDAX spectrum of the highlighted area of the button cell shown in Figure 77.

Figure 80. A SEM micrograph of a 4"x4" cell after testing

Figure 81. EDAX spectrum of the highlighted area of the 4"X4" cell shown in Figure 80

Figure 82. 17-cell hybrid stack baseline test operated in SOFC mode. The hybrid was comprised of 10-SOFECs and 7-SOFCs connected in series. A fuel, which was $\mathrm{H}_{2}$, mixture of $\mathrm{H}_{2}(50 \%)$ and $\mathrm{N}_{2}$, or wet syngas (with $30 \%$ steam), was fed to the anode of SOFECs and SOFCs simultaneously. Air was the oxidant for both SOFECs and SOFCs.

Figure 83. Hybrid stack performance breakdown for the 7-SOFCs and 10-SOFECs

Figure 84. Fuel/air utilizations effects on the hybrid stack performance tested in SOFC mode 
Figure 85. SOFC performance comparisons between the 7-SOFCs and 10-SOFECs at various fuel and air utilizations. Both fuel and air utilizations increased from $40 \%$ to $60 \%$.

Figure 86. A 17-cell hybrid stack performance in the hybrid mode: 10-SOFECs were in the SOFEC mode to produce hydrogen directly from the steam on the cathode; simultaneously 7 SOFCs were in the SOFC mode to generate electric power to drive SOFECs directly.

Figure 87. Performance of a 17-cell hybrid stack and the breakdown for 10-SOFECs and 7SOFCs.

Figure 88. Effects of fuel and oxidant utilizations on the hybrid performance. Wet syngas was the fuel for both SOFECs and SOFCs. Air and steam were the oxidants for the SOFCs and SOFECs, respectively.

Figure 89. A 33-cell $1 \mathrm{~kW}$ class hybrid stack assembly before testing

Figure 90. A $1 \mathrm{~kW}$ class hybrid stack baseline test in the SOFC mode at a furnace temperature of $750^{\circ} \mathrm{C}$. The hybrid was comprised of 20 SOFECs and 13 SOFCs. Diluted hydrogen with 50\% $\mathrm{N}_{2}$ was used as the fuel for both the SOFCs and SOFECs. Utilizations of the fuel and air were fixed at $40 \%$.

Figure 91. The performance comparison of the 33-cell hybrid stack baseline tests using two different fuels: a mixture of $\mathrm{H}_{2}(50 \%)$ with $\mathrm{N}_{2}$ and wet syngas $(30 \%$ steam). The utilizations of both the fuel and air were fixed at $40 \%$. The furnace temperature was set to $750^{\circ} \mathrm{C}$.

Figure 92. A 33-cell stack performance in the hybrid mode to co-generate hydrogen and electricity: 20 SOFECs were in the syngas-assisted electrolyzer mode, and 13 SOFCs were in the SOFC mode to drive electrolyzers. The furnace temperature was $770^{\circ} \mathrm{C}$.

Figure 93. A 33-cell hybrid stack power performance breakdown for the 20 SOFECs and 13 SOFCs.

Figure 94. Stack temperature profiles as a function of the current in the hybrid mode: the stack temperatures, fuel and air inlet temperatures, and the furnace temperature.

Figure 95. Hybrid stack tests for a continuous hydrogen/electricity co-generation. Wet syngas was the fuel for the hybrid. Steam and air were on the cathode of the SOFECs and SOFCs, respectively. The utilizations of fuel and steam were fixed at 50\% and 40\%, respectively, while the air utilization reduced from initial $60 \%$ to $50 \%$ after the first 50 hours test.

\section{A2 Table Captions}

Table 1. Hybrid stack modeling parameters

Table 2. Parametric studies of the LSCM-based cathode (tested at $800^{\circ} \mathrm{C}$ in SOFC mode)

Table 3. Elemental compositions of the button cell cathode

A3 Acronyms

- $\quad \mathrm{ASR}$ - area specific resistance

- $\quad \mathrm{BOP}-$ balance of plant

- $\quad \mathrm{CL}$ - current collector layer 
- $\quad$ CIL - current functional layer

- $\quad$ CTE - thermal expansion coefficient

- $\quad$ DIR - direct internal reforming

- $\quad$ EDAX - energy dispersive X-Ray

- $\quad$ ERS - electrochemical reaction sites

- $\mathrm{GC}$ - gas chromatograph

- $\quad \mathrm{GDC}$ - gadolinium doped ceria

- $\quad$ HTED - high temperature electrochemical devices

- $\quad$ IT-SOFC - intermediate temperature solid oxide fuel cell

- $\quad \mathrm{LCCr}-(\mathrm{La}, \mathrm{Ca}) \mathrm{CrO}_{3}$

- $\quad \mathrm{LSC}-(\mathrm{La}, \mathrm{Sr}) \mathrm{CoO}_{3}$

- $\quad \mathrm{LSCF}-(\mathrm{La}, \mathrm{Sr})(\mathrm{Co}, \mathrm{Fe}) \mathrm{O}_{3}$

- $\quad \mathrm{LSCM}-(\mathrm{La}, \mathrm{Sr})(\mathrm{Cr}, \mathrm{Mn}) \mathrm{O}_{3}$

- $\quad \mathrm{LSCr}-(\mathrm{La}, \mathrm{Sr}) \mathrm{CrO}_{3}$

- $\quad \mathrm{LSM}-(\mathrm{La}, \mathrm{Sr}) \mathrm{MnO}_{3}$

- $\quad \mathrm{LST}-(\mathrm{La}, \mathrm{Sr}) \mathrm{TiO}_{3}$

- $\quad \mathrm{OCV}-$ open circuit voltage

- $\quad$ PEM - proton exchange membrane

- $\quad$ SCCM - standard cubic centimeter per minute

- $\quad$ SDC - samarium doped ceria

- $\quad$ SEM - scanning electron microscope

- $\quad$ SLPH - standard liter per hour

- $\quad$ SLPM - standard liter per minute

- $\quad$ SOEC - solid oxide electrolysis cell

- $\quad$ SOFC - solid oxide fuel cell

- $\quad$ SOFEC - solid oxide fuel-assisted electrolysis cell

- $\quad \mathrm{TC}-$ thermal couple

- $\quad$ XRD - X-Ray Diffraction 